\title{
Dutch direct investments in central and eastern Europe and Central Asia
}

Citation for published version (APA):

van de Laar, M. M. (2004). Dutch direct investments in central and eastern Europe and Central Asia. [Doctoral Thesis, Maastricht University]. Datawyse / Universitaire Pers Maastricht. https://doi.org/10.26481/dis.20041022ml

Document status and date:

Published: 01/01/2004

DOI:

10.26481/dis.20041022ml

Document Version:

Publisher's PDF, also known as Version of record

\section{Please check the document version of this publication:}

- A submitted manuscript is the version of the article upon submission and before peer-review. There can be important differences between the submitted version and the official published version of record.

People interested in the research are advised to contact the author for the final version of the publication, or visit the DOI to the publisher's website.

- The final author version and the galley proof are versions of the publication after peer review.

- The final published version features the final layout of the paper including the volume, issue and page numbers.

Link to publication

\footnotetext{
General rights rights.

- You may freely distribute the URL identifying the publication in the public portal. please follow below link for the End User Agreement:

www.umlib.nl/taverne-license

Take down policy

If you believe that this document breaches copyright please contact us at:

repository@maastrichtuniversity.nl

providing details and we will investigate your claim.
}

Copyright and moral rights for the publications made accessible in the public portal are retained by the authors and/or other copyright owners and it is a condition of accessing publications that users recognise and abide by the legal requirements associated with these

- Users may download and print one copy of any publication from the public portal for the purpose of private study or research.

- You may not further distribute the material or use it for any profit-making activity or commercial gain

If the publication is distributed under the terms of Article $25 \mathrm{fa}$ of the Dutch Copyright Act, indicated by the "Taverne" license above, 


\section{Dutch Direct Investments in Central and Eastern Europe and Central Asia}




\section{(C) 2004 Mindel van de Laar, Maastricht, the Netherlands}

All rights reserved. No parts of this publication may be reproduced, stored in a retrieval system, or transmitted, in any form, or by any means, electronic, mechanical, photocopying, recording or otherwise, without the prior permission in writing, from the author.

Published by M.M. van de Laar, Maastricht University ISBN 90-9018591-7

Cover design and photography by $\mathrm{M}$. van de Laar

Printed by PrintPartners Ipskamp. Enschede/Rotterdam, the Netherlands 


\title{
Dutch Direct Investments in Central and Eastern Europe and Central Asia
}

\author{
PROEFSCHRIFT \\ ter verkrijging van de graad van doctor aan de Universiteit Maastricht, \\ op gezag van de Rector Magnificus, \\ Prof. mr. G.P.M.F. Mols \\ volgens het besluit van het College van Decanen, \\ in het openbaar te verdedigen op vrijdag 22 oktober 2004 om 12.00 uur \\ door
}

Mindel Marete van de Laar 


\section{Promotoren}

Prof. dr. C. de Neubourg

Prof. dr. G. A. Pfann

\section{Beoordelingscommissie}

Prof. dr. L. Soete (voorzitter)

Prof. dr. R. Belderbos (Katholieke Universiteit Leuven, België)

Prof. dr. R. Narula (University of Reading Business School, United Kingdom) 


\section{Preface}

Eight years ago I had a discussion with a friend. During an internship in Poland we decided it could be very profitable to open a hotel/restaurant at the border between Germany and Poland, in order to accommodate the many truck drivers that had to wait endlessly before being allowed to enter Poland. Based on the fact that we did not like the idea of spending much time in our own hotel, in a remote area only surrounded by truck drivers without our family (because we assumed they would not enjoy our hotel either) and the realization that there were probably some bureaucratic obstacles we had not yet considered, we decided not to pursue our plan. Instead, I started writing a dissertation.

About a month ago, on one of my regular commutes to Maastricht, I heart a story on the radio about a project a Dutch businessman started in Latvia. A few years ago he was on holiday, traveling around the Baltic States with a friend, and visited a small island with only one mansion. They spent a nice day on the island, dreaming about the tourist possibilities such a mansion offered. Last year his friend had called him with the news that the mansion was for sale. After a short ten minute phone conversation they decided to buy the mansion and convert it into a hotel. They made this decision without a thorough economic analysis or calculation, based solely on the memories of the nice day they spent there. It turned out to be a good decision; the hotel is now one of the most exclusive tourist accommodations in Latvia.

This story interested me a lot. Although it did not surprise me, it did give me a good feeling. The fact that a Dutch businessman had a similar experience to the one I had eight years ago, and many years later decided to take action based on little less more than a good feeling, confirmed that the topic of this dissertation is still very current seven years after I started it.

When starting as a PhD student I was unsure whether I would be interested in and capable of doing research. The transition countries interested me a lot indeed. Such a large and culturally diverse region at such short distance from the Netherlands, that only recently started reforming, was an ideal object for my study. The major political and economic changes that occurred in the region, the winners and losers of the market economy, individuals but also regions and even countries, all made the choice of a research topic easy. However, the idea of sitting behind my computer for many years in a small, dark office scared me considerably. Only the assurance of Chris de Neubourg that I would be able to do research and combine those research activities with projects and consultancy activities made me decide to try it. It turned out to be a good decision. Most of the time I enjoyed my work, specifically the different aspects of research, teaching and consulting. That is not to say that I enjoyed it all the time. I also suffered from the "great PhD depression", wondering if I would be able to write a book good enough to be defended. During those times, the good times but specifically the less nice periods, I was lucky to be supported by Remco and my family and friends, who encouraged me to continue writing. But it wasn't until the birth of Gijs that I knew I would finish the work. He made me aware of the true value of life and decreased the importance of this book considerably. Exactly that realization, that this book was only important to a certain extent, made it easier to finish. So I did.

Now the birth of this book, my second birth, is a fact. Even though I am extremely satisfied that I finished and am pleased with the content of this dissertation, the result does not compare to the beauty of my first birth. 



\section{Acknowledgements}

Writing a dissertation is a lonely job. Not many people understand the content of the job "researcher", let alone understand what my research is about. Generally people know I am working at Maastricht University, my work has something to do with Central and Eastern Europe and I sometimes worked in Moldova. But what exactly 1 study and why it is important to me remains the question. I hope that the content of this book, specifically the Dutch summary in the back, and my "fifteen minutes of fame" during the introduction of the defense will change that a little and that I will be able to transmit some of the enthusiasm I obtained for research over the last years.

Even though being a PhD researcher is a lonely job, it does not mean I did the job alone. Many people assisted me, some of which I want to thank explicitly. First and foremost I want to thank Chris de Neubourg, for convincing me to write a dissertation and supporting me the whole period. I enjoyed working with you, in an open, friendly and honest environment. I appreciate our discussions and always left our meetings with new energy, numerous new ideas and a smile. Thank you for creating the possibility to combine research with more practical jobs, which enabled me to develop my skills also in other areas than research.

Second, I want to thank Jaap Bos, Ben Kriechel and Allard Bruinshoofd. Having you as roommates and fellow PhD students made my research-life more interesting and a lot more pleasant. I believe the atmosphere in our room was always positive, discussions on every subject were possible and you were always willing to listen, read my work, advice me and assist me when needed. Not only work related. Jaap en Ben, I am convinced your support as paranimf will be equally appreciated. I am glad to have you as friends.

I received a lot of assistance in my research. My work benefited greatly from the advice of Gerard Pfann and the members of the research team at the Business Investment Research Center. I specifically want to express my appreciation to Wilko Letterie for the joint work included in chapter two of this dissertation and Boris Blumberg for his assistance in the development and methodology description of the survey. I also want to express my gratitude to Jaap Bos and his colleagues at De Nederlandsche Bank for their cooperation and comments on the gravity analysis in chapter five. Last, I believe chapter six improved a lot due to the advice of Christiane Schwieren, Piet Keizer and Klaus Meyer. The Q-seminars and later Maastricht Interdepartmental Lecture seminars provided me with the opportunity to present my unfinished work and receive constructive comments, for which I thank the participants.

With all those researchers around, it is important to find a balance between research and daily life. Mieke Drossaert, Celine Duijsens and Susan Roggen excellently took care of the personal aspects at work. They created a nice atmosphere in their office, showing interest in things other than research. I enjoyed the regular short conversations in your room a lot. I also highly appreciate your willingness to assist me, even with less pleasant activities. Susan, thanks for correcting my Dutch summary and bibliography. Sylvia Beenen, thank you for the administrative support. 



\section{Acknowledgements}

Writing a dissertation is a lonely job. Not many people understand the content of the job "researcher", let alone understand what my research is about. Generally people know I am working at Maastricht University, my work has something to do with Central and Eastern Europe and I sometimes worked in Moldova. But what exactly I study and why it is important to me remains the question. I hope that the content of this book, specifically the Dutch summary in the back, and my "fifteen minutes of fame" during the introduction of the defense will change that a little and that I will be able to transmit some of the enthusiasm I obtained for research over the last years.

Even though being a PhD researcher is a lonely job, it does not mean I did the job alone. Many people assisted me, some of which I want to thank explicitly. First and foremost I want to thank Chris de Neubourg, for convincing me to write a dissertation and supporting me the whole period. I enjoyed working with you, in an open, friendly and honest environment. I appreciate our discussions and always left our meetings with new energy, numerous new ideas and a smile. Thank you for creating the possibility to combine research with more practical jobs, which enabled me to develop my skills also in other areas than research.

Second, I want to thank Jaap Bos, Ben Kriechel and Allard Bruinshoofd, Having you as roommates and fellow PhD students made my research-life more interesting and a lot more pleasant. I believe the atmosphere in our room was always positive, discussions on every subject were possible and you were always willing to listen, read my work, advice me and assist me when needed. Not only work related. Jaap en Ben, I am convinced your support as paranimf will be equally appreciated. I am glad to have you as friends.

I received a lot of assistance in my research. My work benefited greatly from the advice of Gerard Pfann and the members of the research team at the Business Investment Research Center. I specifically want to express my appreciation to Wilko Letterie for the joint work included in chapter two of this dissertation and Boris Blumberg for his assistance in the development and methodology description of the survey. I also want to express my gratitude to Jaap Bos and his colleagues at De Nederlandsche Bank for their cooperation and comments on the gravity analysis in chapter five. Last, I believe chapter six improved a lot due to the advice of Christiane Schwieren. Piet Keizer and Klaus Meyer. The Q-seminars and later Maastricht Interdepartmental Lecture seminars provided me with the opportunity to present my unfinished work and receive constructive comments, for which I thank the participants.

With all those researchers around, it is important to find a balance between research and daily life. Mieke Drossaert, Celine Duijsens and Susan Roggen excellently took care of the personal aspects at work. They created a nice atmosphere in their office, showing interest in things other than research. I enjoyed the regular short conversations in your room a lot. I also highly appreciate your willingness to assist me, even with less pleasant activities. Susan, thanks for correcting my Dutch summary and bibliography. Sylvia Beenen, thank you for the administrative support. 
For my consultancy work in Moldova, 1 often traveled together with Jo Boon. Working together for long hours, having strange encounters with even stranger people, long discussions over diner and unforgettable excursions, made our stays often very surprising but always pleasant. I hope we will stick to our intentions to write down our experiences and finish my second book together.

Remco, papa, Fleur, Esther, Jaap, Manon, Ben, Ewout, Riccardo, Patrick, Esther and Rally, thank you for reading my chapters on consistency.

Further, I want to thank my reading committee, Luc Soete, René Belderbos and Rajneesh Narula for your efforts and comments. I believe the book improved a lot due to your advice.

And last, but not least, I want to thank Brooke Hansen, for changing my English into proper English. It was a pleasure working with you and I only regret not asking your English advice a few years earlier. 


\section{Table of Contents}

Chapter 1 Introduction $\quad 1$

1.1

FDI to and trade with Central and Eastern Europe and Central Asia 2

1.2

Dutch FDI to the transition countries: definition and summary statistics

5

1.3

Research questions

Outline of the study

\section{Chapter 2 A theory on foreign direct investment} decision-making

\section{9}

2.1

Introduction

\section{9}

2.2

Real option models

10

2.3 Extension of the model: the possibility to choose between two countries

2.4

Real option model with two countries from a different risk category

18

2.5

Conclusions

23

24

25

\section{Chapter 3 Determinants of Dutch investments in} transition countries

3.1.

Introduction

29

3.2.

Firm characteristics as FDI determinants

3.3.

Facts and figures on Dutch investments and investors

34

3.4 .

First FDI in the Central and Eastern Europe or Central Asia since 1989

38

3.5 .

Multiple investments in Central and Eastern Europe or Central Asia

41

3.6.

Conclusions

Annex 3.1 Methodology of the empirical tests

Annex 3.2 The effect of experience on investment behavior

49

\section{Chapter 4 The investment decision} Testing the predictions derived from the option theory using firm level data 59 
Chapter 5 Explaining foreign direct investment flows to Central and Eastern Europe and Central Asia: a gravity approach $\quad 87$

$\begin{array}{lll}5.1 & \text { Introduction } & 87\end{array}$

$\begin{array}{lll}5.2 & \text { Literature } & 89\end{array}$

5.2.1 FDI Gravity Studies $\quad 89$

$\begin{array}{lll}\text { 5.2.2 Types of Determinants of FDI } & 91\end{array}$

5.2.3 FDI to the CEECs and Central Asia 93

$5.3 \quad$ Methodology 95

5.3.1 A Standard Gravity Equation 95

$\begin{array}{lll}\text { 5.3.2 Analysis of the Determinants of FDI } & 97\end{array}$

$\begin{array}{lll}\text { 5.3.3 Residual analysis } & 98\end{array}$

$\begin{array}{lll}5.4 & \text { Data } & 98\end{array}$

$\begin{array}{lll}5.5 & \text { Empirical Results } & 100\end{array}$

5.5.1 Standard Gravity equation 100

5.5.2 What explains under- and overinvestment? 105

5.5.3 Residual analysis for transition economies $\quad 110$

$\begin{array}{lll}5.6 & \text { Conclusions } & 115\end{array}$

Annex 5.1 Added variables to the basic gravity model $\quad 119$

Annex 5.2 Countries included in the analysis 123

Chapter 6 Integrating emotions and intuition in FDI decision-making

$\begin{array}{lll}6.1 & 125\end{array}$

$\begin{array}{llr}6.2 & \text { Survey results } & 126\end{array}$

$\begin{array}{lll}6.2 .1 & 126\end{array}$

6.2.2 Interesting findings during the analysis of the data 129

6.3 Bounded Rationality 134

$6.4 \quad$ The role of emotions and intuition 136

6.4.1 Emotion and economics $\quad 137$

6.4.2 Intuition and economics 138

6.4.3 Role of emotions and intuition in decision-making 139

6.5 A decision-making model including emotions 143

6.6 Difficulties of modeling emotions and intuition and including

$\begin{array}{lll}\text { 6.6.1 Defining emotions and intuition } & 148\end{array}$

6.6.2 Measuring emotions and intuition 149

$\begin{array}{ll}\text { 6.6.3 Modeling emotions and intuition } & 149\end{array}$

$\begin{array}{lll}6.7 & \text { Conclusions } & 151\end{array}$ 
Chapter 7 Conclusions

7.1

Motivation

153

7.2

Summary

153

7.3

Policy advice

Annex A Methodology of the questionnaire research

"The Foreign Direct Investment Decisions of Dutch Firms"

A1

Introduction

161

A2

The questionnaire

161

A2.1

The population

161

A2.2

The questions

162

A3

The survey procedures

162

A4

The response of the survey

163

A5

Nonresponse bias

166

A6

Conclusions

168

Annex A

Response rates

169

Annex A2 Nonresponse bias tests

171

Annex B Questionnaire forms

173

Bibliography

203

Summary in Dutch

211

Biography

215 


\section{List of tables}

\section{Chapter 2}

Table 2.1:

Overview of studies linking real option models with foreign direct investment decisions

\section{Chapter 3}

Table 3.1: Empirical research on decisions to enter a foreign country

Table 3.2: $\quad$ Summary statistics of investors and noninvestors in the survey 37

Table 3.3: $\quad$ Number of firms in the sample period of 1989-1999 39

Table 3.4: Logit analysis for the first FDI in 1989-1999 40

Table 3.5: Number of firms and investments in the CEE region (1989-1999) $\quad 42$

Table 3.6: Logit regression explaining investments in Central and Eastern Europe and Central Asia after 1989, allowing for multiple investments 42

Table 3.7: $\quad$ Logistic regression 1989-1999, allowing for multiple investments per firm 43

Table A3.2.1: Effect of experience on investment behavior 49

\section{Chapter 4}

Table 4.1: Most frequently mentioned cost, revenue and uncertainty factors used in the analysis

Table 4.2: $\quad$ Reference for expected profitability

Table 4.3: The time between the investment decision and operationalization of the FDI

Table 4.4: Number of alternative host countries that firms considered $(n=117)$

Table 4.5: Conclusions related to the assumptions and hypotheses tests

Table 4.6: The investment preparation of investors and noninvestors 66

Table 4.7: Investment analysis of last FDI compared to first FDI 67

Table 4.8: Evaluation grades for FDI compared to first FDI 67

Table 4.9: Evaluation of the risk of the country and FDI and overall success of the FDI

Table 4.9: Evaluation of the risk of the country and FDI and overall success of the FDI (continued)

Table A4.1.1: Overview characteristics of the firms participating in the survey

Table A4.1.2: Characteristics of investments (investors) and considered investments that were not undertaken (noninvestors)

Table A4.1.3: Number of Dutch FDI in CEE region, by country

Table A4.1.4: Information on the investment decision making procedure of investors considering their first FDI after 1989 and noninvestors considering an $\mathrm{FDI}$ in the CEE region

Table A4.1.5: Comparison of the first and last FDI in the CEE region after 1989

Table A4.2.1: Logit analysis on the impact of the investment preparation 


\section{Chapter 5}

Table 5.1: Overview of Basic FDI Gravity Studies $\quad 90$

Table 5.2: Overview of Types of Determinants of FDI 93

Table 5.3: Cross-country and panel data research to FDI to the CEECs $\quad 94$

Table 5.4: Classification of transition countries, geographically and economically 99

Table 5.5: $\quad$ Summary statistics (2001) 99

Table 5.6: $\quad$ Basic Gravity model for Dutch outward investments 101

Table 5.7: $\quad$ Basic Gravity model of Dutch outward FDI with regional disparities $\quad 101$

Table 5.8: $\quad$ Gravity estimations with regional dummies and time variable $\quad 102$

Table 5.9: Gravity estimations on a yearly basis, including regional dummies $\quad 104$

Table 5.10: Gravity model with additional variables 106

Table 5.11: Gravity Model with Added Variables and OverFDI/UnderFDI Interaction Terms $\quad 108$

Table 5.12: $\quad$ Basic gravity model with new definition of regional dummies 112

Table 5.13: Countries included in OverFDI/UnderFDI group by region 113

Table 5.14: Residual analysis CEECs $\quad 114$

Table A5.1: Added variables to the basic gravity model $\quad 119$

\section{Chapter 6}

Table 6.1: The most important steps of decision-making

Table 6.2: $\quad$ Personal Factors; by investors and noninvestors 132

Table 6.3: Logit analysis on who invests in the CEE region and who does not

\section{Annex A}

Table A1: $\quad$ Response of the overall (among 1550 firms) 166

Table A1.1: Response of the pretest of 48 firms $\quad 169$

Table A1.2: $\quad$ Response of the mail survey 169

Table A1.3: Results of the telephone follow up among 120 firms $\quad 169$

Table A2.1: Comparison of survey respondent with estimation of population

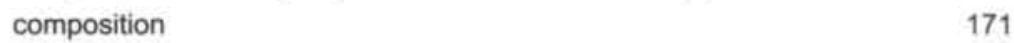

Table A2.2: $\quad$ Probit analysis on response behaviour including all control variables $\quad 171$ 


\section{List of figures, graphs and boxes}

\section{Chapter 1}

Figure 1.1: Central and Eastern Europe and Central Asia

Box 1.1: $\quad$ Trade and FDI in the socialist countries between 1917 and 1991

Graph 1.1: $\quad$ Yearly FDI inflows and stock 6

\section{Chapter 2}

Box 2.1:

Example one

Figure 2.1: FDI decision example including uncertainty 12

Figure 2.2 Visualization of the expected values of project A and B 22

\section{Chapter 3}

Figure 3.1: Stock and Flows of Dutch Outward FDI 35

Figure 3.2: $\quad$ Percentage division of Dutch Investments in the CEECs and FSU (2001) 35

Figure 3.3: Number of investments per country, by firms in the survey $\quad 35$

Figure 3.4: Number of Dutch Investments in the CEEC and FSU by year 36

Figure 3.5: Timing of the $1^{\text {st }}-5^{\text {th }}$ Investment in the CEEC and FSU 36

\section{Chapter 4}

Figure 4.1: Response of the survey 56

Graph 4.1: FDI per risk category (1=very risky, 10=risk-free) 60

Graph 4.2: Ratio of noninvestors and investors by the possibilities available $\quad 61$

Graph 4.3: Investments by risk over time $\quad 61$

Graph 4.4: Percentage division of investments by risk 61

Graph 4.5: Ratio of investors by risk options over time 62

Graph 4.6: FDI by number of alternative host countries $\quad 63$

$\begin{array}{ll}\text { Figure 4.2: } & 72\end{array}$

$\begin{array}{ll}\text { Figure 4.3: } & 74\end{array}$

\section{Chapter 6}

$\begin{array}{ll}\text { Box 6.1: } & 128\end{array}$

Figure 6.1: The relationship between arousal and performance $\quad 141$

$\begin{array}{lll}\text { Figure 6.2 Utility function Net Present Value } & 144\end{array}$

$\begin{array}{ll}\text { Figure 6.3abc: Utility function Emotional Coefficient } & 146\end{array}$

\section{Annex A}

Figure A1: Visualization of the mail survey response and telephone sample response 164 


\section{Chapter 1 Introduction}

"The compelling necessity of the principle of freedom of choice is also clear to us. The failure to recognize this $[\ldots]$ is fraught with very dire consequences, consequences for world peace. Denying that right to the peoples, no matter what the pretext, no matter what words are used to conceal it, means infringing upon even the unstable balance that is [...]. Freedom of choice is a universal principle to which there should be no exceptions."

(Mikhail Gorbachev, 7 December 1988, speech to the UN general assembly)

In his speech to the United Nations general assembly in December 1988, from which this quote was taken, Nobel prize winner Mikhail Gorbachev basically surprised the whole world, by not only stressing the importance of the principle of freedom of choice, but by accompanying those words with the announcement that the Soviet Union would reduce its military presence in Central and Eastern Europe, as well as in the Central Asian border region. This move eventually led to the separation of the Central and Eastern European states in 1989 and 1990 and to the end of the Soviet Union. The most visible starting point of the turnaround, the fall of the Berlin wall on November $9^{\text {th }} 1989$, was one of the most unexpected, impressive and important events of the last century. The countries from Central and Eastern Europe broke with the Soviet Union, stepped away from the socialist ideology and started reforming themselves towards becoming democratic societies. Soon after, the Soviet Union broke up into 15 independent countries, initiated by a separation of the Baltic States and Ukraine who declared full independence in 1991.

The changes for the countries were huge. Major reforms needed to be undertaken. In the short run prices of goods were liberalized and countries opened their borders to free trade and investments. Private ownership of companies became allowed and countries started privatizing state-owned enterprises. Macroeconomic stabilization, including exchange rates and monetary policy, was of high priority. In the longer run institutions needed to be established to deal with the market economy. More importantly, the society needed to adjust to the changing norms and values in the now democratic market economic countries, which were highly different from the previous socialistic planned economies. Individual reward systems, such as wages based on performance, became accepted and private initiatives and entrepreneurship were encouraged. Companies (private and state-owned) needed to become demand driven and profit oriented instead of supply driven, production plan oriented. Countries engaged in these reforms at different paces and using different methods, but in general the focus was put on privatization, liberalization and stabilization.' After more than a decade the reforms in those areas were more or less completed in most of the Central and Eastern European countries. $^{2}$

\footnotetext{
'The Washington Consensus (Williamson 1994), rebuilding entire societies quickly according to a blueprint, was applied to transition countries (Ellman, 1997).

${ }_{2}^{2}$ The actual reforms are meant, not necessarily the implementation of the reforms. For example, the share of private ownership versus state ownership is comparable to other market economies. The question whether the privatised firms are already restructured and function according to market oriented mechanisms as well as firms in Western Europe is not discussed here.
} 
Figure 1.1: Central and Eastern Europe and Central Asia

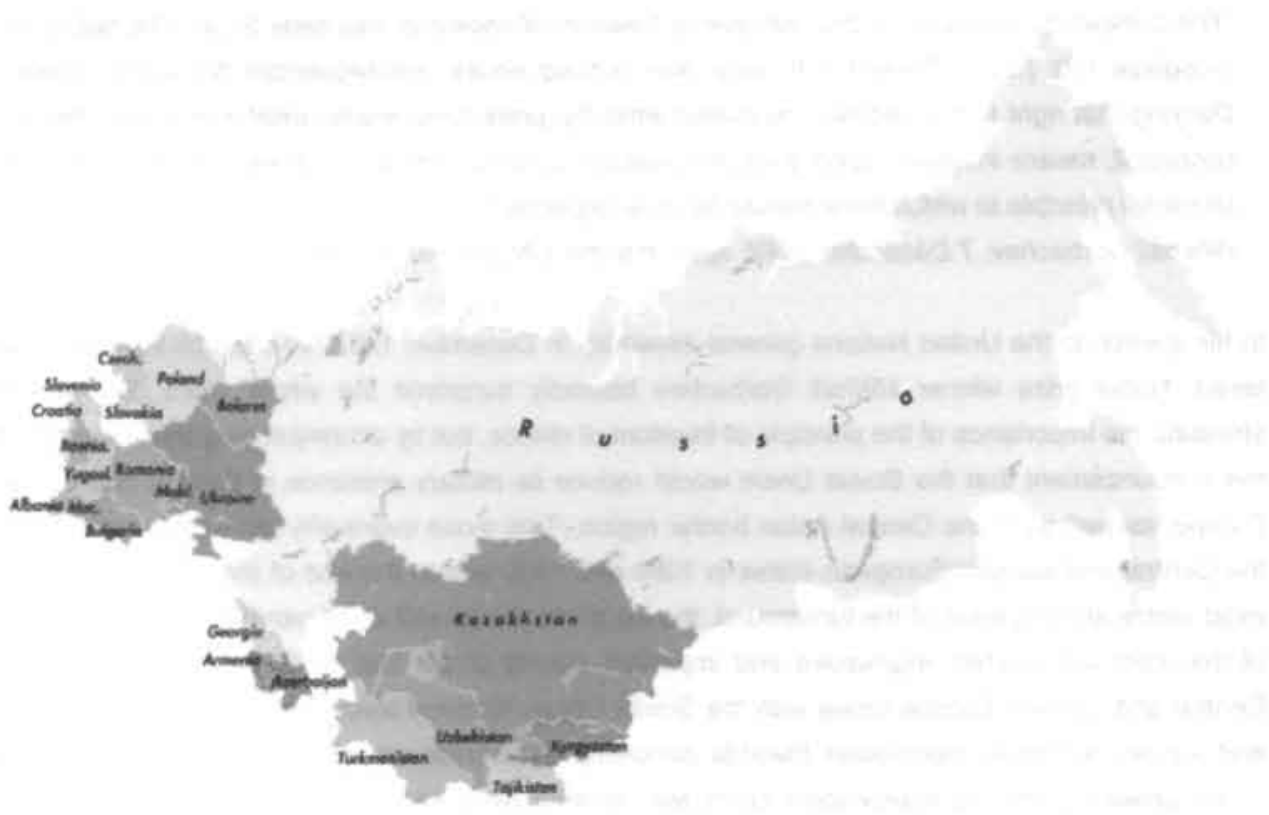

The establishment of institutions and the social changes were often considered less of a priority, both by the countries themselves and by the bilateral and multilateral donor organizations assisting in the developments. As a result, the transition to a market economy has been less complete in those areas. Nowadays the negligence of those two areas is considered a strategic mistake, given that changes in those areas are crucial for the general functioning of the economies (EBRD Transition Report, 2000)

\subsection{FDI to and trade with Central and Eastern Europe and Central Asia}

While clearly the changes were enormous for the CEECs (Central and Eastern European countries) and Central Asia, also for the Netherlands the collapse of communism was influential. Not only the hostility between the East and West decreased as the cold war ended, but at the same time a huge market opened up for trade and investments. Foreign trade and investments were always kept as low as possible in the $20^{\text {th }}$ century, for different reasons (see box 1.1).

Given that the focus in the socialist countries was on industrialization, there was a shortage of consumer goods and the quality of the goods that were available was generally low. The transition countries formed a large new market for foreign (including Dutch) enterprises that could fill this niche. Allowing for FDI and the impact this FDI has on the local economies are two interesting economic phenomena happening in the course of transition. In general FDI is considered a source of growth for the host country for various reasons. 


\section{Box 1.1: Trade and FDI in the socialist countries between 1917 and 1991}

\begin{tabular}{|c|c|}
\hline $1917-1921$ & $\begin{array}{l}\text { After the Russian revolution, a blockade imposed by Western powers virtually put an end to all } \\
\text { foreign trade and FDI. At the same time, Lenin advocated a policy of self-sufficiency, meaning } \\
\text { socialist countries should try to fulfill their basic needs using the production factors and facilities in } \\
\text { their own countries. Trade between socialist countries was allowed. In order to temporarily } \\
\text { substitute the import of foreign goods and capital from the West, mass labor was used. A state } \\
\text { monopoly for foreign trade was installed and state-owned foreign trade organizations were } \\
\text { established. }\end{array}$ \\
\hline $1922-1930$ & $\begin{array}{l}\text { Foreign trade with the West was gradually allowed through the foreign trade organizations and } \\
\text { trade was mostly used as political and economic medium to solve internal issues. Trade occurred } \\
\text { on bilateral level } 4 \text {, solely to fulfill immediate needs for certain goods. The imported goods were paid } \\
\text { for through economic or political concessions, for example restitution of foreign heritage. After } 1925 \\
\text { joint-stock companies were allowed to directly import and export, though always under the } \\
\text { supervision of the state-owned foreign trade organization. Foreign investments were not allowed } \\
\text { (with a few exceptions) since they were contradicting the politically motivated isolationism }\end{array}$ \\
\hline $1930-1939$ & $\begin{array}{l}\text { Stalin strongly advocated economic independence and tried to eliminate foreign trade as much as } \\
\text { possible. Industrialization should lead to the necessary growth and occurred at the expense of } \\
\text { agriculture. Some imports were needed to achieve industrialization and futfill the production targets } \\
\text { set by the central plan. Those imports needed to be balanced by agricultural exports. Demand for } \\
\text { the Soviet Union export goods on the world market was low since the world suffered from the Great } \\
\text { Depression and the quality of those export goods was not high. In order to earn the necessary } \\
\text { income, the Soviet Union sold their exports at extremely low prices, eventually resulting in } \\
\text { accusation and punishment for dumping. }\end{array}$ \\
\hline $1939-1940$ & $\begin{array}{l}\text { At the start of World War Il the Soviet Union allowed only for minimal trade with political reasons. } \\
\text { Trading with nazi-Germany allowed the Soviet Union to prepare their military forces two more years } \\
\text { for war. Trade with other countries was still minimal. }\end{array}$ \\
\hline $1941-1945$ & $\begin{array}{l}\text { During the period the Soviet Union was involved in the Second World War, foreign trade with } \\
\text { western capitalist countries occurred on a lend-lease basis. The capitalist countries needed the } \\
\text { Soviet Union as ally in the war and were willing to export to the Soviet Union without being directly } \\
\text { paid. The settlements of those lend-lease arrangements eventually led to large problems. }\end{array}$ \\
\hline $1945-1970$ & $\begin{array}{l}\text { During the Cold War era, the desirability and possibility for trade with the West diminished. Foreign } \\
\text { trade occurred mainly between the socialist countries, joining the CMEA (Council for Mutual } \\
\text { Economic Assistance }{ }^{5} \text { ). Coordination was done by the Soviet Union, where prices or exchange } \\
\text { rules were created by bureaucratic organizations. Since the currencies were not convertible, trade } \\
\text { was often done on bilateral basis using barter. FDI was still hardly present, not even between the } \\
\text { CMEA countries. }\end{array}$ \\
\hline $1970-1985$ & $\begin{array}{l}\text { In the } 1970 \text { s the situation changed, mainly because of the discovery of oil and natural gas in the } \\
\text { Soviet Union. Given that those resources could easily be traded for hard currency on the world } \\
\text { market and the price for oil was high, this discovery led to a large export. This allowed the Soviet } \\
\text { Union to buy technology without becoming indebted. In addition, the West changed its attitude } \\
\text { positively, increasing the willingness to trade and grant credits to the socialist countries. Still, CMEA } \\
\text { trade based on barter remained the most dominant form of trade in the socialist countries. In } \\
\text { addition, industrial cooperation became more intensive. Yugoslavia (1967). Romania (1971) and } \\
\text { Hungary (1972) were the first countries that introduced joint venture laws, allowing foreign } \\
\text { participation. Hungary extended its laws frequently in the years after to accommodate foreigners. } \\
\text { But, because of the unstable political situation and weak economic development of those countries, } \\
\text { the inflow of FDI remained very limited. In addition, private production was also limited, and only } \\
\text { allowed at small scale in Poland (agriculture) and Hungary (small businesses), In 1980. Bulgaria } \\
\text { introduced a law allowing joint ventures with up to } 99 \text { percent foreign participation. }\end{array}$ \\
\hline $1986-1991$ & $\begin{array}{l}\text { Czechoslovakia, Poland and the Soviet Union opened up for joint ventures with foreign participation } \\
\text { in } 1985 \text { and } 1986 \text {. Gorbachev's reforms further liberalized the markets, but a decrease in oil prices } \\
\text { blocked further increase in trade. Since export revenues decreased, the Soviet Union had to limit } \\
\text { the imports. New legislation allowed for joint ventures and a careful step towards enterprise zones. } \\
\text { The implementation of those plans never happened, since transition started in } 1989-1990 \text {. }\end{array}$ \\
\hline
\end{tabular}

\footnotetext{
Ideally, a socialist universe would be created, in which socialist countries freely traded according to the socialist principles. However, this ultimate aim of the revolution - a politically and economically unified universe - was never achieved (Trotsky. 1918, described in Gueullette, 1991).

"Germany was the first country that signed such a bilateral trade agreement. The USA remained the exception; the Soviet Union never traded with the USA.

${ }^{5}$ CMEA is often referred to as Comecon. It was set up in 1949 and dissolved in 1991. Members were the Soviet Union. Bulgaria, Czechoslovakia, East Germany, Hungary, Poland, Romania, Cuba, Mongolia and Vietnam. Yugoslavia and Albania were initially members, but left the CMEA before 1991.

"The initial reforms allowing private ownership and foreign involvement on a small scale in Hungary and Poland were part of the reasons why those two countries performed relatively well in the early years of transition.
} 
FDI contributes directly to country development by providing capital and creating employment possibilities. In addition, foreign human capital enters the country as well as firms with a higher level of technology than the local firms. Local people and firms benefit from these skills; they contribute to increased local human capital in the form of labor and management skills and increased technology adoption. The presence of foreign firms helps develop institutional structure, creating distribution channels and changing the business culture. Foreign firms can also give a boost to the local economy, given that they may buy inputs from the local firms and the fact that employees of the firm spend (part of) their salaries in the local retail stores. Last, the inflow of FDI decreases the chance for policy reversals, which was especially important in the early years of transition. Once foreign firms had entered the market, it was harder for politicians to revert to the closed economy of the socialist past.

It is very interesting to study which countries in transition have been successful in attracting FDI and what the host country determinants of the FDI flows are. If the inflows of FDI indeed lead to positive economic development, it is useful to know more about the motivations of firms that have invested in the region in order to be better capable of attracting FDI in the future.

In this study the focus is on Dutch direct investments to Central and Eastern Europe and Central Asia. Engaging in an FDI in a transition country during the 1990 s could offer attractive prospects for Dutch enterprises. Allowing foreign enterprises to become active in transition countries meant opening up a land of opportunities in the form of a large region with abundant natural resources relatively close by. In addition, the region was characterized by a lack of production and entrepreneurial skills to develop the market in the short run. Given the fact that local and foreign investments were low, possibilities were present in almost every field to set up a company without facing much competition. In other words, if a company delivered a product or service that was absent or of better quality than the supply in a transition country, or if a company was better able to manage its company efficiently, there were ample opportunities to become profitable. An increase of Dutch FDI in the region in the $1990 \mathrm{~s}$ was therefore expected and those investments were also expected to be successful.

It remains unclear whether the expectations were met, since studies on Dutch FDI in transition countries are limited. There exists a large body of theoretical literature on FDI, but empirically not many studies have focused on outward Dutch FDI. ${ }^{7}$ No study focuses on all aspects of Dutch direct investments, including macrolevel and microlevel analyses. This study intends to fill this abovementioned gap. First, it studies firm-level characteristics in order to find out whether some firms are more likely to invest than other firms. Second, a microlevel analysis is included, with specific information on the investment decision at the firm level. Third, it includes a macrolevel analysis of Dutch FDI flows to the transition countries.

\footnotetext{
'Hogenbirk (2002) gives an interesting overview of inward FDI. Drogendijk (1998) focuses on the transition countries, but studies more cultural aspects. Beiderbos (1992) studies the interdependence of the investments of Dutch multinational enterprises in the Netherlands and foreign locations. Carmeaux and Huisman (1986) focus on Dutch FDI to developing countries. Less academic, more business oriented research exists of several guidebooks or leaflets, often published on a yearly basis, describing how to engage in FDI and what aspects to take into account (e.g. Fenedex, KPMG, Price Waterhouse Coopers). There are also country studies describing the most recent developments in the CEE region and Central Asia published on a regular basis, often including a chapter on FDI (EBRD country studies). Lastly, some publications were written on the success and failure of Dutch FDI in the CEE region (VNO-NCW (1997), Hastenberg en van Rietbergen (1993)).
} 


\subsection{Dutch FDI to the transition countries: definition and summary statistics}

Foreign direct investment is defined as net inflows (or stock) of investment to acquire a lasting management interest (ten percent or more of voting stock) in an enterprise operating in an economy other than that of the investor. It is the sum of equity capital, reinvestment of earnings, other long-term capital and short-term capital as shown in the balance of payments (International Monetary Fund, Balance of Payments Statistics Yearbook). ${ }^{8}$

The main motivation to focus on FDI, instead of exports or portfolio investments in this study is the long-term perspective firms mostly have when engaging in an FDI. Investment sums are often large and involve sunk costs, making the investment irreversible. That makes an FDI less suitable for the pursuit of short run profit. There are generally speaking four kinds of FDI (Dunning, 2000):

- Market seeking FDI, in order to satisfy the foreign market.

- Resource seeking FDI, to gain access to natural resources.

- Efficiency seeking FDI, in order to achieve a more efficient division of labor or more efficient use of another asset.

- Strategic asset seeking FDI, designed to protect advantages a firm possesses at the moment of the investment, or reduce possibilities for the competitors.

In 1989 the total stock of Dutch direct investments in the world was 73443 million euro, equaling 32 percent of the Dutch GDP. 48 percent of this amount was invested in Europe, 45 percent in North and South America and eight percent in the rest of the world. Dutch FDI to Europe flows mainly to the countries from the European Union. In 1989 less than one percent of the stock was invested in the CEECs or Soviet Union. None of the countries in the CEE region or the former Soviet Union record a stock of Dutch FDI above one million euro. The FDI stock is especially low when considered per capita. EU countries receive an FDI per capita of 88,4 euro, the FDI per capita in the CEECs and FSU equals two eurocent in 1989. Based on these data a catch up effect of the CEECs and FSU could be expected, leading to high FDI inflows in the 1990s.

Dutch FDI to the CEECs and FSU indeed has increased enormously since 1989 (see figure 1.1). In 2002, the total FDI stock in the region was 13.600 million euro, resulting in an FDI stock per capita of 37.5 euro. This amount is almost 1900 times as high as the FDI per capita in 1989. However, the division of FDI over the countries shows large inequalities. The Czech Republic, Hungary, Poland and Russia jointly received about 90 percent of the total FDI, leaving the other 21 countries with only ten percent. This large inequality is clearly shown by the trend lines in figure 1.1 ; the EU accession countries received more FDI than the rest of Central and Eastern Europe and Central Asia.

\footnotetext{
"Outward FDI stocks are positive in this analysis. FDI flows can be negative on firm level but also on country level. This situation occurs if firms quit with the FDI, disinvest or repay loans in the home country more than they invest in the host country.
} 


\section{Graph 1.1: Yearly FDI inflows and stock (million euro)}
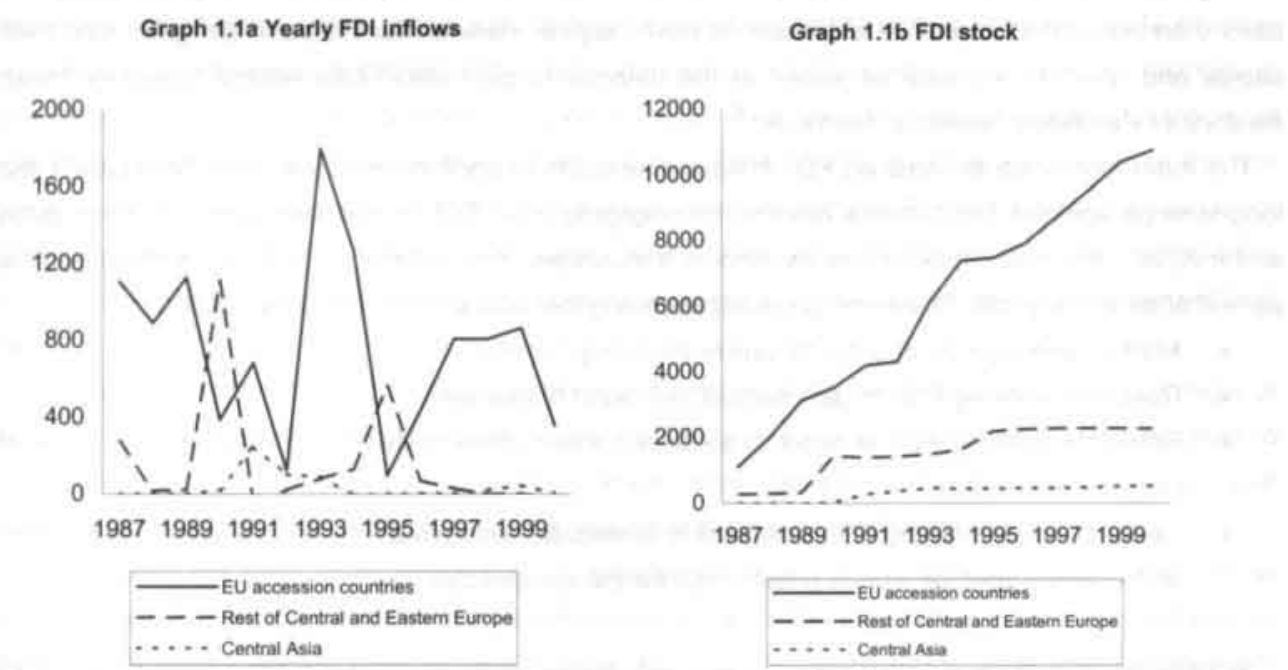

\subsection{Research questions}

The purpose of this dissertation is to obtain a better idea of the complete investment decision process of Dutch firms investing abroad. The research questions are i) Which firm characteristics increase the chance a firm invests, ii) What does the investment decision process of firms look like and is it different for investors and noninvestors?, iii) Which country determinants attract Dutch investments to transition countries? and iv) How does personal influence relate to direct investment decisions?

The microlevel analysis in this dissertation focuses on the home-country firms (supply side). Studying the firm's characteristics and reasons gives insight in the question why some Dutch enterprises invest in a transition country, whereas others firms decide not to invest. This could be simply a matter of firm characteristics, meaning there is an attractiveness of the region for a certain type of firms. Firms from the oil sector for example are in general interested in the countries with natural resources and the banking sector was in principle interested in the transition countries since this sector was not well developed in 1989. Summarizing, having certain firm characteristics can be a reason to invest in a transition country.

But the decision to invest is more complicated and does not solely depend on firm characteristics. The internal investment decision processes of firms are very different and are likely to affect the final investment decision. The information provision with respect to an investment is important, as are the analysis and interpretation of this information. Some firms will be certain to invest based on only limited information, whereas others will need a lot more information before they decide to invest or not. Studies on the investment processes of firms are limited and therefore additional knowledge can increase the effectiveness of investment-supporting institutions in home and host country in helping 'firms decide. This not only means information is needed on the investment decision processes of firms that decided to set up an FDI, but also information on the processes of those firms that - after 
serious considerations - decided not to invest.

Instead of looking at the supply side (home country firms), the host country perspective can be placed central. Why do some countries receive high FDI inflows, whereas others countries from the same region hardly benefit from the Dutch entrepreneurial activities. In other words, what are the determinants of Dutch investments to transition countries? The macrolevel analysis is based on a dataset containing yearly Dutch FDI flows and country specific macroeconomic indicators. Looking at the yearly aggregate FDI flows gives a clear picture which countries are receiving most Dutch FDI and show a large discrepancies of inflows over the countries.

A last microlevel problem discussed in this study relates to the unexplained decisions factors. One of the interesting findings of studying the investment procedures at firm level was the importance of personal influences in decision making. Some firms base their investment decision not necessarily on economic motivations, such as profit expectations, but rely more on personal aspects. Examples of personal influences are the nationality of the firm's owner. Such kind of personal motivations have so far been excluded from direct investment decision theories, but can play an important role. Therefore it is important to include those factors in both theoretical models and empirical research to investment decisions of firms.

In order to answer the microlevel research questions raised here, specific firm-level data are needed. Given that the available databases did not contain sufficient information, including both company characteristic and FDI information, a survey was developed. The main advantage of constructing a new database is that the information in the database is tailor-made to answer the research questions posed. Disadvantage of using survey data is that a questionnaire can only contain a limited number of questions, thus limiting the amount of information available and the information provided can be subjective. Following the informed observer approach, relying not only on the knowledge and intuition of the researcher but also basing the main research questions on the knowledge of the informed observers (the Dutch entrepreneurs active in transition countries) benefited the practical relevance of this survey. ${ }^{9}$ In addition, all of the firms to whom the survey was sent were interested in the transition economies, but some decided to invest and others did not. The inclusion of both investors and non-investors makes a comparison of the investment process possible, providing information on possible differences in preparatory processes. Such a database has not been studied before, neither in the Netherlands nor in other countries and it can add to the general understanding related to investment decisions.

\subsection{Outline of the study}

The first part of the dissertation contains a microlevel analysis. Chapter two provides a theoretical overview of the direct investment decision literature used in this study, the real option theory. In section 2.2 a description is given of the basic option model. I argue that this model is theoretically well suited to model FDI decision making, since it incorporates the irreversibility as well as the uncertainty of the investment. In section 2.3 the option model is extended so as to include the possibility to choose from several investment projects and section 2.4 allows for different degrees of uncertainty in the projects from which to choose. The theoretical overview and extension of the option model give an indication of the main research questions of this dissertation. Chapters three and four include

\footnotetext{
The informed observer approach is a central concept within the NWO Pionier project to which this research was linked.
} 
empirical studies testing the expectations based on the option model using Dutch microlevel data. In chapter three a short overview of Dutch FDI flows to transition countries is given. In addition the survey data are used to find out which Dutch firms are most likely to invest in the CEE region. Chapter four studies the internal investment decision processes of firms in order to detect if there is a deviation in investment processes for investors and noninvestors. The influence of experience is also tested, checking how the investment decision process with respect to the first FDI in the CEE region relates to the process followed for the firms' latest FDI in the region. Finally an investment framework relates the availability of information to the investment decision. I argue that firms will continue to collect information in a decision process up to the point the firm is confident to decide whether or not to invest, as long as the benefits of having additional information exceed the costs of obtaining the information. One of the important finding when studying the firms' investment processes was that personal motivations are important in the decision making.

Part two of this dissertation includes a macrolevel analysis of Dutch FDI flows. In chapter five macro data are used to estimate a gravity model for Dutch FDI worldwide. This model is used to see whether transition countries have been able to improve their weak start-of-transition positions as host countries of Dutch investments and if they are now receiving a share of FDI inflows that could be expected based on their macroeconomic characteristics and performance.

Part three of this study, chapter six, builds on the conclusion made in chapter four that personal motivations play an important role in decision making. The information from the survey shows that many firms incorporate personal motivations in their investment decision. In this chapter I argue that these kind of personal motivations can be linked to individual concepts, such as personal intuition and emotions. I argue that this intuition and emotion of the decision-maker are of importance in a firm's investment decision, even though they are rarely included in economic theory. In section $6.5 \mathrm{I}$ use a utility model including the utility of the firm as well as the utility of the decision-maker to incorporate emotions and intuition in an investment decision model.

Chapter seven summarizes the research and provides policy advice based on the results of the dissertation.

Since existing databases did not have sufficient data to answer the main problem statements, I developed a survey. Annex A describes the methodology of the survey. Annex B consists of the translated questionnaires sent to the investors and noninvestors. 


\title{
Chapter 2 The real option model applied to foreign direct investment decision-making
}

\begin{abstract}
"A good chess player that lost a game is seriously convinced his loss was the result of a mistake he made. He searches for that mistake in the opening of the game but forgets that in each stage of the match he made similar mistakes and none of his moves was perfect. He only notices one specific mistake, to which he devotes his attention, because his opponent made use of it. How much more complicated is the game of war, that is placed within a certain time span and in which there is not one will dictating to move obstacles, but in which everything is the result of endless collisions of the willpower of most divergent individuals".
\end{abstract}

(Leo N. Tolstoj (1868), War and Peace).

\subsection{Introduction}

Several theoretical models have been developed in order to explain outward foreign direct investment flows and stocks. Macroeconomic models are used to describe the size and direction of the FDI flows to specific host countries, taking into account country-specific conditions, such as the general economic development of the countries, labor market situations or sector specific influences. At the firm level, case studies or management studies use elaborate frameworks to describe or model the preconditions, reasons and motivations for firms to engage in an FDI. Microeconomic models look at firm decision-making, where different investment strategies result in different cost and benefit factors being taken into account.

These theoretical studies have been accompanied by a string of empirical studies that have been published the last decades. Still, a direct link between macro and micro FDI models and business investment frameworks has not yet been formulated. Many FDI models co-exist, but the links between the different fields of expertise often remain unclear. This absence is at least surprising given that it is likely that firms, when making an investment decision, will take some aspects of each of the fields into account. First, FDI is subject to a required set of preconditions and motivations, as described in the business literature. Second, firms may want to consider macroeconomic conditions in order to select the host country that appears most interesting to them. Third, firms will need to evaluate internally whether an investment is interesting from a cost and benefit point of view.

This chapter focuses mainly on the third point mentioned. The combination with point one and two is relatively straightforward. I assume that firms interested in an FDI will i) have the necessary preconditions and motivations, otherwise they would not consider an FDI and ii) will select one or more potential host countries before making cost and benefit analyses (see chapter five for a macroeconomic study on host country determinants). With respect to cost-benefit FDI decisions, there are two main references I would like to mention before engaging in this chapter's addition to the theory. First, the cost/benefit analyses of FDI that is most referred to is a model on the direct investment decision of a firm by Buckley and Casson (1981). In their Net Present Value analysis (NPV), the timing of an investment and mode of market servicing is determined on the basis of several variables.' They assume non-recoverable set-up costs of an FDI, recurrent fixed costs

\footnotetext{
'Production costs, transportation costs, costs of tariffs, costs of doing business abroad, market size, growth of the host country and level of development of the host country.
} 
(independent from output) and recurrent variable costs (dependent on output). Only one mode of market servicing can be used at the time and depends crucially on the stage of development of the host country. In an application of their model, they explain how a firm may choose between exporting to a foreign country, licensing or FDI. Second, Meyer (1998) in his dissertation added a lot to the understanding of the impact of many different variables influencing an investment decision. He provided an excellent literature review, linking many different FDI theories and variables to an investment decision. ${ }^{2}$ In addition he develops a transaction costs model and tests the impact of the variables using microeconomic survey data.

The approach chosen in this chapter build on those two references. However, the main difference is the use of a real option model instead of a transaction cost or NPV model. The merit of the real option model is the possibility to incorporate the impact of irreversible set-up costs and uncertainty on the investment decision, without losing the possibility to include all the different variables influencing the investment decision, as described by Meyer. Irreversible set-up costs and uncertainty directly influence the timing of an FDI. Since FDIs often involve large irreversible costs and transition countries are still relatively risky host countries, the option model is more suitable to model the timing of an FDI-decision than the NPV-model.

In section 2.2 a basic option model, dealing with a firm's investment decision to invest in one country or not, is described. Variables included in the business, microeconomic and macroeconomic theories can all be included in this specific model and the timing of an investment is a crucial factor. I will show why exactly this option model is more suitable in modeling the various aspects of decisionmaking to an uncertain region like the CEE states during the last decade. ${ }^{3}$ In section 2.3 , the basic option model is extended to include the possibility for a firm to choose from several countries in which to invest. By allowing several countries from which to choose, the model becomes more realistic since in practice firms can also choose from several locations when considering investing abroad and the number of alternatives to choose from influences the timing of the investment. In section 2.4, different possibilities are given on how the model can be adjusted further to describe the real life situation better, by broadening the uncertainty assumptions of section 2.3 . Where in section 2.3 uncertainties are assumed equal for all countries considered, in section 2.4 different degrees of uncertainty are allowed between countries. Given that countries are at different stages of economic development and their macroeconomic conditions clearly influence the uncertainty related to the investment, the investment choice is different for each country. Section 2.5 provides a summary and conclusions are drawn with respect to expectations to be further researched in the chapters three and four of the dissertation.

\subsection{Real option models}

The real option model builds on the same principles as a Net Present Value model. The basic idea is that companies calculate or estimate expected revenues and costs and discount those values in order to make a decision taking future flows into account. The criticism of the NPV model is the lack of

\footnotetext{
${ }^{2}$ Meyer, 1998, chapter three and four, pp. 59-112.

${ }^{3} \mathrm{CEE}$ region = Central and Eastern Europe.

4 Section two is a description of the real options model, with application to foreign direct investment decisions. Readers familiar with the real option model are advised to go to section four. The real options model is elaborately explained in for instance Pindyck (1991), Dixit \& Pindyck (1994) and Trigeorgis (1996).
} 
flexibility and the fact that the model neglects the irreversible nature of some costs. The real option model explicitly incorporated those two critiques, by modeling irreversible investment costs and allowing for postponement of an investment due to uncertainty. Comparison of the NPV and real option model shows that because of those two factors, outcomes of a similar investment decision can be different. This is visualized in investment example one in box 2.1.

Assume a firm can invest in an FDI, but the investment costs are irreversible.' This irreversibility means that once a firm has invested in period $t=0$, it will not be able to stop the investment free of costs and invest in a different FDI in period $t=1$ if that turns out to be more beneficial. According to the $E(N P V)$ decision rule the firm invests in the FDI at time $t=0$ if the $E(N P V)$ of the investment is positive. However, it is possible that, if the firm postpones the investment at time $t=0$ and instead invests at time $t=1$, the $E$ (NPV) of the same FDI will be higher due to for instance a growing demand in the market or an increase in the price of the product. If the firm already invested at time $t=0$ the presence of the irreversible costs make it impossible to invest again at time $t=1$. In that case it would have been better for the firm to wait with its investment, in order not to lose its option to invest at a later time. This situation, indicating the negative implications of lack of flexibility, is numerically explained in example one.

The real option theory incorporates the possibility to wait with investment today and postpone the investment. It does so by assuming that a firm can buy an option with the right to invest in the same host country in the next period, but with no obligation for the firm to do so. If in period $t=1$ it is beneficial for the firm to invest it can exercise its option, but in case developments are negative, it will not have to exercise its option right." The real option theory thereby models the uncertainty in the economy.

In real life, firms always face uncertainty when making a foreign direct investment decision. For example, the economy of the host country is an uncertain environment for the investor and this uncertainty may influence the return on the investment of the firm over time. Uncertainty occurs at many levels. The preferences of the consumers may change over time, costs of production change over time and macroeconomic situations in the host countries are variable as well. The discount rate only includes a risk-free rate. The uncertainty is captured by the different probabilities and expected pay-offs of the scenarios included in the example.

The investment decision model following the options theory is further extended using continuous time. The most common definitions used are:

$V_{0} \quad$; the value of the investment at time $t=0$.

$I_{0} \quad$; the irreversible investment costs of the FDI at time $t=0$.

$F_{0}$; the value of the investment opportunity today, which is what a firm is willing to pay to have an option to invest in an FDI later.

$F_{1}$; the value of the investment opportunity next period.

\footnotetext{
${ }^{5}$ Meaning a reversal of the decision, scaling down or stopping the investment will inevitably lead to a loss of the set-up costs.

"This kind of option has the same characteristics as the call options in the financial sector.
} 


\section{Box 2.1: Example one}

A firm has the opportunity to set up an FDI in the CEE region at $t=0$ or in the next period $t=1$. The investment is irreversible with setup costs of $\mathrm{l}=5000$, so once invested in period $\mathrm{t}=0$ the firm cannot stop with that investment free of costs and invest in period $t=1$ if that is more profitable. The risk is diversifiable, so I use a risk-free discount rate of $\rho=10$ percent

The firm sells one good per year, at price $P$. At time $t=0, P_{0}=1000$. Due to uncertainty two different scenarios are possible for period $t=1$. If the economy is growing, the price will increase to $P_{1}=1500$. but if the economy enters a recession, $P_{1}$ decreases to 500 . After period one the price remains stable. Each scenario has a probability $p=1 / 2$ to occur and which scenario will occur depends on an event that cannot be predicted. Summarizing:

$i=5000$

$\mathrm{P}_{0}=1000$

$P_{1}=500$ with probability of 0,5 (scenario one) or $P_{1}=1500$ with probability of 0,5 (scenario two) $r=10$ percent

The situation is depicted in figure 2.1.

Following the standard NPV calculation, the E(NPV) if the firm would invest in period $t=0$ is

$E(N P V)_{t=0}=-5000+\sum_{t=0}^{\infty} 1000 /(1,1)^{t}=-5000+11000=6000$

The firm would thus invest in the FDI at time $t=0$, since the current value of the investment is positive. In this example this decision would not be the most optimal. The option theory includes both the presence of uncertainty, leading to the two different scenarios in period $t=1$, as well as the possibility to wait with the investment. If the firms waits one year with the investment, it keeps the option to invest if the price increases and not to invest if the price decreases. The expected NPV in period $t=0$ of investing in period $\mathrm{t}=1$ would thus be:

$E(N P V)_{t=0}=1 / 2\left(-5000 / 1.1+\sum_{t=1}^{\infty} 1500 /(1.1)^{t}\right)+1 / 2(0)=1 / 2((-5000+15000) / 1.1)=9090.90$

Clearly it is more optimal for the firm to wait to invest at time $t=0$ and only invest at time $t=1$ as the prices increase to 1500 .

The value of waiting one year equals $9090.90-6000=3090.90$

Figure 2.1: FDI decision example including uncertainty.

Time $\quad t=0 \quad t=1 \quad t=2$

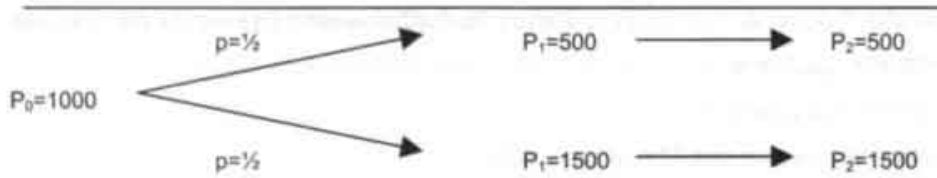


For the determination of $F_{f}$ uncertainty plays a role. If the asset of the FDI in period one, $\left(V_{1}, I_{1}\right)$, is positive, the option value is $F$, equals that amount. However, if $\left(V_{1}-I_{1}\right)$ is negative, the firm will not use the possibility to invest at time $t=1$ and $F_{\text {, equals }} 0$. When the information on $F_{1}$ for each scenario is known, it is possible to determine $F_{0}$, using a risk-free discount rate. As long as the value of $F_{0}$. calculated using the risk-free portfolio, exceeds the payoff from investing today $\left(V_{0}-l_{0}\right)$, the firm should wait to invest and keep the option to invest later.

Summarizing, the firm has to decide whether it is optimal to invest the sunk cost of the project $I$ and receive the value of the project $V$ at time $t=0$, or to wait and keep the option to invest. The value of a project is given by equation one, where the current value $\mathrm{V}$ of a project is known and the future value of the project is uncertain ( $\sigma \mathrm{Vdz}$ ) but changes over time in V are observed ( $\mathrm{aVdt}$ )?

$$
d V=\alpha V d t+\sigma V d z
$$

The value of the option to investment is given by $F(V)$. The investment opportunity is equal to a call option, meaning the firm buys the right to invest in a later period, but it does not have the obligation to invest. The firm's optimization problem is to maximize option value of the investment, which can be done solving the Bellman equation two:

$$
\rho \cdot F(V) \cdot d t=E(d F(V))
$$

This equation states that over the time $d t$, the expected return on the investment opportunity, $\rho \cdot F\left(V_{A}\right) \cdot d t$, should be equal to the expected rate of capital appreciation given by $E\left(d F\left(V_{A}\right)\right)$. ' In addition the following three boundary conditions must be satisfied:

$-F(0)=0 \quad$ If $V$ goes to 0 , it will stay at 0 and the option to invest is worthless.

$-F\left(V^{*}\right)=V^{*}-1: V^{*}$ is the value of the project at which it is optimal to invest. When investing at $\mathrm{V}^{*}$, the firm receives a net payoff of $\mathrm{V}^{*}-1$.

$-F\left(V^{*}\right)=1$ :Smooth pasting condition: $F(V)$ should be continuous and smooth at $V^{*}$.

If $\mathrm{V}_{0}>\mathrm{V}^{*}$ it is optimal to invest now, otherwise the option value of waiting is more valuable than the expected payoff of investing today. $V^{*}$ is therefore called the critical value of a firm to invest.

The impact of uncertainty on the model is twofold. First, the critical value of an FDI, $V^{*}$, increases as uncertainty increases, leading to a lower number of investments. Second, the option value of an investment, $F(V)$, increases when uncertainty increases. With higher uncertainty it is more interesting to keep an option since the value of the FDI may increase or decrease over time and keeping the option creates the possibility to see which one of the trends will occur without running the risk of losing money.

The implication of the real option approach with respect to explaining FDI decision-making models is enormous. Many articles, theoretical and empirical, have explored the possible consequences of this model on FDI decisions. A summary of some of those articles is included in table 2.1. The papers

\footnotetext{
${ }_{7}^{7}$ Following a Wiener process, with a Brownian motion, see Dixit and Pindyck (1994), chapter three.

'Using the Dynamic Programming method, see Dixit and Pindyck (1994), chapter five, pp. 135.

'See Dixit and Pindyck (1994), chapter 5.2, pp. 140.
} 
discussed in the first part of the table are mostly theoretical, focusing on the choice of an investment mode through the real option theory. The second part of the table contains empirical articles that test the link between real options and FDI. Summarizing this literature, a few trends become clear. The theoretical articles uniformly conclude that applying the option price theory on FDI decisions may lead to a postponement of these investments, possibly indefinitely (McDonalds and Siegel (1985), Capel (1992), Rivoli and Salorio (1996)). In addition, small-scale investments like a platform investment or participation in a joint venture do not necessarily have to be seen only as an investment project, but can also be considered an option to invest more or divest at a later stage (Kogut and Kulatilaka (1994), Chi and McGuire (1996), Mollgaard and Overgaard (1999)), In that sense, the initial FDI can lead to various subsequent investment decisions the firm has to face in the future periods. These follow-up decisions may also influence the initial investment choice. It is possible that an FDI at the current stage may not be very profitable, but the possibility the FDI offers to expand later may be so valuable that it will positively influence the current investment decision. Last, an FDI will most likely have a higher option value than a joint venture or a license agreement. This higher option value is mainly due to the fact that an FDI has higher irreversible set-up costs and often only one owner. Higher set-up costs increase the option value of waiting and being a single owner increases the flexibility of the firm to opt for a delay without having to discuss with partner firms. So, only if the current value of an FDI project is sufficiently high, will the investment be undertaken (Buckley and Tse 1995, Rivoli and Salorio (1996), Pennings and Sleuwagen (1997)).

Empirically, there are several studies based on the option model. A selection is included in the second part of table 2.1. Kogut (1991) shows that firms do not use joint ventures as options to expand their FDI. Several case studies indicate that for large multinationals the real option theory may be useful in making strategic management decisions (Kemna, 1993). In addition, several studies look at the impact of uncertainty and irreversibility on FDI behavior. Most studies conclude that uncertainty and risk negatively affect the decision to invest.

However, in some studies the results less clearly supported the option theory, resulting in recommendations for better specifications of variables or more elaborate research (Peters (1999), Guiso and Parigi (1999), Lehmann (1999), Vonnegut (2000), Altomonte (2000) and Calcagnini and Saltari (2001)).

With respect to direct investments in transition countries, several conclusions can be drawn based on theory and empirical tests. First, the real options model can explain.why firms will not always invest immediately when the prospects are profitable, but wait longer to reduce uncertainty. Second, the real option model can give an explanation why developing countries or transition countries, due to a higher uncertainty within the region, do not attract high FDI flows, even though in terms of natural resources or market potential these countries can be very attractive. However, the model also explains why so many firms are in principle interested in investing in these high-risk regions. The high uncertainty in fact increases the option value of an investment. These markets can be very interesting in the future, so many companies will keep their eyes open for opportunities, but postpone their investment for the moment. 


\section{Table 2.1: Overview of studies linking real option models with foreign direct} investment decisions

\begin{tabular}{|c|c|c|c|c|}
\hline Author: & Tule. & Year & Main problem addressed & Resulits \\
\hline \multicolumn{5}{|c|}{ Theoretical papers } \\
\hline $\begin{array}{l}\text { McDonald \& } \\
\text { Siegel }\end{array}$ & $\begin{array}{l}\text { Investment } \\
\text { and the } \\
\text { valuation of } \\
\text { firms when } \\
\text { there is an } \\
\text { option to shut } \\
\text { down }\end{array}$ & 1985 & $\begin{array}{l}\text { Study of the valuation of } \\
\text { investment projects, when } \\
\text { there is an option to } \\
\text { temporarily and shut down } \\
\text { production free of costs } \\
\text { when variable costs } \\
\text { exceed operating } \\
\text { revenue. }\end{array}$ & $\begin{array}{l}\text { Using the real options approach leads to three main } \\
\text { results, namely 1) Increases in output price uncertainty } \\
\text { can raise or lower the current value of a project, 2) } \\
\text { Futures prices permit the firm to value the project without } \\
\text { having to estimate future commodity prices and 3) High } \\
\text { profits in the far future may have a greater current value } \\
\text { than uncertain profits in the near future. }\end{array}$ \\
\hline Capel & $\begin{array}{l}\text { How to } \\
\text { service a } \\
\text { foreign } \\
\text { market under } \\
\text { uncertainty: A } \\
\text { real option } \\
\text { approach }\end{array}$ & 1992 & $\begin{array}{l}\text { Market servicing is a } \\
\text { dynamic problem and } \\
\text { when choosing a mode for } \\
\text { market servicing these } \\
\text { dynamics should be taken } \\
\text { into account. }\end{array}$ & $\begin{array}{l}\text { The article of Buckley and Casson (1981), describing } \\
\text { market servicing choices as a transaction cost model, is } \\
\text { taken as a basic model. It has been described using real } \\
\text { options terminology and assumptions. It is shown that } \\
\text { uncertainty fosters postponement of investments, } \\
\text { possibly indefinitely. }\end{array}$ \\
\hline $\begin{array}{l}\text { Kemna \& } \\
\text { Morley }\end{array}$ & \begin{tabular}{|l|} 
Note on \\
cross-border \\
valuation
\end{tabular} & 1992 & $\begin{array}{l}\text { Do exchange rates } \\
\text { influence investment } \\
\text { behavior? }\end{array}$ & $\begin{array}{l}\text { Especially for FDI, exchange rate fluctuations not only } \\
\text { influence operating investments but also influence the } \\
\text { option values of future investments. This influence } \\
\text { affects a firm's decision whether or not the option to } \\
\text { invest will be exercised. }\end{array}$ \\
\hline $\begin{array}{l}\text { Kogut and } \\
\text { Kulatilaka }\end{array}$ & $\begin{array}{l}\text { Options } \\
\text { thinking and } \\
\text { platform } \\
\text { investment: } \\
\text { investigation } \\
\text { opportunity }\end{array}$ & 1994 & $\begin{array}{l}\text { Can a platform investment } \\
\text { in a foreign country at the } \\
\text { current stage be } \\
\text { considered an option to } \\
\text { invest in that same } \\
\text { country at a later stage? }\end{array}$ & $\begin{array}{l}\text { Platform investments can be made with relatively small } \\
\text { investments, but keep the possibility open to invest later. } \\
\text { The major problem with this line of thinking is the fact } \\
\text { that the value of these platform investments is not } \\
\text { directly visible at this moment. Their payoff will only } \\
\text { occur later and firms will therefore need a longer-term } \\
\text { view in order to engage in these investments. As such, } \\
\text { firms that are not aiming at short-term profit } \\
\text { maximization will be the ones most likely to benefit from } \\
\text { these kinds of option investments. }\end{array}$ \\
\hline $\begin{array}{l}\text { Buckley and } \\
\text { Tse }\end{array}$ & \begin{tabular}{|l|} 
Real \\
operating \\
options and \\
foreign direct \\
investment - \\
a synthesis of \\
international \\
business and \\
finance \\
theory
\end{tabular} & 1995 & $\begin{array}{l}\text { Besides E(NPV) the value } \\
\text { of options will also differ in } \\
\text { different modes of market } \\
\text { servicing. How do they } \\
\text { affect the entry mode } \\
\text { decision? }\end{array}$ & $\begin{array}{l}\text { Maintaining ownership in a foreign activity also means } \\
\text { maintaining the position to value future options. } \\
\text { Therefore the option of an FDI is most likely higher than } \\
\text { an option of a license agreement. Besides, being } \\
\text { physically present in a country will translate into better } \\
\text { ability on the spot and as such will result in a larger } \\
\text { option value. Thus, firms are expected to prefer FDI } \\
\text { earlier under the real option model than according to the } \\
\text { E(NPV) model, since the option value of an FDI will be } \\
\text { relatively high compared to the option value of other } \\
\text { modes of entry. }\end{array}$ \\
\hline $\begin{array}{l}\text { Chi and Mc- } \\
\text { Guire }\end{array}$ & $\begin{array}{l}\text { Collaborative } \\
\text { ventures and } \\
\text { value of } \\
\text { leaming. }\end{array}$ & 1996 & $\begin{array}{l}\text { How do transaction costs } \\
\text { and strategic option } \\
\text { considerations interact to } \\
\text { influence a firm's } \\
\text { evaluation of joint } \\
\text { ventures as a market } \\
\text { entry mode? }\end{array}$ & $\begin{array}{l}\text { Joint ventures can be considered as an option to buy out } \\
\text { or sell shares to the partner at a later time. Different } \\
\text { valuations of the situation ex-post, with the awareness } \\
\text { ex-ante that this occurs, are main motivation to engage } \\
\text { in such a joint venture. Transaction cost issues, such as } \\
\text { information costs and sunk costs, need to be taken into } \\
\text { account, even in the real options approach. }\end{array}$ \\
\hline $\begin{array}{l}\text { Rivoli and } \\
\text { Salorio }\end{array}$ & $\begin{array}{l}\text { Foreign direct } \\
\text { investment } \\
\text { and } \\
\text { investment } \\
\text { under } \\
\text { uncertainty }\end{array}$ & 1996 & $\begin{array}{l}\text { Do real option settings } \\
\text { affect the assumptions } \\
\text { and links made in the OLI } \\
\text { paradigm? }\end{array}$ & $\begin{array}{l}\text { In uncertain environments ownership and internalization } \\
\text { advantages are negatively rather than positively } \\
\text { associated with FDi. Ownership advantages often make } \\
\text { it possible to delay the FDI, while internalization } \\
\text { advantages often serve to make it less reversible. Both } \\
\text { indicate the value of waiting is high and investment may } \\
\text { be delayed. }\end{array}$ \\
\hline $\begin{array}{l}\text { Pennings } \\
\text { and } \\
\text { Sleuwaegen }\end{array}$ & $\begin{array}{l}\text { The choice } \\
\text { and timing of } \\
\text { foreign } \\
\text { market entry } \\
\text { under } \\
\text { uncertainty }\end{array}$ & 1997 & $\begin{array}{l}\text { Which mode of entry in a } \\
\text { host country is most } \\
\text { beneficial under different } \\
\text { tax and information } \\
\text { conditions? }\end{array}$ & $\begin{array}{l}\text { Export has the lowest option value of waiting, followed by } \\
\text { a joint venture (assuming profits are lower taxed in case } \\
\text { of the joint venture). Obviously cooperation is a very } \\
\text { important factor in choosing the mode of entry, since } \\
\text { with no cooperation the joint venture is no attractive } \\
\text { mode of entry at all. Only if the value of the project is } \\
\text { high, setting up a direct investment becomes attractive. } \\
\text { since this is clearly the most risky mode of entry for the } \\
\text { foreign firm. }\end{array}$ \\
\hline
\end{tabular}




\begin{tabular}{|c|c|c|c|c|}
\hline $\begin{array}{l}\text { Mollgaard } \\
\text { and } \\
\text { Overgaard }\end{array}$ & $\begin{array}{l}\text { Partnerships. } \\
\text { buy-out } \\
\text { options and } \\
\text { investments } \\
\text { in emerging } \\
\text { markets }\end{array}$ & 1999 & $\begin{array}{l}\text { Following Kogut and } \\
\text { Kulatilaka, a joint venture } \\
\text { as platform investment is } \\
\text { considered in a two-period } \\
\text { game theoretical } \\
\text { approach. }\end{array}$ & $\begin{array}{l}\text { A firm will start its investments in a foreign country by } \\
\text { means of a joint venture, in order to find out whether the } \\
\text { foreign partner is a "good" or " bad" type of firm. A price at } \\
\text { which the firm will buy shares in the foreign partner is } \\
\text { determined ex-ante, as well as an amount of capital that } \\
\text { is invested in the joint venture by both the foreign and } \\
\text { home firm. After the first period, the firm can either } \\
\text { acquire the total foreign firm if it is a good firm, keep its } \\
\text { option in the form of the joint-venture one more period, or } \\
\text { sell its shares when the foreign partner is a bad type of } \\
\text { firm. Several garne-theoretic approaches are described, } \\
\text { with strategies that would be optimal for good type of firm. } \\
\text { bad type of firms and the home firm. }\end{array}$ \\
\hline $\begin{array}{l}\text { Moretto } \\
\text { and } \\
\text { Valbonesi }\end{array}$ & $\begin{array}{l}\text { Foreign direct } \\
\text { investment. } \\
\text { policy } \\
\text { uncertainty } \\
\text { and } \\
\text { irreversibility. } \\
\text { an option } \\
\text { pricing } \\
\text { approach }\end{array}$ & 1999 & $\begin{array}{l}\text { To what extent are the } \\
\text { values of options to invest } \\
\text { or disinvest altered by the } \\
\text { government's policies of } \\
\text { entry and exit controls and } \\
\text { restrictions on the } \\
\text { repatriation of profits? }\end{array}$ & $\begin{array}{l}\text { Using a two-period model, several conclusions can be } \\
\text { made. The risk of exit controls acts like investment } \\
\text { irreversibility, depressing the investment flows in period } \\
\text { one. Expropriation represents an extreme form of exit } \\
\text { control and reduces investment even further. The risk of } \\
\text { entry restrictions on market size acts by encouraging FDI } \\
\text { in period one (given that the additional investments in } \\
\text { period two may be restricted because of policy reversals). } \\
\text { This last argument is opposing previous research, } \\
\text { indicating that the higher the risk for policy reversal (and } \\
\text { imposing entry controls) the larger the amount of } \\
\text { investment. }\end{array}$ \\
\hline \multicolumn{5}{|c|}{ Empirical papers testing the link between the Real Options theory and foreign direct investments: } \\
\hline Kogut & $\begin{array}{l}\text { Joint } \\
\text { ventures and } \\
\text { the option to } \\
\text { expand and } \\
\text { acquire }\end{array}$ & 1991 & $\begin{array}{l}\text { A test to see if a joint } \\
\text { venture functions as an } \\
\text { option to a real FDI. } \\
\text { Empirical test using } 92 \\
\text { American manufacturing } \\
\text { firms engaged in a joint } \\
\text { venture. If a jv is } \\
\text { undertaken as a platform } \\
\text { investment and an option } \\
\text { will be exercised once the } \\
\text { firm will expand its foreign } \\
\text { activities. If the jv is closed } \\
\text { or disinvested the option } \\
\text { is not used. }\end{array}$ & $\begin{array}{l}\text { Of the } 92 \text { joint ventures initially included in the dataset } 55 \\
\text { percent of the firms were closed after one year and } \\
\text { aimost } 70 \text { percent of the firms were closed after two } \\
\text { years. As such can be concluded a large percentage of } \\
\text { the firms did not effectively use their option to expand. } \\
\text { The factors found that did increase the likelihood of } \\
\text { exercising the option of expansion were an unexpected } \\
\text { increase in the value of the venture and the degree of } \\
\text { concentration in the industry. All other factors included in } \\
\text { the analysis were insignificant. }\end{array}$ \\
\hline Kemna & $\begin{array}{l}\text { Case studies } \\
\text { on real } \\
\text { options }\end{array}$ & 1993 & $\begin{array}{l}\text { How applicable is the } \\
\text { option theory in practice? }\end{array}$ & $\begin{array}{l}\text { Three case studies, on a timing option, growth option and } \\
\text { abandonment option, are tested in practice in a } \\
\text { multinational. In all cases the option value was explained } \\
\text { to managers and the difference between the E(NPV) } \\
\text { model and option model made clear. Managers found the } \\
\text { technique useful, especially in investment questions } \\
\text { where flexibility in strategic thinking was needed. }\end{array}$ \\
\hline Peters & $\begin{array}{l}\text { Culture and } \\
\text { the timing of } \\
\text { FDI: the case } \\
\text { of Poland,the } \\
\text { Czech } \\
\text { Republic and } \\
\text { Hungary }\end{array}$ & 1999 & $\begin{array}{l}\text { How should timing affect } \\
\text { investment decisions to } \\
\text { transition countries, also } \\
\text { focusing on cultural } \\
\text { aspects? }\end{array}$ & $\begin{array}{l}\text { In a multiple linear regression, FDI flows from the EU to } \\
\text { the Visegrad countries are checked to find the factors } \\
\text { predicting timing of entry. Variables specified by OLI- } \\
\text { Gravity and real option models are included. In general } \\
\text { the results do not indicate any significant influence of the } \\
\text { option variables included, Deing uncertainty and risk } \\
\text { indicators, on timing of entry. }\end{array}$ \\
\hline $\begin{array}{l}\text { Guiso and } \\
\text { Parigi }\end{array}$ & $\begin{array}{l}\text { Investment } \\
\text { and demand } \\
\text { uncertainty }\end{array}$ & 1999 & $\begin{array}{l}\text { What are the effects of } \\
\text { uncertainty on investment } \\
\text { decision, based on results } \\
\text { from a sample of about } \\
1000 \text { italian manufacturing } \\
\text { firms? }\end{array}$ & $\begin{array}{l}\text { This study does not deal with FDI investments, but does } \\
\text { show clearly the impact of uncertainty on investment } \\
\text { behavior. A subjective uncertainty indicator was created, } \\
\text { using the expectations of firms with respect to growth in } \\
\text { demand in the next three years. Several tests show that } \\
\text { expected demand has a positive effect on the decision to } \\
\text { invest, while uncertainty has a negative effect. The } \\
\text { irreversibility of the investment also plays a significant } \\
\text { role; the impact of uncertainty is more negative if } \\
\text { investments are more irreversible. The impact of } \\
\text { uncertainty is also more negative if the firm has a larger } \\
\text { degree of market power. }\end{array}$ \\
\hline
\end{tabular}




\begin{tabular}{|c|c|c|c|c|}
\hline Lehmann & $\begin{array}{l}\text { Country risiks } \\
\text { and the } \\
\text { investment } \\
\text { activity of } \\
\text { U.S. } \\
\text { multinationals } \\
\text { in developing } \\
\text { countries } \\
\end{array}$ & 1999 & $\begin{array}{l}\text { Develop and test a real } \\
\text { options model that } \\
\text { demonstrates the role of } \\
\text { country specific risks and } \\
\text { sunk costs in determining } \\
\text { a firm's choice of mode of } \\
\text { entry between export and } \\
\text { FDI. } \\
\end{array}$ & $\begin{array}{l}\text { A model is developed to specifically describe an FDI } \\
\text { choice with host countries with different uncertainty } \\
\text { perspectives. Empirical tests are consistent with the } \\
\text { theory prediction that higher risks discourage capitat } \\
\text { expenditures and thus discourage FDI investments. } \\
\text { Investor risk sensitivity goes up in sectors with significant } \\
\text { plant-specific sunk costs. }\end{array}$ \\
\hline Vonnegut & $\begin{array}{l}\text { Joint } \\
\text { ventures and } \\
\text { the option to } \\
\text { expand and } \\
\text { acquire }\end{array}$ & 2000 & $\begin{array}{l}\text { Case study approach } \\
\text { among four investors. } \\
\text { Do irreversibility of an } \\
\text { investment, the urgency of } \\
\text { the investment, the impact } \\
\text { and expectations of } \\
\text { structural shocks and the } \\
\text { uncertainty of the } \\
\text { investment increase the } \\
\text { waiting period before } \\
\text { investing? }\end{array}$ & $\begin{array}{l}\text { A country that wants to attract FDI should focus mainly on } \\
\text { the institutionally dependent investments since firms with } \\
\text { only SR goals are not interesting for the LR development } \\
\text { of a country and resource based FDI does not need any } \\
\text { additional stimulation. In general all firms considered } \\
\text { irreversibility of their investment, the urgency of the } \\
\text { investment, the impact and expectations of structural } \\
\text { shocks and the uncertainty of their investment important } \\
\text { and the way they affected their investment decision was } \\
\text { in accordance with theory. The conclusion of the case } \\
\text { study approach was therefore that the real option theory } \\
\text { does explain investment decisions better than the E(NPV) } \\
\text { rule. }\end{array}$ \\
\hline Altomonte & $\begin{array}{l}\text { FDI in } \\
\text { CEECs and } \\
\text { the theory of } \\
\text { real options: } \\
\text { an empirical } \\
\text { assessment }\end{array}$ & 2000 & $\begin{array}{l}\text { Panel data including } 2500 \\
\text { FDI in CEEC. } \\
\text { Do the real options } \\
\text { variables "opportunity } \\
\text { costs of waiting". } \\
\text { "uncertainty of the local } \\
\text { environment" and } \\
\text { "irreversibility of the } \\
\text { investment" enhance } \\
\text { understanding of FDI } \\
\text { flows, when added to OLI, } \\
\text { Gravity and neo-classical } \\
\text { trade variables? }\end{array}$ & $\begin{array}{l}\text { The inclusion of three real options variables "opportunity } \\
\text { costs of waiting", "uncertainty of the local environment" } \\
\text { and "irreversibility of the investment" in a panel data } \\
\text { analysis explaining FDI flows yieided very promising } \\
\text { results. Both uncertainty variables were significant, with } \\
\text { the expected sign. However, the variable included to } \\
\text { capture the irreversibility of the investments is not } \\
\text { significant. In his conclusion Altomonte states that even } \\
\text { though his results seem to support the real options } \\
\text { theory, still better specifications of country, sector and } \\
\text { firm effects are needed. }\end{array}$ \\
\hline $\begin{array}{l}\text { Calcagnini and } \\
\text { Saltari }\end{array}$ & $\begin{array}{l}\text { Investment } \\
\text { and } \\
\text { uncertainty: is } \\
\text { there a } \\
\text { potential role } \\
\text { for a common } \\
\text { European } \\
\text { Policy? }\end{array}$ & 2001 & $\begin{array}{l}\text { Are investments in the } \\
\text { private sector higher in } \\
\text { areas with lower demand } \\
\text { volatility than in countries } \\
\text { with higher demand } \\
\text { volatility? }\end{array}$ & $\begin{array}{l}\text { Using data from business surveys of seven European } \\
\text { countries, results indicate that investment is positively } \\
\text { associated with higher expected growth rates of } \\
\text { production and lower growth rate volatility. Lower } \\
\text { uncertainty results in higher investments. }\end{array}$ \\
\hline
\end{tabular}




\subsection{Extension of the model: the possibility to choose between two countries}

The real options model, as described in section 2.2, already incorporates many features that make it suitable to interpret real-life investment decisions. Firms use all kinds of cost and benefit variables and can postpone investments. In this model uncertain environments can be modeled accordingly and taken into account in the decision-making. ${ }^{10}$ However, in this model firms still only have the option to choose from one project or country." In reality, firms can select two or more projects they consider interesting for investments. In this section, I will present an extension of the previous model that includes the possibility to select between two FDI alternatives in different countries. ${ }^{12}$ In order to do so, some of the parameters will be defined slightly differently. An elaborate mathematical explanation of this section is included in annex 2.1.

Assume a firm with a single FDI possibility, $\mathrm{FDI}_{\mathrm{A}}$ in country $\mathrm{A}$. The set-up costs of an investment are not included anymore as parameter $\mathrm{I}$, but will be included in $\mathrm{V}$. $V_{A}{ }^{\prime}$ is the net return of the investment in $\mathrm{FDI}_{\mathrm{A}}$ in period one and equals to the value of $\mathrm{FDI}_{\mathrm{A}}$ in period one minus the investment costs $I_{A}$. The net present value rule suggests investing as soon as $V_{A}{ }^{\prime}>0$. However, as was mentioned in section three, the value of $V_{A}{ }^{\prime}$ should be compared with the expected net present value the investment yields if the firm delays its decision. Suppose that the firm also has the option to start $\mathrm{FDI}_{A}$ in period two. " Then if the firm invests in period two the net value of the $\mathrm{FDI}_{\mathrm{A}}$ is equal to $V_{A}{ }^{2}$. If the firm invests in the first period, it cannot recover the initial sunk cost of the investment and restart $\mathrm{FDI}_{A}$ in period two. These sunk costs preclude the firm from setting up $\mathrm{FDI}_{\mathrm{A}}$ at better terms in period two and realizing the potentially higher value $V_{A}^{2}$, because the initial investment is irreversible. To capture the notion that future realizations are uncertain, $V_{A}{ }^{2}$ is a random variable, which is uniformly distributed on the interval $[\mu-\sigma, \mu+\sigma]$. Both $\mu$ and $\sigma$ are strictly positive. The parameter $\mu$ denotes the expected value of $V_{A}^{2}$. The variance of $V_{A}^{2}$ equals $1 / 3 \sigma^{2}$. Therefore, a higher $\sigma$ implies a higher degree of uncertainty surrounding the future benefits of $\mathrm{FDI}_{\mathrm{A}}$. It is not possible to postpone the investment decision even after period two. If the firm's management has delayed the investment decision in period one, it will undertake $\mathrm{FDI}_{\mathrm{A}}$ in period two if the realization of $V_{A}{ }^{2}$ exceeds zero. In case the firm does not invest in period two the investment option expires. An additional assumption is that $\mu<\sigma$. This assumption implies that the probability that the firm does not implement $F I_{A}$ in the second period is strictly positive, because in the worst case scenario $V_{A}^{2}=\mu-\sigma<0^{\text {"4 }}$. To decide whether to invest in period one the firm calculates the expected value of the option to invest in the second period:

$$
F\left(V_{A}\right)=\int_{0}^{\mu+\sigma} \frac{1}{2 \sigma} V_{A}^{2} d V_{A}^{2}=\frac{(\mu+\sigma)^{2}}{4 \sigma}=E>0
$$

The symbol $E$ is introduced to facilitate the discussion in later parts, when two investment choices

\footnotetext{
${ }^{10}$ See Dixit and Pindyck, 1994.

${ }^{11}$ In this section, I assume firms consider an FDI in two different countries. For simplicity I assume in each country, A and B, only one investment can be made. The FDI in country $\mathrm{A}$ is therefore called $\mathrm{FDI}_{\mathrm{A}}$ and the $\mathrm{FDI}$ in country $\mathrm{B}$ is called $\mathrm{FDl} \mathrm{B}_{\mathrm{B}}$

12 The model is taken from Laar van de, M. and W. Letterie, "The delaying effect of financing constraints on investment" (2004), Bulletin of Economic Research, 56 (3), pp. 271-282. This article is also available as Meteor Research Memorandum RM $03 / 2001$.

${ }^{14}$ Without losing generality, I abstract from discounting or similarly, assume the risk-free discount rate equals 0 percent.

${ }^{14}$ The case where $\mu<\sigma$ is definitely more interesting than the alternative case with $\mu>0$, because then the expected value of $\mathrm{FDI}_{\mathrm{A}}$ in period two is always positive and equal to $\mu$. If the investment in period one is postponed, the firm will always invest in period two. limiting the role of uncertainty in the final decision.
} 
are possible. It is optimal to invest in period one if $V_{A}>F\left(V_{A}\right)$. Otherwise the firm will postpone the investment decision until period two. In fact equation three shows that the net present value of the investment in period one, $V_{A}{ }^{1}$, should be strictly larger than zero to be willing to invest in period one. Furthermore it can be shown straightforwardly that the higher the uncertainty as measured by $\sigma$, the higher the value of delaying the investment: $\partial E / \partial \sigma>0$. This result indicates that higher uncertainty tends to inhibit investment. Various studies provide empirical support for this claim (see for instance Guiso and Parigi, 1999; Ghosal and Loungani, 2000). Finally, the delay of the investment becomes more likely as the expected value of $V_{A}{ }^{2}$ increases: $\partial E / \partial \mu>0$.

So far, this section basically repeated the general investment decision model for one project. In reality firms may have to choose among different investment projects due to the lack of financial means. A firm can have an interest in investing in a newly set-up company or joint venture in a foreign country. With such an investment a firm faces large set-up costs and high uncertainty. A firm that is interested in the booming region of Central Europe, based on information available such as macroeconomic performance and business climate indicators, selects for example Poland and the Czech Republic as potential host economies for its FDI. If the company has sufficient resources available to cover all costs involved it can opt for an FDI in both of these countries as long as each of them is expected to have a positive NPV. However, due to limited financial resources a firm may have to choose between Poland and the Czech Republic as a location for its FDI. Based on profitability estimates, the best option today may be to invest in Poland instead of in the Czech Republic. However, imagine the firm knows that next year the Czech Republic adopts a new set of laws that favors foreign investors and thereby increases the prospects of an FDI there tremendously. If the firm invests in Poland today it will not be able to invest in the Czech Republic next year. Due to this uncertainty regarding the enactment of the new law, the firm can decide to postpone its investment in order to keep the possibility to invest in the Czech Republic next year in case this new law is adapted.

The real options approach predicts that the incentive to postpone an investment increases with the amount of uncertainty surrounding the future value of the project. Hence, the higher the uncertainty the higher the probability the firm will suspend investment. Irreversibility plays an important role in the model. If the firm has decided to invest in a certain project previously, it will not be able to recover the initial expenses and use these to start an alternative project later. Similarly, it will not be able to restart the same project at better terms later. Therefore binding financial constraints tend to increase the incentive to wait with investing. The presence of multiple projects provides the firm with an incentive to learn which is the best project.

Suppose now that in addition to $\mathrm{FDI}_{\mathrm{A}}$ the firm has an alternative investment option called $\mathrm{FDI}$. If the firm chooses to invest in $\mathrm{FDl}_{\mathrm{B}}$ in period one this investment yields $V_{B}{ }^{\prime}$. The net present value of $\mathrm{FDI}_{\mathrm{B}}$ in the second period is randomly distributed as well. To simplify the analysis it is assumed that $V_{B}{ }^{2}$ is also uniformly distributed on the interval $[\mu-\sigma, \mu+\sigma]$. In addition, that $V_{A}^{2}$ and $V_{B}{ }^{2}$ are independent. These assumptions affect the generality of the results. However, the main argument presented, that the firm has an incentive to learn which project is the most profitable one, holds in a more general setting as well.

Irreversibility is an important assumption. Suppose that the firm is able to recover the initial expenses of its investments. In that case the firm can for instance invest its financial resources in 
$\mathrm{FDI}_{A}$ in period one. If $\mathrm{FDl}_{B}$ turns out to be more profitable the firm can reverse its decision to implement $\mathrm{FDI}_{A}$ and start $\mathrm{FDI}_{B}$ instead. Irreversibility does not allow for this possibility. Irreversibility implies that a firm has an incentive to wait with investing in a particular project, because the future returns of another competing project may be very promising. An implicit assumption is that the returns of a project implemented in period one are insufficient to provide the required funds to start another project in period two as well.

To simplify the analysis, it is also assumed the firm is not able to acquire any additional external funds to finance investment. The financial resources of the firm may be used to start an investment project. If financial constraints are not binding the firm may choose to invest in both $\mathrm{FDI}_{\mathrm{A}}$ and $\mathrm{FDI}_{\mathrm{B}}$. In fact, the firm should apply the methodology described for one investment possibility to both FDis separately, since the value of the firm is additive in the values of the two FDIs. Thus, the firm will invest in $\mathrm{FDI}_{\mathrm{A}}$ in the first period if and only if $V_{A}^{\prime} \geq F\left(V_{A}\right)$ and consider its investment in the second period otherwise. The firm will undertake $F \mathrm{Fl}_{B}$ in period one if and only if $V_{B}{ }^{\dagger} \geq F\left(V_{B}\right)$ and decide on investment in the second period otherwise. Obviously the value $F\left(V_{B}\right)$ can be derived using the methodology described before.

However, if the firm faces a financial constraint it has the possibility to undertake one project at most. The financial constraint implies that by investing in $\mathrm{FDI}_{\mathrm{A}}$ the firm gives up the option to invest in $\mathrm{FDI}_{\mathrm{B}}$. The decision whether to invest in the first period depends on the expected value of $\mathrm{FDI}_{\mathrm{A}}$ and $\mathrm{FDI}_{\mathrm{B}}$ projects $\mathrm{A}$ and $\mathrm{B}$ in the second period. Therefore, the starting point is solving the firm's decision in the second period.

$\begin{array}{lll}\text { (4) A firm invests in } \mathrm{FDI}_{A} \text { if: } & V_{A}^{2} \geq V_{B}^{2} \text { and } V_{A}^{2} \geq 0, \\ & \text { invests in } \mathrm{FDl}_{B} \text { if: } & V_{B}^{2}>V_{A}^{2} \text { and } V_{B}^{2} \geq 0, \\ \text { does not invest if: } & V_{A}^{2}<0 \text { and } V_{B}^{2}<0 .\end{array}$

Figure 2.2 shows in which instances the firm invests in either $\mathrm{FDI}_{A}, \mathrm{FDl}_{B}$ or abstains from investing in period two. The horizontal axis denotes the possible realizations of $V_{A}^{2}$. The vertical axis depicts the values $V_{B}^{2}$ can assume. In the areas I and II (where $V_{A}^{2} \geq V_{B}^{2}$ and $V_{A}^{2} \geq 0$ ) the firm selects $\mathrm{FDI}_{A}$. The firm prefers $\mathrm{FDI}_{B}$ in the areas denoted by III and IV (where $V_{B}{ }^{2}>V_{A}{ }^{2}$ and $V_{B}{ }^{2} \geq 0$ ). The firm does not invest if $V_{A}{ }^{2}<0$ and $V_{B}{ }^{2}<0$, in which case areas $V$ and $V I$ are relevant. The presence of $F D I_{B}$ in addition to $\mathrm{FDI}_{\mathrm{A}}$ affects the expected net return from investing in period two for two reasons. First, $\mathrm{FDI}_{B}$ allows the firm to obtain a higher return from investment in area III, where the firm would have earned $V_{A}^{2}<V_{B}^{2}$ if $\mathrm{FDl}_{B}$ did not exist. Second, the possibility of selecting $\mathrm{FDl}_{B}$ allows the firm to invest in more instances (area IV).

In the model the firm cannot sell the investment option that it did not implement to another firm, because the option results from firm-specific resources or capabilities that cannot be imitated or transferred to other companies. Therefore in the first period the expected value of the two investment projects is given by (see annex 2.1): 


$$
\begin{aligned}
F\left(V_{A}, V_{B}\right) \quad & =\int_{0}^{\mu+\sigma} \int_{\mu-\sigma}^{V_{A}} \frac{V_{A}}{4 \sigma^{2}} d V_{B} d V_{A}+\int_{0}^{\mu+\sigma} \int_{\mu=\sigma}^{V_{A}} \frac{V_{B}}{4 \sigma^{2}} d V_{A} d V_{B}= \\
& =\frac{\frac{1}{3}(\mu+\sigma)^{3}-\frac{1}{2}(\mu+\sigma)^{2}(\mu-\sigma)}{2 \sigma^{2}}
\end{aligned}
$$

Given the assumption that $\sigma>\mu$ it can be shown after some straightforward calculations that:

(6) $F\left(V_{A}, V_{B}\right)$

$$
=E\left(1 \frac{2}{3}-\frac{1}{3} \frac{\mu}{\sigma}\right)>1 \frac{1}{3} E
$$

where $E$ is defined in equation three. To recall, the quantity $E$ represents the critical value for each investment opportunity at which the firm is willing to undertake either $\mathrm{FDI}_{\mathrm{A}}$ or $\mathrm{FDI}_{\mathrm{B}}$ in period one if the firm does not face a financial constraint. Equation six indicates that the presence of two investment opportunities in combination with a financial constraint raises the critical benchmark at which the firm finds it optimal to invest in the first period by more than 33 percent. This increase is due to the fact that by investing in either $\mathrm{FDI}_{\mathrm{A}}$ or $\mathrm{FDI}_{\mathrm{B}}$ the firm gives up the opportunity to invest in the other project later, which is undesirable because it may yield a favorable outcome in the future.

The results above suggest that the timing of an investment made by financially constrained and unconstrained firms will differ. Suppose that a population of firms exists in which each firm considers the same investment projects, $\mathrm{FDI}_{\mathrm{A}}$ and $\mathrm{FDI}_{\mathrm{B}}$. Firms that do not face a shortage of cash are more likely to start project $\mathrm{FDI}_{\mathrm{A}}$ or $\mathrm{FDI}_{\mathrm{B}}$ in the first period than financially constrained firms, because the critical value $E$ at which these firms are willing to invest is lower than that of the constrained firms. If $\mathrm{FDI}_{\mathrm{A}}$ refers to investing in Poland and $\mathrm{FDI}_{\mathrm{B}}$ denotes the possibility to invest in the Czech Republic, then firms that have enough financial resources and are interested in these regions are more likely to be early investors than their constrained counterparts, since the latter are more inclined to see which region is the best environment.

It can be shown that if the expected value of the future returns of the two projects, $\mu$, increases that:

$$
\frac{\partial F\left(V_{A}, V_{B}\right)}{\partial \mu}=\frac{\mu+\sigma}{2 \sigma}\left(\frac{3}{2}-\frac{1}{2} \frac{\mu}{\sigma}\right)>\frac{\mu+\sigma}{2 \sigma}>0
$$

This result implies that the firm's incentive to delay the investment decision increases with a higher expected future return $\mu$. The same holds if the parameter $\sigma$ measuring the amount of uncertainty surrounding the projects increases:

$$
\frac{\partial F\left(V_{A}, V_{B}\right)}{\partial \sigma}=\frac{\partial E}{\partial \sigma}\left(1 \frac{2}{3}-\frac{1}{3} \frac{\mu}{\sigma}\right)+\frac{1}{3} E \frac{\mu}{\sigma^{2}}>\frac{\partial E}{\partial \sigma}\left(1 \frac{1}{3}\right)+\frac{1}{3} E \frac{\mu}{\sigma^{2}}>0
$$

Therefore, higher uncertainty tends to increase the incentive to postpone investment. 
Figure 2.2: Visualization of the expected values of project $A$ and $B$

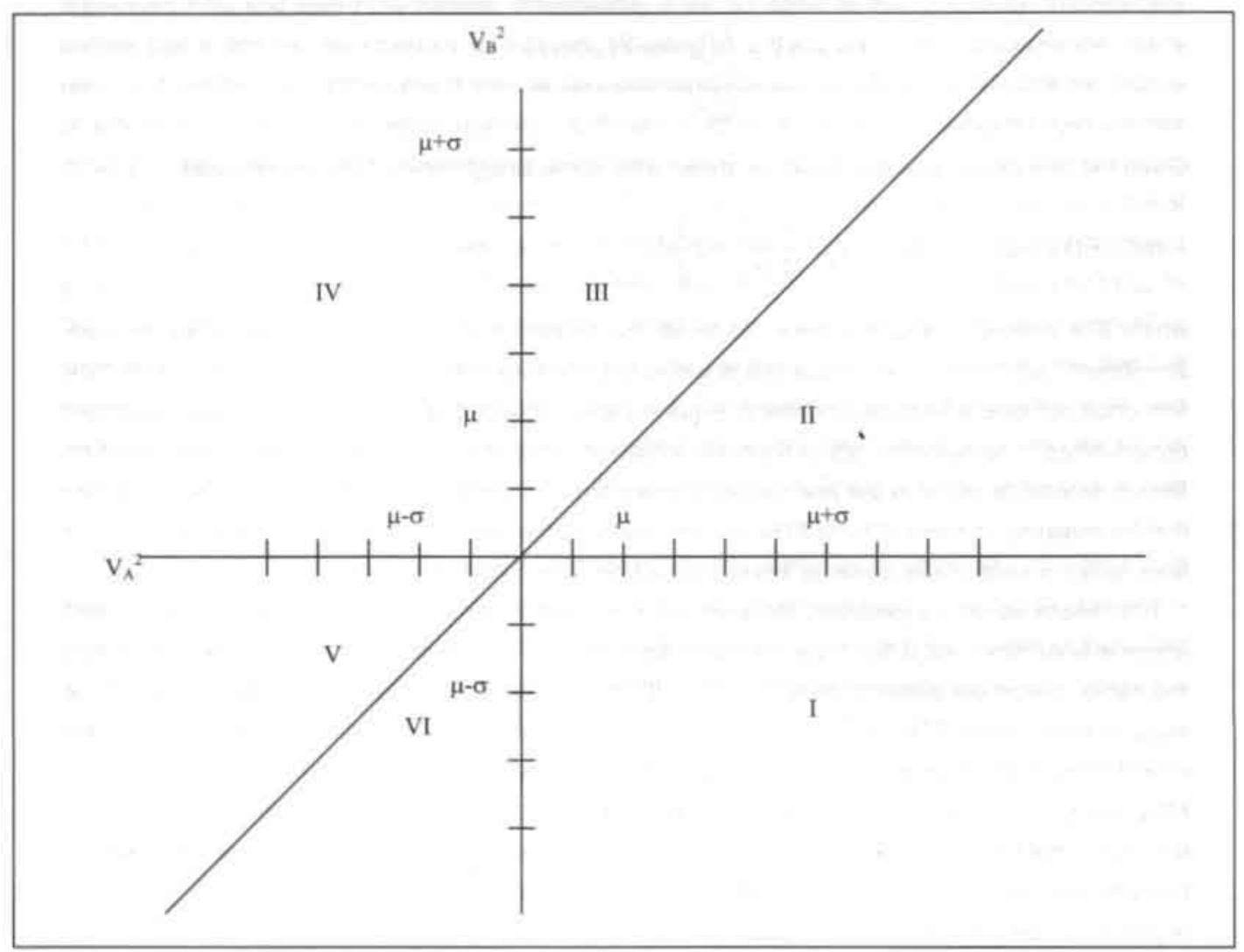

These results also hold if the analysis is extended towards an unlimited amount of firms. The theoretical analysis, in which we expand the investment model from two to $\mathrm{N}$ investment projects from which the firm can choose, can be found in section four of van de Laar and Letterie (2004). The analysis there shows that the more investment projects the firm has to choose from, the higher the possibility is that one of those projects will have a high expected value of future returns. Thus, as $\mathrm{N}$ approaches infinity, the probability that the investment is postponed approaches 100 percent. In conclusion we find that having a larger group of possible projects has several consequences. For financially unconstrained firms, investment decisions can be made separately per project. They will invest in each project that is expected to become profitable. Financially constrained firms will have to select the best alternative for them. This lack of financial means leads those firms to postpone their investment more often. In addition, a higher expected future return of a project also delays the investment decision, as well as a higher rate of uncertainty does. 


\subsection{Real option model with two countries from a different risk category}

The model described in section 2.2 is restrictive, because the firm can only choose from one country in which to invest. In section 2.3 the model is extended and allows for a choice between several FDis in different host countries. However, this model is still restrictive because of the assumption that these countries have equal expected values and equal uncertainty parameters. In reality these assumptions are never the case. Countries differ in many aspects, all influencing a project's expected value and uncertainty.

In this section I argue that, when choosing between two countries with different uncertainty, the investment decision will more likely be postponed than when looking at only one project or two projects with equal uncertainty. I build my reasoning on the results obtained in the previous sections and refrain from mathematical derivations.

Assume that the same conditions hold as in the previous section, being that investments are irreversible and investment is only possible in either period one or period two. ${ }^{15}$ If a firm only considers an FDI in country $\mathrm{A}$, it will invest in period one as long as investing today will be profitable $\left(V_{1}^{1}>0\right)$ and investing today will be more beneficial than waiting one more period and invest in period two, so $V_{A}^{1}>F\left(V_{A}\right)$. If the choice of a firm is extended with one more country, the conditions are extended accordingly. A firm will now only invest in period one in $\mathrm{FDI}_{\mathrm{A}}$ if that is more profitable than investing in country $\mathrm{B}\left(\mathrm{FDl}_{\mathrm{B}}\right)$ in period one, but also more beneficial than investing in $\mathrm{FDI}_{\mathrm{A}}$ or $\mathrm{FDI}_{\mathrm{B}}$ in period two. These assumptions are summarized in equation eleven.

(9) Invest in $\mathrm{FDI}_{A}$ in period one if: $\quad-V_{A}^{1}>0$

$$
\begin{aligned}
& -V_{A}^{1}>F_{0}\left(V_{A}^{2}\right) \\
& -V_{A}^{1}>V_{B}^{1} \\
& -V_{A}^{1}>F_{0}\left(V_{B}^{2}\right)
\end{aligned}
$$

If one of these conditions does not hold, the investment will be postponed until period two. If the expected values $\mu$ for $F D I_{A}$ and $F D l_{B}$ in period two, as well as variances $\sigma^{2}$ of $V_{A}{ }^{2}$ and $V_{B}{ }^{2}$ are equal, the probability of investing in $\mathrm{FDI}_{\mathrm{A}}$ in period one (respective two) is the same as the probability of investing in country $B$ in period one (two).

Now assume due to some incident, the uncertainty of country $B$ increases to twice the uncertainty in country $\mathrm{A}$ and the expected value $\mu$ remains equal for both $\mathrm{A}$ and $\mathrm{B}$. As was mentioned in section 2.3 , the impact of uncertainty on the model is twofold. As uncertainty increases, the critical value of a firm to invest in an FDI in period one, $V$, increases and the option value of an investment, $F(V)$. increases. With higher uncertainty it is more interesting to keep an option.

The increase of uncertainty in country $\mathrm{B}$ means that the critical value $\mathrm{V}^{*}$ of $\mathrm{FDl}_{\mathrm{B}}$ in period one increases, as well as the option value $F\left(V_{B}\right)$. A postponement of the investment in $\mathrm{FDI}_{B}$ will be more likely. In addition, as can be seen from equation eleven, a postponement of $\mathrm{FDI}_{\mathrm{A}}$ will be more likely. even though the uncertainty or expected value in country A did not increase. This increased chance of postponement is due to the condition that investment in country $\mathrm{A}$ in period one will only be undertaken if the value of the investment is also higher than the option value of investing in country $B$

\footnotetext{
${ }^{15}$ Discrete two period time model.
} 
in period two, namely $V_{A}^{1}>F\left(V_{B}\right)$. No changes have occurred on the left hand side of this equation, whereas the right-hand side increased in value.

In practice, this interrelated effect of uncertainty may be important when looking at alternative host countries. An increase in the uncertainty of one host country can lead to the postponement of an investment in another - still lower risk - alternative host country. Given the fact that considering countries with a higher uncertainty will also lead to postponement of possibly viable investment with a lower uncertainty risk, it seems reasonable to assume that firms will only consider countries of equal risk as alternative host countries. A country that considers an investment in Poland may think of the Czech Republic as a nice alternative, but may not yet consider Kazakhstan or Afghanistan, since those host countries deviate largely in investment uncertainty with Poland.

\subsection{Conclusions}

In this chapter I gave a description and literature overview of the reak option model and extended the model. In order to explain FDI decisions better, the option model is an appropriate model. The option model assumes the investment decision is uncertain and investments are irreversible.

In section 2.2 the option model is described in detail. The option model provides a decision rule based on expected values of investments and argues firms will invest as long as the expected value of investment is positive and the expected value of investing today is higher than the expected value of investing later. Still, due to uncertainty and irreversibility of the investments it can be more beneficial to wait with an investment and invest at a later time. By buying an option, a firm has the right to invest at a later time, but it does not have the obligation to do so. Thus, if the situation changes negatively, the firm does not have to exercise the option and will postpone the investment. In section 2.3 and 2.4 the option model is extended as to allow for several investment projects from which to choose. Instead of only considering one investment alternative, firms may consider two, three or even more alternatives before deciding where to invest. The analysis shows that by allowing for several projects from which to choose, firms are more likely to postpone their investment.

Summarizing, based on the models theoretical predictions investment decisions of direct investments are dependent on four important aspects, being the irreversible set-up costs, uncertainty of the investment, financial constraints and number of alternative host countries. Companies without financial constraints are more likely to invest sooner, as well as companies with low irreversible set-up costs. A higher uncertainty will delay an investment decision and companies that consider several alternatives are also less likely to invest than companies that consider only one possible FDI location. 


\section{Annex 2.1 Mathematical derivations related to section 2.3}

$V_{A}{ }^{1}$ is the value of the project in period one. $V_{A}{ }^{2}$ is the expected value of the project in period two and is assumed to be a random variable, which is uniformly distributed on the interval $[\mu-\sigma, \mu+\sigma]$. Both $\mu$ and $\sigma$ are strictly positive. The parameter $\mu$ denotes the expected value of $V_{A}{ }^{2}$ and the variance of $V_{A}{ }^{2}$ equals $1 / 3 \sigma^{2}$.

\section{Proposition 1:}

If the management of the firm delays the investment in period one, it will invest in period two if $V_{A}^{2}$ exceeds zero. The expected value of the option to invest in period two equals $E$. Thus, $V_{A}{ }^{t}$ should be strictly larger than $\mathrm{E}$ (and thus than zero) in order to invest in period one.

$$
F\left(V_{A}\right)=\int_{0}^{\mu+\sigma} \frac{1}{2 \sigma} V_{A}^{2} d V_{A}^{2}=\frac{(\mu+\sigma)^{2}}{4 \sigma}=E>0
$$

Proof:

A firm invests in period two if the value of the project is positive, so the sum between 0 and $\mu+\sigma$ of the values at which the firm will invest gives the option value.

$$
\begin{aligned}
& F\left(V_{A}\right)=\int_{0}^{\mu+\sigma} \frac{1}{2 \sigma} V_{A}^{2} d V_{A}^{2}=\left[\frac{\left(V_{A}\right)^{2}}{4 \sigma}\right]_{0}^{\mu+\sigma}=\left[\frac{(\mu+\sigma)^{2}}{4 \sigma}-\frac{(0)^{2}}{4 \sigma}\right]=\frac{(\mu+\sigma)^{2}}{4 \sigma} \text { and } \\
& \mathrm{E}=\frac{(\mu+\sigma)^{2}}{4 \sigma}>0
\end{aligned}
$$

A firm invests in period one if $V_{A}^{1}>F\left(V_{A}\right)$ thus if $V_{A}^{1}>\mathrm{E}$.

\section{Proposition 2a:}

A higher uncertainty $\sigma$ leads to a larger possibility of delaying the investment.

Proof:

$\frac{d E}{d \sigma}=\frac{4 \sigma(2(\mu+\sigma) 1)-(\mu+\sigma)^{2} 4}{(4 \sigma)^{2}}=\frac{4 \sigma^{2}-4 \mu^{2}}{(4 \sigma)^{2}}=\frac{\sigma^{2}-\mu^{2}}{4 \sigma^{2}}$

Given $\sigma>\mu$, and $4 \sigma^{2}>0$, then $\frac{d E}{d \sigma}>0$.

Since $\mathrm{E}$ increases if $\sigma$ increases, $V_{A}^{1}$ should be higher as well to exceed $\mathrm{E}$

\section{Proposition 2b:}

A higher expected value of the investment leads to a higher possibility of delaying the investment.

Proof:

$$
\frac{d E}{d \mu}=\frac{4 \sigma(2 \mu+2 \sigma)}{(4 \sigma)^{2}}=\frac{\mu+\sigma}{2 \sigma}
$$


Given $\mu+\sigma>0$ and $\sigma>0, \frac{d E}{d \mu}>0$.

Since $E$ increases if $\mu$ increases, $V_{A}^{1}$ should be higher as well to exceed $\mathrm{E}$.

\section{Proposition 3:}

Extending the investment choice with an alternative investment, increases the chance a firm will postpone its investment in period one.

\section{Proof:}

In section 2.3 is assumed that $\mu$ and $\sigma$ are equal for project $\mathrm{A}$ and $\mathrm{B}$, thus the two projects can be considered equal in mathematical calculations.

$$
\begin{aligned}
& F\left(V_{A}, V_{B}\right)=\int_{0}^{\mu+\sigma} \int_{\mu-\sigma}^{V_{A}} \frac{V_{A}}{4 \sigma^{2}} d V_{B} d V_{A}+\int_{0}^{\mu+\sigma} \int_{\mu=\sigma}^{V_{B}} \frac{V_{B}}{4 \sigma^{2}} d V_{A} d V_{B}=2 \int_{0}^{\mu+\sigma^{2}} \int_{\mu-\sigma}^{V_{A}} \frac{V_{A}}{4 \sigma^{2}} d V_{B} d V_{A} \\
& F\left(V_{B}\right)=\frac{V_{A} V_{B}}{4 \sigma^{2}} \text { and } \frac{\partial F\left(V_{B}\right)}{\partial V_{B}}=\frac{V_{A}}{4 \sigma^{2}} \\
& F\left(V_{A}, V_{B}\right)=2 \int_{0}^{\mu+\sigma}\left[\frac{V_{A} V_{B}}{4 \sigma^{2}}\right]_{\mu-\sigma}^{\beta_{A}} d V_{A}=2 \int_{0}^{\mu+\sigma} \frac{V_{A}^{2}-V_{A}(\mu-\sigma)}{4 \sigma^{2}} d V_{A}= \\
& \frac{1}{2 \sigma^{2}} \int_{0}^{\mu+\sigma} V_{A}\left(V_{A}-\mu+\sigma\right) d V_{A} \\
& F\left(V_{A}\right)=\frac{1}{3} V_{A}^{3}-\frac{1}{2} \mu V_{A}^{2}+\frac{1}{2} \sigma(\mu+\sigma)^{2} \text { and } \frac{\partial F\left(V_{A}\right)}{\partial V_{A}}=V_{A}^{2}-\mu V_{A}+\sigma V_{A} \\
& \text { As } F\left(V_{A}, V_{B}\right)=\frac{1}{2 \sigma^{2}}\left[\frac{1}{3} V_{A}^{3}-\frac{1}{2} V_{A}^{2}+\frac{1}{2} \sigma V_{A}^{2}\right]_{0}^{\mu+\sigma^{A}} \text {. } \\
& F\left(V_{A}, V_{B}\right)=\frac{\frac{1}{3}(\mu+\sigma)^{3}-\frac{1}{2}(\mu+\sigma)^{2}(\mu-\sigma)}{2 \sigma^{2}}= \\
& \frac{2 / 3(\mu+\sigma)^{2}(\mu+\sigma)-\left(\mu+\sigma^{2}\right)(\mu-\sigma)}{4 \sigma^{2}} .
\end{aligned}
$$

Include $\mathrm{E}=\frac{(\mu+\sigma)^{2}}{4 \sigma}$ in equation 5 leads to

$$
\mathrm{F}\left(\mathrm{V}_{\mathrm{A}}, \mathrm{V}_{\mathrm{B}}\right)=\mathrm{E}\left(\frac{2 / 3(\mu+\sigma)-(\mu-\sigma)}{\sigma}\right)=E\left(\frac{5}{3}-\frac{1}{3} \frac{\mu}{\sigma}\right)
$$

By assumption, $\sigma>\mu$, so $\frac{\mu}{\sigma}<1$. Thus, $\left(\frac{5}{3}-\frac{1}{3} \frac{\mu}{\sigma}\right)>\frac{4}{3}$.

$\mathrm{F}\left(\mathrm{V}_{\mathrm{A}}, \mathrm{V}_{\mathrm{B}}\right)>\frac{4}{3} E$, thus $\mathrm{F}\left(\mathrm{V}_{\mathrm{A}}, \mathrm{V}_{\mathrm{B}}\right)>\mathrm{F}\left(\mathrm{V}_{\mathrm{A}}\right)$ 


\section{Proposition 4a:}

A higher expected value of the investment $\mu$ leads to a higher value of delaying the investment.

Proof:

$$
\frac{\partial F\left(V_{A}, V_{B}\right)}{\partial \mu}=\frac{3}{6 \sigma^{2}}(\mu+\sigma)^{2}-\left(\frac{2}{4 \sigma^{2}}(\mu+\sigma)(\mu-\sigma)+\frac{1}{4 \sigma^{2}}(\mu+\sigma)^{2}\right) .
$$

Further mathematical simplifications lead to:

$$
\frac{\partial F\left(V_{A}, V_{B}\right)}{\partial \mu}=\frac{\mu+\sigma}{2 \sigma}\left(\frac{3}{2}-\frac{1}{2} \frac{\mu}{\sigma}\right) .
$$

Given $\sigma>\mu, \frac{3}{2}-0.5\left(\frac{\mu}{\sigma}\right)>1$, then

$$
\frac{\partial F\left(V_{A}, V_{B}\right)}{\partial \mu}=\frac{\mu+\sigma}{2 \sigma}\left(\frac{3}{2}-\frac{1}{2} \frac{\mu}{\sigma}\right)>\frac{\mu+\sigma}{2 \sigma}>0
$$

\section{Proposition 4b:}

A higher uncertainty $\sigma$ leads to a higher probability of delaying the investment.

Proof:

$$
\frac{\partial F\left(V_{A}, V_{B}\right)}{\partial \sigma} \mid F\left(V_{A}, V_{B}\right)=E\left(\frac{5}{3}-\frac{1}{3} \frac{\mu}{\sigma}\right)=\frac{\partial E}{\partial \sigma}\left(\frac{5}{3}-\frac{\mu}{3 \sigma}\right)+E\left(\frac{\mu}{\sigma^{2}}\right)
$$

Given $\sigma>\mu, \frac{\mu}{\sigma}<1$, and given $\frac{\partial E}{\partial \sigma}\left(\frac{5}{3}-\frac{\mu}{3 \sigma}\right)>\frac{4}{3}$ then $\frac{\partial F\left(V_{A}, V_{B}\right)}{\partial \sigma}>0$. 


\title{
Chapter 3 Determinants of Dutch investments in transition countries
}

\author{
"The usurpation, so characteristic for times of chaos and confusion, spreads. All kinds of \\ commanders, leaders, innovators and liberators come and go. The best test in such countries is \\ to visit them a few times a year. Each time you see new faces and hear new names. But what \\ happened to the old ones? Unknown. Did they hide? Did they set up a new company? Did they \\ mention they would be right back? It is for a reason that such a ride in an amusement park, that \\ goes up and down with enormous speed, is called 'Russian Mountain"' \\ (Ryszard Kapuścinski (1993), Imperium, Decline of a World Power)
}

\subsection{Introduction}

The determinants of Foreign Direct Investments (FDI) are frequently studied. The reason is straightforward: if the determinants of FDI are known, policy to attract FDI can be better targeted. The determinants of FDI can be divided in macro- and microdeterminants. The macro level determinants are exogenous to the firm, for instance the GDP of the host country. Many macroeconomic determinants significantly explain FDI flows. The influence of those factors for Dutch FDI flows is discussed in chapter five. The microlevel determinants are endogenous to the firm, like the size of the firm or the expenditures on research and development. This chapter focuses on the relation between those micro- or firm-level determinants and Dutch FDI flows and tries to answer which Dutch firms invest in transition countries and which factors influence those investments decisions.

Much research exists on which firms are most likely to be internationally active and what variables determine or influence foreign investments. There are four major reasons to focus on these questions in this dissertation again, instead of simply summarizing the results of those studies. First, the real option model is taken as starting point for this chapter (see chapter two). Reason to do so is the fact that the new insights from the model can lead to expectations or hypotheses on investment determinants that deviate from the expectations of other economic models. Second, the internationally accepted results from theory and empirics might not hold for Dutch firms. The Dutch people have always been considered a nation of traders. For centuries they have been active in international business and as a consequence an international orientation may be more present in the Dutch business culture than in other countries. In addition, the Netherlands is a small country that needs to be internationally oriented to thrive economically. Third, the internationally accepted results also might not hold when the host countries of the foreign direct investments are located in Central and Eastern Europe and Central Asia (transition countries). The transition countries have been predominantly closed to international investments and trade during the last 45 to 70 years.' Even after the regime changes in the early 1990 s the business environment contains relatively few international firms active in the market, the institutional framework is underdeveloped and the political and economic environment is rather unstable. All these factors increase the uncertainty in this region, but

\footnotetext{
'The countries of the former Soviet Union started their planned economies early 20th century. The countries of Central and Eastern Europe were added to this group of countries after the Second World War. Since 1967 only six countries allowed foreign participation, mainly in the form of joint ventures. For more information see chapter one box 1.1.
} 
it remains questionable whether these factors also decrease the attractiveness of the region. Fourth, the results might not hold when only firms that are interested in investing internationally are considered in the analysis. In most research, the sample of firms studied includes both firms that are interested in FDI as well as firms that are not at all interested in investing internationally. This study is based on a unique dataset that includes a specific sample of Dutch firms. The main advantage of the dataset is that all firms included in this study were interested in the Central and Eastern Europe and Central Asia when participating in the survey of Dutch investments in this region. The firms had already applied for information on this region or participated in seminars on doing business or investing in the region. Of those firms, firms invested in the CEE region and firms decided not to invest, but all had a serious interest in the region. Literature suggests there are differences between firms that invest internationally and firms that do not have any interest in international business operations. However, it is very likely that the differences are less distinctive when only firms that all had seriously considered investing abroad are included in the sample."

The second paragraph of this chapter gives a literature overview of the theoretical and empirical research on the different characteristics of internationally and nationally oriented firms. The different expectations with respect to investment behavior of Dutch firms, when considering the option theory as guideline, are clarified in this section. Section three provides information on Dutch FDI behavior over the last decades, specifically in the transition region. In addition, summary characteristics of the firms included in the survey are given, divided in firms that invested in one or more transition countries (investors) and firms that did not invest in this region (noninvestors). This section is based on both nationally aggregated and survey data. Section 3.4 includes an analysis on the first investment of Dutch firms in a transition country after 1989, using the survey data as source of information. The main question discussed is which factors influence whether a firm invests in this region. In section 3.5 allowing for multiple investments by one firm extends the analysis. All investments, including investments in different countries as well as several locations in the same country, are included. Thereby, the effect of experience of investments in other transition countries and previous investments in the same country is taken into account when trying to determine what factors influence investments. Section 3.6 concludes.

\subsection{Firm characteristics as FDI determinants}

The choice to start an FDI is in principle based on several factors, including factors like return, risk and control (Agarwal and Ramaswami (1992), Dunning (1988), Meyer (1998)), In investment decisions, like FDI decisions, there is a trade off between returns and risks. The more uncertain an investment in a foreign country is, the higher the expected return must be to make an FDI interesting for a firm. In addition, a firm will only invest if it expects the investment to be profitable and if investing now is expected to be more profitable than investing at a later time ${ }^{2}$ Control refers to the necessity to directly influence the functioning of the firm in the foreign market. When the need for control is high, FDI is a suitable investment mode for a firm. If control is less important, export or license agreements are more appropriate investment modes (Agarwal and Ramaswami (1992). Erramilli and Rao (1993),

\footnotetext{
${ }^{2}$ The possibility of postponing an investment is extensively elaborated on in the investment option literature. This is discussed in chapter 2.2 of this dissertation. See for instance Dixit and Pindyck (1994) or Trigeorgis (1999). For a theoretical approach of the option theory specifically applied to FDI decisions, see Capel (1992).
} 
Hennart and Larimo (1998)). The focus on the factors return, risk and control coincide largely with the OLI theory of Dunning, where an ownership choice, location choice and internalization choice are placed central (see for instance Dunning (1977, 1988, 2001). Ownership advantages should be present for a firm from the home country to operate more efficient than firms in the host country. Location advantages must be present in the host country compared to other countries including the home country to make it attractive to invest there. Internalization advantages must be present in order to make it more beneficial to integrate all activities within the firm than to subcontract the activities. In order for the real option model to be applicable, I assume the ownership advantages are present for the firms seriously interested in an FDI. If location advantages and internalization advantages are sufficiently high for a certain host country, the decision to invest will be taken based on the option model. ${ }^{2}$

The option model as described in section 2.2 and 2.3 mentions three major aspects that influence an investment decision; financially binding constraints, uncertainty of an investment and irreversibility of an investment. Firms need human and financial resources to absorb the increased costs and activities related to an investment. The theory assumes that firms without financially binding constraints can invest in all alternative projects as long as the expected value is positive and exceeds the option value of waiting for each of those projects separately. Firms with a financial constraint have to choose between the alternative projects and are therefore more inclined to postpone an investment. Measuring financial constraints is difficult. Size, profitability, or growth in the firm often serve as a proxy for the amount of skills and resources of a firm. In general larger firms are expected to have more internal resources available for an investment or have better possibilities to finance its investment externally. ${ }^{4}$ Thus, larger firms more likely do not have a financially binding constraint and invest sooner. Most empirical research confirms a positive relationship between size and FDI (Horst (1972), Grubaugh (1987), Agarwal and Ramaswami (1992), Li and Guisinger (1992), Pennings and Sleuwaegen (1997), Meyer, (1998), Altomonte (1998)). Existing high profitability and growth are also expected to increase FDI activities, but the empirics suggest these effects are less important and many studies also find an insignificant or even negative relation ( $\mathrm{Li}$ and Guisinger (1992). Pennings and Sleuwaegen (1997), Horst (1972), Kimura and Lee (1998), Meyer (1998)). Age can also be considered an indication of financial constraints. Older firms have more experience in business and therefore may have a more creditworthy status than younger firms. They may have less difficulty in obtaining the necessary financial means to support their investment. However, empirical studies do not show a significant age effect in FDI decisions.

Uncertainty influences the investment decision negatively; the higher the uncertainty, the larger the chance a firm will postpone its investment. The uncertainty of an investment is broadly said dependent on the characteristics of the host country as well as the characteristics of the firm. In chapter five the impact of host country characteristics is described more elaborately, but generally speaking a the economic development of a country, a stable business climate and a stable political environment decrease investment uncertainty and increase the chance a firm invests. With respect to firm level characteristics, specific skills, like management skills or experience in a region, decrease the uncertainty surrounding the investment and increase the chance for a firm to engage in an FDI.

\footnotetext{
${ }^{3}$ To review the decision mechanism for an FDI in one or multiple host countries, see section 2.2 and 2.3 of this dissertation.

In some theories low growth and profitability may serve as a reason to look for alternative possibilities abroad and will increase the chance to start an FDI. See for instance Kimura and Lee, 1998.
} 
The presence of international activities and the existence of trade relations with the host country at the time of the new investment are often used as proxies for these skills (Agarwal and Ramaswami (1992), Li and Guisinger (1992), Kimura and Lee (1998)).

The irreversible set-up costs of an investment negatively influence the investment decision; the higher those irreversible set-up costs are, the larger the chance the firm will postpone its investment. The sector the firm is active in can serve as proxy for those set-up costs. There are basically three kinds of FDI; market seeking FDI, cost oriented FDI and strategic investments. The market seeking FDI is set up to serve the local market with existing products. ${ }^{6}$ This generally does not involve the establishment of costly production facilities and these activities often can start at small scale. Therefore the irreversible costs are relatively low and firms invest sooner. Examples of sectors that are market seeking are the retail sector or logistic sector. An investment in sectors where production is reallocated is often cost oriented. Cost saving often occurs in labor intense, resource specific or technological advanced production processes (Pennings and Sleuwaegen (1997). (Altomonte (1998), Pennings and Sleuwaegen, (1997), Djarova (2004)). Examples of sectors with relatively many cost oriented investments are the industrial sector, agricultural sector and construction sector'. Because of the involvement of production facilities, irreversible set-up costs are high and investments in those sectors are more often postponed. The last form of FDI, strategic FDI, is harder to be linked to a specific sector. Strategic asset investments are for example undertaken in order to diversify risks geographically or to deal with foreign or local competition (first mover advantage ${ }^{a}$ ). These investments are most likely small-scale investments involving low irreversible set-up costs. In the option literature they are considered an option to expand the activities later. Investments in joint ventures are often taken as proxy for a platform investments, with greenfield or brownfield investments as marketseeking or cost-oriented counterparts." The relation between sector of activity and investments based on the option model contradicts the general findings in the literature. Altomonte (1999) and Penning and Sleuwaegen (1997) find that firms in sectors in which economies of scale are more likely or sectors where production is labor intense more often engage in FDI, based on the cost-saving arguments. On the other hand, other researchers found that sector divisions do have an insignificant effect in FDI choices (Horst (1972), Grubaugh (1987)). Last, research and development expenditures (R\&D) are often included in analysis, since the firms engaging in more technology oriented sectors are often more innovation minded and have a competitive advantage in product differentiation. In addition technology oriented firms have a better negotiating position with the host economies with respect to their terms of entrance (Grubaugh (1987), Kimura and Lee (1998), Meyer (1998), Altomonte (1999)). A literature overview, summarizing these results, is included in table 3.1.

\footnotetext{
"On the other hand, investments in risky environments often offer possibilities for short term successes or relatively large profits, for instance because the market is not served yet, local and foreign competition is absent or regulations are unclear and leave room for a lot of flexibility.

'Starting an FDI in a host country can be with the purpose to increase sales in the host country (opening a sales office, no production facility), resulting in an increase in the scale of production at home with lower per unit costs (economies of scale in the home country). Other arguments for market seeking FDI are the replacement of exports to the host country or finding a market for products that are no longer in demand in the home country (Djarova, 2004).

"If firms from the construction sector invest in sector-specific machinery the set-up costs are high. If, however, they are purely market oriented, try to serve the local market and use the production factors from the mother firm, the irreversible set-up costs will be lower.

"First mover investments (or other strategic investment decisions) can lead to a market position that in the short run may not be profitable, but that will prevent local or foreign competitors to enter the market. Therefore the longer run presence in the market, that is expected to be profitable, will be guaranteed. (Kogut, and Kulatilaka (1994)).

${ }^{9}$ Greenfield investments are newly established firms, brownfield investments are takeovers.
} 
Table 3.1: Empirical research on decisions to enter a foreign country

\begin{tabular}{|c|c|c|c|c|c|c|c|c|c|c|}
\hline Study & Title & Sample & Test & $\frac{\mathrm{c}}{\mathrm{N}}$ & 율 & $\frac{9}{8}$ & 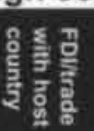 & 쭝 & $\frac{B}{6}$ & कू \\
\hline Horst (1972) & $\begin{array}{l}\text { Firm and Industry } \\
\text { Determinants of } \\
\text { the Decisions to } \\
\text { Invest Abroad: an } \\
\text { Empirical Study }\end{array}$ & $\begin{array}{l}1191 \text { US } \\
\text { manufactu- } \\
\text { ring firms }\end{array}$ & $\begin{array}{l}\text { Which factors } \\
\text { are } \\
\text { determinants } \\
\text { for investing in } \\
\text { Canada }\end{array}$ & + & - & - & & & Insig & Insig \\
\hline $\begin{array}{l}\text { Grubaugh } \\
\text { (1987) }\end{array}$ & $\begin{array}{l}\text { Determinants of } \\
\text { Foreign } \\
\text { Investment }\end{array}$ & $\begin{array}{l}300 \text { US } \\
\text { manufactu- } \\
\text { ring firms }\end{array}$ & $\begin{array}{l}\text { Which factors } \\
\text { are } \\
\text { determinants } \\
\text { for becoming } \\
\text { multinational }\end{array}$ & + & & & & + & & Insig \\
\hline $\begin{array}{l}\text { Agarwal and } \\
\text { Ramaswami } \\
\text { (1992) }\end{array}$ & $\begin{array}{l}\text { The choice of } \\
\text { foreign market } \\
\text { entry mode: } \\
\text { impact of } \\
\text { ownership. } \\
\text { location and } \\
\text { internalization } \\
\text { factors }\end{array}$ & $\begin{array}{l}97 \text { US } \\
\text { leasing firms }\end{array}$ & $\begin{array}{l}\text { Which factors } \\
\text { are } \\
\text { determinants } \\
\text { for becoming } \\
\text { multinational }\end{array}$ & + & & & + & & Insig & \\
\hline $\begin{array}{l}\text { Li and } \\
\text { Guisinger. } \\
\text { (1992) }\end{array}$ & $\begin{array}{l}\text { The globalization } \\
\text { of service } \\
\text { multinationals in } \\
\text { the TRIAD } \\
\text { regions: Japan, } \\
\text { Western Europe } \\
\text { and North } \\
\text { America }\end{array}$ & $\begin{array}{l}168 \text { largest } \\
\text { service firms } \\
\text { from Japan. } \\
\text { Western } \\
\text { Europe and } \\
\text { the US }\end{array}$ & $\begin{array}{l}\text { Which factors } \\
\text { are } \\
\text { determinants } \\
\text { for becoming } \\
\text { multinational }\end{array}$ & + & + & + & + & & Insig & \\
\hline $\begin{array}{l}\text { Pennings } \\
\text { and } \\
\text { Sleuwaegen } \\
\text { (1997) }\end{array}$ & $\begin{array}{l}\text { International } \\
\text { Relocation: Firm } \\
\text { and Industry } \\
\text { Determinants }\end{array}$ & $\begin{array}{l}92 \text { Belgian } \\
\text { firms }\end{array}$ & $\begin{array}{l}\text { What are the } \\
\text { determinants } \\
\text { of international } \\
\text { relocations of } \\
\text { firms }\end{array}$ & + & + & + & & & Insig & + \\
\hline $\begin{array}{l}\text { Kimura and } \\
\text { Lee (1998) }\end{array}$ & $\begin{array}{l}\text { Korean Direct } \\
\text { Investment in } \\
\text { manufacturing: in } \\
\text { patterns and } \\
\text { determinants - an } \\
\text { empirical analysis }\end{array}$ & $\begin{array}{l}414 \text { Korean } \\
\text { manufactu- } \\
\text { ring firms }\end{array}$ & $\begin{array}{l}\text { Pattem and } \\
\text { determinants } \\
\text { of Korean FDI } \\
\text { in } \\
\text { manufacturing } \\
\text { industries }\end{array}$ & & - & - & + & + & Insig & \\
\hline Meyer (1998) & $\begin{array}{l}\text { Direct Investment } \\
\text { in Economies in } \\
\text { Transition }\end{array}$ & $\begin{array}{l}229 \text { British } \\
\text { and German } \\
\text { firms }\end{array}$ & $\begin{array}{l}\text { Which factors } \\
\text { determine } \\
\text { activity in } \\
\text { Central and } \\
\text { Eastem } \\
\text { Europe }\end{array}$ & + & - & 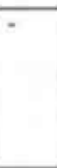 & & + & Insig & \\
\hline $\begin{array}{l}\text { Altomonte } \\
\text { (1998) }\end{array}$ & $\begin{array}{l}\text { FDI in the CEECs } \\
\text { and the Theory of } \\
\text { Real Options: an } \\
\text { empirical } \\
\text { assessment }\end{array}$ & $\begin{array}{l}2500 \\
\text { investments } \\
\text { undertaken } \\
\text { by European } \\
\text { Multinational } \\
\text { Enterprises }\end{array}$ & $\begin{array}{l}\text { What are the } \\
\text { determinants } \\
\text { of FDI in } \\
\text { Central and } \\
\text { Eastern } \\
\text { Europe }\end{array}$ & + & & & & + & Insig & + \\
\hline
\end{tabular}

Note: $+(-)$ indicates a positive (negative) significant effect of that factor on investments. Insig stands for insignificance of the factor. An empty box indicates the factor was not included in that study.

Based on the literature review, I expect Dutch firms with an FDI in a transition country to be larger and older than Dutch firms without an FDI, since those firms are less often financially constrained. In addition I expect a firm with several owners of different nationalities to have an FDI more often than firms with full Dutch ownership, since firms that face international influence are possibly also more internationally focused. Furthermore firms that already had trade relations with a firm(s) in a transition country are expected to invest in the region more often than firms without these trade relations. Those factors all decrease the uncertainty of the investment. Last, based on the size and irreversibility of the 
set-up costs I expect firms in the agricultural, industrial and construction sectors to be less likely to invest than firms in other sectors. On the other hand investments in those sectors are likely to benefit from lower production costs, which could be a valid argument to reverse the expectations. I do not expect the results to be as distinctive as can be expected based on the literature. The fact that the firms in the sample already showed serious interest in the region makes the distinction between the investors and noninvestors less large..$^{10}$

Up to this point, only the empirical literature on the decision to invest or not is discussed. An additional aspect of an FDI decision is the timing of investments. The timing of the investment is a complex decision, which is highly affected by the risk indication of the host country. Investing in a risky country may lead to more profitable opportunities than investing in a low risk country, but it is also more risky for the company. This argument is particularly valid for when looking at the region of Central and Eastern Europe. Investing immediately after the start of transition, in the years 1989 to 1991, was risky since legal frameworks, property rights, institutions and economic reforms were not yet in place. On the other hand an early move could lead to high profits (early mover advantages). The further countries proceed in the transition process, the more stable they become. I anticipate country stability to be more influential than early mover advantages and expect the chances that firms invest, both for the first as well as for subsequent times, to increase as time goes on.

\subsection{Facts and figures on Dutch investments and investors}

The flows and stock of Dutch outward direct investments increased constantly since 1987 (see figure 3.1). Europe" and North America ${ }^{12}$ are the main receivers of Dutch FDI. Looking at the worldwide percentage division of Dutch FDI stock, the share invested in Europe increased from 45 to 60 percent of the total stock, whereas the share in North America decreased over the last years from 45 to 30 percent. The percentage stock invested in the rest of the world has remained more or less stable between 10 and 15 percent. Within Europe the majority of Dutch investments go to the countries of the European Union. In 1987 the stock of Dutch investments in Central and Eastern Europe and the Soviet Union was only five million euro, but it increased to almost 13600 million euro in 2002 . Within the transition countries the division of Dutch investments is highly variable, with the majority invested in the most developed Central European countries and only marginal amounts in the less developed Eastern European and Central Asian countries. Figure 3.2 shows that the joint Dutch investment stock in Poland, the Czech Republic, Russia and Hungary equals 89 percent of the total Dutch investments in the region in 2001, while in terms of population those countries only make up 50 percent of the total regions population.

This trend is confirmed by the data from the survey. Among the respondents of the survey, Poland is the most popular host country in which to invest, followed by Hungary. Remarkably, the Czech Republic only takes fifth place as receiver of Dutch FDI, after Russia and Romania (see figure 3.3).

\footnotetext{
10 I am aware that the analyses in sections 3.3 and 3.4 suffer from an omitted variable bias. Competitive firms are more likely to invest abroad than their less competitive counterpart. However, the survey data used show a relatively high item non-fesponse in the question to indicate profitability of the firm, disabling me to include profit as indicator for competitiveness (exception is model four in table 3.4). Also liquidity indicators to proxy financial constraints would have been a valuable addition to the dataset, that are unfortunately not included now.

"Europe includes Western Europe, Central and Eastern Europe and the countries from the former Soviet Union.

${ }^{12}$ North America includes Canada, USA and Mexico.
} 
Figure 3.1: Stock and Flows of Dutch Outward FDI (million euro)
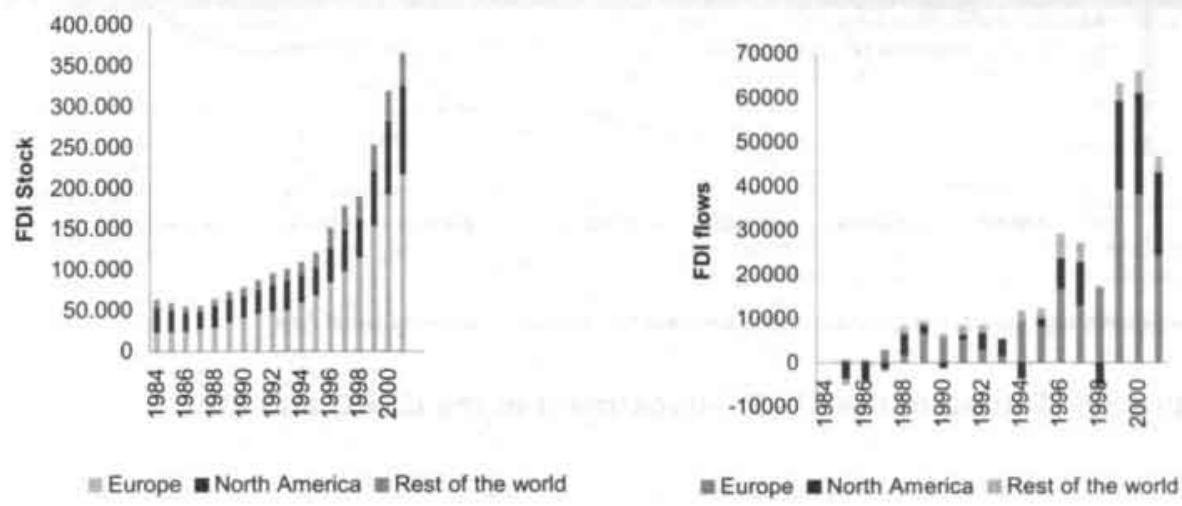

Source: De Nederlandsche Bank Balance of Payment data

Figure 3.2: Percentage division of Dutch FDI in the CEEC and FSU (2001)

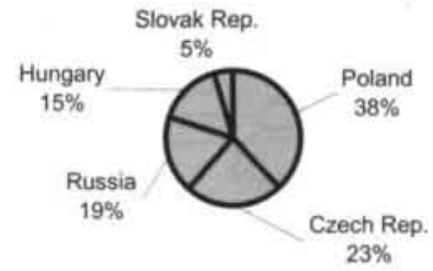

Source: De Nederlandsche Bank Balance of Payment

Figure 3.3: Number of investments per country, by firms in the survey

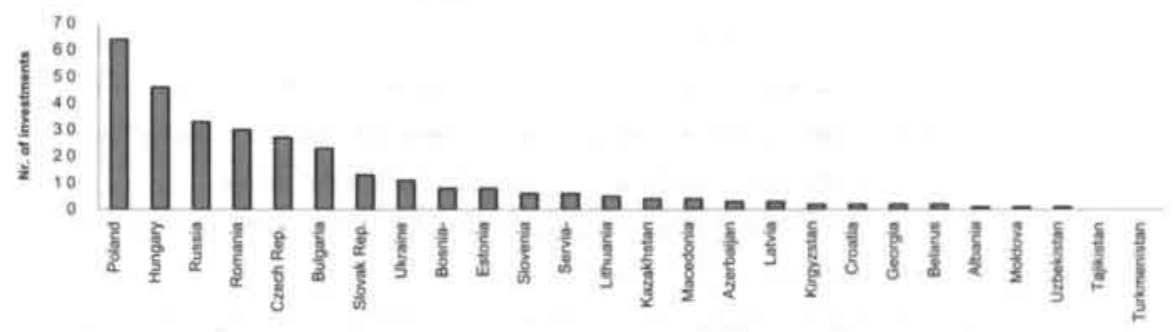

Source: Survey data 'Dutch direct investments in Central and Eastern Europe and Central Asia" 


\section{Figure 3.4: Number of Dutch Investments in the CEEC and FSU by year}

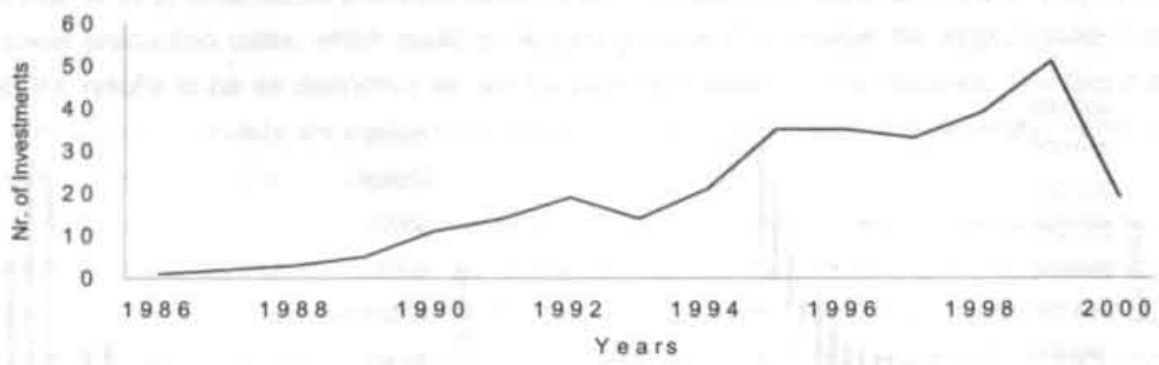

Source: Survey data "Dutch direct investments in Central and Eastern Europe and Central Asia"

\section{Figure 3.5: Timing of the $1^{\text {st }}-5^{\text {th }}$ Investment in the CEEC and FSU}

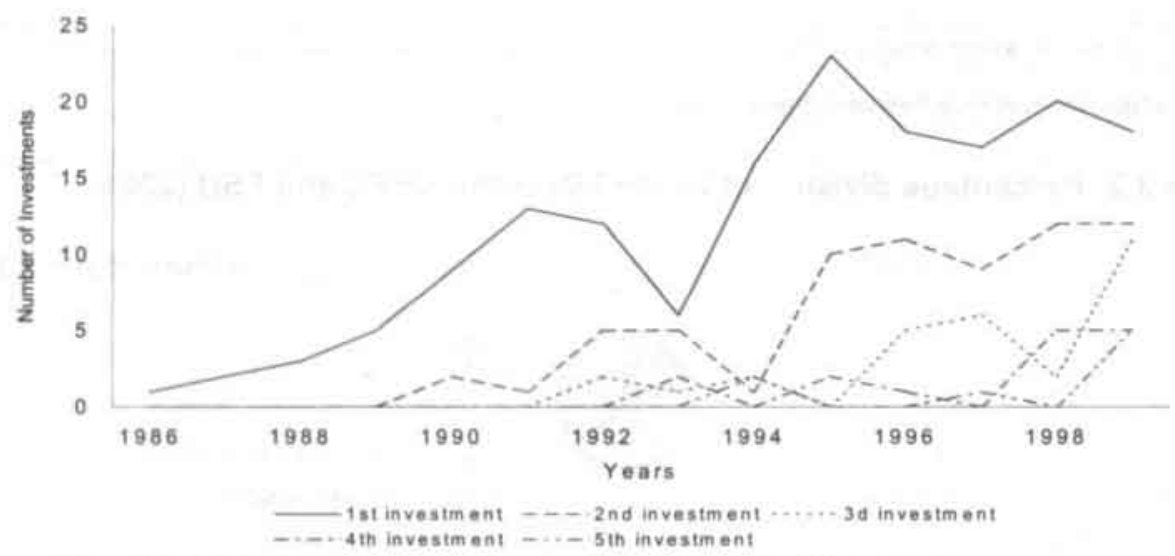

Source: Survey data "Dutch direct investments in Central and Eastern Europe and Central Asia"

As expected, the bulk of inflow of Dutch investments started in the early 1990 s and the amount of investments has continued to grow ever since (see figure 3.4). ${ }^{13}$ Looking at the timing of the $1^{\text {st }}$ until the $5^{\text {th }}$ investment in the region it is clear that follow up investments become more important and more frequent over time. This tendency indicates that several firms are successfully exploring the region and expanding their business. The number of first investments, the upper line in figure 3.5 , is stable at around 20 new investments per year since 1995. This number indicates that, besides the growing number of follow-up investments, many Dutch entrepreneurs still take the step to invest either in the region for the first time or in a transition country where their company is not yet active.

The dataset used in the remainder of this chapter includes information on all eligible respondents of the survey between 1989 and 1999, being 79 Dutch firms with a direct investment in Central and Eastern Europe or Central Asia and 211 Dutch firms without an investment in this region. ${ }^{14}$ All 290 firms had some business interest in the transition countries when answering the questionnaire. ${ }^{15}$

\footnotetext{
The decline of investments in 2000 is caused by the fact that the survey was taken in the first half of 2000 , so the data for that year are underestimated since more than half of the year is not included.

"The total sample includes 81 investors and 217 noninvestors, but 2 investors and 6 noninvestors indicated they invested or were interested before 1989 or after 1999.

${ }^{73}$ More specifics on the survey procedures and respondents can be found in Annex A.
} 
Table 3.2: Summary statistics of investors and noninvestors in the survey

\begin{tabular}{|c|c|c|c|c|c|}
\hline $\begin{array}{l}\text { Characteristi } \\
\text { cinfluencing } \\
\text { international } \\
\text { activities }\end{array}$ & \multicolumn{2}{|c|}{$\begin{array}{l}\text { Summary statistics } \\
\text { Investors } \\
\text { (79 firms) }\end{array}$} & \multicolumn{2}{|c|}{$\begin{array}{l}\text { Summary statistics: } \\
\text { Noninvestors } \\
\text { (211 firms) }\end{array}$} & $\begin{array}{l}\text { Result of test difference investors - noninvestors } \\
\text { (1) }\end{array}$ \\
\hline \multirow[t]{2}{*}{ Sector } & \multicolumn{4}{|c|}{ Percentage distribution } & \multirow{2}{*}{$\begin{array}{l}\text { The sector division is significantly different between firms that } \\
\text { invested and firms that did not invest, at a } 1 \% \text { level. } \\
\text { (Pearson chi2 }(5)=16.3196, \mathrm{Pr}=0.006\end{array}$} \\
\hline & $\begin{array}{l}\text { Agriculture } \\
\text { Industry } \\
\text { Construction } \\
\text { Logistics } \\
\text { Retail } \\
\text { Other }\end{array}$ & $\begin{array}{l}12 \% \\
37 \% \\
4 \% \\
15 \% \\
19 \% \\
14 \%\end{array}$ & $\begin{array}{l}\text { Agriculture } \\
\text { Industry } \\
\text { Construction } \\
\text { Logistics } \\
\text { Retail } \\
\text { Other }\end{array}$ & $\begin{array}{l}12 \% \\
51 \% \\
9 \% \\
5 \% \\
18 \% \\
6 \%\end{array}$ & \\
\hline \multirow[t]{2}{*}{ Age } & \multicolumn{2}{|l|}{$\begin{array}{l}\text { Average age: } \\
35 \text { years }\end{array}$} & \multicolumn{2}{|l|}{$\begin{array}{l}\text { Average age: } \\
42 \text { years }\end{array}$} & \multirow{2}{*}{$\begin{array}{l}\text { The age difference in years between investors and } \\
\text { noninvestors is significant at a } 10 \% \text { level }(p>t=0,0674) \text {. Non } \\
\text { investors are significantly older than investors at a } 5 \% \text { level } \\
(P>t=0.0337) \\
\text { However, when taking age categories, the age difference is } \\
\text { insignificant (Pearson chi2 }(5)=8.2350 \quad \mathrm{Pr}=0.144)\end{array}$} \\
\hline & \begin{tabular}{l|}
$1-5$ \\
$6-10$ \\
$11-25$ \\
$26-50$ \\
$51-75$ \\
76 -older \\
\end{tabular} & $\begin{array}{l}11 \% \\
15 \% \\
28 \% \\
20 \% \\
14 \% \\
12 \% \\
\end{array}$ & $\begin{array}{l}1-5 \\
6-10 \\
11-25 \\
26-50 \\
51-75 \\
76 \text {-oider } \\
\end{array}$ & \begin{tabular}{l|}
$7 \%$ \\
$7 \%$ \\
$27 \%$ \\
$27 \%$ \\
$13 \%$ \\
$19 \%$ \\
\end{tabular} & \\
\hline $\begin{array}{l}\text { Size } \\
\text { Number of } \\
\text { offices }\end{array}$ & \multicolumn{2}{|c|}{$\begin{array}{l}\text { Average number: } \\
3.2 \text { offices }\end{array}$} & \multicolumn{2}{|c|}{$\begin{array}{l}\text { Average number: } \\
2,4 \text { offices }\end{array}$} & $\begin{array}{l}\text { Investors have on average more offices in The Netherlands, } \\
\text { but the difference with noninvestors is insignificant. } \\
\text { Nr. of offices absolute numbers: } P>|t|=0.1682 \\
\text { Categories: Pearson chi2(5) }=7.4316 \quad \mathrm{Pr}=0.190\end{array}$ \\
\hline Revenue & \multicolumn{2}{|c|}{$\begin{array}{l}\text { Average: } \\
476 \text { million guilders }\end{array}$} & \multicolumn{2}{|c|}{$\begin{array}{l}\text { Average: } \\
220 \text { million guilders }\end{array}$} & $\begin{array}{l}\text { The difference in revenue between investors and noninvestors } \\
\text { is insignificant when taken in absolute numbers, but significant } \\
\text { at } 5 \% \text { level when looking at categories. } \\
\text { Revenue absolute numbers: } P>|t|=0.1169 \\
\text { Categories: Pearson chi2 } 2(7)=18.1646 \quad \mathrm{Pr}=0.011\end{array}$ \\
\hline $\begin{array}{l}\text { Number of } \\
\text { Employees }\end{array}$ & \multicolumn{2}{|c|}{$\begin{array}{l}\text { Average: } \\
1091 \text { employees }\end{array}$} & \multicolumn{2}{|c|}{$\begin{array}{l}\text { Average: } \\
339 \text { employees }\end{array}$} & $\begin{array}{l}\text { Investors are significantly larger than noninvestors, at a } 5 \% \\
\text { level when looking at the absolute numbers, but the difference } \\
\text { is insignificant when comparing size categories. } \\
\text { Absolute numbers: } P>|t|=0.0266 \\
\text { Categories: Pearson chi2 }(8)=12.8097 \quad \mathrm{Pr}=0.171\end{array}$ \\
\hline $\begin{array}{l}\text { Liquidity } \\
\text { Profit }\end{array}$ & \multicolumn{2}{|c|}{$\begin{array}{l}\text { Average: } \\
68 \text { million guilders }\end{array}$} & \multicolumn{2}{|c|}{$\begin{array}{l}\text { Average: } \\
24 \text { million guilders }\end{array}$} & $\begin{array}{l}\text { There is no significant difference in profits between investors } \\
\text { and noninvestors, when taken in absolute numbers or in } \\
\text { categories } \\
P>|t|=0.1333 \\
\text { Categories: Pearson chi2 }=3.3333 \operatorname{Pr} 0.343\end{array}$ \\
\hline $\begin{array}{l}\text { Growth of } \\
\text { number of } \\
\text { employees }\end{array}$ & \multicolumn{2}{|c|}{$\begin{array}{l}\text { Average growth } \\
94-99: 14 \%\end{array}$} & \multicolumn{2}{|c|}{$\begin{array}{l}\text { Average growth } \\
\text { 94-99: } 19 \%\end{array}$} & $\begin{array}{l}\text { Noninvestors grew faster, but the difference is insignificant. } \\
P>|t|=0.4034\end{array}$ \\
\hline Ownership & \multicolumn{2}{|c|}{$\begin{array}{l}100 \% \text { Dutch: } 91 \% \\
\text { Multinat. owners: } 9 \% \\
\text { Average foreign } \\
\text { owners: } 0.086\end{array}$} & \multicolumn{2}{|c|}{$\begin{array}{l}100 \% \text { Dutch: } 77 \% \\
\text { Multinat. owners: } 23 \% \\
\text { Average foreign } \\
\text { owners: } 0.226\end{array}$} & $\begin{array}{l}\text { There is a significant difference at } 10 \% \text { level, that } \\
\text { internationally owned firms invest less in the CEE region. } \\
P>|t|=0.0030 \\
\text { Pearson chi } 2(1)=7.5093 \quad \mathrm{Pr}=0.006\end{array}$ \\
\hline $\begin{array}{l}\text { Previous } \\
\text { business in } \\
\text { the CEE } \\
\text { region }\end{array}$ & \multicolumn{2}{|c|}{$\begin{array}{l}\text { No previous trade } \\
\text { relation: } 26 \% \\
\text { Previous trade } \\
\text { relation: } 74 \%\end{array}$} & \multicolumn{2}{|c|}{$\begin{array}{l}\text { No previous trade } \\
\text { relation: } 69 \% \\
\text { Previous trade } \\
\text { relation: } 31 \%\end{array}$} & $\begin{array}{l}\text { Investors have significantly more previous business } \\
\text { experience in the CEE region } \\
\text { Pearson chi2(1) }=43.9667 \quad \mathrm{Pr}=0.000\end{array}$ \\
\hline $\begin{array}{l}\text { (Expected) } \\
\text { mode of FDI } \\
\text { (2) }\end{array}$ & \multicolumn{2}{|c|}{$\begin{array}{l}\text { Full Dutch } \\
\text { Ownership: } 56 \% \\
\text { Joint venture: } 44 \%\end{array}$} & \multicolumn{2}{|c|}{$\begin{array}{l}\text { Full Dutch } \\
\text { Ownership: } 33 \% \\
\text { Joint venture: } 67 \%\end{array}$} & $\begin{array}{l}\text { Investors more often considered full ownership than joint } \\
\text { ventures } \\
\text { Pearson chi2(1) }=6.4300 \text { Pr } 0.011\end{array}$ \\
\hline
\end{tabular}

Source: Survey data "Dutch direct investments in Central and Eastern Europe and Central Asia"

(1) All Pearson Chi2 tests are done with equal variance assumption.

(2) With respect to expected mode of FDI, I have taken the mode chosen by investors and the mode considered by noninvestors. This information was only available for 49 noninvestors, that made an analysis before they decided not to invest and provided information in the questionnaire on their investment analysis.

In line with what was expected based on the literature overview in section 3.2 , investors are on average larger than noninvestors, though the result is either significant or insignificant depending on the variable chosen to measure size. Firms with an FDI are only significantly larger than noninvesting firms when size is measured by number of employees. The variable measuring previous trade relations also shows the expected results; before making the investment investors did have trade 
relations with companies in a transition country significantly more often than noninvestors. Investors and noninvestors have different sector divisions, in line with the expectations based on the option model. Investors are in general less active in agriculture, industry and construction than noninvestors. On the other hand, several variables show opposite signs from what was expected. The expectation that investors are on average older entities is not apparent in this dataset. At a five percent level of significance noninvestors are older than investors. Firms that invested in a transition country more often have a complete Dutch ownership than noninvestors, whereas was expected that they would have a more multinational ownership division. And last, firms that invested in a transition countries more often used an investment mode with full ownership than noninvestors intended to do. This could be an indication that the use of joint ventures as platform investments may not be so regular, though this conclusion would be too hard based on these data and a lot more research should be undertaken to support that statement. ${ }^{16}$

In section 3.4 I test whether the factors that significantly differ between investors and noninvestors in 2001 are also the factors that increase the probability that a firm invests in a transition country.

\subsection{First FDI in the Central and Eastern Europe or Central Asia since 1989}

This section includes a logit analysis to find out which microlevel firm characteristics influence the first investment of a firm in a transition country since 1989. A logit regression is selected as the most suitable econometric test, given the fact that investing is a binary variable. Firms included in the database either invested or did not invest and in this analysis I study which firm characteristics can explain this investment behavior. For a more elaborate explanation of the logit regression model, see annex 3.1.

A survival time analysis or hazard rate analysis would methodologically have been an elegant solution to include the timing of those investments as well. Hazard rate models calculate the probability firms are at risk for a certain event, taking into account the time that has passed and the events that have occurred before. However, a survival time analysis was not possible with this dataset since there were only a limited number of time periods and multiple events per period (more firms invested in the same year). In this database the investments in a single year cannot be ordered chronologically in terms of time, since the month of investment was unknown." Therefore I opt for logit regression including only the first investments of each firm as dependent variable. In section 3.5 multiple investments per firm are allowed and event related variables incorporating FDI experience are included." All regressions included in sections 3.4 and 3.5 were also run correcting for nonresponse bias. The results of the regressions with probability weights do not change in terms of signs and significance of variables compared to the unweighted regressions, therefore only the unweighted results are presented in these sections. ${ }^{10}$

\footnotetext{
"Full ownership modes of FDI are Greenfield and Brownfield investments; joint ventures include joint ventures with existing firms as well as newly started enterprises with a local partner.

"Defining time on a monthly basis would not only have increased the number of time periods but aiso decreased the periods in which multiple events occurred. Unfortunately information on the month of investment was unavailable.

"I am aware that more competitive firms are more likely to invest sooner. The impact of this effect is lost in the analysis, since no data are available to include a variable for competitiveness.

10 In Annex A I show that larger older firms were more likely to respond to the survey. In order to control for that effect I calculated probabilities of response, based on company characteristics including age and size. The inverse of this probability is included as probability weight in the weighted regressions. The results of these regressions do not change in terms of signs and significance of the coefficients. Therefore those results are not included here.
} 
Table 3.3: Number of firms in the sample period of 1989-1999

\begin{tabular}{|l|l|l|l|l|l|l|l|l|l|l|l|l|l|l|l|l|l|}
\hline $\begin{array}{l}\text { Years } \\
\begin{array}{l}\text { Firms that invested in } \\
\text { this year for the first } \\
\text { time in the CEE region }\end{array}\end{array}$ & 1 & 3 & 6 & 5 & 7 & 7 & 7 & 7 & 8 & 1097 & 1998 & 9 & 1999 \\
\hline $\begin{array}{l}\text { Total nr. of firms that } \\
\text { invested in the CEE for } \\
\text { the first time since } \\
1989\end{array}$ & 1 & 4 & 10 & 15 & 22 & 29 & 36 & 43 & 51 & 61 & 71 & 80 & 81 \\
\hline
\end{tabular}

- Two firms that invested in 1986 and 2000 are excluded from the logit analysis.

The dependent variable of the logit regression is whether the firm invested in a transition country during the years 1989-1999. ${ }^{20}$

In table 3.2 the summary statistics show that investors are on average larger and younger than noninvestors, prefer 100 percent Dutch ownership and had trade experience in the region more often than noninvestors. In terms of sector division, investors are more often active in the sectors logistics and others and less often in industry or construction than noninvestors. Based on these findings I expect larger, younger, 100 percent Dutch firms with trade experience to invest more often and sooner in a transition country than other firms.

In total 79 firms invested in the region in the period 1989-1999. Most of the first investments were made during the second half of the 1990s (see table 3.3). The variables included in the analysis are the firms age in 1988, size of the firm measured in number of employees, sector dummies, number of owners, percentage of Dutch ownership, trade experience in the country before investing in that country and FDI experience in one of the transition countries before 1989. The variables revenue, profit, growth and mode of FDI are included only in the fourth model due to the many missing observations that may bias the results. ${ }^{\text {.1 }} 22$

The results included in table 3.4 show that age affects a first investment negatively; being older in 1989 decreases the relative chance the firm will invest in the region the next decade for the first time. The size of the firm does not significantly influence the odds of a first investment. These results contradict the argument that firms without financially binding constraints (older larger firms) are more likely to invest. With respect to sector division, only firms active in logistics are significantly more likely to invest than firms in the industrial sector. As expected, construction and agriculture carry a negative sign but the coefficients are insignificant. ${ }^{23}$ Equally, the sector trade and other have the expected positive sign, but they are insignificant as well. This is in line with the expectations that high irreversible set-up costs, often present in the agricultural, industrial and construction sector, lead to postponement of an investment. Trade experience increases the relative chance a firm will invest in the region significantly, confirming that experience decreases uncertainty. However, experience with an FDI only negatively affects the odds of investing.

\footnotetext{
${ }^{20}$ The survey was taken in spring 2000 , so the number of investments made in 2000 included in the results is incomplete. Therefore the investments undertaken in 2000 were excluded in order to avoid underestimation of investments.

21 There is a possibility that only firms with positive revenue and profits answered this question in the questionnaire.

22 See note two table 3.2 for information on missing observation of the variable mode of FDt.

23 There are only four firms in the sector that invested in the region. Those firms vary from small to large. Based on these data it is hard to conclude whether these firms are market seeking service oriented offices without large set-up costs or larger offices that invested in machinery and thus face larger set-up costs. I am aware that the evidence to conclude that the sign is as expected is limited, but the conclusion is already weak given the fact that the coefficient is insignificant.
} 
Table 3.4: Logit analysis for the first FDI in 1989-1999

\begin{tabular}{|c|c|c|c|c|}
\hline $\begin{array}{l}\text { Dependent vanable: } \\
\text { ist FDI since } 1 / 1 / 1989\end{array}$ & Model 1 & Model 2 & Model 3 & Model 4 \\
\hline \multirow[t]{2}{*}{ Age in 1988} & -0.024 & -0.039 & -0.054 & -0.028 \\
\hline & $(2.61)^{* *}$ & $(1.30)$ & $(2.70)^{* *}$ & $(1.95)$ \\
\hline \multirow[t]{2}{*}{ Size in 1989} & 0.000 & 0.000 & 0.005 & 0.004 \\
\hline & $(1.22)$ & $(1.14)$ & $(1.89)$ & $(2.19)^{*}$ \\
\hline \multirow[t]{2}{*}{ Agriculture } & -0.973 & $-0,976$ & -3.560 & -1.474 \\
\hline & $(1.33)$ & $(1.34)$ & $(2.44)^{*}$ & $(1.53)$ \\
\hline \multirow[t]{2}{*}{ Construction } & -1.395 & -1.341 & -1.420 & -0.689 \\
\hline & $(1.38)$ & $(1.33)$ & $(0.90)$ & $(0.54)$ \\
\hline \multirow[t]{2}{*}{ Logistics: } & 1.786 & 1.789 & 0.510 & 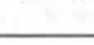 \\
\hline & $(2.23)^{*}$ & $(2.23)^{\circ}$ & $(0.33)$ & 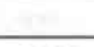 \\
\hline \multirow[t]{2}{*}{ Trade } & 0.400 & 0.378 & -0.026 & 0.797 \\
\hline & $(0.70)$ & $(0.66)$ & $(0.03)$ & $(0.90)$ \\
\hline \multirow[t]{2}{*}{ Other } & 0.871 & 0.934 & -0.645 & -1.623 \\
\hline & $(0.96)$ & $(1.01)$ & $(0.43)$ & $(1.23)$ \\
\hline \multirow[t]{2}{*}{ Number of owners } & 0.740 & 0.777 & 0.196 & 1.794 \\
\hline & (1.29) & $(1.35)$ & $(0.20)$ & $(1,45)$ \\
\hline \multirow[t]{2}{*}{$\begin{array}{l}\text { Percentage of Dutch } \\
\text { Ownership }\end{array}$} & 0.008 & 0.009 & 0.009 & 0.014 \\
\hline & $(0.70)$ & $(0.75)$ & $(0.46)$ & $(0.66)$ \\
\hline \multirow[t]{2}{*}{ Trade experience before 1989} & 3.419 & 3.428 & 3.306 & 0.798 \\
\hline & $(6.50)^{* *}$ & $(6.51)^{* *}$ & $(3.79)^{* *}$ & $(1.06)$ \\
\hline \multirow[t]{2}{*}{ FDI experience before 1989} & -2.448 & -2.526 & -1.147 & -2.858 \\
\hline & $(1.99)^{\circ}$ & $(2.02)^{\circ}$ & $(0.67)$ & $(1.65)$ \\
\hline \multirow[t]{2}{*}{ Age2 } & & 0.000 & & \\
\hline & & $(0.50)$ & & 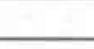 \\
\hline \multirow[t]{2}{*}{ Size2 } & & -0.000 & & \\
\hline & & $(0.54)$ & & \\
\hline \multirow[t]{2}{*}{ Revenue (in million euro, 1989) } & & & 0.001 & \\
\hline & & & $(0.28)$ & \\
\hline \multirow[t]{2}{*}{ Profit (in million euro, 1989) } & & & -0.016 & \\
\hline & & & $(0.78)$ & \\
\hline \multirow[t]{2}{*}{ Growth (in employees) } & & & 0.002 & \\
\hline & & & $(0.94)$ & \\
\hline \multirow[t]{2}{*}{ Joint venture } & & & & 4.653 \\
\hline & & & & $(2.86)^{* *}$ \\
\hline \multirow[t]{2}{*}{ Constant } & -3.277 & -3.220 & -1.540 & -8.291 \\
\hline & $(1.96)$ & $(1.92)$ & $(0.55)$ & $(2.16)^{\circ}$ \\
\hline Observations & 197 & 197 & 93 & 78 \\
\hline Pseudo R2 & 0.3785 & 0.3805 & 0.4216 & 0.3761 \\
\hline
\end{tabular}

" $10 \%$ significant, " $5 \%$ significant, ${ }^{* \cdots} 1 \%$ significant; Absolute value of $\mathrm{z}$ statistics in parentheses; Prob $>\mathrm{CHI}: 0.0000$ in all four regressions. Industry is taken as baseline.

Note 1) Two successes completely determined in model 3 and 4 . Those observations are dropped from the regression. Note 2) In model four the dummy variable logistics predicts failure perfectly. This is a one-way causation problem. The observations with sector logistics are dropped (9 observations). Note 3 ) The variables Revenue and Profit (million euro) are taken for 1989. In case this observation was missing it was replaced with the value of 1994 or 1999 . Note 4) Growth is measured in growth of employees in 1989-1994. In case this value is missing it is replaced with the growth rate of 1994-1999. Note 5) Joint venture observations are available for only 130 firms that seriously considered an investment in the CEEC. All observations without this variable are excluded from this regression. 
Adding squared variables for age and size does not add explanatory power to the model. Neither does the inclusion of three variables used as indicators for competitiveness and the likeliness of financially binding constraints. Higher revenues and higher growth have a positive but insignificant coefficient and the coefficient of profit is even negative. Investing in (or intending to invest in) a joint venture increases the relative probability a firm invests; it carries a highly positive coefficient. Thus, there is some evidence for the argument that investments in joint ventures increase the chance a firm actually invests and this could be explained by the platform investment argument.

\subsection{Multiple investments in Central and Eastern Europe or Central Asia}

Contrary to section 3.4, in this section multiple investments are included in the dataset. Every investment of a firm, be it the first, second or tenth FDI, is counted as an event. Firms do not fall out of the sample if an investment is made, but remain included for the full 11-year sample period. Thus, investments in different years and in different countries are included, as well as several investments in one country. More investments done by one firm in one year are incorporated in the changing of two event-related variables, but are measured only as one event in the logit regression. ${ }^{2 t}$

Two event-related variables measuring the experience of a firm are included as explanatory variables. The variable total measures the total number of investments a firm has in the region at the start of the year. The variable experience measures the number of years of experience a firm has with investing in the CEE region. I expect both variables to have a positive sign, indicating that firms with more experience are more certain about the situation in the region and invest sooner. These two experience variables incorporate to some extent the competitiveness effect mentioned before; more competitive firms invest sooner than their less competitive counterparts. Table 3.5 shows the number of firms that invested in each year of the sample period and registers if that was the first FDI of the firm in a transition country or a subsequent one.

A yearly analysis, for the years 1989 - 1999 was undertaken to see whether a time effect was visible over the years. If the region became less uncertain and more stable over time this development could influence investment behavior, and the sign or significance of the coefficients of the control variables and experience variables could change. As firm characteristics the control variables age, size and number of owners are included. The sector dummies, which were insignificant when included in the regression, are excluded from the logit regression displayed here since their inclusion frequently resulted in a one-way dummy bias, leading to a drop of many observations. ${ }^{2}$ The variable indicating the percentage of Dutch ownership is excluded, since it was insignificant and caused observations to drop out due to missing values. Similar arguments apply for the exclusion of revenue, profit and growth. ${ }^{26}$

\footnotetext{
${ }^{24}$ When a firm makes an FDI in a specific year, the dependent variable changes from zero to one. A second or even third or fourth investment in the same year does not change the dependent variable, since this variable already registered that an FDI was started in that specific year.

${ }^{2}$ One-way dummy bias is caused by the fact that for instance all firms from the sector transport do not invest in one year. Thus, as the dummy transport equals zero, the dependent variable invest also equals zero.

${ }^{25}$ When included the coefficients of the variables were insignificant, the coefficient of revenue was positive and the coefficients of profit and growth were negative.
} 
Table 3.5: Number of firms and investments in the CEE region (1989-1999)

\begin{tabular}{|c|c|c|c|c|c|c|c|c|c|c|c|c|}
\hline $\begin{array}{l}\text { Number of } \\
\text { firms } \\
\text { investing in a } \\
\text { year }\end{array}$ & 1989 & 1990 & 1991 & 1992 & 1993 & 1994 & 1995 & 1996 & 1997 & 1998 & 1999 & Total \\
\hline Total & 3 & 77 & 10 & 16 & 13 & 18 & 21 & 24 & 26 & 30 & 37 & 208 \\
\hline $\begin{array}{l}\text { Of which } \\
\text { existing } \\
\text { investors }\end{array}$ & 0 & 1 & 5 & 9 & 6 & 11 & 14 & 16 & 16 & 20 & 28 & \\
\hline $\begin{array}{l}\text { Of which } \\
\text { new } \\
\text { investors }\end{array}$ & 3 & 6 & 5 & 7 & 7 & 7 & 7 & 8 & 10 & 10 & 9 & \\
\hline
\end{tabular}

Table 3.6: Logit regression explaining investments in Central and Eastern Europe and Central Asia after 1989, allowing for multiple investments

\begin{tabular}{|c|c|c|c|c|c|c|c|c|c|c|c|}
\hline Dependent variable: invest that year or not & 1989 & 1990 & 1991 & 1992 & 1993 & 1994 & 1995 & 1996 & 1997 & 1998 & 1999 \\
\hline Age & -0.007 & 0.022 & 0.018 & 0.009 & -0.02 & -0.004 & -0.002 & -0.01 & -0.008 & -0.011 & -0.009 \\
\hline Size & 0.326 & 0.07 & 0.059 & 0.123 & $-0,004$ & 0,118 & 0.141 & 0.028 & $0.168^{*}$ & $0,143^{\circ}$ & 0.102 \\
\hline Number of owners & 0.558 & -1.637 & $0.816^{*}$ & 0.372 & $0.708^{*}$ & 0.483 & -0.12 & 0.245 & 0.156 & 0.128 & 0.363 \\
\hline Total number of FDI at start of the year & 1.096 & $12.800^{* \cdots}$ & $21.72 \cdots$ & $1.062^{* *}$ & $1.515^{* *}$ & 0.23 & $0.600^{* *}$ & $1.022^{* * *}$ & $0.710^{\cdots *}$ & $0.309^{* *}$ & $0.542^{* \cdots}$ \\
\hline $\begin{array}{l}\text { Number of years experience in CEE } \\
\text { since first FDI }\end{array}$ & 0.202 & -9.168 & -20.544 & 0.283 & -0.189 & $0.534^{\cdots *}$ & 0.096 & -0.154 & -0.098 & 0.011 & 0.108 \\
\hline Pseudo R2 & 0.1165 & 0.2889 & 0.2538 & 0.213 & 0.2826 & 0.2561 & 0.181 & 0.2767 & 0.2496 & 0.1279 & 0.3326 \\
\hline Significance of the whole regression & & $\cdots$ & $\cdots$ & $\cdots$ & $\cdots$ & $\cdots$ & $\cdots$ & $\cdots$ & $\cdots$ & $\cdots$ & $\cdots$ \\
\hline
\end{tabular}

The table displays the coefficients

Number of observations: 290

- significant at $10 \%$ level, $"$ significant at $5 \%$ level, $" *$ significant at $1 \%$ level

With respect to the logit analyses, several facts can be observed (see table 3.6). First, age, size and number of owners are mainly insignificant. The most influencing variables are the event-related variables total number of FDI in the transition countries at the start of the year and number of years of experience in the transition countries after FDI1. When included in a logit regression separately, both variables display a positive coefficient and are significant over the whole time period ${ }^{p}$ Having experience in the region increases the relative chance that the firm invests again in the following year. The impact of one additional unit (FDI) or year of experience declines over time (in other words, the coefficient becomes smaller). It shows an inverse relationship with the increasing value of total experience, since the number of investments and the years of experience since the first FDI was undertaken both show a continuously increasing trend over time. In general, therefore, the effect of an additional investment or year since the first investment still increases the odds ratio of investing next year (see annex 3.2 for a more detailed explanation of this effect). When both event-related variables are included jointly in the analysis, the effect becomes less clear. The total number of FDI mainly shows a positive and significant effect, but the number of years of experience becomes insignificant for some years and sometimes even negative. ${ }^{20}$ Still, the model including both variables is highly significant in total and the fit is better than in the models including only one of the experience-related variables.

\footnotetext{
${ }^{27}$ These regression results are not included in the table; the table shows the coefficients when both event-related variables are jointly included.

20 In the years 1990 and 1991 the variables total and experience display a collinear relation. This explains the fact that the coefficients of both variables are rather unstable during those two years, when both variables are included simultaneously.
} 
Table 3.7: Logit regression 1989-1999, allowing for multiple investments per firm

\begin{tabular}{|c|c|c|c|c|c|c|c|c|}
\hline & Model 1 & Model 2 & Model 3 & Model 4 & Model 5 & Model 6 & Model 7 & Model 8 \\
\hline Year & $0.189 * \cdots$ & $0.096^{* \cdots \cdot}$ & $0.097^{* \cdots}$ & $0.095^{* \cdots *}$ & $0.095^{* * *}$ & $0.092^{* \ldots}$ & $0.092^{* * *}$ & $0.090^{* \cdots *}$ \\
\hline Age & -0.001 & -0.004 & -0.000 & -0.000 & -0.000 & -0.002 & -0.002 & -0.004 \\
\hline Size & $0.112^{* * *}$ & $0.088^{* \cdots \cdot}$ & $0.104^{\cdots \cdots}$ & $1.104^{* \cdots}$ & $0.103^{* *}$ & $0.094 \cdots$ & $0.094 \ldots$ & $0.086 * \cdots$ \\
\hline Agriculture & -0.088 & 0.194 & -0.059 & 0.080 & 0.067 & 0.012 & 0.010 & 0.098 \\
\hline Construction & $-1.056^{* *}$ & -0.645 & -0.724 & -0.649 & -0.646 & -0.694 & -0.695 & -0.598 \\
\hline Transport & $0,723^{* *}$ & $0.446^{* *}$ & $0.559^{* *}$ & $0.552^{* *}$ & $0.564 *$ & $0.521^{* *}$ & $0.524^{* *}$ & $0.543^{* *}$ \\
\hline Trade & -0.097 & 0.077 & 0.127 & 0.150 & 0.149 & 0.101 & 0.103 & 0.044 \\
\hline Other & 0.339 & 0.018 & -0.137 & 0.163 & 0.188 & 0.073 & 0.068 & -0.139 \\
\hline Number of owners & $0.224^{* *}$ & $0.206^{*}$ & $0.191^{*}$ & 0.167 & 0.151 & 0,163 & 0.162 & 0,142 \\
\hline $\begin{array}{l}\text { Total number of FDI in CEE } \\
\text { before start of year }\end{array}$ & & $0.650 \cdots$ & & & & & & $1.083^{\cdots *}$ \\
\hline $\begin{array}{l}\text { Years of experience in CEE } \\
\text { since FDI1 }\end{array}$ & & & $0.355^{\cdots *}$ & $0.211 \cdots$ & $0.205^{* \cdots}$ & $0.216^{* \cdots}$ & $0.216^{* *}$ & 0.044 \\
\hline $\begin{array}{l}\text { Years of experience in CEE } \\
\text { since FDI2 }\end{array}$ & & & & $0.254^{\cdots *}$ & $0.325^{* \cdots *}$ & $0.329^{* *+}$ & $0.329 * \cdots$ & -0.008 \\
\hline $\begin{array}{l}\text { Years of experience in CEE } \\
\text { since FDI3 }\end{array}$ & & & & & -0.091 & $-0.382^{* *}$ & $-0.378^{* *}$ & -0.438 \\
\hline $\begin{array}{l}\text { Years of experience in CEE } \\
\text { since FDI4 }\end{array}$ & & & & & & $0.413^{* *}$ & $0.394^{*}$ & -0.066 \\
\hline $\begin{array}{l}\text { Years of experience in CEE } \\
\text { since FDI5 }\end{array}$ & & & & & & & 0.027 & -0.794 \\
\hline Adjusted R2 & 0.0698 & 0.2145 & 0.1623 & 0.1712 & 0.1716 & 0.1761 & 0.1761 & 0.2431 \\
\hline
\end{tabular}

Number of observations: 3190

Sector industry is the baseline sector.

Size is defined in categories 1-5, 5-20, 20-50, 50-100, 100-200, 200-500 and $>500$ employees.

All models were significant at $1 \%$ level, displaying a Prob>chi2: 0.0000

- Coefficient is significant at $10 \%$ level, " significant at $5 \%$ level, ${ }^{\cdots *}$ significant at $1 \%$ level

Table 3.7 shows the results of a similar regression, but the time is now added as a separate variable. All firms are included in the sample with one observation per year, no firms drop out. Control variables age, size, sector ${ }^{20}$, number of owners and percentage of Dutch ownership $p^{30}$ are included, as well as six event-related experience variables. The variable total counts the number of investments a firm has in the transition countries before the start of a year. The variables years of experience onefive count the number of years of experience a firm has in the region since the first, second, third, fourth and fifth investment. The basic model, without including event-related variables (model one), shows a significantly positive time trend; the more years passed since 1989, the larger the relative chance is a firm will make an investment. In addition, larger firms are significantly more likely to make investments in a transition country (the odds of investing increase with 12 percent per increase of one size category).

Firms from the transport sector are more likely to invest than firms with an industrial activity. The number of owners also positively influences the relative chance that a firm will invest once or more in the region positively. The odds ratio of investing compared to not investing of a firm with two owners increases with 25 percent compared to the odds ratio of a firm with only one owner. The largest

\footnotetext{
${ }^{20}$ Due to the increase in number of observations it is possible to include the dummy variables for sector again without causing a one-way dummy bias leading to a drop in observations.

${ }^{30}$ Given that there were a substantial number of missing observations for the variable percentage ownership, the variable is not included in the regressions that are reported in the text. When percentage was included in all variations of the logit regression, the variable had a slightly positive coefficient $(0.003)$ and was insignificant.
} 
impact comes from the event-related experience variables that are included in models two to eight. The total number of investments in the CEE region, when included separately, has a positive significant coefficient. Per additional investment a firm has in the CEE region the odds that it will invest in the next period increase by 92 percent (model two). Models three to seven include the variables measuring the years of experience of doing business in the CEE region, determined for the first five investments. The experience gained from the first two investments consistently shows a positive significance, so firms with basic experience in the region are more likely to invest in the region the next period. The years of experience after the third, fourth and fifth investment give less consistent coefficients, with both positive and negative influence and changing from significant to insignificant. With respect to years of experience, the conclusion therefore is that the maximum effect of experience comes from the first two investments in the region and all additional investments fail to significantly influence the investment decision. In model eight of table 3.8 all experience variables are jointly included. The variable total number of investments in the CEE region becomes dominant. With a coefficient of 1.083 and significance at one percent level, every additional FDI a firm has in the CEE region at the start of a year increases the odds that a firm will invest in the CEE region that year with almost 200 percent. The years of experience after investing, irrespective of whether they are after the first up to the fifth investment, all become insignificant."

\subsection{Conclusions}

The literature studying the investment behavior of firms generally finds that older and larger firms are more likely to invest abroad than their smaller counterparts. In addition, it is often expected that firms in labor intensive industries, or industries where scale economies are possible are more internationally active. Based on the option theory these expectations are adjusted in this chapter. In agreement with the mentioned literature in chapter two I expect larger older firms to be less financially constrained, better able to obtain finance for their investments and thus invest sooner. Firms active in sectors that have high irreversible set-up costs, like industry, construction and agriculture are expected to invest less often than firms in sectors that require a lower initial investment sum. Experience is expected to have a positive impact on investment decisions, since experience is likely to decrease the uncertainty surrounding an investment.

This chapter uses data from the Dutch sample described in Annex A, which deviates from a random firm sample most often used in similar kinds of studies. The Dutch firms included in the sample are all firms that at some point between 1989 and 1999 were interested in investing in Central and Eastern Europe or Central Asia to some extent. Results in section 3.3 show that of those Dutch firms that considered international activities, the ones that decided to become active in the region are significantly larger than the firms that decided not to invest. They are also, as expected, less often active in the industrial and construction sector. In contradiction to the expectations, they are younger than firms that did not invest and firms with a diverse international ownership are not more likely to invest in a transition country. Firms that invested in a transition country did have more experience with trade and FDI. These results deviate from the earlier literature. This can be explained by several

\footnotetext{
"In an additional analysis, a variable containing the combined years of experience after investment one to five was included instead of the five different experience variables. Contrary to the expectations, the coefficient of this variable was significantly negative (coefficient equal to -0.085 ) at a 5 percent level. However, the coefficient of the variable total increased compared to the coefficient in model two to 0.88 and remained significant at a one percent level.
} 
factors. First, the sample selection is different. When taking a random sample of firms, many small local firms are included that may not have any interest in investing abroad. By selecting only those firms that are interested in international operations, the characteristics of the firms included in this sample are already much more converged and the difference between those firms investing and not investing becomes less evident. In addition, only looking at firms interested in investing in a high-risk region like the transition region just after its transition started is already a preselection. The results indicate that risky regions attract young adventurous enterprises more, whereas older established firms are more interested in the stable economic environments.

The logit regressions in section 3.4 test which characteristics influence the chance a firm invests in a transition country, all indicate that firm characteristics are not the major explanatory variables for investment decisions. In fact, only larger firms are more likely to invest. The age, sector, number of owners and percentage of Dutch ownership hardly influence the investment choice. Experience effects are of great importance in explaining investment behavior; having experience increases the odds that firms invest in the region. Allowing for multiple investments per firm, in section 3.5, does not change the results a lot. Addition of a time effect shows that transition time influences the investment decision. The more time that has elapsed after transition started, the more likely firms are to invest in the region, indicating that some time to make the investment decision and prepare the investment is needed. In addition, as time went by, many transition countries developed economically and institutionally and became less risky. This changed the economic environment for an FDI considerably and the region as a whole became increasingly popular as investment destination. In addition to time, mainly size and experience are most important in explaining FDI decisions.

The results all support the option theory, that predicts that small firms invest later, since firms with a binding financial constraint postpone their FDI more often than firms without financial constraints. The option theory also predicts that firms invest more often as the risk decreases. In transition countries the country risk decreased continuously over the decade described and as expected time influences the investment decision, since the year effect on investments is positively significant. The analyses in this chapter also indicate that uncertainty related to an investment decision is important at the microlevel. Firms with more experience with FDIs or trade in the transition countries are probably also the firms that have a lower uncertainty attached to their investment decision. They already have experience; possibly have networks and maybe better access to information as well. Those factors all decrease the uncertainty of an investment decision, increasing the chance a firm invests.

The complete transition region in 1989 was a very risky region in which to invest, but it displayed large deviations in the country risks over the last decade. Some transition countries in 2002 had almost reached the levels of development and stability of the least developed EU countries, whereas some other, mostly former Soviet Union Republics, can still be classified as high-risk regions. This diversification of risk over the region, with the uncertainty surrounding investments in the transition region in some countries decreasing and in others remaining rather high, leaves a market interesting for firms willing to take higher risks with their investment, but also for firms that are more interested in a stable investment climate. 



\section{Annex 3.1 Methodology of the empirical tests}

The question to be answered in this chapter is which characteristics indicate what firms invest in the CEE region once or multiple times after 1989 and which firms do not invest. The dependent variable $y$, to invest or not, is binary. Investors in the CEE region are assigned a value of $y=1$ and noninvestors are assigned a value of $y=0$. The independent variables $x$ are a vector of firm characteristics, that are used to predict which firms are more likely to invest in the CEE region.

In order to answer this question empirically, a limited dependent variables model is used. The two approaches most often used are the logit and probit model. In this section I follow the description of Maddala, chapter two section 2.5 (Maddala (1983)). Both assume that there is an underlying response variable $y_{i}^{*}$, defined by:

$y_{i}^{*}=\beta^{\prime} x_{i}+u_{i}$

In the probit analysis the cumulative distribution function for $u_{i}$ is normal, so $F\left(-\beta^{\prime} x_{j}\right)$ is normally distributed. In the logit model the cumulative distribution for $u_{i}$ is logistic. Generally speaking the outcomes of both models are similar using small samples with limited outliers and different with samples with large outcomes in the tails. In the estimations of the chapter the logit analysis was followed (assuming less outliers), though the results of the analysis using a probit model are not distinctly different in this chapter.

In practice the underlying $y_{i}^{*}$ is unobservable. What is observed is the dummy variable $\mathrm{y}$, defined by:

$$
\begin{aligned}
& y_{i}=1 \text { if } y_{i}^{*}>0, \text { indicating the firm invested in the CEE region } \\
& y_{i}=0 \text { if } y_{i}^{*} \leq 0 \text {, indicating the firm did not invest in the CEE region }
\end{aligned}
$$

In the logit model $\beta^{\prime} x_{i}$ equals $E\left(y_{i}^{*} \mid x_{i}\right)$. Therefore the probability of a firm to invest in the CEE region equals:

$\operatorname{Prob}\left(y_{i}=1\right)=\operatorname{Prob}\left(u_{i}>-\beta^{\prime} x_{i}\right)=1-F\left(-\beta^{\prime} x_{i}\right)$, where $\mathrm{F}$ is the cumulative distribution function for $u$.

The distribution function equals: $F\left(-\beta^{\prime} x_{i}\right)=\frac{\exp \left(-\beta^{\prime} x_{i}\right)}{1+\exp \left(-\beta^{\prime} x_{i}\right)}=\frac{1}{1+\exp \left(\beta^{\prime} x_{i}\right)}$

The likelihood function $L$ equals:

$L=\prod_{y_{i}=0}\left(-\beta^{\prime} x_{i}\right) \prod_{y_{i}=1} 1-F\left(-\beta^{\prime} x_{i}\right)$

The results of the logit probability model show which variables increase or decrease the likelihood of investing in the CEE region and whether these influences are significant. 
For example, the estimates of all combined variables for the period 1989-1999, which are described in table 3.4 of the chapter, are significant. $\mathrm{P}>\mathrm{Chi} 2=0.000$, which is low enough to reject the hypothesis that all coefficients equal zero.

The predicted logit, L, equals the constant + the coefficient times the variables. The predicted

logit equals $L=\ln \left(\frac{P(\text { invest }=1)}{P(\text { inves } t=0}\right)$

The coefficients of the variables can be interpreted as follows. The coefficient for the variable "Age in 1988 " in the logit regression in table 3.4, a variable significantly different from zero at a five percent level, is -0.024 . This coefficient describes the effect of age on the odds ration to invest in the CEE region versus not to invest. An increase of a firm's age with one year decreases the odd with 2.4 percent. Thus, image that for a firm of 50 years, the relative odd to invest versus not to invest is 2 . This odd ratio decreases with 2.4 percent for a firm which is one year older (51 years), thus the relative odds to invest versus not to invest for this firm of 51 years old firm would be approximately 1.952. The impact of this variable age is significant, since the coefficient is significantly different from zero at a five percent level. 


\section{Annex 3.2 The effect of experience on investment behavior}

\section{Table A3.2.1: Effect of experience on investment behavior}

\begin{tabular}{|c|c|c|c|c|c|c|c|c|c|c|c|}
\hline Years & 1989 & 1990 & 1991 & 1992 & 1993 & 1995 & 1995 & 1996 & 1997 & 1998 & 1999 \\
\hline $\begin{array}{l}\text { Coefficient of total number of FDI } \\
\text { at start of the year }\end{array}$ & 0.9957 & 2.2857 & 1.2774 & 1.5200 & 1.1606 & 0.8852 & 0.7387 & 0.8356 & 0.6204 & 0.3256 & 0.7360 \\
\hline Average number of total FDI & 0.0217 & 0.0515 & 0.0793 & 0.1276 & 0.1931 & 0.2515 & 0.3138 & 0.5355 & 0.5552 & 0.669 & 0.8103 \\
\hline $\begin{array}{l}\text { Multiplying coefficient of total } \\
\text { number of FDI with the average } \\
\text { number of FDI }\end{array}$ & 0.0216 & 0.0956 & 0.1013 & 0.1812 & 0.2251 & 0.2136 & 0.2318 & 0.3630 & 0.3555 & 0.2172 & 0.5956 \\
\hline
\end{tabular}

The coefficient for total number of FDI at the start of each year is positive in all years. This means that the more direct investments a firm has in the transition countries at the start of a year, the larger the relative chance it will invest that year again. However, the coefficient is declining, indicating the impact of one additional FDI becomes less important over time. On the other hand, the second row in table A3.2.1 shows that the average number of investments firms have in the transition region increases over time. Thus, as becomes clear from the third row, the combined effect of experience increases, meaning that the more experienced firms are with direct investments in the region, the more likely they are to invest again (relatively to not investing). 


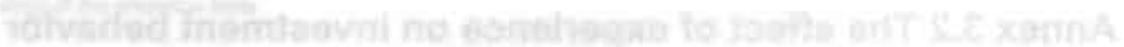

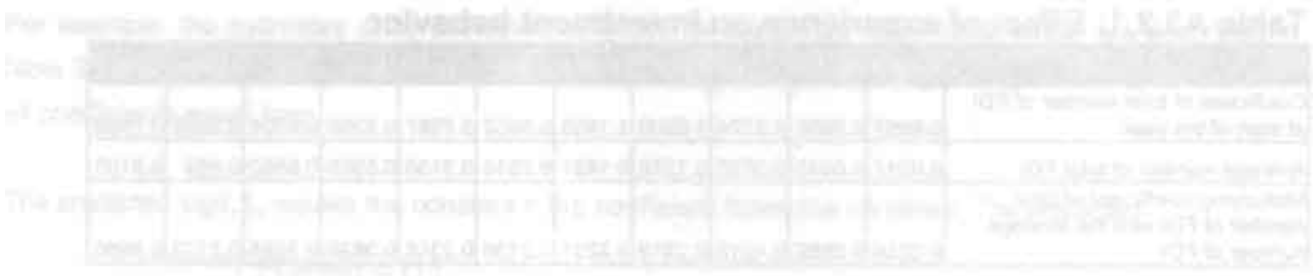

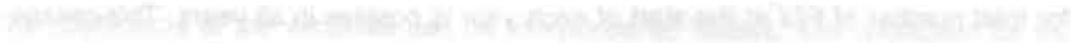

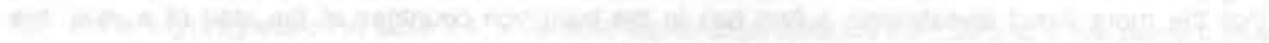

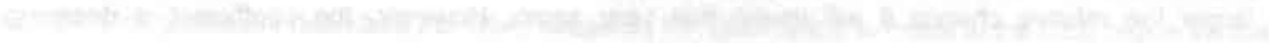

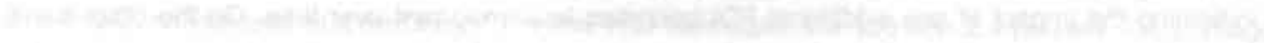

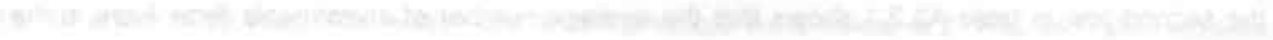

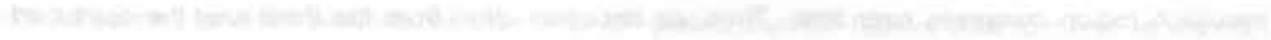

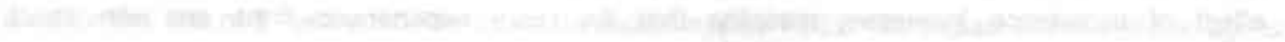

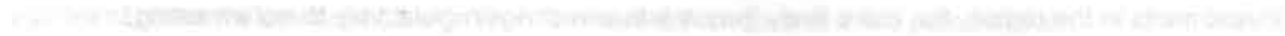




\section{Chapter 4 The investment decision}

Recently several Dutch businessmen in Moscow and I had a meeting with the Russian ambassador. "Write down on a piece of paper why western businesses won't invest in Russia", Fjodorov (vice president) said. The Dutch businessmen looked at each other a little bewildered. Where for heaven's sake to start? Stability, [...], if they would start not changing the rules every week. Investors want to make plans. Debts, [...], as long as the debts are not settled, no Western company will invest in Russia. Russia still owes governments and businesses billions. Taxes, [...], on goods imported from the west you pay more than 50 percent. Russia says it needs capital, but in reality it scares us away. The law, [...], laws are contradictory in almost every area. It is a mess; in such an investment climate no one will invest. Corruption, [...], how can you do business if the civil servants at all levels are corrupted. Honest companies can hardly do business here. Hierarchy, [.... . it is totally unclear who in the government is responsible for which issue. Stick to agreements, [...], one of our fellow businessmen recently built a factory in Russia. The agreement was that the government would buy part of the production. They just don't commit; after three months the factory is closed again.

I looked at the ambassador and said, "Try to summarize that on a piece of paper". (Derk Sauer (2001), Typisch Russisch)

\subsection{Introduction}

In this chapter the main research questions are how firms make an investment decision, what kind of decision processes and decision rules they follow and if this process of decision-making can be modeled. In chapter three the characteristics of firms were discussed that influenced whether a firm invests. Now the focus is on how the firm decides whether to invest. In order to answer this question, several assumptions and predictions on investment decisions, based on the option theory literature, are formulated in section 4.2. This chapter builds on survey data containing information on the decision-making process of Dutch firms (see annex A). The data contain information on the process leading to the decision whether to invest in the CEE region. They are used to see if the derived assumptions and predictions with respect to the firm's decision-making are confirmed by firm level data. The focus is on the investment decision process of the first investment of the firm in the CEE region since 1989 (section 4.3). ${ }^{1}$ One of the advantages of this survey database is that it includes information on the investment process of firms that decided to invest in the CEE region after 1989, as well as that of firms that were interested in an investment but decided not to invest. Therefore, it is possible to check whether the process was substantially different for the hereafter-called "investors" and "noninvestors" (section 4.4.1). The information also allows to test whether investment decision processes are influenced by the presence of experience with a direct investment in the CEE region. Several firms indicated they have more than one FDI in the region. The survey included questions related to the investment process of both their first and last investments in the region after $1989 .^{2}$ In

\footnotetext{
1The CEE region includes the transition countries from Central and Eastern Europe and Central Asia.

${ }^{2}$ The survey data are very suitable for bivariate analysis, mostly used in this chapter. They are less suitable for multivariate analyses; the only multivariate analysis included is the logit analysis in section 4.4.1.
} 
section 4.4.2 a comparison of the process of their first FDI with the last FDI is made. Last, in section 4.4.3 I check whether there is a link between the format and extensiveness of the investment decision process and the degree of satisfaction with the FDI at the time of the survey. Section 4.5 provides a framework that allows us to explain the decision process of companies. The basis for the framework is the trade off between the costs and benefits of information. Collecting information costs time and money, but information reduces the uncertainty attached to the investment decision. Assuming markets and information are imperfect, the investment decision process can be considered a way to increase or decrease the perceived risk of the actual investment, leading to the choice whether to invest. $^{3}$

In this chapter the investment process is defined as the complete process a firm follows from the moment it considers an investment up to the moment it decides whether to invest. It includes all forms of information acquisition and analysis, but also internal discussions, study trips or meetings with possible partner firms or contact persons. The investment calculation or investment analysis is the study undertaken to investigate the viability of the investment. This is not a strictly defined concept and can be interpreted differently per firm. For one firm a calculation can, for instance, be a simple single-page description of some key data, whereas another firm makes complete business plans or uses external advisors to map out the investment alternatives. The calculation or analysis is part of the investment process and considered a tool on which to base the investment decision.

\subsection{Hypotheses based on assumptions and predictions of the option theory}

The real option model is an appropriate instrument to describe an investment decision, specifying a rule to invest if the expected value of an investment is positive and higher than the option value to wait. While often applied in the financial sector, it is also very useful to apply to direct investments to Central and Eastern Europe since it specifically includes uncertainty and timing issues. The option theory, while with clear rules when to invest, does not specify how firms can implement these rules in their decision-making. In the current FDI literature there are, as far as I know, no empirical studies relating the firm's decision-making process to the theoretical decision rules. This observation may be due to the fact that the investment literature is complicated and hard to apply empirically as a complete model. However, based on the assumptions from the option model and the prediction from theoretical extensions of the option model, it is possible to define a number of hypotheses that focus on certain aspects of the option model and can be directly related to firm-level decision processes. For example, based on the option theory, I expect that larger firms invest abroad more often and sooner than smaller firms. ${ }^{4}$ In chapter three several assumptions related to the characteristics of firms investing abroad were tested and these tests confirm that the option model is suitable for investments in Central or Eastern Europe or Central Asia. Other expectations based on the option model can be related to the company decision-making processes and can only be tested using company-specific information related to the decision-making process. Therefore, in this chapter several hypotheses are

\footnotetext{
${ }^{3}$ Note that information reduces the uncertainty attached to the investment decision, not the risk and uncertainty of the actual investment. Additional negative information can very well increase the perceived risk of the investment, thereby decreasing the uncertainty of the decision not to invest.

"If firms face a binding financial constraint, theory predicts they invest less often and less soon than firms without such a constraint (Chapter two, section 2.3). I assume smaller firms face financial constraints more often than larger firms and thus smaller firms invest less often and later than larger firms.
} 
tested using the survey data on Dutch FDI.

Following the option model, firms invest when the expected value of an investment is positive. This implies that the firm somehow has to quantify future revenues and costs in order to evaluate whether an investment is viable. The terminology used in this chapter explains that firms make an investment calculation or investment analysis. In practice however, firms do not have to make an investment analysis.

In addition, the option theory decision rule implies that if the expected value of a firm is positive, firms will invest. The expected value of the investment is generally defined as the discounted expected revenues minus costs. In order to estimate the expected value, economic indicators are often used, but firms can have different arguments for their investment decision as well. Profit may just be one of the many decision criteria; profit expectations do not always have to be the main guideline for the decision. Economic indicators, like expected cost and revenue, are not always the best tools for making an investment decision. Firms can for example rely more on networks or experience of other firms and base their expected value of the investment on the opinion of those informed people, instead of on economic indicators.

A third assumption of the option model is that uncertainty surrounding an investment plays an important role in the investment decision. The higher the risk of an investment project is, the lower the probability that a firm will invest in that project since the expected profit should be able to compensate for the higher risk (thus, the expected profit should be higher). It is therefore interesting to find out whether firms take the risk or uncertainty into account in the investment decision calculation and link the concept of uncertainty to expected profit.

Another aspect of the option model is that firms include time as a variable in their decision models. Firms not only consider the possibility of investing at the current moment, but also take the option to postpone the investment into account. This behavior does not mean they decide not to invest at all, but they do not invest at that moment and remain interested in investing at a later time. In option terminology, a firm can take a "call option" on the FDI, keeping the right to invest (buy) at a later time without having to engage in the FDI now.

Summarizing, the option theory builds on the idea that firms make some kind of investment analysis or calculation before making an investment-decision and use mainly economic or business indicators in this calculation. They explicitly take uncertainty into account in their decision and also consider timing of an investment, allowing for the possibility to postpone an investment.

Aside from these assumptions, the option theory extensions in section 2.3 and 2.4 of this dissertation led to several predictions, which can be formulated in terms of testable statements. The first extension of the basic option model is to combine the ability to postpone an investment with the various degrees of uncertainty investment projects have. Following the option theory, a higher uncertainty of a country or project leads to a larger chance an investment will be postponed. This impact of uncertainty can be reflected in the choice of the host countries. An FDI in a low-risk country will have a lower option value of waiting and thus firms will invest more often or sooner in low-risk countries. A higher risk surrounding the FDI in a host country leads to a higher uncertainty for the investing firm and a higher option value of waiting, which may cause the firm to decide not to invest or to postpone the investment. ${ }^{5}$

\footnotetext{
${ }^{5}$ There is a causal relation between the risk of a country and the uncertainty of the investment project in that country. If a
} 
H1. Firms will invest more often and earlier in low-risk countries than in high-risk countries (ceteris paribus). ${ }^{6}$

Another extension of the basic option model is the possibility to consider more investment projects with similar degrees of risk, while being able to postpone an investment for the moment. Firms not only consider one investment project (or one host country) in their investment process, as is assumed in the basic model in section 2.2, but look at several alternatives from which to select the best one (see section 2.3). In theory, the "perfect" investment possibility for a firm is always available, especially when considering many investment projects and a long time span. Theory therefore predicts that the more alternative investment options the firm considers, the less likely a firm is to invest and to invest early.

H2. Firms that consider more alternative host countries when making an investment decision will invest less often or later than firms with only one host country alternative.

The last theoretical extension made in section 2.4 allows for different degrees of uncertainty between the countries from which a firm can choose. The conclusion of that section is that the more diverse the uncertainty between the host countries, the more likely it is that the firm will postpone its investment.

H3. A firm is more likely to postpone the investment if the uncertainty between the possible host countries is diverse.

In order to test these assumptions and three predictions, information on the actual decision-making processes of companies is analyzed. The only possible way to obtain such detailed information is by approaching companies directly. Therefore a survey was developed (annex A) and these survey data were used to obtain a clearer picture on the investment decision process. In the next section, the assumptions described and hypotheses formulated in this section are tested using these survey data.

\subsection{The investment decision process in practice}

In section 4.3 and 4.4 survey data from the questionnaire Dutch FDI in the CEE region are used. Figure 4.1 gives an overview of the response rates relevant to this section. In total 1550 firms were asked to participate in the survey. All firms were interested in doing business in the CEE region and either participated in a seminar or had requested information about doing business in the CEE region from the Dutch Chambers of Commerce. Of the 1550 firms in the sample, 322 firms responded by answering the questionnaire. A total of 86 had an FDI in the CEE region and 236 did not have an FDI, including the pretest results of two investors and six noninvestors. Eligible criteria for this research were that the firm had to be (partially) Dutch and the investment decision was made in the Netherlands. As a result, 32 firms were ineligible based on those criteria and excluded from the

country has high risk, the uncertainty of the investment results in that country is also high, since they depend directly on the country's economy.

"Due to the limited number of time periods included in this survey, postponing an investment until after the year 2000 is transtated in this analysis as "not investing". 
database. Before questioning firms about their investment process, those firms interested in the CEE region but not interested in an FDI were excluded ( 74 firms), as well as those firms that were in principle interested in an FDI but not in an FDI in the CEE region (94 firms). 130 firms remained in the dataset that had entered the investment process and indicated that they seriously considered an FDI in the region. Their answers were the basis for the analyses in sections 4.3 and 4.4 . For section 4.4 .2 only the answers of 37 firms with several FDIs in the CEE region were used.

\subsubsection{Testing the assumptions related to investment decision-making}

The first assumption I test is if firms base their decision on an investment analysis or calculation and if they use economic indicators in this analysis. The survey data, depicted in figure 4.1 , show that this assumption is not confirmed (summary statistics of the survey data are included in annex 4.1). Of the 288 eligible firms that visited a seminar on business in the CEE region, only 130 firms answered that they were seriously considering an FDI in the CEE region. 74 firms were not interested in FDI but interested in the CEE region for other business purposes and 94 firms were interested in an FDI but not in an FDI in the CEE region. Those 168 firms decided not to invest without making an investment calculation. Of the 130 firms that were interested in an FDI in the CEE region, 72 percent (94 firms) indicated that they made some kind of investment analysis to support their decision; 28 percent answered they did not make any investment calculation. The three most frequently mentioned arguments firms gave why they did not back up their decision with an analysis were: 1) the personal relationship of the owner with an individual or company in the host country, 2) the fact that an FDI was a logical continuation of existing trade relations and 3 ) the availability of natural resources limited the choice options. The assumption that firms make an investment analysis is thus only partially true. There can be numerous arguments, ranging from personal relations to the mere presence of natural resources in a specific region, that make a time-consuming investment calculation unnecessary.

The idea that firms mainly use economic or business indicators in their investment calculations is confirmed by the data. Not all firms that enter the investment process make an investment calculation, but still 94 firms indicated they made some kind of calculation to support their investment decision. The question remains what firms consider being "an analysis". Following the option theory decision rule, firms estimate the expected value of their investment. Even though many firms estimate this value without any calculation, economic theory often assumes economic indicators like the expected NPV are useful tools on which to base estimations. The expected value of an FDI can be calculated by discounting the expected revenues minus the expected costs.

If that approach is followed in practice, firms need to specify expected values for the costs and the revenue of their FDI, and they need to target a discount rate. The survey data show this assumption is realistic since firms often take economic indicators into account. 87 of the 94 firms that indicated they made an investment analysis used cost and revenue factors in their calculation.?

\footnotetext{
${ }^{7}$ Onty three of the 130 firms indicated they did not use any cost factors, another three indicated they did not use any revenue factors and only two indicated they did not use any uncertainty factors. Therefore the answers to these questions should be considered with care. Answering survey questions is subjective and when asked to answer about events of a number of years ago, one loses accuracy. The fact that the variables were mentioned and firms were asked to mark them creates a bias in firms marking one or more variables because while reading them it seems reasonable that they used them, while in practice they may not have considered this variable at the time.
} 


\section{Figure 4.1: Response of the survey}

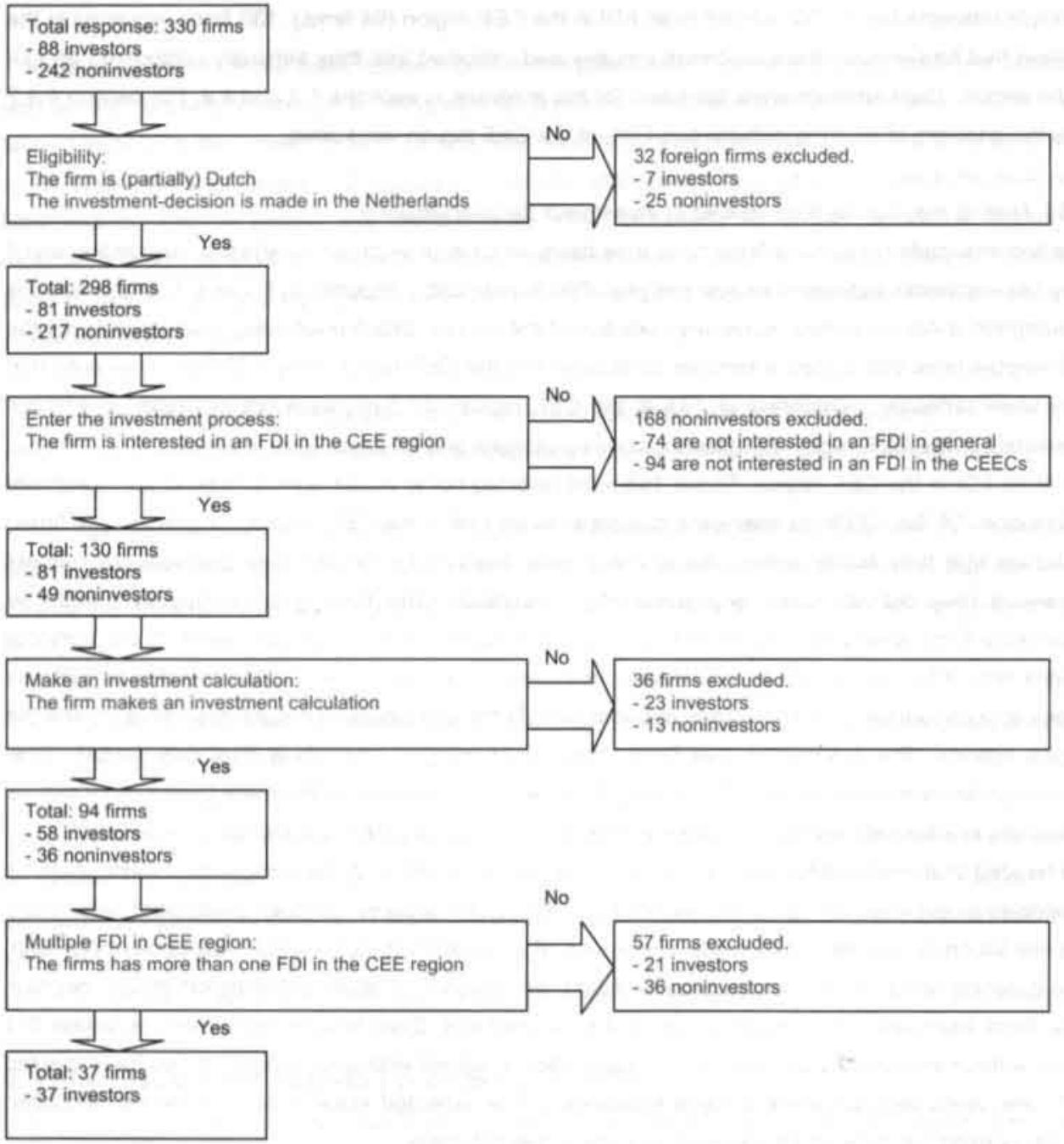


Table 4.1: Most frequently mentioned cost, revenue and uncertainty factors used in the analysis

\begin{tabular}{|l|l|}
\hline Cost of buying or renting a location & Percentage of firms that considered this factor (n=94) \\
\hline Cost of furniture and equipment & $84 \%$ \\
\hline Labor cost & $83 \%$ \\
\hline GDP per capita & $78 \%$ \\
\hline Expected market share & $62 \%$ \\
\hline Income growth in the host country & $62 \%$ \\
\hline Total population & $61 \%$ \\
\hline Political stability & $59 \%$ \\
\hline Distance in km. & $84 \%$ \\
\hline Cultural differences & $80 \%$ \\
\hline
\end{tabular}

The variables most often referred to by firms as being used in the investment calculation were the costs of buying or renting the location, costs of furniture and equipment and labor costs as cost factors and GDP per capita, expected market share, income growth and population size of the host country as revenue factors. ${ }^{8}$

Concluding, the assumption that firms make an investment calculation or analysis to base their decision on was not confirmed by the survey data. Many firms indicated they were interested in doing business in the CEE region or in setting up an FDI, but knew without any calculation they were not interested in a direct investment in the CEE region. In addition, many firms that were seriously interested in an FDI in the CEE region did not make any analysis to support their investment decision and used other forms or mechanisms to support their choice. However, of those firms that indicated they did make an investment analysis, the majority answered they indeed used economic indicators in their decision process.

The option theory also assumes that firms take uncertainty into account while making an investment decision. This hypothesis can be tested in two ways. Firstly, the survey includes a question enabling firms that made an investment analysis to report which uncertainty factors they took into account. As can be seen in table 4.1 the indicators political stability of the host country, distance in $\mathrm{km}$ and cultural differences were often mentioned as uncertainty factors and a large majority of the firms that made an analysis included these indicators in their calculations (about 80 percent) (see footnote eight).

Another way to see whether firms take uncertainty into account is the reference they use to target the success of the FDI. There is a trade off between risk and return. As the risks surrounding an investment are high, the expected return should be high as well. Consider, for example, a Dutch firm that has funds to invest and has three investment alternatives. It can put its money risk-free in a Dutch savings account and receive a low but secure interest rate. It can also invest in an expansion of the firm in the Netherlands.

\footnotetext{
"A table including the complete answers of this question is included in Annex A4.1
} 
Table 4.2: Reference for expected profitability

\begin{tabular}{|l|l|}
\hline Reference for expected profitability & Percentage of firms that selected this reference $(n=90)$ \\
\hline Profit percentage Dutch company & $36 \%$ \\
\hline Revenue on stock and shares & $10 \%$ \\
\hline Interest revenue NL & $1 \%$ \\
\hline Revenue on obligations & $1 \%$ \\
\hline Other & $17 \%$ \\
\hline No reference & $23 \%$ \\
\hline
\end{tabular}

Doing so is more risky than putting the money in the bank and therefore the expected return of that investment should be higher than the risk-free interest rate the bank offers. The expected return could for instance be compared to the profit rate of the Dutch headquarters. The third alternative is an investment in an FDI. Of the three alternatives, this is the most risky one and therefore the expected return of that investment must be the highest in order to remain interesting.

The firms that participated in the survey mostly mentioned that the target of their FDI in terms of expected return was the profit of their Dutch firm. Thus, as long as the FDI had a profit rate as high as the Dutch profit rate, the Dutch firm considered the FDI successful. Other references often mentioned were the returns on shares in the Netherlands. Other risk-free returns, such as the interest rate in the Netherlands or the return on Dutch obligations were not often mentioned. This leads to the conclusion that the risk-return trade-off is partially confirmed. Firms did consider the FDI to be more risky than relatively risk-free investments such as saving accounts and expected the FDI to have a higher return. However, in their answers they did not reflect the fact that the FDI is more risky than an investment in the Dutch firm, since they selected the Dutch profit margin most often as benchmark for their FDIs.

Overall can be concluded that the assumption that firms take uncertainty into account is correct. Not only do those firms that make an investment calculation often include uncertainty indicators in their analysis, but also firms most often compare the expected results of the FDI with the moderately risky profit rate of their Dutch enterprise, instead of a rather risk-free interest rate.

The last assumption relates to the possibility that firms can postpone their investment. This can be verified using the survey data received by those firms that considered an investment in the CEE region, but decided not to invest (noninvestors). 49 noninvestors mentioned the country in which they considered an FDI. Those firms were asked if they were interested in an FDI in the CEE region within the next two years, even though they did not initially engage in an FDI. Of the 49 firms, 26 firms (53 percent) mentioned that they were considering a new investment in the CEE region within two years and of those 26 firms, and 20 even considered an FDI in the same country in which they initially decided not to invest. Clearly this confirms that the postponement of an investment does occur.

The main reasons firms gave to initially postpone their investment were the lack of time and capacity in the Netherlands to sufficiently support the investment (34 percent of the 49 firms), the high uncertainty in the host market (27 percent) and insufficient expected profits or returns in the Netherlands at that time to support an FDI investment (ten percent). 


\begin{tabular}{|c|c|c|}
\hline & Number of firms that answered & Percentage division of answer options \\
\hline$<1$ month & 9 & $16 \%$ \\
\hline 1.3 months & 12 & $21 \%$ \\
\hline $4-6$ months & 11 & $19 \%$ \\
\hline 7.12 months & 17 & $29 \%$ \\
\hline$>1$ year & 7 & $12 \%$ \\
\hline
\end{tabular}

Another way to test whether postponing an investment occurs is to look at the time between an actual investment decision of a firm to invest in the CEE region and the time of implementation of this investment. This information was gathered from the 58 firms that did set up an FDI and made an investment analysis. As table 4.3 indicates, in most of the cases there was a lag between deciding to invest and actually investing, which was often substantial. For 72 percent of the firms this time period was longer than expected. If the time period was longer than expected, it could be interpreted as a postponement of the implementation of the investment. The main reasons for postponing the implementation were the regulations that made getting paperwork right and obtaining the necessary documents and licenses difficult (36 percent), unstable economic or political developments in the host country (21 percent and 14 percent respectively) and the fact that the Dutch company found a more appropriate alternative in which to invest, like a new host country or partner firm (14 percent).

\subsubsection{Testing the predictions derived from the option theory using firm level data}

The assumptions made by the option theory are largely confirmed by the firm level survey data. It still remains unclear if the conclusions derived from the mostly theoretical derivations of the option theory are also relevant. The remainder of this section will therefore include tests whether the predictions, as formulated in hypotheses one to three, hold in practice or need to be rejected based on the survey data.

The first prediction of the option theory is summarized in hypothesis one. It states that firms invest more often and earlier in low-risk countries than in high-risk countries, ceteris paribus. This hypothesis relates to the effect of uncertainty on an investment decision; higher uncertainty increases the chance a firm will postpone its investment at this moment. One way to check these conclusions is to combine the actual investments of Dutch firms in the CEE region with the country risk indicator for the respective countries. ${ }^{9}$ This risk indicator provides each country with a score between zero and ten; zero being extremely risky and ten being risk-free. Graph 4.1 represents the number of firms that invested in the CEE region to the risk score of the country they invested in. If the firms invested more often in low-risk countries than in high-risk countries, the bars should display an increasing trend. This upward sloping relation is indeed visible.

\footnotetext{
"For this comparison, the euromoney country risk indicator was used, Country risk data were available for all countries in the CEE region and all years included in the survey database.
} 


\section{Graph 4.1: FDI per risk category (1=very risky, $10=$ risk-free)}

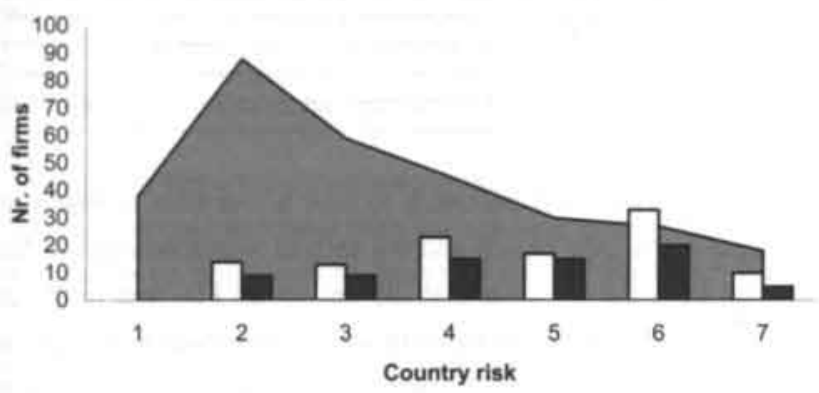

aTotal division of risk in transition countries $\mathbf{Q}$ Nr. of firms interested $\mathbf{m}$ Number of firms invested

The fact that the number of firms investing in low-risk countries with scores higher than seven is zero is not because firms were not interested in investing in such low-risk countries, but because no transition country had a risk score above seven in the respective years. This is represented by the area behind the bars, indicating the possibility to invest in a country with that score (total number of countries that had that risk score in 1989-1999). There were only a few possibilities to invest in a country with a risk score of seven or higher. Graph 4.2 shows the number of investments in the CEE countries divided by the number of possibilities to invest in a country with that score, as well as the number of interested but noninvesting firms divided by the possibilities. ${ }^{10}$ Both ratios show an increasing trend up to a risk score of six and a decline for the low-risk score of seven. This confirms that firms are investing more often in low-risk countries than in high-risk countries, again with a bias given the fact that there were not many low-risk transition countries.

Including the timing of an investment, the option model predicts that firms are more likely to invest sooner in low-risk countries than in high-risk countries. In graph 4.3 the investments are included by year of investment, with number of firms divided in three country risk categories. Graph 4.4 gives a yearly percentage division of investments per risk category. If firms invest not only more often but also sooner in low-risk countries than in high-risk countries, the bars indicating the number of investments in low-risk countries should be higher than those of the medium-risk countries and the bars of the medium-risk countries should exceed the bars of the high-risk countries. This result is not obvious from graph 4.3 and 4.4 , where in fact the number of investments in high-risk countries is larger in the early years of transition than the investments in medium and low-risk countries. However, this outcome is again largely due to the fact that in the early years of transition there were only limited lowrisk investment options. In fact, the absence of investment in low-risk countries in 1991, 1992 and 1993 is caused by complete absence of low-risk countries in the region.

${ }^{10}$ The possibilities to invest are the sum of countries that had that risk score in 1989-1999. 
Graph 4.2: Ratio of noninvestors and investors by the possibilities available

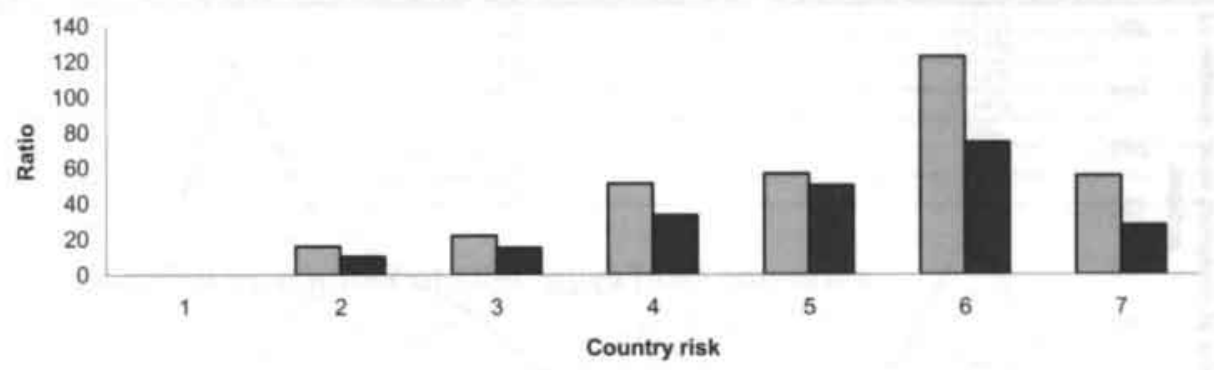

口Ratio if interested firms to options $\mathbf{m}$ Ratio of investing firms to the options

\section{Graph 4.3: Investments by risk over time}

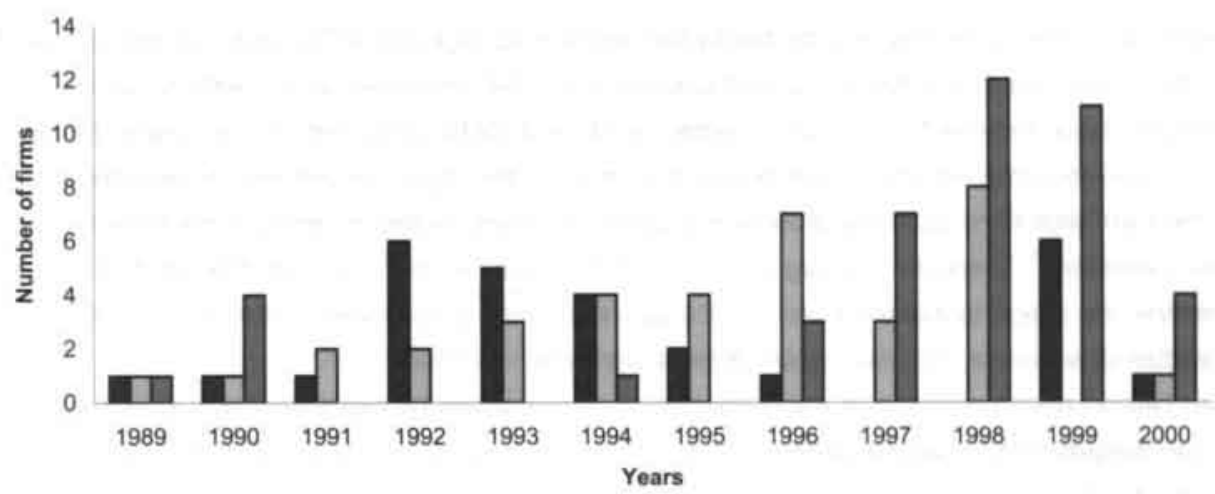

Dhigh risk score 1,2,3 Dmedium risk 4,5 Dlow risk 6,7

\section{Graph 4.4: Percentage division of investments by risk}

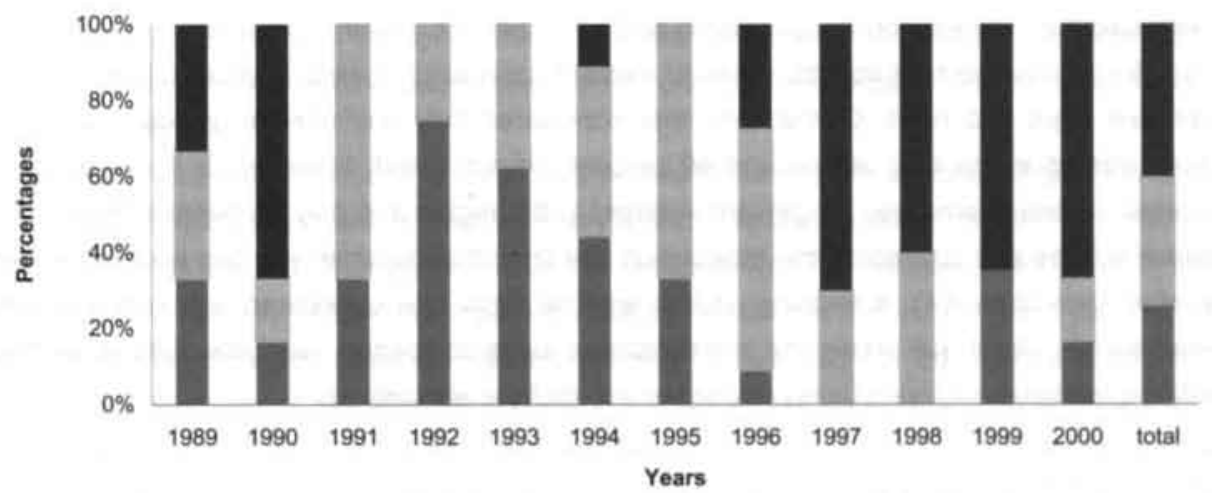

$\mathbf{m} \%$ high risk $=\%$ medium risk $\mathbf{m} \%$ low risk 


\section{Graph 4.5: Ratio of investors by risk options over time}

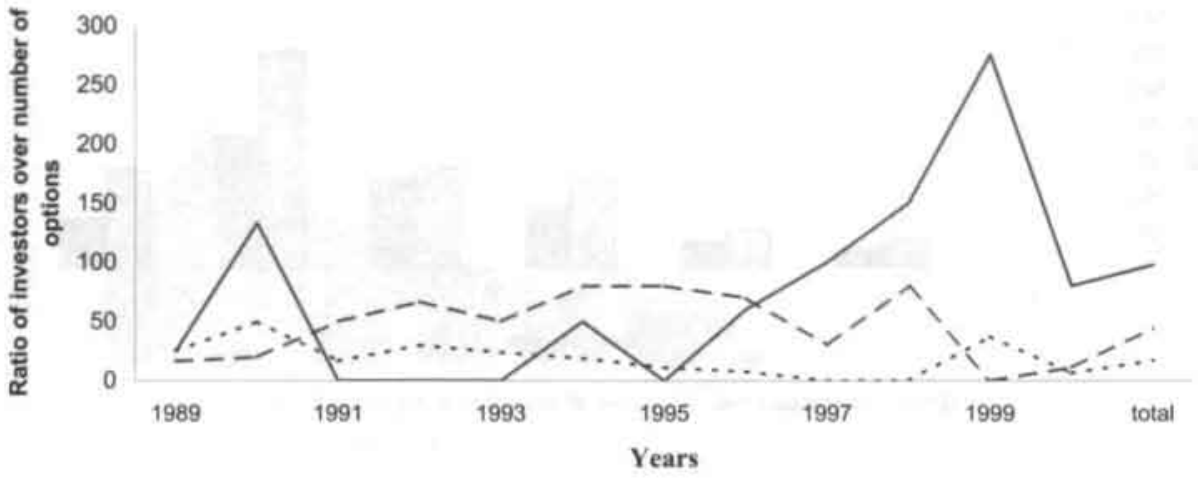

... high risk score $1,2,3-$ - medium risk $4,5-$ low risk 6,7

Graph 4.5 corrects for this fact, by taking the yearly ratio of investors in each risk group over the number of countries in that risk group that specific year. The results are in line with the option theory predictions since the line for low-risk countries (excluding 1991-1993) generally exceeds the line for medium risk countries, which is again higher than the line for high-risk countries. A deviation in small and medium/large firms does not show any additional findings, neither in timing if the investments nor in risk selection." Therefore the argument that platform investments in high risk countries can be considered an option to expand later is not supported; there is no evidence that smaller firms invest more often or sooner in high risk regions than larger firms.

The second main prediction of the option theory, summarized by hypothesis two, is that firms use several investment alternatives when making a decision. It is realistic to assume that firms consider several countries as possibilities to invest in during the investment process, instead of focusing solely on one host country. Firms use their investment analysis to choose which country is most appropriate for their firm to invest in. The option theory predicts that firms that consider several alternative investment possibilities will invest less often and later than firms that consider only one investment alternative, since the option value of waiting in the first scenario is higher. ${ }^{12}$ Of the firms in the survey that indicated they were seriously considering an FDI in the CEE region, 43 percent considered only one country as possible host country, while 57 percent considered several alternative host countries (hypotheses eight and nine). Of the firms that considered only one alternative host country, 60 percent invested in the CEE region and 40 percent did not invest. However, of those firms that considered several alternatives 76 percent invested in the region and only 24 percent did not. This difference is large and contradicts the expectation that firms that consider only one alternative invest more often (see table 4.4). It remains unclear whether firms that considered only one alternative invested sooner. Graph 4.6 shows the investments of these companies over time, split up by those firms that considered only one country and those with multiple alternatives.

\footnotetext{
"Small firms are firms with less than 50 employees. The results of this additional test are not included in this chapter.

${ }^{12}$ If more countries are considered as investment alternatives, there are different uncertainty scenarios. The chance is higher that one of the alternatives will perform very well in the next period. This increases the value of that project in the next period and given the uncertainty of investing now, it will be more attractive to wait. Thus, the option value of waiting is high (see chapter 2.4).
} 
Table 4.4: Number of alternative host countries that firms considered $(n=117)$

\begin{tabular}{|l|l|l|}
\hline Number of alternatives that firms considered & Number of firms & Percantage \\
\hline No alternative & 50 & $21 \%$ \\
\hline 1 & 24 & $21 \%$ \\
\hline 2 & 16 & $14 \%$ \\
\hline 3 & 16 & $14 \%$ \\
\hline 4 & 3 & $3 \%$ \\
\hline 5 & 4 & $3 \%$ \\
\hline$>5$ & 4 & $3 \%$ \\
\hline
\end{tabular}

\section{Graph 4.6: FDI by number of alternative host countries}

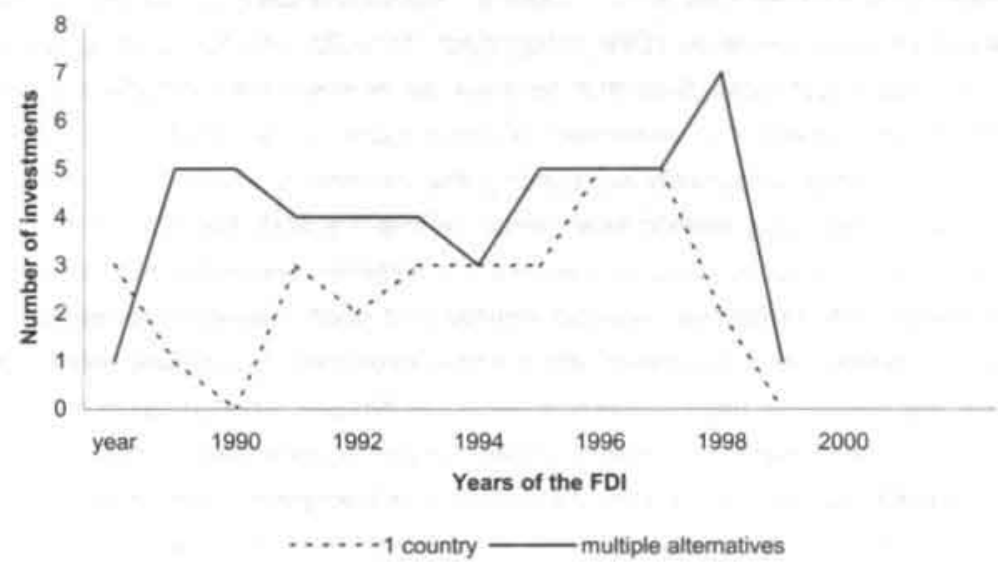

If the predictions of the option model are in line with the data, the line of firms with only one alternative should on average be higher than the line of firms with several alternatives. This conclusion is not true. The number of investments made by firms that considered several alternatives is over the whole sample period equal or higher than that of the companies that consider only one investment. When considering several alternatives, the possibility that one of those alternatives is interesting for the firm to invest in, is higher than when considering only one alternative. This idea is contrary to the predictions of the option theory extension in section 2.4 , that firms are more inclined to wait when considering several alternatives, since one of those alternatives may be even more promising next year. ${ }^{13}$

The third hypothesis mentioned is section 4.2 relates to the diversity in uncertainty. If the degree of uncertainty related to the various host countries a firm considers is large, the firm is more likely to postpone the investment. The reason is that the expected value of the investment today in the host country should not only exceed the expected value of investing in that country next year, but should also exceed the expected value of investing this year or next year for the alternative country. The higher the uncertainty of the alternative country, the higher the expected value of investing in that country next year will be, making an investment less likely. To see if these theoretical expectations also hold for the Dutch firms in the sample, pairs of alternative countries are grouped and combined with the country risk indicators of their specific years. If the hypothesis can be accepted, the years of

\footnotetext{
${ }^{4}$ Again, a test dividing the sample in small ( $<50$ employees) and medium/large firms does not change this conclusion.
} 
investment should be negatively related to the deviation in country risks of the alternatives. ${ }^{14}$ This is not confirmed by the data. There is no relation between the deviation in country risk and year of (considering the) investment. In addition, the deviation in country risk is also an insignificant indicator in explaining whether a firm will invest. ${ }^{15}$

In section 4.2 assumption the option model builds on were given and three hypotheses were formulated based on the option theory extensions in chapter two. In this section those statements were tested, using Dutch firm level survey data, in order to see whether the assumptions of the option theory related to the investment decisions, as well as predictions derived from the option theory hold in practice. Table 4.5 gives an overview of the results. These tests show that even though the option theory does not give any hints on how firms should make an investment decision but only derives decision rules, a large part of the assumptions of the option theory fit reality well. Firms do not always make an investment calculation, but those firms that do make an analysis often include economic variables. In addition the postponement of an investment, a crucial aspect of the option model, occurs frequently in practice. As expected, uncertainty surrounding the investment affects the investment choice negatively. This is an interesting phenomenon, because this indicates that if a country has possibilities to decrease uncertainty surrounding an investment in a country, the amount of FDI to that CEE country likely increases. Sound policies, political stability and good institutions decrease the uncertainty of a country. In chapter five, using the gravity analysis, I conclude that a lower country risk positively influences FDI to a country. In practice this is a longer run process for countries to influence the FDI inflow positively, firms themselves can hardly influence country uncertainty. ${ }^{16}$ However, the three hypotheses formulated based on the theoretical extensions of the option model in section 2.3 and 2.4 are partially rejected based on the data. Firms invest more often and sooner in low-risk countries. But considering several alternative host countries increases the probability a firm invests instead of leading to postponement of an investment. In addition, even though uncertainty influences an investment decision, the uncertainty differences between alternative host countries influence an investment decision less than expected. It is interesting to consider to what extent a firm can limit the uncertainty surrounding its FDI in advance, by means of a thorough investment analysis. Is it true that firms with a more extended investment analysis are also the ones more confident about the investment? Do they engage in an FDI more often?

Chapter three concluded that experience with FDI in the CEE region increases the chance a firm will invest again in the region, indicating a learning effect. An interesting question is whether factors such as experience directly decrease the uncertainty surrounding a new FDI. To what extent can those factors function as a substitute for an investment calculation? Are they just complementary to each other in reducing the uncertainty? Those questions will be elaborated on in section 4.4.

\footnotetext{
${ }^{14}$ This test would yield a more accurate result if the deviation in the host country's risks were be measured at the start of the investment process and this deviation were related to the year of investment. In this analysis, the year of investment were also considered the year of country risk. The deviation selected was the largest deviation between the preferred host country and the alternative countries. Thus, if a company selected one host country and two alternative host countries, the difference in country risk was calculated for both alternatives and the highest difference was used.

it This relationship was tested by means of a probit analysis.

16 Of course, when firms invest, the country may economically benefit from those investments and country risks may decrease. However, at the decision-making time, this consideration does not decrease the uncertainty surrounding the FDI. In addition, FDI helps local institution building and decreases the chance for policy reversals. Last, FDI present in a host country serves as attractive factor for new FDI.
} 


\section{Table 4.5: Conclusions related to the assumptions and hypotheses tests}

\begin{tabular}{|c|c|}
\hline Assumptions and hypotheses & iclusions from test. \\
\hline $\begin{array}{l}\text { A1. Firms make an investment calculation before making an } \\
\text { investment decision }\end{array}$ & No, many firms do not make an investment analysis. \\
\hline A2. Firms use economic indicators in their investment analysis & $\begin{array}{l}\text { Yes, firms that mentioned that they made an analysis } \\
\text { often use cost and benefit indicators. }\end{array}$ \\
\hline $\begin{array}{l}\text { A3. Firms take uncertainty of an investment into account in their } \\
\text { investment decision }\end{array}$ & $\begin{array}{l}\text { Yes, firms that mentioned they made an analysis often } \\
\text { use uncertainty indicators. }\end{array}$ \\
\hline $\begin{array}{l}\text { A4. Firms can postpone an investment and decide not to invest at } \\
\text { the current moment but wait until at a later time }\end{array}$ & $\begin{array}{l}\text { Yes, of the firms that decided not to invest in a country, a } \\
\text { large percentage still considers an investment in the } \\
\text { same country within two years. }\end{array}$ \\
\hline $\begin{array}{l}\text { H1. Firms will invest more often and sooner in low-risk countries } \\
\text { than in higher-risk countries. }\end{array}$ & $\begin{array}{l}\text { Yes, countries with low or medium country risk received } \\
\text { more FDI than high-risk countries. }\end{array}$ \\
\hline $\begin{array}{l}\text { H2. Firms that consider several alternative host countries when } \\
\text { making an investment decision will invest less often or later in the } \\
\text { CEE region than firms with only one host country alternative. }\end{array}$ & $\begin{array}{l}\text { No, there is no significant relation between investment } \\
\text { behavior and number of alternative host countries. }\end{array}$ \\
\hline $\begin{array}{l}\text { H3 Firms that consider alternative host countries with large } \\
\text { deviations in country risk will invest less often and later in the CEE } \\
\text { region than firms with only one host country alternative or small } \\
\text { deviation in country risk of the alternative host countries. }\end{array}$ & $\begin{array}{l}\text { No, there is no significant relation between investment } \\
\text { behavior and timing of the investment and deviation in } \\
\text { host country risks. }\end{array}$ \\
\hline
\end{tabular}

\subsection{Differences in the decision-making process}

\subsubsection{Investors versus noninvestors}

If thorough preparation reduces uncertainty of the investment decision, firms with an in-depth preparation process should be the ones more likely to invest. Naturally, this argument could be reversed easily: if firms are not sincerely interested in an FDI, they will not need an extensive preparation before they decide not to invest. Either way, I expect that firms with an FDI (investors) make an investment analysis more often than noninvestors and investors include more decision variables in the preparation analysis.

Table 4.6 gives an overview of information on the investment process of investors and noninvestors. The assumption that investors make a more elaborate investment analysis is not confirmed by the data. A similar percentage of investors and noninvestors make an investment analysis (71 versus 73 percent). Investors indicate they made the analysis slightly more often then noninvestors and for this analysis they also use slightly more revenue, cost and uncertainty variables. On the other hand, noninvestors indicate they visited seminars more often, made study trips more often and performed market research or were more often advised by institutions. None of the preparation variables differed significantly between investors and noninvestors, with the exception of "advice from institutions", which was significantly more given to noninvestors ${ }^{17}$. Thus, there is no evidence that the kind of investment analysis differs between investors and noninvestors. In addition, in a logit analysis testing whether any of those variables significantly influenced investment behavior, all variables were insignificant. The results of this logit analysis are included in annex A4.1. Consequently, it is not possible to conclude that firms doing extensive analysis invest more often.

\footnotetext{
"For each variable Chi2 tests were taken to test the difference between investors and noninvestors, with significant difference accepted at the ten percent level.
} 
Table 4.6: The investment preparation of investors and noninvestors

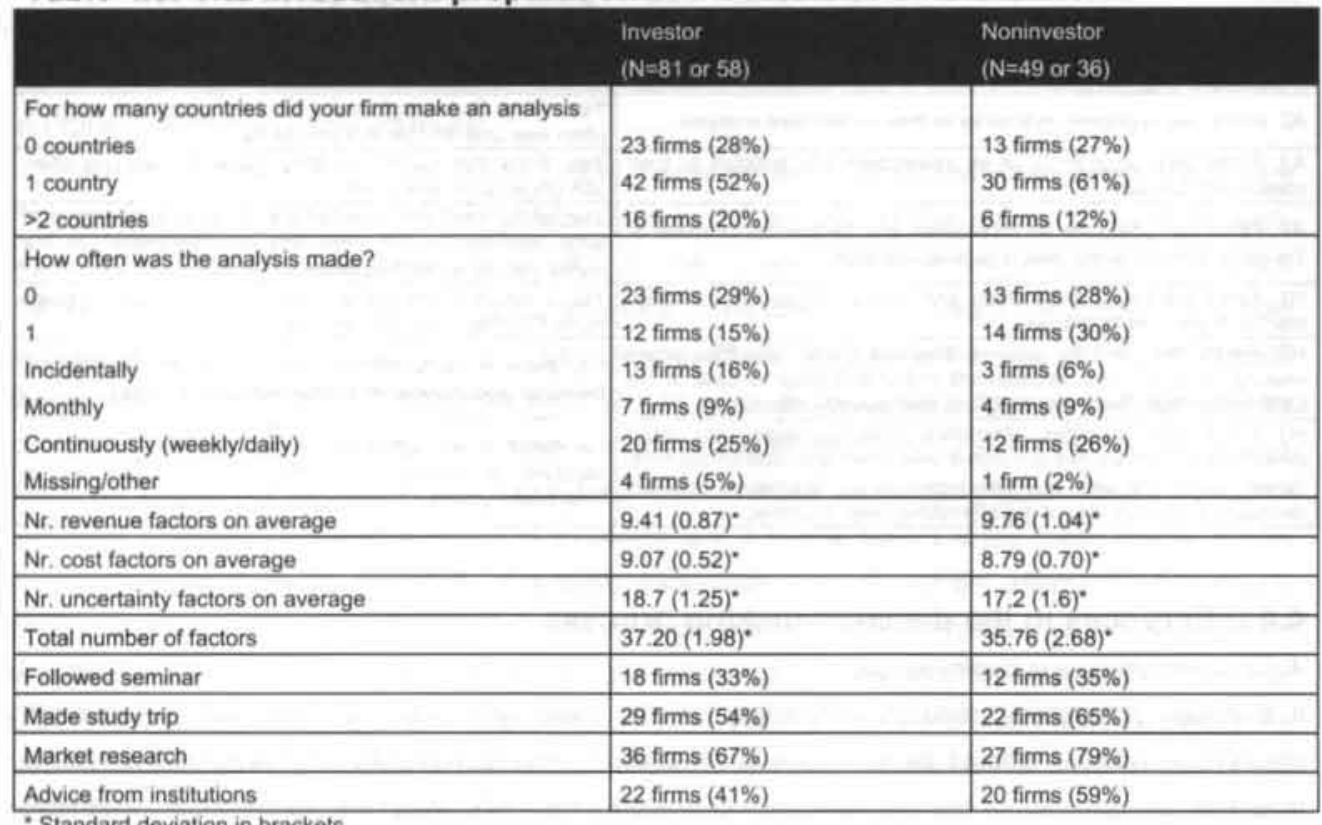

- Standard deviation in brackets

\subsubsection{First versus last investment in the CEE region}

The information on the investment decision was collected for the first and last investment a firm made in the CEE region between 1989 and 1999. As was evident from chapter five, experience is important. Experience with an investment in the region decreases the uncertainty surrounding a new investment. Based on such findings I expect firms with an FDI in the region to have a reduced risk perception with respect to a new FDI in the CEE region. Because of this experience they feel more confident about this second or later investment in the region than about the first FDI. This could result in a less elaborate preparation or decision process, a shorter time span between the start of the investment process and the time the firm becomes operational, or a lower risk valuation the firm attaches to the host country.

Firms indicated the investment analysis with respect to their last FDI was in most cases (68 percent) equal or more extensive than for their first FDI. For 14 percent of the firms, the time period between the investment decision and operationality for the last investment was still longer than expected, compared to 24 percent for the first FDI in the CEE region. Thus, firms were less often negatively surprised by this time period, but the percentage is still rather high. Interestingly, the reasons for the delay in implementation varied. For the first FDI, procedural issues (obtaining the necessary documents) and the unstable political and economic situation in the host country caused most delay. For the last FDI, in addition to the unstable political and economic situation in the host country, financial difficulties as well as problems with the partner firm in the host country caused most of the delays. The time required to handle bureaucratic issues was less of a burden for the last FDI. 
Table 4.7: Investment analysis of the last FDI compared to the first FDI

\begin{tabular}{|l|l|}
\hline Investment analysis of the last FDI compared to first FDI was: & Last FDI \\
\hline No analysis & $7(19 \%)$ \\
\hline Less thorough and less elaborate & $5(14 \%)$ \\
\hline Exactly same analysis & $14(38 \%)$ \\
\hline More thorough and elaborate & $11(30 \%)$ \\
\hline Time between decision and operationally was (1): & \\
\hline Shorter & $14(38 \%)$ \\
\hline Exactly the same & $12(32 \%)$ \\
\hline Longer & $5(14 \%)$ \\
\hline
\end{tabular}

(1) For six firms the answer was missing for either the first or last FDI, making the comparison impossible.

Table 4.8: Evaluation grades for the last FDI compared to the first FDI

\begin{tabular}{|l|l|l|}
\hline & First FDI & \multicolumn{2}{|c|}{ Last FDI } \\
\hline Percentage of firms still operational & $86 \%$ & $84 \%$ \\
\hline Evaluation grade (between 1-10) for all investors (unpaired)(1) & $\begin{array}{l}6.12 \\
(\mathrm{~N}=58)\end{array}$ & $\begin{array}{l}7.23 \\
(\mathrm{~N}=30)\end{array}$ \\
\hline Evaluation grade for investors who gave grades for both first and tast FDI (paired)(2) & $\begin{array}{l}6.68 \\
(\mathrm{~N}=22)\end{array}$ & $\begin{array}{l}7.45 \\
(\mathrm{~N}=22)\end{array}$ \\
\hline
\end{tabular}

(1) The grade for the last FDI is significantly larger than for the first FDI, at $5 \%$ significance $(t=1.9432, P<t: 0.0276)$

(2) The grade for the last FDI is not significantly larger than for the first FDI

Another relevant and interesting question is how valuable or effective experience is for the success of a firm. Are firms more likely to remain operational if they already have experience with an FDI in the region? Do they evaluate their last FDI more positively than their first FDI? As the data in table 4.8 show, 86 percent of the firm's first investments in the CEE region is still operational. This percentage is almost equal for their last FDls (84 percent). In terms of evaluation, a distinction is visible. Firms were asked to give both FDls a success grade, with zero being completely unsuccessful and ten being highly successful. Firms evaluate the success of their last FDI on average one score higher than their first FDI, indicating that experience leads to more successful companies in transition economies.

\subsubsection{Influence of the investment analysis and evaluation of the FDI afterwards}

Another interesting question is whether the preparation method affects the risk of an FDI once the decision to invest is made. It is likely that firms with a very extensive preparation face less uncertainty than firms with a less extensive preparation. They probably less frequently face unexpected events during the setup of the FDI or once the FDI started operating. Equally, firms that rushed into the investment without thorough preparation probably encounter more hindrance from circumstances they had not expected beforehand and experience such events as negative. An example is the acquisition of documents. In the early years of transition the institutional process to set up an FDI was often unclear. Obtaining the necessary documents was crucial to setting up the FDI, but took a long time, a lot of money and often included informal processes as well. Firms, that considered those bureaucratic processes during preparation and incorporated the time and money it would take into their decision and preparation processes, were more likely quicker in receiving the documents than firms not considering bureaucracy. They knew what kinds of documents were needed and where they could be acquired. In addition, they would not be negatively surprised by the time and money involved to obtain the documents. Firms that decided to invest without much preparation could be overwhelmed by the enormous bureaucracy and translate this into a negative feeling towards their investment. 
Table 4.9: Evaluation of the risk of the country and FDI and overall success of the $\mathrm{FDI}$ ( 1 = very risky/unsuccessful, 10 = risk-free/successful)

\begin{tabular}{|c|c|c|c|}
\hline & Risk orade county & Risk grade FDI & Evaluation score FDI in total \\
\hline $\begin{array}{l}\text { Considered } \\
\text { No alternatives } \\
1 \text { alt. country } \\
2 \text { alt. countries } \\
3 \text { alt. countries } \\
>3 \text { Countries }\end{array}$ & $\begin{array}{l}3.86 \\
4.2 \\
4.63 \\
5.57 \\
5.17 \\
\end{array}$ & $\begin{array}{l}3.86 \\
4 \\
4.75 \\
5.26 \\
4.83 \\
\end{array}$ & $\begin{array}{l}5.25 \\
6.08 \\
5 \\
5.86 \\
7.09 \\
\end{array}$ \\
\hline $\begin{array}{l}\text { Year FDI was made } \\
<1991 \\
1992-1993-1994 \\
1995-1996-1997 \\
1998-1999-2000\end{array}$ & $\begin{array}{l}4.83 \\
4.64 \\
3.86 \\
5.77\end{array}$ & $\begin{array}{l}4.58 \\
3.91 \\
4.07 \\
5.69\end{array}$ & $\begin{array}{l}6.07 \\
6.69 \\
6.12 \\
5.64\end{array}$ \\
\hline
\end{tabular}

The survey contained three questions in which firms were asked to evaluate the current risk of their FDI, the current risk of the host country and the overall success of the FDI. The grades ranged from one, being extremely risky or extremely unsuccessful, to ten being risk-free and very successful. Table 4.9 includes summary statistics related to the evaluation scores. When looking at the number of countries a company included in their analysis, the evaluation scores show that conclusions regarding the amount of preparation are correct. With respect to the starting year of the FDI, I expect the risk of the FDI undertaken in the early years to be lowest (the highest score), assuming the risk of the firm decreases with the number of years the firm is operational. However, the data show that firms that were established latest (1998-2000) are the firms that consider their FDI and host country least risky. A lower level of experience of those firms that invested latest could possibly explain this. They are not as familiar with the FDI and region they invested in yet and do not fully acknowledge the risks involved. All risk scores are below the value of six, meaning on average firms consider both their FDI and the host country risky. The success grades have a slightly higher average, score six, thus the investments are evaluated sufficiently successful.

In the second part of table 4.9, the same average risk and evaluation scores are given, split up according to different aspects of the investment calculation. I expect a firm that has more knowledge about the host country, either through experience or through a more elaborate investment calculation, to evaluate the country and the FDI less risky. If good preparation pays off, the evaluation of the success of the FDI should correspondingly be higher. Indeed, more experience in the region leads to a higher success evaluation of the investment, but it does not lead to a lower risk evaluation. Experience is thus useful in coping better with the risk, but the experienced firms do not consider the region or their investment less risky than firms with less experience. A more extensive investment preparation, measured by the numbers of variables included in the analysis or activities undertaken during the preparation, does not lead to higher success evaluations of the FDI or lower risk evaluation.

There is an increase in success evaluations visible when looking at the frequency of the analysis. Firms that continuously reconsidered their investment choice evaluate their FDI now more successfully than firms that made the analysis only once. Experience does increase the value the firms gave to their investment; the most recent investment the firm made scores on average higher in terms of success than their first investment. 
Table 4.9 continued: Evaluation of the risk of the country and FDI and overall success of the FDI

( 1 = very risky/unsuccessful, $10=$ risk-free/very successful)

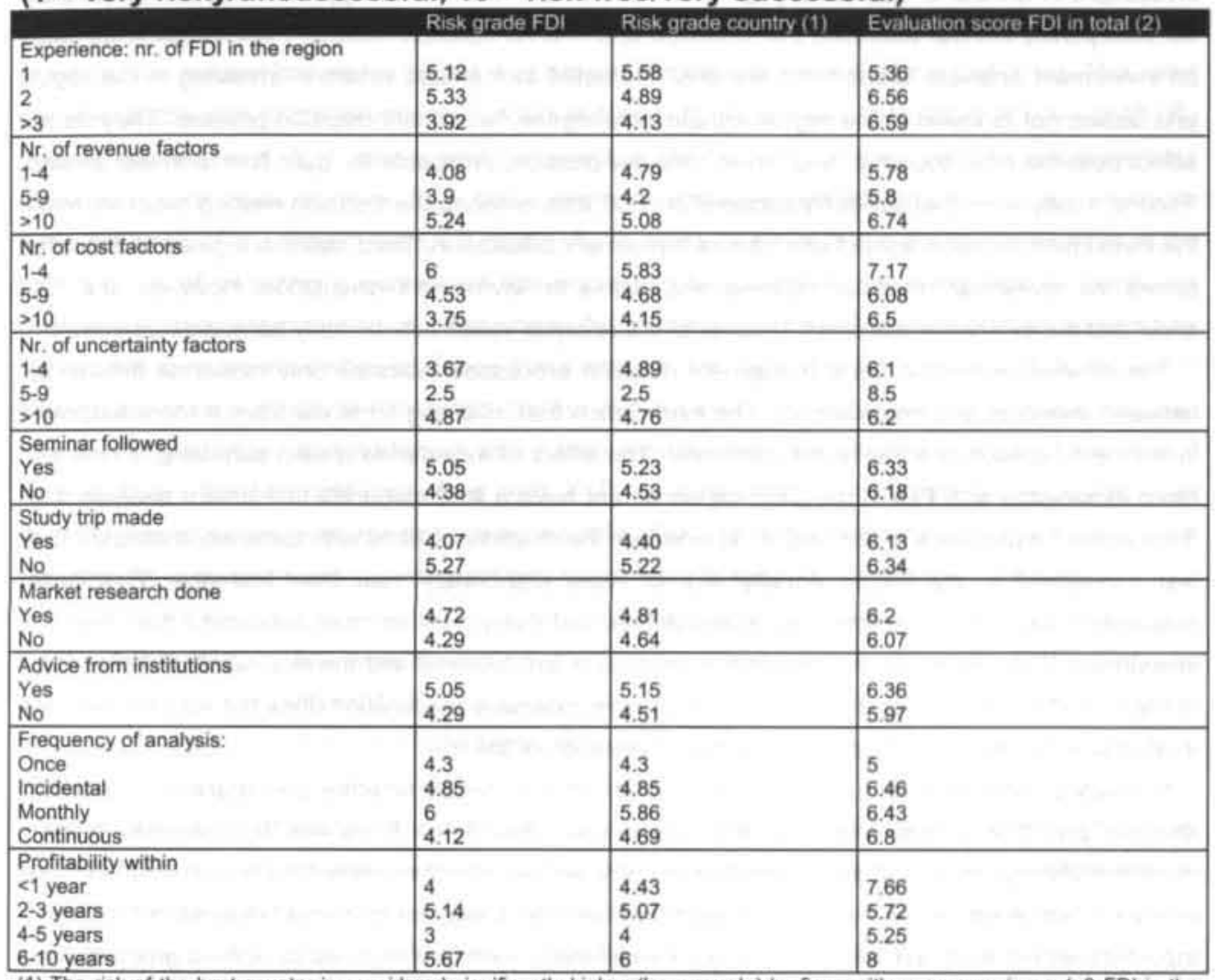

(1) The risk of the host country is considered significantly higher (lower grade) by firms with more experience ( $>3$ FDI in the region) and significantly lower by firms that received advice from institutions than by firms that did not receive this advice. All other risk sources, for both country and FDI are not significantly different with respect to the variables included in the table.

(2) The evaluation of success of the FDI increases significantly as the number of revenue factors included in the preparation increases, but the difference is insignificant for all other variables mentioned.

Based on these results it is not possible to give conclusions on the impact of an investment preparation to the success of an FDI. It appears that those firms with elaborate analysis evaluate the success of their investment higher than those firms with limited analysis, but the distinction is marginal and not significant in most cases. Experience increases awareness of country and investment risks, but also leads to higher success evaluations.

\subsection{An investment decision framework}

The tests in section 4.3 and 4.4 show that some kind of decision rule, as formulated by the option theory, is often applied at firm level. Firms often incorporate cost and benefit expectations in their investment decision process. In addition firms indeed take the impact of uncertainty and the strategic possibility to invest at different times into account during their investment decision process. However, the theory does not explain the process of firm's investment decisions. All kinds of factors can be 
included in the model and the decision rule when to invest is well defined, but how firms arrive at certain conclusions remains unclear. After studying the survey data of Dutch firms considering an investment in Central or Eastern Europe and Central Asia, it becomes apparent that the model does not incorporate several situations that occurred at firm level decision-making. First, not all firms make an investment analysis. Many firms are only interested to a limited extent in investing in the region and decide not to invest in the region without entering the investment decision process. They do not select possible host countries and never consider possible prospects for their firm to invest abroad. Second, many firms that seriously consider an FDI, thus entering the decision-making process, make the investment decision without any form of investment calculation. Third, there is a group of firms that enters the investment decision process and makes an investment calculation. However, the data show that the extensiveness and frequency of the analysis varies substantially between those firms.

The information on the firms' investment decision processes indicates only moderate differences between investors and noninvestors. The expectation that investing firms will have a more extensive investment decision process is not confirmed. The effect of experience is also surprising. Firms with more experience with FDI in the CEE region do not have a less elaborate investment analysis than firms without experience in the region. In addition, the majority of firms with experience prepare their last investment in the region equally well or more elaborately than their first one. This better preparation pays off, since firms also evaluate their last investment as more successful than their first investment. With respect to the preparation process a firm followed and the evaluation of the success of the FDI afterwards, it can be concluded that more extensive preparation does not lead to lower risk evaluations but does lead to a better success evaluation of the FDI.

In practice there appears to be a mechanism for firms to decide whether they make an investment analysis and if any, how extensive that analysis will be. Some firms are, for whatever reason, confident enough to invest in a transition country without any investment calculation. Other firms indicated that, even though they were interested in visiting a seminar on doing business in the region, they decided not to invest without making an additional investment calculation. A third group of firms studied the costs and benefits of the investment in detail before deciding whether to invest. The perceived risk surrounding the investment is a crucial factor for a firm to determine whether to start the investment process and seriously consider investing in a transition country.

In this section I build a framework that adds to the understanding of FDI decisions. I follow the line of reasoning of Wadeson (2000), who introduces the theory of meta rationality. Wadeson argues that firms face the situation of bounded rationality, given there is imperfect information. ${ }^{18}$ Being aware of this situation, firms need to make decisions based on the information they have, realizing they will never be able to completely incorporate everything that is available. While collecting information, firms take the cost of collecting into account and only collect information up to the point at which they find additional information worth spending money on.

The focus in this section is on the investment process within the firm. Assume the investment decision process is a multiperiod one and firms that enter the investment process are in principle

\footnotetext{
"Bounded rationality refers to the fact that given rational choice, firms may not be utility (profit) maximizing and full information is absent. Decision-making under uncertainty is difficult, since predicting the future is hard and humans face cognitive limitation. Those critiques are largely accepted and theory is adjusted based on empirical evidence. The decision-making solution bounded rationality offers is that firms do not attempt to search for all investment possibilities but choose a solution satisfying to all parties (Simon, 1997).
} 
interested in an FDI in the CEE region. Each firm (or owner of a firm) initially attaches a certain perceived risk to the FDI in the CEE region. This initial risk level varies between firms since it is not an objective risk indicator but the perceived risk of a firm. It is based on the subjective view of the decision-maker and is influenced by for instance history of the firm, the links of the firm to the country or region, the general knowledge of investing abroad, personal ties to the region and so on. This initial risk level at the start of the investment process is called $R_{0}$. In addition each firm has a threshold $R$, a maximum risk level $R_{\max }$ above which in principle the firm will not even consider an investment abroad and a minimum risk level $R_{\min }$, below which the firm will invest abroad without any calculation. If the risk level of investing in the CEE region $R_{0}$ is below or equal to the minimum risk level of the firm, the risk of investing is considered low enough to invest without spending time or money on collecting additional information. In other words, the probability that additional information collected by the firm will increase the perceived risk so that it exceeds the risk threshold $R$ is zero. If $R_{0}$ equals or exceeds the maximum risk level of a firm, the firm will not even consider setting up an FDI in the CEE region. The probability that additional information will decrease the perceived risk so much that it declines below the threshold level $R$ is zero. If $R_{0}$ is higher than the minimum risk level and lower than the maximum risk level, the firm will not be able to decide at that time whether to invest and it will postpone its investment and look for additional information to support its investment decision.

(1) A firm will:

$$
\begin{aligned}
& \text { Not invest if: } R_{0} \geq R_{\max } \\
& \text { Invest if: } R_{0} \leq R_{\min } \\
& \text { Postpone investing if: } R_{\min }<R_{0}<R_{\max }
\end{aligned}
$$

Firms that either invested, or decided not to invest leave the investment process. Firms that postponed the investment start an investment analysis that will assist them in determining whether to invest in the next period. The firm can acquire information (I) in order to reduce the uncertainty of the investment decision. Obtaining information is costly and the costs increase progressively. Thus, the more information a firm already obtained, the more expensive it is to collect additional information. Intuitively, this is clear. If a firm has limited background information on the possible host country, it will be relatively easy and cheap to become better informed by, for instance, reading books or searching the Internet. If a firm is already well informed, books do not add much to the knowledge of the firm and it will have to rely on more expensive sources of information such as field trips to the host country. The costs of obtaining information are included in equation two. The cost efficiency of collecting information, $\mathrm{c}$, is low if firms are very efficient in collecting information.

(2) $\mathrm{C}(\mathrm{I})=\mathrm{F}(\mathrm{I}) \quad$ with $\frac{\partial C}{\partial I}>0$ and $\frac{\partial^{2} C}{\partial^{2} I}>0$ 


\section{Figure 4.2: The cost and benefit functions of information}

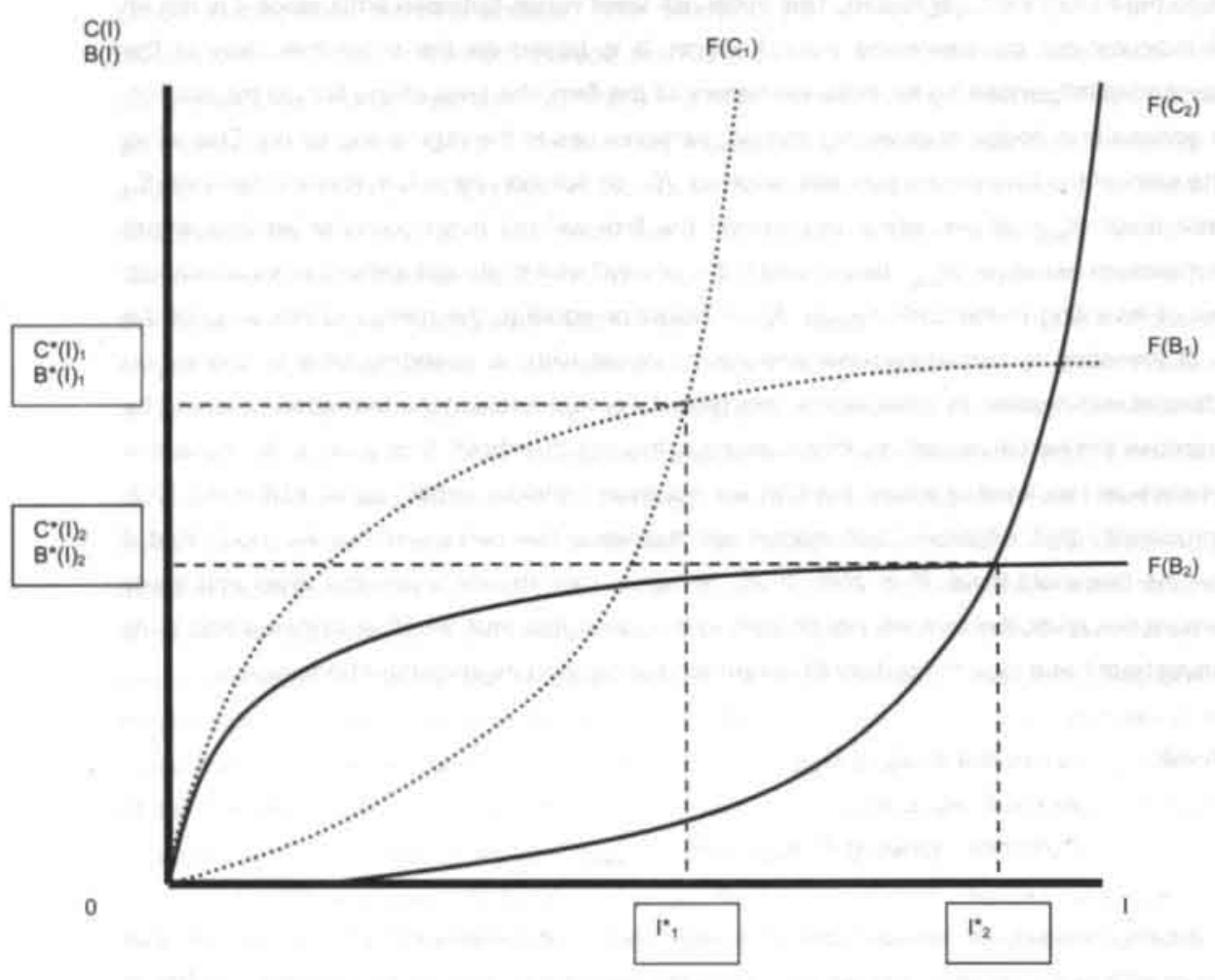

The obtained information will decrease the uncertainty the firm faces when making an investment decision. The more information related to the FDI is known, the less uncertain is the choice the firm faces regarding the investment. I define this decrease in uncertainty the benefit of information gathering (B). The decrease in uncertainty per unit of additional information varies among firms. Some firms will be very sensitive for information and every additional source of information will lead to a large decrease in uncertainty, whereas the same information would lead to only a limited change for another firm. This difference is included by means of a sensitivity indicator $\mathbf{s}$. The impact of information on uncertainty is of decreasing scale, meaning that the marginal return on information is higher for the first unit of information than for following units.

(3) $B(1)=F(1)$

$$
\text { with } \frac{\partial B}{\partial I}>0 \text { and } \frac{\partial^{2} B}{\partial^{2} I}<0
$$

A firm will collect information as long as the costs of obtaining the information are lower than the benefits it receives of the information in the form of a lower uncertainty of the investment decision. Figure 4.2 depicts the cost and benefit function of two different firms. Firm one has a steep upward sloping cost curve, indicating that the acquisition of information is expensive and the firm is not efficient in obtaining the information. The benefit function of firm one is also steeper than the benefit 
function of firm two, so the firm benefits a lot from the first units of information. Its equilibrium is at $1 *$. the maximum amount of information firm one will collect because for every additional unit of information above $\mathrm{I}^{*}$, the costs of obtaining the information are higher than the benefits of the information in lowering uncertainty surrounding the investment decision. Firm two is less sensitive to information, but is more cost efficient in collecting information. The result is a higher equilibrium level of information $\mathrm{I}_{2}$. This larger amount of information is less costly but also yields less benefit in lowering uncertainty than $\mathrm{I}^{*}$, does for firm one.

The risk a firm attaches to an FDI in the CEE region is a function of the initial risk assessment, the amount and kind of information obtained and the impact (i) the information has on the firm's perceived risk. Assume the firm can absorb one unit of information per time period and will collect this information as long as $B(I)>C(I)$. The information can be positive or negative with respect to the investment in the host country. Negative information will increase the firm's perceived risk of the FDI; positive information will decrease this risk. The impact of the information on the risk perception of each firm is different. Firms with a large impact will increase or decrease their risk rate more than firms with a low impact coefficient. After each time period in which the firm collected information, it will incorporate this information in its risk rate and make an investment decision based on the decision rule stipulated in equation one, If the firm decides to invest or not, it leaves the investment process. If the firm again postpones the investment, because the perceived risk is above $R_{\min }$ but below $R_{\max }$ the firm will remain in the decision process and start obtaining additional information in the next period.

$$
\text { (4) } R_{1}=\mathrm{F}\left(R_{0}, I_{\text {pos, }} I_{\text {neg }}\right) \quad \text { with } \frac{\partial R}{\partial I_{\text {pas }}}<0, \frac{\partial R}{\partial I_{\text {meg }}}>0 \text { and } \frac{\partial^{2} R}{\partial^{2} I}<0
$$

The complete model is depicted in figure 4.3. In the upper right section, the cost and benefit functions of information are included. The horizontal axis measures the information in units and since firms can only obtain one unit of information per time period it also represents time. Given the shapes of these two curves, the maximum amount of information a firm will collect is $1^{*}$. In the lower right section, this is shown per time period. In each period, a firm will collect one unit of information until $I^{*}$. In the upper left quarter of the figure the risk curves of three firms are included. At time $t=0$, each firm has an initial risk perception of the FDI, in all cases above $R_{\min }$ and below $R_{\max }$. Thus, all firms start collecting information. After period one this information is incorporated in their risk perception. Firm one is now more certain about the investment, decreases its risk perception $R_{1}$ to below $R_{\min }$ and decides to invest. Firm two also consideres the received information as positive and decreases its risk perception, but it is still uncertain about its investment decision. The firms keeps collecting information in period two, three and four. After each period it postpones the investment decision, since its risk remains between $R_{\min }$ and $R_{\max }$. Even after five periods, when the firm has reached the point that it is no longer beneficial to collect more information, it still postpones the investment decision. Firm three initially also postpones its investment decision. The risk perception increases after incorporating the information in period one, two and three. After period three $R_{3}$ exceeds $R_{\max }$ and firm three decides not to invest. 
Figure 4.3: The investment decision process

R

C(1)

B(I)

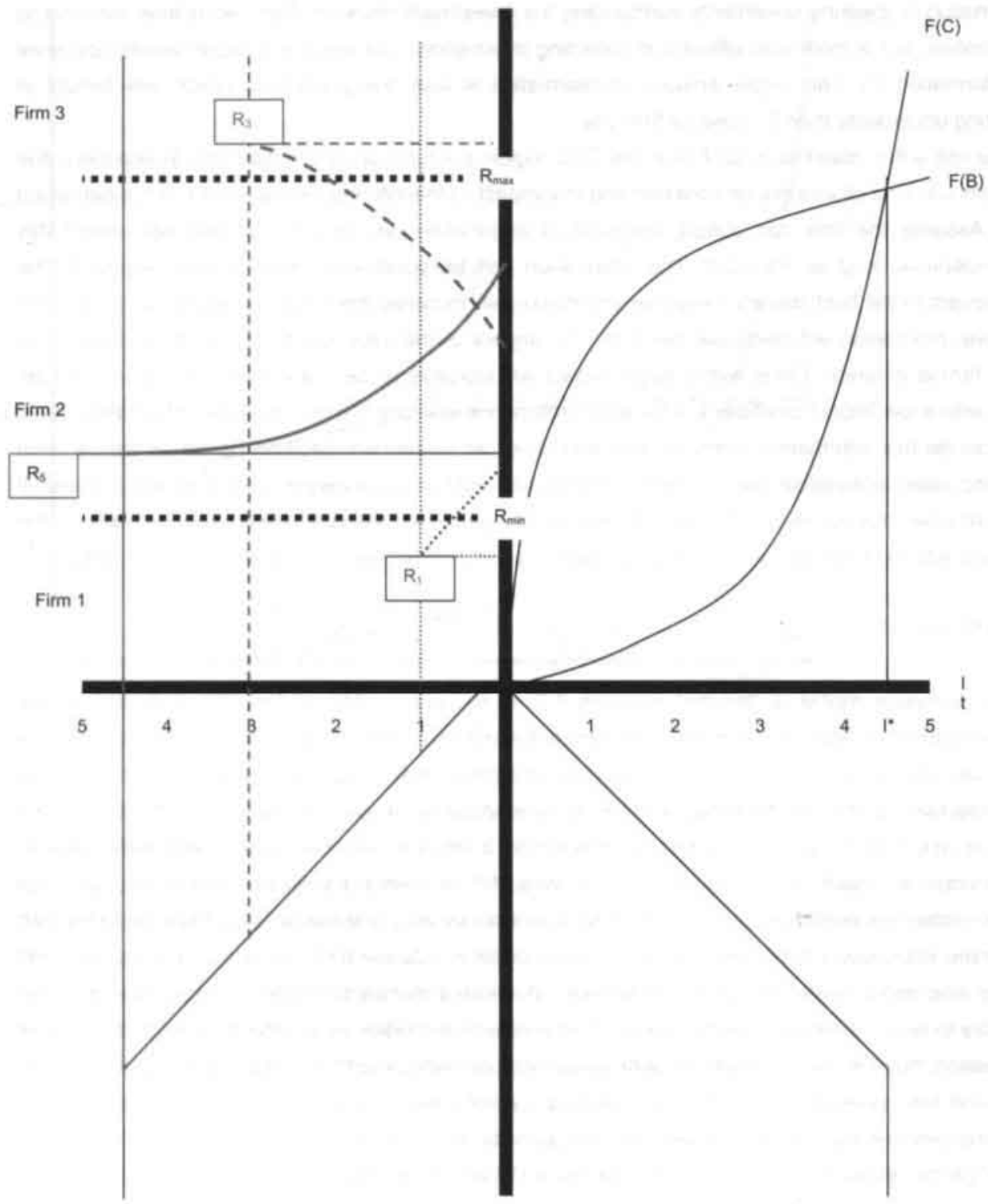


The interpretation of the framework provides the possibility to answer some of the finding arising from the firm level data that remained unexplained by the option theory. All firms that initially have a highrisk perception of the CEE region will never enter the investment decision process, but decide immediately that this region is unfit for their investment. Equally, firms with a very low-risk perception do not engage in an investment analysis, since they are confident enough to invest without further collection and analysis of information. In addition the framework can put forward an explanation as to why some firms collect more information than others and take a longer time to make their decisions.

For example, the data indicated that firms with experience with an FDI in the CEE region prepared their follow-up investments more careful and thorough than their first investment. This observation could be due to the fact that, because of their experience in the region, they are able to determine a more precise risk indication of the FDI, possibly higher than of the inexperienced firms. Given the fact that they are aware of the problem areas, they may want to collect more information in various fields, resulting in a longer decision period.

The survey data additionally indicated that firms that decided not to invest in the CEE region did not have a less extensive investment preparation. This can be very well explained using the example, comparing firms one and firm three in figure 4.3. Firm one decided to invest after having collected only a limited amount of information, but given that its initial risk perception was close to the threshold level $R_{\min }$ and the information it collected was positive, the firm decided the risk of the investment was acceptable after one time period. Firm three not only had a higher initial risk perception, but also interpreted the information negatively. As a result the firm decided, after having collected three units of information, that the risk of the investment was too high. The example is of course based on nonexistent firms, but the context shows that collecting and analysing information does not have to lead to a decreasing perceived risk but might as well increase the firms perception of the investment risk. Equally, increases or decreases in the perceived risk do not always increase or decrease the investment decision uncertainty. The closer the risk perception is to the risk threshold, the larger the uncertainty of the investment decision is.

The fact that firms invest less often and later in high-risk regions can also be explained using the framework. Investments in high-risk regions most likely have a high perceived risk rate at the start of the analysis. Relatively more information is needed in order to decrease the uncertainty surrounding the investment decision than for countries with a lower initial risk perception.

The framework should not be seen as an alternative to the option model, but can be considered a useful addition to the option model. Both the option theory and this framework focus on the large role uncertainty plays when making large, irreversible investments and are therefore very suitable for modelling and explaining FDI investments in high-risk regions.

\subsection{Conclusions}

The option theory is a flexible and useful tool in modeling investment decisions. Uncertainty and timing play an especially important role in the model, making the option model very suitable for studying direct investments in high-risk regions. However, the option model basically only provides rules regarding when to invest and does not indicate how firms should interpret or implement these rules. In this chapter the main focus was to give an answer to exactly that question: how or on what basis do firms make an investment decision? 
In order to be able to answer that question the assumptions the option model builds on as well as three hypotheses derived from the predictions of the theoretical extensions of the model in chapter two were tested. These hypotheses were tested in section 4.3, using the survey data from the questionnaire research Dutch FDI in the CEE region. One of the interesting findings was that of the many firms that were interested in the CEE region decided not to invest without even entering the decision process and without applying any decision rules. They were either not interested in direct investments in general, or not in a direct investment in one of the transition countries.

In addition, many firms indicated they had considered a direct investment in the CEE region, but decided whether to invest without making any type of analysis or calculation. On the other hand, many firms also mentioned they did make some kind of analysis to support their investment decision and often they used cost, revenue and uncertainty indicators in the analysis.

The country risk of the host country negatively affects the investment decision. Firms invest more often in countries with a lower country risk and also invest sooner in those countries. However, while low and medium risk countries were more popular than the high-risk countries in the region, firms do not take this country risk and thereby the higher uncertainty of the firms performance into account in their expectations of the investment. Most firms expect the FDI to produce a profit rate equal to the Dutch investment. The idea that if an investment is undertaken in a high-risk region the return or profit should likewise be higher in order to make up for this higher risk is not apparent in the firms' answers.

Many firms consider more than one country as alternative host country when making an investment decision. Considering multiple possibilities does not affect the decision to invest or the timing of the investment. Though the theory of section 2.3 and 2.4 concluded that several alternatives would lead to postponement of the investment, the data indicate the reverse is true. The more alternatives considered, the larger the chance one of the alternatives is an interesting host country for the FDI.

With respect to the investment analysis the data show two interesting findings. First, the internal investment analysis was equally large or extensive for firms that decided to invest and firms that decided not to invest. This outcome contradicts the idea that firms that decide not to invest are less well informed than firms that decide to invest. Second, firms with an FDI in the CEE region prepare consecutive direct investments equally well or even more thoroughly. The presence of experience with an FDI in the region does not lead to a more restricted analysis, but in fact extends the analysis. The extensiveness of the investment analysis influences the success evaluation of the firm positively, though the differences are small and often insignificant.

Combining these results, there is no direct evidence that a good investment analysis leads to more or more successful investments. In section 4.5 a framework is developed explaining these findings by comparing the costs of collecting information and the benefits of the information in terms of decreasing the uncertainty surrounding the investment decision. Firms collect information as long as the benefits of this information exceed the costs of collecting the information. In addition, firms have a perceived risk of the direct investment and subjective (firm specific) risk threshold values. Firms invest if the perceived risk of the FDI is lower than a for them maximum acceptable risk of investing and do not invest if the risk exceeds the threshold of risk above which investment is not worthwhile anymore. Between those two risk threshold levels the firm will postpone the investment decision and remain collecting information. Applying this framework, many of the findings contradicting the expectations based on the option model can be explained. First, firms do not need an investment analysis if their 
initial risk perception is above the maximum threshold or below the minimum threshold, since then they decide immediately respectively not to invest or to invest. Second, a long investment analysis period is no indication that firms invest eventually, since the additional information can increase the perceived risk as well as decrease it. Third, the fact that firms invest less often and later in high-risk countries than in low-risk countries can be explained by an initial high-risk perception of investing in those countries. More information is needed in order to reduce the uncertainty of an investment decision related to investing in those countries, thus before investments reach an acceptable risk level for the firm.

For host countries these conclusions can be interpreted in different ways. Easily comprehensible and accessible information concerning investments in the country could be a relatively cheap channel of attracting FDI. Clear information on the necessary processes, institutions and requirements can decrease the perceived risk of firms. On the other hand, good FDI promotion institutions and information can only do part of the job. FDI goes hand in hand with good macroeconomic developments and political stability. Once negative news reaches the investor, because of for instance internal conflicts, political upheaval or economic recessions, firms will adjust their risk perception negatively. For transition countries this deviation is clear. Countries with a relatively welldeveloped economic climate, good institutions and stable macroeconomic developments attract the most FDI. The less developed, more risky countries, irrespective of their supply of information to potential investors, have not been able to attract much FDI. Uncertainty of the investment decision, directly linked to the perceived risk of the investment, are key factors in the investment decisions of firms. 



\section{Annex 4.1 Questionnaire summary tables}

Table A4.1.1: Overview characteristics of the firms participating in the survey

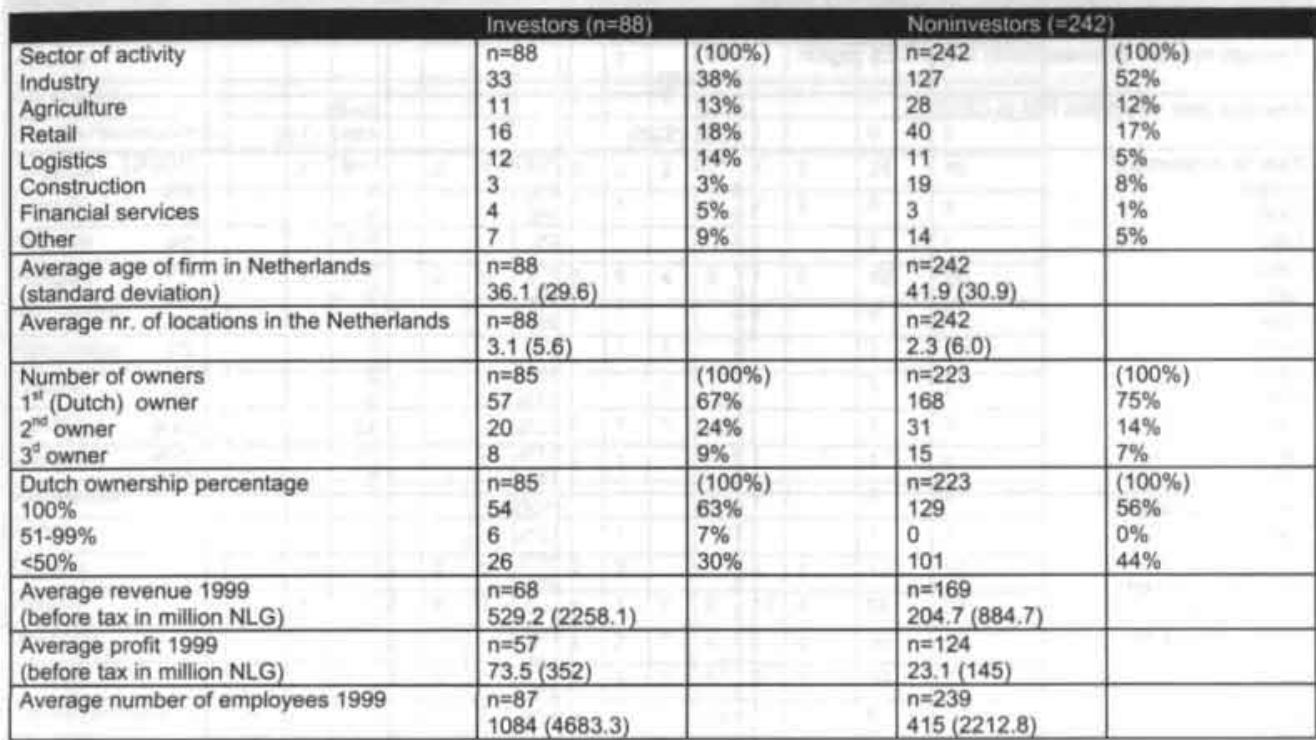




\section{Table A4.1.2: Characteristics of investments (investors) and considered investments that were not undertaken (noninvestors)}

\begin{tabular}{|c|c|c|c|c|}
\hline & \multicolumn{2}{|l|}{ Investors } & $\begin{array}{l}\text { Noninvestors } \\
\text { (considered FDI) }\end{array}$ & \\
\hline Average number of investments in the CEE region & $\begin{array}{l}n=81 \\
3.9(4.3)\end{array}$ & & & \\
\hline Average year setup first FDI in CEEC & $\begin{array}{l}n=81 \\
1995(3.20)\end{array}$ & & $\begin{array}{l}n=49 \\
1997(3.9)\end{array}$ & \\
\hline $\begin{array}{l}\text { Year of investment" } \\
<1989 \\
1990 \\
1991 \\
1992 \\
1993 \\
1994 \\
1995 \\
1996 \\
1997 \\
1998 \\
1999 \\
2000\end{array}$ & $\begin{array}{l}n=79 \\
4 \\
6 \\
5 \\
7 \\
6 \\
7 \\
6 \\
8 \\
10 \\
10 \\
9 \\
1\end{array}$ & $\begin{array}{l}(100 \%) \\
4 \% \\
8 \% \\
6 \% \\
9 \% \\
8 \% \\
9 \% \\
8 \% \\
10 \% \\
13 \% \\
13 \% \\
11 \% \\
1 \% \\
\end{array}$ & $\begin{array}{l}n=47 \\
1 \\
3 \\
0 \\
1 \\
2 \\
3 \\
1 \\
3 \\
3 \\
12 \\
14 \\
6\end{array}$ & $\begin{array}{l}(100 \%) \\
2 \% \\
6 \% \\
0 \% \\
2 \% \\
4 \% \\
6 \% \\
2 \% \\
6 \% \\
6 \% \\
24 \% \\
29 \% \\
12 \%\end{array}$ \\
\hline $\begin{array}{l}\text { Sector of activity } \\
\text { Agriculture } \\
\text { Industry } \\
\text { Natural resources } \\
\text { Construction } \\
\text { Hotel/restaurants } \\
\text { Logistics } \\
\text { Finance } \\
\text { Retail } \\
\text { Other }\end{array}$ & $\begin{array}{l}n=79 \\
10 \\
29 \\
2 \\
5 \\
1 \\
13 \\
3 \\
14 \\
4\end{array}$ & $\begin{array}{l}(100 \%) \\
12 \% \\
36 \% \\
2 \% \\
6 \% \\
1 \% \\
16 \% \\
4 \% \\
17 \% \\
5 \% \\
\end{array}$ & & 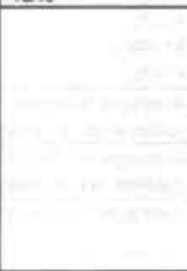 \\
\hline Average number of employees 99 & $\begin{array}{l}n=53 \\
11.8(9.0)\end{array}$ & & & \\
\hline $\begin{array}{l}\text { Kind of FDI } \\
\text { Greenfield } \\
\text { Brownfieid } \\
\text { Joint Venture } \\
\text { Other }\end{array}$ & $\begin{array}{l}n=81 \\
10 \\
35 \\
27 \\
9\end{array}$ & $\begin{array}{l}(100 \%) \\
12 \% \\
43 \% \\
33 \% \\
11 \% \\
\end{array}$ & $\begin{array}{l}n=49 \\
12 \\
4 \\
26 \\
7\end{array}$ & $\begin{array}{l}(100 \%) \\
24 \% \\
8 \% \\
53 \% \\
14 \% \\
\end{array}$ \\
\hline $\begin{array}{l}\text { Number of owners } \\
1 \text { Dutch owner } \\
2 \text { owners } \\
3,4,5 \text { owners }\end{array}$ & $\begin{array}{l}n=79 \\
40 \\
24 \\
15\end{array}$ & $\begin{array}{l}(100 \%) \\
51 \% \\
30 \% \\
19 \% \\
\end{array}$ & & \\
\hline $\begin{array}{l}\text { Average percentage Dutch ownership } \\
100 \% \\
50-99 \% \\
<50 \%\end{array}$ & $\begin{array}{l}n=79 \\
40 \\
27 \\
12\end{array}$ & $\begin{array}{l}(100 \%) \\
51 \% \\
34 \% \\
15 \% \\
\end{array}$ & & \\
\hline $\begin{array}{l}\text { Average percentage local ownership } \\
100 \% \\
50-99 \% \\
50 \% \\
0 \%\end{array}$ & $\begin{array}{l}n=79 \\
4 \\
12 \\
18 \\
45\end{array}$ & $\begin{array}{l}(100 \%) \\
5 \% \\
15 \% \\
23 \% \\
57 \% \\
\end{array}$ & $\rightarrow$ & \\
\hline $\begin{array}{l}\text { Financial options used / considered"* } \\
\text { Private capital } \\
\text { Funds Dutch company } \\
\text { Borrowed by Dutch company in NL } \\
\text { Borrowed in host country } \\
\text { Capital provided by other owners } \\
\text { Other }\end{array}$ & $\begin{array}{l}n \approx 81 \\
\text { Considered by: } \\
16 \\
61 \\
9 \\
1 \\
5 \\
4 \\
\end{array}$ & $\begin{array}{l}\text { Considered by } \\
\% \text { of investors } \\
20 \% \\
75 \% \\
11 \% \\
1 \% \\
6 \% \\
5 \% \\
\end{array}$ & $\begin{array}{l}n=49 \\
\text { Considered by: } \\
9 \\
30 \\
12 \\
5 \\
6 \\
3 \\
\end{array}$ & $\begin{array}{l}\text { Considered by } \% \\
\text { of noninvestors } \\
18 \% \\
61 \% \\
24 \% \\
10 \% \\
12 \% \\
6 \% \\
\end{array}$ \\
\hline Received or applied for subsidy? & 6 & $8 \%$ & 10 & $22 \%$ \\
\hline
\end{tabular}

"Only investments done just before or during transition are included, the investments done before 1985 are excluded.

$*$ Numbers and percentages do not add to 100 . multiple answers were possible, so $10 \%$ means $10 \%$ of the investors used this option. 
Table A4.1.3: Number of Dutch FDI in CEE region, by country $(n=81)$

\begin{tabular}{|c|c|c|c|c|c|c|c|c|c|c|c|c|c|c|c|}
\hline Country & $<89$ & 89 & 90 & 91 & 92 & 93 & 94 & 95 & 96 & 97 & 98 & 99 & 2000 & Total & $\begin{array}{l}\text { Planned } \\
2002 \text { (1) }\end{array}$ \\
\hline Albania & & & & & & & & & 1 & & & & & 1 & 0 \\
\hline Azerbaijan & & & & & & & & 1 & & 1 & 1 & & & 3 & 2 \\
\hline Bosnia-Herzegovina & t & & & & & & 1 & & & 3 & 3 & 1 & & 8 & 2 \\
\hline Bulgaria & - & 2 & 2 & & 2 & 1 & 1 & 2 & 3 & 2 & 2 & 4 & 3 & 24 & 19 \\
\hline Estonia & & & & & & & 1 & 1 & 1 & & 1 & 2 & 2 & 8 & 3 \\
\hline Georgia & 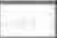 & & 1 & & & & & & & & & 1 & & 2 & 1 \\
\hline Hungary & 2 & 1 & 4 & 2 & 2 & 3 & 2 & 6 & 5 & 4 & 5 & 7 & 5 & 48 & 28 \\
\hline Kazakhstan & & & & 1 & & & & 1 & 1 & & & 1 & & 4 & 3 \\
\hline Kyrgyzstan & & & & & & & & & 1 & 1 & & & & 2 & 1 \\
\hline Croatia & & & & & & & & & & 1 & 1 & & & 2 & 2 \\
\hline Latvia & & & & & & & & 1 & 1 & 1 & & & & 3 & 3 \\
\hline Lithuania & & & & 1 & & 1 & & 1 & 1 & & & 1 & & 5 & 4 \\
\hline Macedonia & & & & & & & & & & & 2 & 2 & & 4 & 4 \\
\hline Moldava & & & & & & & & & 1 & & & & & 1 & 3 \\
\hline Ukraine & 1 & & & 1 & 2 & 1 & & 3 & 2 & & & 1 & 1 & 12 & 10 \\
\hline Poland & 2 & 3 & 1 & 2 & 4 & 3 & 4 & 8 & 7 & 7 & 9 & 12 & 4 & 66 & 39 \\
\hline Romania & & & & 2 & & & 2 & 4 & 2 & 7 & 4 & 5 & 4 & 30 & 18 \\
\hline Russia & & & 1 & 3 & 3 & 2 & 5 & 3 & 5 & 2 & 5 & 3 & 1 & 33 & 21 \\
\hline Serbia-Montenegro & & & & & 1 & 1 & 1 & 1 & & & 1 & 1 & & 6 & 0 \\
\hline Slovenia & & & & & 1 & & & 1 & 1 & 1 & & 1 & 1 & 6 & 11 \\
\hline Slovak Republic & & & & 1 & & 2 & 2 & 1 & & 3 & & 4 & & 13 & 12 \\
\hline Tajikistan & & & & & & & & & & & & & & 0 & 0 \\
\hline Czech Republic & 1 & & 2 & 1 & 2 & 1 & 1 & 2 & 3 & 1 & 7 & 7 & 1 & 29 & 24 \\
\hline Turkmenistan & & & & & & & & & & & & & & 0 & 2 \\
\hline Uzbekistan & & & & & 1 & & & & & & & & & 1 & 2 \\
\hline Beiarus & & & & & 1 & & 1 & & & & & & & 2 & 2 \\
\hline
\end{tabular}

(1) The planned investments before 2002 are the results of a question whether firms planned to invest in the CEE region in the next two years and include the response for 79 investors and 236 noninvestors. 
Table A4.1.4: Information on the investment decision making procedure of investors considering their first FDI after 1989 and noninvestors considering an FDI in the CEE region

\begin{tabular}{|c|c|c|c|c|}
\hline & Investors: & & Noninvest & \\
\hline $\begin{array}{l}\text { Preparation activities } \\
\text { - Seminars } \\
\text { - Study trips } \\
\text { - Internal market research } \\
\text { - External market research } \\
\text { - Advice from Dutch institutions } \\
\text { - Advice from local institutions } \\
\text { - Other }\end{array}$ & $\begin{array}{l}n=58 \\
18 \\
30 \\
34 \\
8 \\
15 \\
12 \\
14 \\
\end{array}$ & $\begin{array}{l}(100 \%) \\
32 \% \\
54 \% \\
61 \% \\
14 \% \\
27 \% \\
21 \% \\
25 \% \\
\end{array}$ & $\begin{array}{l}n=36 \\
13 \\
23 \\
23 \\
13 \\
18 \\
11 \\
9\end{array}$ & $\begin{array}{l}(100 \%) \\
36 \% \\
64 \% \\
64 \% \\
36 \% \\
50 \% \\
31 \% \\
25 \% \\
\end{array}$ \\
\hline Average number of alternative locations & $\begin{array}{l}n=81 \\
1.4(1.6) \\
\end{array}$ & & $\begin{array}{l}n=36 \\
0.9(1.7)\end{array}$ & \\
\hline $\begin{array}{l}\text { An investment analysis made for: } \\
-0 \text { countries } \\
-1 \text { country } \\
-2 \text { or more }\end{array}$ & $\begin{array}{l}n=81 \\
23 \\
42 \\
16 \\
\end{array}$ & $\begin{array}{l}28 \% \\
52 \% \\
20 \%\end{array}$ & $\begin{array}{l}n=49 \\
13 \\
30 \\
6\end{array}$ & $\begin{array}{l}26 \% \\
61 \% \\
12 \%\end{array}$ \\
\hline $\begin{array}{l}\text { Nr. of factors in analysis considered } \\
\text {-Revenue factors } \\
\text { - Cost factors } \\
\text {-Risk factors }\end{array}$ & $\begin{array}{l}n=58 \\
9.3(6.4) \\
9.0(3.8) \\
17.1(9.2)\end{array}$ & & $\begin{array}{l}n=36 \\
9.6(6.1) \\
8.7(4.2) \\
18.9(9.3)\end{array}$ & -2 \\
\hline $\begin{array}{l}\text { Number of analysis undertaken } \\
-1 \\
- \text {-Incidental } \\
\text {-Monthly } \\
\text {-Continuous } \\
\text {-Other }\end{array}$ & $\begin{array}{l}n=56 \\
12 \\
13 \\
7 \\
20 \\
2\end{array}$ & $\begin{array}{l}21 \% \\
23 \% \\
13 \% \\
36 \% \\
4 \%\end{array}$ & $\begin{array}{l}n=34 \\
14 \\
3 \\
4 \\
12 \\
0\end{array}$ & $\begin{array}{l}41 \% \\
9 \% \\
12 \% \\
35 \% \\
0 \% \\
\end{array}$ \\
\hline $\begin{array}{l}\text { Goais for the FDI } \\
\text {-Profitability } \\
\text {-Presence in market } \\
\text {-Growing market share } \\
\text {-Brand familiarity } \\
\text {-Leaming curve } \\
\text { - Other }\end{array}$ & $\begin{array}{l}n=58 \\
57 \\
31 \\
23 \\
22 \\
18 \\
10\end{array}$ & $\begin{array}{l}98 \% \\
71 \% \\
45 \% \\
43 \% \\
35 \% \\
20 \%\end{array}$ & $\begin{array}{l}n=36 \\
33 \\
13 \\
14 \\
3 \\
0 \\
11 \\
\end{array}$ & $\begin{array}{l}92 \% \\
36 \% \\
39 \% \\
8 \% \\
0 \% \\
31 \% \\
\end{array}$ \\
\hline $\begin{array}{l}\text { How long did you expect it to take before profitability } \\
\text {-Less than a year } \\
-2-3 \text { years } \\
-4-5 \text { years } \\
-6-10 \text { years }\end{array}$ & $\begin{array}{l}n=58 \\
15 \\
33 \\
4 \\
3 \\
\end{array}$ & $\begin{array}{l}26 \% \\
57 \% \\
7 \% \\
5 \% \\
\end{array}$ & $\begin{array}{l}n=36 \\
6 \\
22 \\
4 \\
1 \\
\end{array}$ & $\begin{array}{l}17 \% \\
61 \% \\
11 \% \\
3 \% \\
\end{array}$ \\
\hline $\begin{array}{l}\text { How much time elapsed between your investment decision and becoming } \\
\text { operational } \\
-<1 \text { month } \\
-1-3 \text { months } \\
-4-6 \text { months } \\
-6-12 \text { months } \\
-1 \text { year or more }\end{array}$ & $\begin{array}{l}n=58 \\
9 \\
12 \\
11 \\
17 \\
7\end{array}$ & $\begin{array}{l}16 \% \\
21 \% \\
19 \% \\
29 \% \\
12 \% \\
\end{array}$ & & \\
\hline $\begin{array}{l}\text { Was that longer than expected? } \\
\text {-Yes } \\
\text {-No }\end{array}$ & $\begin{array}{l}n=58 \\
14 \\
42\end{array}$ & $\begin{array}{l}24 \% \\
72 \%\end{array}$ & & \\
\hline $\begin{array}{l}\text { Grading between } 1-10 \\
\text {-Risk of the FDI } \\
- \text { Risk of the host country } \\
\text {-Succes of the FDI }\end{array}$ & $\begin{array}{l}n=58 \\
4.6(3.4) \\
4.8(3.5) \\
6.1(2.8)\end{array}$ & & & \\
\hline
\end{tabular}




\section{Table A4.1.5: Comparison of the first and last FDI in the CEE region after 1989}

\begin{tabular}{|c|c|c|}
\hline & Investor: & \\
\hline 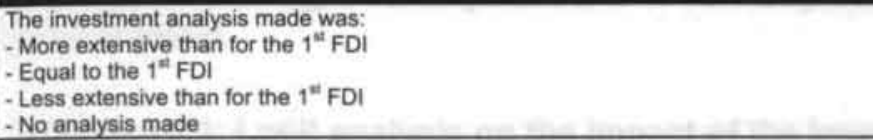 & $\begin{array}{l}11 \\
14 \\
5 \\
7 \\
\end{array}$ & $\begin{array}{l}30 \% \\
38 \% \\
14 \% \\
19 \% \\
\end{array}$ \\
\hline $\begin{array}{l}\text { How much time elapsed between your investment decision and becoming operational } \\
<1 \text { month } \\
1-3 \text { months } \\
4-6 \text { months } \\
6-12 \text { months } \\
1 \text { year or more }\end{array}$ & $\begin{array}{l}10 \\
9 \\
6 \\
7 \\
3\end{array}$ & $\begin{array}{l}27 \% \\
24 \% \\
16 \% \\
19 \% \\
8 \%\end{array}$ \\
\hline $\begin{array}{l}\text { Was that longer than expected? } \\
\text {-Yes } \\
\text {-No }\end{array}$ & $\begin{array}{l}5 \\
30\end{array}$ & $\begin{array}{l}14 \% \\
81 \%\end{array}$ \\
\hline $\begin{array}{l}\text { Grading between } 1-10 \\
\text { - Risk of the FDI } \\
\text { - Risk of the host country } \\
\text { - Success of the FDI }\end{array}$ & $\begin{array}{l}4.6(3.6) \\
5.0(3.7) \\
7.2(1.9)\end{array}$ & \\
\hline
\end{tabular}





\section{Annex 4.2 Logit analysis on the impact of the investment preparation}

Table A.4.2.1: Logit analysis on the impact of the investment preparation

\begin{tabular}{|l|l|}
\hline Variable & Coefficient \\
\hline Analysis done? & 0.336 \\
\hline Once & -0.528 \\
\hline Incidental & 0.876 \\
\hline Monthly & 0.004 \\
\hline Weekly & 0.199 \\
\hline Number of cost variables included & -0.029 \\
\hline Number of revenue variables included & 0.017 \\
\hline Number of political variables included & 0.033 \\
\hline Visited a seminar/study day or lecture & 0.054 \\
\hline Made a studytrip & -0.366 \\
\hline Internal or external market research & -0.672 \\
\hline Advice from Dutch or host country institutions & -0.517 \\
\hline Constant & 0.570 \\
\hline
\end{tabular}

Number of observations $=130$

" significant at $10 \%$ level, $"$ significant at $5 \%$ level, ${ }^{\cdots}$ significant at $1 \%$ level

LR chi2 $(12)=11.27$

Prob $>$ chi2 $=0.5062$

Pseudo $R 2=0.0654$

The logit regression tests the impact of the investment preparation variables on the decision to invest, with 1 being an investment and 0 being no investment. The investment preparation variables are all insignificant. Thus, once companies engage in an investment analysis, the extensiveness of this analysis does not influence odds of investing. This is in line with the conclusions of chapter four. 



\title{
Chapter 5 Explaining foreign direct investment flows to Central and Eastern Europe and Central Asia: a gravity approach'
}

\begin{abstract}
A tradition honored until today by the Cossacks mentions that Tsar Ivan the Terrible came to the shores of the Terek, sent for the most senior of the Grebenj, donated them land on this side of the river, urged them to be united and promised them they would never be forced to subjugation and renunciation of their religion. Until today many Cossack families believe that they are related to the Chechen people; their love for freedom, idleness, robbery and war are the most distinctive features of their character.
\end{abstract}

(Leo N. Tolstoj (1863), The Cossacks)

\subsection{Introduction}

In 1989/1990, the transition from communist states to market economies started for most of the countries in Central and Eastern Europe and Central Asia. One of the major aspects of transition was the liberalization of markets, allowing foreign goods and services to enter the market either through trade or direct investments. Soon after the start of transition, it became clear that there was a large deviation in the amounts of direct investments among the transition countries; a few countries received a large proportion of the total inflows whereas most other countries in the region received very low amounts of FDI inflows. The respective countries often considered these large differences unfair, but studies using the gravity model show that the size of the FDI inflows can largely be explained by a limited number of basic country characteristics (Brenton et al. (1999)).

In this chapter I compare Dutch FDI flows to the ten EU accession countries ${ }^{2}$ with the FDI flows to the other Central and Eastern European and Central Asian countries ${ }^{3}$ and the rest of the world. In doing so, I try to find out why some transition economies receive relatively more FDI than other countries. Can the investment flows be explained by the degree of economic reform or development of the respective countries, or are the EU accession countries receiving preferential treatment?

There are several important reasons for studying these investment flows. First, the more integrated the EU accession countries are with the EU, the smoother the accession to the EU is expected to be. Second, and somewhat counter to the previous argument, those accession countries that currently experience levels of investment flows below what is expected stand to gain the most from future EU accession. Third, the stage of and relative position in the accession process influences net investment flows to the different countries entering the EU. Fourth, a medium- to long-term catch-up effect of the transition countries needs to be financed. There is ample evidence in both the more theoretically oriented growth literature (see Barro (1997) for an overview) and the more empirically oriented research into the finance-growth nexus (De Haas (2002), Szanyi (1998), EBRD Transition Report

\footnotetext{
'This chapter is written jointly with Jaap Bos, working at the department of Banking and Supervision Strategies of De Nederlandsche Bank. I thank Ralph de Haas, Chris de Neubourg. Gerard Pfann, Ben Kriechel , Allard Bruinshoofd, Jan Kakes, Iman van Lelyveld and the participants at the Nederlandsche Bank and Maastricht University seminars for their comments. I also thank De Nederlandsche Bank and specifically Danny v.d. Kommer and Hans Ammerlaan for constructing and providing this excellent database.

${ }^{2}$ Since the focus is on transition countries, there are only ten countries included as EU accession countries, of which eight countries are joining the EU in 2004 (Czech Republic, Estonia, Hungary, Latvia, Lithuania, Poland, Slovak Republic and Slovenia) and two countries are still negotiating EU accession (Bulgaria and Romania). The remaining three countries joining the EU or negotiating (Cyprus, Malta and Turkey) are not in transition from a socialist state to a market economy, and thus not considered as EU accession countries in this chapter.

${ }^{3}$ The countries of Central and Eastern Europe are in the literature often referred to CEECs.
} 
(1999), Borenszstein, de Gregorio and Lee (1998)) that significant well-allocated investments are crucial to a country's ability to structurally enhance its economic growth. At the same time, there is evidence (Koivu (2002), Bonin and Wachtel (2000) and Pissarides (2001)) that the financial system that serves to facilitate and channel investments is still underdeveloped in (most of) the transition countries. FDI can play a very important role in providing these countries with the necessary investment money. Finally, whereas research of trade flows is frequently undertaken, studies on FDI flows are still relatively rare for the Central and Eastern Europe and Central Asia.

In order to see whether if there is a split between advanced and less advanced transition countries, yearly investment flows from the Netherlands to the transition economies are studied in the empirical section. I use a modified version of the standard gravity model, which allows measuring overinvestment or underinvestment compared to what is expected based on a country's economic, geopolitical and social fundamental characteristics. From a theoretical point of view, the Netherlands is very appealing for this type of study. It is an EU member state, but lacks the historical ties with the CEEC region that some other EU member states (cf. Austria) have. As a result, it is possible to emphasize the receiving countries' characteristics in explaining FDI flows. The Netherlands is also a small, open economy. Its foreign direct investment outflow constituted on average 7.22 percent of its GDP over the period $1987-2001$ and 12.57 percent in $2001^{4}$, which was directed towards a large number of countries.

The database used is a balanced panel of FDI flows to 207 countries over the period 1987-2001, as well as 1987 FDI stocks. These data are matched with a (unbalanced) panel of economic and sociopolitical data from other sources."

This chapter contributes to the existing literature in two respects. First, the scope and depth of the data set allows reaching beyond a standard gravity model. It includes FDI determinants for a large group of 207 countries $^{6}$ over a relatively long period of 15 years. In addition, the analysis is not limited to basic macroeconomic fundamentals, but takes into account other factors that influence the distribution of FDI flows. The second contribution to the literature is that in examining the results from a standard gravity model, I use a series of different methods trying to extract as much information as possible from the data.

The remainder of this chapter continues as follows. Section 5.2 contains a literature overview. In section 5.31 present the methodology. Section 5.3.1 contains an introduction of the basic gravity equation, which indicates how Dutch FDI flows are in general related to a set of basic indicators. Next, I discuss the recent advances with respect to the estimations of gravity models and elaborate on a number of inherent problems with the standard gravity model. In addition, I make a case for a second stage analysis, in which I want to analyze whether under- and overinvestment can be explained by different factors. Section 5.3.3 elaborates on how to use the information contained in the basic gravity model in the most effective way. In section 5.4 the data are introduced. Section 5.5 contains the empirical results. In section $\mathbf{5 . 5 . 1}$ are the results of the most rudimentary version of a gravity model, and 5.5.2 focuses on the over- and underinvestment patterns. In section 5.5.3 a set of country-specific variables are added to explain the investment behavior over the last 14 years. In addition, this analysis gives an indication of whether additional catch up effects for transition countries are to be expected in the near future, or if the major catching up has already taken place. Section 5.6 concludes.

\footnotetext{
'Sources: DNB and the OECD.

${ }^{5}$ IMF, World Bank, Euroscope, Euromoney, ClA.

"All the countries in the world.
} 


\subsection{Literature}

This section contains a brief overview of the literature on the gravity model that is used as the basic vehicle to study relative investment flows. The focus is on studies that have estimated this model for transition economies. In section 5.2.2, I elaborate on some studies that have tried to identify the major types of determinants of foreign direct investment. Section 5.2.3 includes a discussion of a number of articles that have tried to explain differences in FDI flows to the CEECs.

\subsubsection{FDI Gravity Studies}

The gravity equation is often used in comparative FDI studies. The standard gravity equation relates the outflow of FDI from country $i$ to country $j$ to country $j$ 's GDP, population (POP) and the distance (Dist) between both countries. Thus:

$$
F D I_{i j}=f\left(G D P_{i}, P O P_{j}, D_{i s t_{i j}}\right)
$$

If predicted investment, $F \hat{D} I_{i j}$, exceeds actual investment 1 observe underinvestment, and if predicted investment falls below actual investment, there is overinvestment?. The gravity model predicts that the effects of GDP and population on FDI are positive, since investments are expected to be larger if the host market is larger and more developed. Distance can have a negative effect, since countries that are further apart are likely to have larger economic and cultural differences, thus making FDI less attractive. However, distance can also have a positive effect, since an increase in distance means that trade (through an increase in transportation costs) becomes more expensive and is substituted by FDI. Distance itself is then both geographical distance and psychic distance $e^{t}$. Table 5.1 presents an overview of studies that have adapted a (somewhat extended) version of the basic gravity model to transition economies.

Döhrn (1996) specifically focused on EU enlargement and its role in channeling investment flows from the EU to the CEECs. In an effort to quantify the effect of EU enlargement, he estimates a gravity model, albeit without correcting for the size of population. He includes a variable that measures net trade flows. With the help of a separate regression, he makes trade orthogonal on (factors that explain) FDI in order to better capture possible substitution effects between trade and FDI. In order to reduce bias from differences in starting levels of investment, Döhrn estimates the model both with FDI flows and FDI stocks as dependent variable. Although the results included in table 5.1 are for the flow estimations, the results for stock estimation are qualitatively similar. The models are estimated using OECD data for 1990-1992. The coefficient for GDP has the expected, positive sign; distance has a negative sign. On the basis of these estimations, Dohrn concludes that "the enlargement of the EU as well as the transformation in Eastern Europe have significant consequences for international FDI. The magnitude of the impact of the EU enlargement, however, is far from being clear. This is due to the fact that the rather complex process of 'integration' can be introduced into the regressions only by some dummy variables" (p. 130).

\footnotetext{
${ }^{7}$ The terms overinvestment and underinvestment are new to the gravity literature, and will be used according to this definition throughout this chapter.

'Psychic distance covers geographical, cultural, legal, religious, linguistic, historical, economic and ethnic aspects of the differences between two locations of business activity. In practice, geographical distance proxies for psychic distance. See Meyer (1998, pp.101) or Johansson and Wiedersheim-Paul (1975).
} 
Table 5.1: Overview of Basic FDI Gravity Studies

\begin{tabular}{|c|c|c|c|c|c|c|c|}
\hline Paper & Characteristic & GDP & POP & DIST & Period & Obs: & Riad: \\
\hline Bevan \& Estrin (2000) & Level estimation (model one) & $+\operatorname{sig}$ & $-\operatorname{sig}$ & n.a. & 1994-98 & 558 & 0.35 \\
\hline Bevan \& Estrin (2000) & First differences estimation (model two) & + sig & insig & n.a. & 1994-98 & n.a. & 0.05 \\
\hline Brenton et al. (1999) & Bilateral gravity & $+\operatorname{sig}$ & $-\operatorname{sig}$ & - sig & $1982-95$ & $304-514$ & $0.33-0.60$ \\
\hline Brenton \& Di Mauro (1999) & Extended gravity model & $+\operatorname{sig}$ & $-\operatorname{sig}$ & $-\operatorname{sig}$ & $1992-95$ & $122-159$ & $0.50-0.64$ \\
\hline Buch et al. (2001) & Substitution with trade & $+\operatorname{sig}$ & +1. & $-\operatorname{sig}$ & $1991-97$ & $+1-30$ & $0.40-0.60$ \\
\hline Dohm (1996) & Trade included orthogonal on other factors & $+\operatorname{sig}$ & n.a. & $-\operatorname{sig}$ & $1990-92$ & 310 & $0.44-0.78$ \\
\hline Garibaldi et al. (2002) & Gravity models for FDI and portfolio investment & $+\operatorname{sig}$ & $+\mathrm{sig}$ & n.a. & $1990-99$ & $145-179$ & $0.90-0.93$ \\
\hline
\end{tabular}

In case a study contained several gravity estimations, the results reflected by the majority of those regressions are included in this table

Buch et al. (2001) also look at possible substitution effects. However, they focus specifically on substitution between different regions. They estimate a basic model using FDI from Austria, Belgium, France, Germany, Italy, the Netherlands, the U.K., U.S. and Japan to 48 host countries for 1991 , 1993. 1995 and $1997 .^{\circ}$ After performing out-of-sample tests, specifically for Germany, the authors conclude that no evidence is found for substitution of FDI flows from Southern countries to the CEECs. The observed increase in FDI to the CEECs can be explained as a stock adjustment.

The results of Bevan and Estrin (2000) are somewhat difficult to compare with Buch et al. (2001), since distance is missing in their analysis and there is no overlap with respect to the period estimated. Bevan and Estrin use bilateral FDI flows from the EU-14 (Belgium and Luxembourg are merged), Korea, Japan, Switzerland and the U.S. to the CEECs. They estimate a panel of 151 bilateral FDI connections, for the period 1994-1998. Again, the coefficient for GDP carries a significant, positive sign. Population negatively and significantly affects the FDI stock. With an $R^{2}$-adjusted of 0.35 , the fit is remarkably low. With the help of structural shift dummy variables for key announcements of progress in EU accession, the authors show that EU accession has influenced FDI, but country credit ratings have no effect. When the analysis is performed using first differences (model two), these results remain standing, but the fit worsens to 0.05 .

Brenton et al. (1999) use a bilateral gravity model approach to assess the impact of the growing integration between the EU and the CEECs, in an attempt to see whether an increase in the attractiveness of the CEECs to foreign investors has affected the magnitude of FDI going to other European countries. The authors add an adjacency variable and separate the two possible effects distance has on FDI (as mentioned above). The authors test what the effect is of concurrent trade and investment liberalization. Their methodology differs somewhat from the studies discussed so far. First, they estimate a gravity model using FDI stocks. Then, they also estimate a gravity model using exports and imports. Next, they use the residual from the FDI regressions in the import and export regressions in order to assess the impact of FDI on bilateral trade. They let these residuals interact with dummies for different groups of countries. Finally, they investigate "whether changes in FDI flows to particular countries or regions, in response to an increase in economic integration, had a noticeable impact upon the flows of FDI going to other, excluded, regions" (p. 119). They do so by graphically comparing the distribution of FDI flows over time (specifically for Spain and Portugal). The analysis is performed for all EU countries. Table 5.1 shows that the coefficient for GDP carries the expected positive sign. Population is negative, as is distance. Again, however, no substitution effect between FDI and trade is found. For Spain and Portugal also no evidence for substitution of FDI between the

\footnotetext{
"They also run a separate analysis for FDI flows from Germany to 37 countries, for the period 1981-1997. Results for this analysis are not presented here, but are very similar.
} 
CEECs and other European countries is found.

In Brenton and Di Mauro (1999), the main aim is to check whether inflows of FDI from EU countries to CEECs are "disappointingly low" (p. 59). Both for (net) exports and FDI, Brenton and Di Mauro first estimate an extended gravity model, with dummy variables representing preferential relationships. Next, they regress the residuals from the trade model on the residuals from the FDI model, in order to find out whether there are substitution effects. The analysis is performed with pooled FDI and export data over the years 1992-1995, for Germany, France, the U.K. and the U.S. and a panel of around 35 destination countries. The fit is reasonable $\left(R^{2}\right.$-adjusted ranges between 0.50 (U.K.) and 0.64 (France)). The results are as expected, with a positive significant impact for GDP. The distance variable is negative and significant, indicating that countries further away receive less FDI inflow. Population is insignificant. The authors conclude "the amount of overseas investment by EU countries in the more advanced transition economies [is] already greater than one would expect given their current level of income" (p. 59). With respect to regional preference, Brenton and Di Mauro find that EU countries receive about three times more FDI from their EU neighbors Germany, France and the UK than can be expected based on the gravity model. The transition countries Poland, Hungary and the Czech Republic receive more FDI than the gravity variables predict as well, but Romania and Bulgaria receive a smaller share than expected based on their gravity variables. Contradictory to some of the other studies described so far, they find complementarities between exports and FDI.

Garibaldi et al. (2002) go one step further and distinguish between different types of capital flows. They estimate an extended gravity model for both FDI and portfolio investment. Their study is indirectly motivated by the fact that, unlike FDI, portfolio investment does not involve large sunk costs. As a result, portfolio investments can be withdrawn rather quickly in adverse conditions. This possibility to withdraw the money puts the transition economies at a risk, especially in times when they desperately need foreign capital. Garibaldi et al. (2002) try to find differences between the behaviors of both types of capital. They use data for the CEECs and the former Soviet Union for the period 19901999. Their regressions have a very high fit and the gravity variables carry the expected sign. The findings indicate a diverse pattern for overall capital flows, but FDI is found to be a "relatively stable source of financing in most countries during the early transition years, and continued to play an important role in most [...] countries at least until 1998" (p. 30). In contrast to FDI, "portfolio investment is very poorly explained by fundamentals" (p. 30 ).

Summing up, the results of empirical research using the gravity model indicate that a higher GDP in a host country leads to higher FDI inflows. However, contrary to expectations, a larger population not always leads to a larger FDI inflow. Smaller countries indeed receive relatively more investments than larger countries. Distance between the host and home country limits FDI flows; the farther the host country away the less often firms invest there. In general, the conclusion from the studies cited up to this point is that the countries from Central and Eastern Europe receive an amount of FDI as high as can be expected on the basis of the simple gravity model.

\subsubsection{Types of Determinants of FDI}

Given the fact that only three variables are included in standard gravity model, the model's explanatory power is surprisingly large. However, aside from the very basic effects of relative size and distance, the model tells very little about the forces of gravity that cause a country is actual flow of FDI to another country $j$ to differ from the expected flow of FDI. The fact that it has thus far proven impossible 
to derive a single formal underpinning to the model means I have very few priors as to what the major determinants of foreign direct investment are. In the empirical literature, however, there is a growing body of evidence pointing to specific determinants. Even though most of these studies do not conclude whether a region is receiving as much FDI inflow as can be expected based on its performance, the macroeconomic variables that significantly determine FDI flows may also increase the fit of the gravity model. In addition, some specific aspects for transition economies can be included in the gravity model to increase the fit.

Several different groups of factors can be traced in the literature. They are summarized in table 5.2. Altomonte (2000) and De Haas (2002) emphasize the importance of a strong legal framework. Although rarely made explicit, there is a distinction between the political situation and country risk that several others (Bevan \& Estrin (2000), Holland \& Pain (1998) and Lehmann (2002)) have identified. The main difference is the extent to which the uncertainty resulting from a sub-optimal situation can be deemed structural. A temporary political crisis can be caused by but also worsened through the lack of a strong legal framework. However, a weak legal framework can exist without causing a political crisis.

The role played by differences in national or regional culture, as emphasized by Hogenbirk (2002). is hard to quantify and perhaps therefore rarely included in an analysis of determinants of FDI. ${ }^{10}$ The price of labor, on the other hand, plays an important role. Lansbury et al. (1996), Meyer (1995) and Hogenbirk (2002) find that the relative cost of labor is a very important determinant of FDI flows. The quality of labor, and overall productivity can also stimulate investment, as described by Altomonte (2000), Holland \& Pain (1998), Lansbury et al. (1996), Lehmann (2000) and Altomonte (1998) with the help of e.g. production indices.

Of special importance to the CEECs is the finding that the choice and timing of a particular privatization scheme can help explain FDI flows. In sum, direct sales to investors are found to be more successful than voucher schemes and management buyouts (cf. Holland \& Pain (1998)) and early privatization schemes perform the best (Resmini (1999) and Lansbury et al. (1996))." Related, the size and trustworthiness of the financial system (mostly banks in transition economies) helps channel investment flows (De Haas (2002) and Holland \& Pain (1998)).

A good infrastructure and a good overall economic climate help promote foreign direct investment (Martinez-Zarzoso \& Nowak-Lehmann (2003) and Altomonte (1998)). Surprisingly enough, exchange rates are not very often included as a determinant (cf. Martinez-Zarzoso \& Nowak-Lehmann (2003)), perhaps because of the inherently long-term nature of FDI. Existing trade and other economic links with the country that receives the FDI have received a lot of attention (Hogenbirk (2002). Holland \& Pain (1998), Lansbury et al. (1996) and Meyer (1995)).

\footnotetext{
${ }^{10}$ Hogenbirk uses Holstede's four cultural dimensions to determine the cultural distance between two countries (Hogenbirk, 2002, pp.71).

"Outsider privatization is a sale of the company to an external party, often by means of an auction or direct sale. This form of privatization allows foreigners to buy the company, and often leads to restructuring of the firm, Insider privatization is a sale or giveaway of shares to the company's management or employees. Due to conflict of interest, this form of privatization often leads to postponement of restructuring. and does not allow for foreign influence. In mass or voucher privatization shares are sold or given to the population of a country. Due to dispersion of the ownership rights this form of privatization often delays reforms, and foreign ownership is only possible in a second degree, through establishing privatization funds or by buying shares on the stock market.
} 
Table 5.2: Overview of Types of Determinants of FDI

\begin{tabular}{|c|c|c|c|c|c|c|c|c|c|c|c|c|}
\hline & & 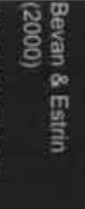 & 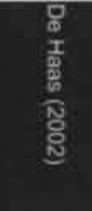 & 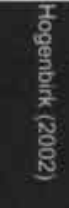 & 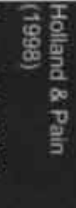 & $\begin{array}{l}\frac{\pi}{2} \\
\frac{1}{3} \\
\frac{8}{0}\end{array}$ & 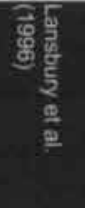 & 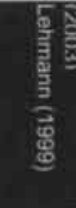 & 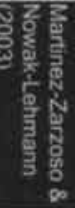 & $\frac{\text { के }}{\overrightarrow{9}}$ & 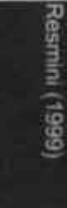 & 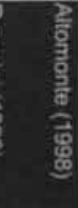 \\
\hline Institutional/Legal framework & $x$ & & $\mathrm{X}$ & & & & & & & & & \\
\hline Political situation/Country risk & & $x$ & & & $x$ & & & $\bar{x}$ & & & & \\
\hline Culture & & & & $\bar{x}$ & & & & & & & & \\
\hline Labor price & & & & $\bar{x}$ & & & $x$ & & & $\mathrm{x}$ & & \\
\hline Labor quality (productivity) & $x$ & & & & $x$ & & $\mathrm{x}$ & $\mathrm{X}$ & & & & $x$ \\
\hline Privatization scheme & & & & & $x$ & & $x$ & & & & $x$ & \\
\hline Financial system & & & $x$ & & & $x$ & & & & & & \\
\hline Infrastructure & & & & & & & & & $\bar{x}$ & & & $\mathrm{x}$ \\
\hline Exchange rates & & & & & & & & & $\bar{x}$ & & & \\
\hline Existing (trade) links & & & $\bar{x}$ & $\bar{x}$ & $\mathrm{x}$ & & $\mathrm{X}$ & & & $x$ & & \\
\hline
\end{tabular}

So far I have discussed a number of articles written on the determinants of FDI. Summing up, I observe two things. First, no study really takes the full spectrum of possible determinants into account. As a result, it is difficult to assess the relative importance of each variable. Second, not all studies focus explicitly on the characteristics of transition economies.

\subsubsection{FDI to the CEECs and Central Asia}

I therefore now discuss more elaborately a number of articles that have studied the forces explaining the development of FDI to transition countries. These studies are summarized in table 5.3.

Claessens et al (1998) suggest that FDI flows to transition economies are largely the result of their economic reforms. In their panel data analysis (OLS) they use a sample of 21 countries for the period 92-96, and distinguish between push and pull factors in their analysis. They find that mainly the reform index and EU accession dummy are highly positively significant in attracting FDI.

Brock (1998) studies Russian FDI inflow, and specifically looks at regional division. He finds FDI is very much concentrated in Moscow and St. Petersburg, and mainly the variables output, education and crime are influencing FDI. Institutional development and tax rates are not important in determining FDI inflows. Using a five-year panel data set for the period 1992-1996 including 11 transition economies, Holland and Pain (1998) try to find to what extent FDI is increasing technological knowledge in the transition region. They find, in contradiction to several other studies, that lower labor costs (measured in levels, differentials over countries and productivity) do attract FDI. In addition, the way privatization was undertaken is important. Outsider privatization is more suitable for attracting FDI than insider or mass privatization. ${ }^{12}$ Resmini (1999) focuses on sector patterns of FDI in the CEECs, in order to see whether the influence of certain characteristics varies among sectors. For a cross-section of 3000 observations, she finds that the degree of openness of a country, measured by trade divided by GDP is positively influencing FDI inflows, and the country risk has a negative effect on FDI inflows in transition economies. However, wage differentials are insignificant. She finds an unequal division of FDI in the region, with some countries being specialized in more technologically advanced FDI (vertical), and others are still more specialized in the horizontal low wage FDI.

\footnotetext{
${ }^{12}$ See footnote 11.
} 
Table 5.3: Cross-country and panel data research to FDI to the CEECs

\begin{tabular}{|c|c|c|c|c|c|c|c|}
\hline & & & & 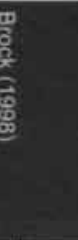 & 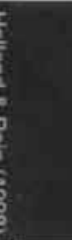 & 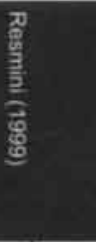 & 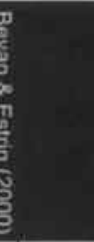 \\
\hline \multirow{10}{*}{$\begin{array}{l}\text { 3. } \\
0 \\
0 \\
\$ \\
8 \\
0 \\
3 \\
3\end{array}$} & GDP growth & & & & & & $+\operatorname{sig}$ \\
\hline & Growth in OECD & + sig & & insig & & insig & \\
\hline & \begin{tabular}{|l|l|} 
Inflation \\
\end{tabular} & & & & & & unclear \\
\hline & Fiscal balance & insig & & & & & $+\operatorname{sig}$ \\
\hline & \begin{tabular}{|l|} 
Private savings \\
\end{tabular} & - sig & & & & & \\
\hline & Change country reserves & - sig & & & & & \\
\hline & Domestic credit & insig & & & & & \\
\hline & Natural resources & & & & & & $+\operatorname{sig}$ \\
\hline & \% with higher education & & + sig & & & & \\
\hline & Local tax rate & & insig & & & & \\
\hline \multirow{4}{*}{$\begin{array}{l}\overline{5} \\
\end{array}$} & Wage level & & & - sig & & - sign & insig \\
\hline & Wage differentials & & & - sig & insig & & \\
\hline & Wage / output & & & - sig & & & \\
\hline & Manual outputGDP & & & & - sig & & \\
\hline \multirow{6}{*}{$\begin{array}{l}\text { ग0 } \\
\text { क् } \\
\text { | }\end{array}$} & Liberalization index & + sig & & & & & $+\operatorname{sig}$ \\
\hline & \begin{tabular}{|l|} 
Privatization index \\
\end{tabular} & & & & & & + sig \\
\hline & Institutionalization index & + sig & insig & & & & $+\operatorname{sig}$ \\
\hline & Method of privatization & & & + sig & & & $+\operatorname{sig}$ \\
\hline & Share of private sector & & insig & insig & & & \\
\hline & Possibility to buy land & & insig & & & & \\
\hline \multirow{3}{*}{$\frac{\text { गु }}{\bar{x}}$} & Risk index (higher=low risk) & & insig & & insig & $+\operatorname{sig}$ & \\
\hline & Market perceptions & & & & & & + sig \\
\hline & Crimes per capita & & - sig & & & & \\
\hline \multirow{6}{*}{$\begin{array}{l}\vec{\nabla} \\
\frac{0}{6}\end{array}$} & Exports & & & & & & \\
\hline & EU import/total import & & & & & insig & \\
\hline & Trade/GDP & & & insig & $+\operatorname{sig}$ & & \\
\hline & Competitiveness indicator & & & & & & $+\operatorname{sig}$ \\
\hline & Trade liberalization & & & & & & $+\operatorname{sig}$ \\
\hline & Restrictions to FDI & & & & & & $-\operatorname{sig}$ \\
\hline$\frac{\pi}{3}$ & US dollar interest rate & + sign & & & & & \\
\hline & \begin{tabular}{|l} 
Interest rate dif. \\
\end{tabular} & insig & & & & insig & \\
\hline 8 & Pegged exchange rate & & & & & & $+\operatorname{sig}$ \\
\hline
\end{tabular}

Bevan and Estrin (2000) have a panel data set of FDI from 18 countries to 11 transition countries over the period 1994-1998. They use these data to estimate two regressions, in order to determine the indicators significantly explaining FDI inflow. First, they create a risk indicator based on private sector share, privatization progress, macroeconomic variables and a bribe tax indicator. This risk indicator, jointly with several other variables, is used to determine the significance of FDI inflows. They find that of the 10 variables they added to the gravity equation, only the risk indicator (high risk leads to low FDI), labor costs (low wage attracts FDI) and regional dummy variables ${ }^{13}$ are significant.

Garibaldi et al (2002) use capital flow data of 25 transition economies for the period of 1991 to 1999 , to find out to what extent inward FDI to transition countries can be accounted for by individual country characteristics. The study distinguishes between FDI and portfolio investments. For FDI flows, 32 variables are included, grouped in scale variables, macroeconomic variables, interest rate data, structural reform variables, institutional quality variables, initial conditions, market perceptions and

\footnotetext{
${ }^{13}$ Germany invests more than average in transition economies, and the Baltic countries receive a proportional larger share of FDI compared to other CEEC countries.
} 
specific FDI variables such as wage, trade index, FDI restrictions index and a privatization variable ${ }^{14}$. Using a general to specific model, the most significant variables are selected. Besides the general gravity variables, fiscal balance, liberalization and trade reforms positively influence FDI flows, while insider privatization and FDI restrictions negatively influence FDI flows. Inflation seems to influence FDI with arbitrary signs, and wages do not influence FDI if GDP and GDP growth are included. Variables measuring the degree of institutionalization, and a subjective variable indicating managers' market perceptions are highly correlated, and may be more influential than the general macroeconomic predictors.

Based on this literature overview it is hard to conclude which variables are significantly influencing FDI flows. Studies do not use the same variables, and variables are often significant in one study and insignificant in another. Therefore a broad selection of variables has been made to include in this study to provide a more complete picture of the individual and joint effects on FDI.

\subsection{Methodology}

This section includes a description of the methods used in this chapter for analyzing whether or not the transition countries in Central and Eastern Europe and Central Asia receive a proportional share of Dutch FDI when compared to the rest of the world. It starts with a critical discussion of the standard gravity equation. Subsequently, I introduce my own method for finding out what the major determinants for FDI are, and discuss some alternative ways to analyze the residuals from a gravity model.

\subsubsection{A Standard Gravity Equation}

FDI flows are generally volatile in nature. Sizes of the flows differ highly between countries and over time. The gravity model is often used on order to explain some of the high variance often observed in the FDI flows. The basic gravity model was developed in the 1960 s to explain bilateral trade flows from a home country $i$ to host country $j$ (Linnemann (1966), Bikker (1982 \& 1987), Morsink (1997), Brenton et al. (1999)). The concept of gravity refers to the forces that are expected to, over time, bring actual trade flows in line with expected trade flows. In that respect, the term 'gravity model' is somewhat of a misnomer: the gravity model explains expected trade flows and is thereby used to measure gravity". It does not, however, give any guidance as to what the forces of gravity are. The gravity model is of a highly applied nature. Much of its success can be attributed to its remarkable predictive power and its intuitive appeal. The latter can be seen from the basic gravity equation (applied to FDI and in line with Deardorff (1995)):

(2) $F D I_{i j}=A_{i j} *\left(\frac{G D P_{i}^{*} G D P_{f}}{\text { Dist }_{i j}}\right)$

with:

$F D I_{i j}=$ the actual FDI flow from home country i to host country $\mathrm{j}$.

$G D P_{i}=$ the actual GDP of the home country.

$G D P_{j}=$ the actual GDP of the host county.

\footnotetext{
"The privatization variable is a categorical variable indicating how a country is privatized, being by direct sales, mass privatization or insider privatization.

${ }^{15}$ Gravity refers to the fact that countries attract trade or FDI based on some basic pull factors it has and cannot easily influence, such as population size and distance.
} 


\section{Dist $_{i j}=$ distance between the home country $\mathrm{i}$ and host country $\mathrm{j}$.}

This equation is seen as a long-run equilibrium condition and 1 expect $F \hat{D} I_{i j}=F D I_{i j}$ (with $F \hat{D} I_{i j}$ as predicted FDI). In the short run, however, the equilibrium does not have to hold. Hence, if $F \hat{D} I_{i j}>F D I_{i j}$ a country receives less FDI than expected based on the gravity variables, and if $F D I_{i j}<F D I_{i j}$ a country receives more FDI than expected. The model is multiplicative to ensure that as $G D P_{i}$ (or $G D P_{j}$ ) approaches zero, so does $F D I_{i j}$. In this basic model therefore, the variables $G D P_{i}$ and $G D P_{j}$ measure the relative potential to invest. Second order effects from $G D P_{i}$ and $G D P_{i}$ are negative. It also follows that Dist $_{i}$, the distance between countries $i$ and $j$, is always larger than one kilometer, thus strictly positive. Finally, the model has incorporates a proportionality vector $A_{i j}$. When applied to predict FDI flows, population size of both home and host country are often included as variables in $\mathrm{A}_{\mathrm{j}}$, assuming larger populations support and attract larger FDI flows. Here those variables are the only proportionality variables included in the basic model, thus the model becomes:

$$
F D I_{i j}=\left(P O P_{i}^{*} P O P_{j}\right) *\left(\frac{G D P_{i}^{*} G D P_{j}}{\text { Dist }_{i j}}\right)
$$

where $F D I_{i j}$ increases with $P O P_{j}$ and $P O P_{i}$. This can be rewritten as:

$$
F D I_{i j}=\left(P O P_{i}^{*} G D P_{i}\right) *\left(P O P_{j}^{*} G D P_{j}\right) * \frac{1}{\text { Dist }_{i j}}
$$

Now FDI flows are defined as a function of per capita GDP in two countries and the distance between these countries. Since $\frac{G D P_{i}}{P O P}$ is equal for all host countries and thus cannot explain deviations over countries, the term is idropped. In logarithmic terms, the estimation made in this chapter becomes:

$$
\text { (5) } \quad \ln F D I_{i j}=\beta_{0}+\beta_{1} \ln G D P_{j}+\beta_{2} \ln P O P_{j}-\beta_{3} \ln D i s t_{i j}
$$

Since the home country per capita GDP is equal for the countries, it is absorbed by the constant $\beta_{0}$. The gravity model predicts that the coefficients $\beta_{1}$ and $\beta_{2}$ are positive, since investments are expected to be larger if the host market is larger and more developed. Distance can have a negative effect, since countries that are farther apart are likely to have larger economic and cultural differences thus making FDI less attractive. However, distance can also have a positive effect, since an increase in distance means that trade (through an increase in transportation costs) becomes more expensive and is substituted by FDI. Distance itself is then both geographical and psychic distance. Therefore, the coefficient $\beta_{3}$ can be either positive or negative depending on which effect dominates.

The model is a good predictor of the FDI flows to a country in the long run. With the help of this gravity model, it is also possible to examine whether transition countries receive more, sufficient or not enough FDI, compared to this long run equilibrium amount. The deviation of the actual FDI and the long run equilibrium amount is caused by the volatility in FDI flows, and is of a short run nature. This amount and direction of this deviation (above or below the predicted FDI) can be explained by adding more variables to the basic gravity model.

In the discussion of the gravity studies (section 5.2.3) that have tried to identify these major short

" Contrary to Deardorff (1995), I allow this measure to vary per country. As a result, the derivations that follow are my own. 
run determinants of the (relative) FDI flow to a transition country, there are three recurring problems. First, all studies assume that key determinants affect countries that receive more FDI than expected the same way they affect countries that receive less than expected. A second problem, as Dóhrn (1996) observed at the end of his study, is that the use of regional dummies to measure short run FDI excesses or shortages is a very crude measure. "A third problem is that the basic gravity equation is generally estimated using only a limited number of host countries, after which this gravity regression is used to draw conclusions for those same countries. Specific region or country effects are then already included in the basic gravity model, making the conclusions less reliable." The next section includes a theoretical solution to the first problem. An alternative to the use of regional dummies follows in section 5.3.3, and the extensive dataset used in this chapter as described in section 5.4 solves the third problem.

\subsubsection{Analysis of the Determinants of FDI}

Section 5.3.1 started with the following basic gravity model, estimating a long run equilibrium level:

$$
F D I_{i j}=A_{i j} *\left(\frac{G D P_{i}^{*} G D P_{j}}{D_{i s t}}\right)
$$

Extending the model to include a set of determinants to FDI amounts to minimizing:

(7) $\left|F \hat{D} I_{i j}-F D I_{i j}\right|$

Put differently, I expand the vector $A_{i j}$ so as to minimize the prediction error. Empirically, this means adding a set of variables $C_{k}$, to control for country-specific factors. However, it is uncertain that for each measure $k, \partial F D I_{i j} / \partial C_{k j}$ is strictly positive or negative. A certain control variable may not have the same impact on countries that receive more FDI than expected and countries that receive less than expected. To take this into account, a theoretical solution is the following: for any distribution of the residual $\varepsilon_{v}$ from the standard gravity equation, one can conclude that countries with positive values of $\varepsilon_{i j}$ receive more investment and countries with negative values of $\varepsilon_{i j}$ receive less investment than expected based on the standard gravity equation. Thus, it is possible to identify what I define as overinvestment and underinvestment. And for any distribution of $\varepsilon_{i j}$, one can be certain that the higher (lower) its value for a country $i$, the higher the probability that there is indeed overinvestment (underinvestment). I therefore create separate dummy variables for the $50 \%$ largest positive (for overinvestment) and negative (for underinvestment) values of $\varepsilon_{i j}$. The interaction terms of these dummy variables with the FDI determinants in the gravity model, allow to identify $A^{*}, A^{*}$ and $A$. For $k=1, \ldots, K$ the model becomes:

\footnotetext{
"Problem of omitted variables, meaning other factors not included in the equation very likely explain some of the FDI flows that are now all captured by one regional dummy variable.

${ }^{11}$ In many gravity studies for the transition region, the basic gravity model is estimated using FDI flows to a limited number of host countries located in the transition region. Conclusions with respect to FDI flows can then only be seen in relation to those countries. No generalization with respect to Dutch investment behavior can be made, only conclusions with respect to FDI flows in the region. In this study, Dutch FDI flows to all countries in the world are included in the basic gravity model, given the most correct estimation of the Dutch investment behavior in general. This gravity equation can be used to draw conclusions related to over or underinvestment in the transition countries compared to the rest of the world. Countries in this region are found to receive their predicted amount of FDI, or face Dutch underinvestment.
} 


$$
\begin{aligned}
& \ln F D I_{i j}=\beta_{0 K^{+}} \beta_{1} \ln G D P_{j}+\beta_{2} \ln P O P_{j}+\beta_{3} \ln \text { Dist }_{i j}+ \\
& \sum_{k=1}^{K} \beta_{4, k} C_{i j k}+\sum_{k=1}^{n} \beta_{5, k} D^{+} C_{i j k}+\sum_{k=1}^{n} \beta_{6, k} D^{-} C_{j k k}+\varepsilon
\end{aligned}
$$

where $D^{+}$and $D^{-}$are dummy variables for countries with overinvestment and countries with underinvestment, based on the standard gravity equation. This way, I can measure the marginal effect of a determinant $k$ on overinvestment or underinvestment respectively, and test whether this impact is significantly different from what I observe for the observations where investment is in line with what can be expected based on standard gravity model. ${ }^{19}$

Based on the literature described in section 5.2.2 and 5.2.3, an extensive range of possible determinants of FDI is selected. Table A1 in annex 5.1 contains an overview of these variables, and the expected sign on FDI inflows. In addition, the dummy variables overinvestment and underinvestment are used as interaction variables, in order to see whether some additional variables may be more suitable to explain overinvestment or underinvestment specifically.

\subsubsection{Residual analysis}

As a final part of the analysis, I take a closer look at the performance of individual transition countries in three ways. First, it is possible to evaluate the sensitivity of the model results to the definition of regional dummies. Second, I analyze the extent to which individual countries structurally receive overor underinvestment and/or if there are certain turning points in time. Finally, I graphically demonstrate the volatility of actual investments vis-à-vis predicted investments.

\subsection{Data}

For this research the database includes yearly data for 207 countries for the period of 1987 to 2001. A list of countries in included in Annex 5.1 table A-2. The FDI flows are country aggregated investment data from the Dutch Central Bank. ${ }^{20}$ The GDP, and population data have been taken from the World Development Indicators 2001 (WDI). Distance in $\mathrm{km}$ is calculated based on the geographic coordinates of the capitals. ${ }^{21}$ This leaves a dataset of 3090 observations.

With respect to regional classifications, several dummy variables in order have been created to capture the transition effect sufficiently. The variable Western Europe consists of all countries and citystates geographically located in Western Europe, that are not transition economies. ${ }^{2}$

\footnotetext{
${ }^{19}$ The decision to define overinvestment and underinvestment at the $50 \%$ level is arbitrary. In order to find out how sensitive the approach is to the choice of 50 percent as a cut-off point, the percentage over-and underinvestment has been set at different levels between 25 percent and 75 percent, in order to check whether the model fit and marginal effects change significantly. The regressions using 50 percent as boundary gave the best fit. The coefficients did not change in signs or significance.

* Quarterly flow data have been accumulated to figure yearly flow data, and have been converted from Dutch Guilders to USD using the average yearly exchange rate. In order to deal with the negative and zero values of FDI flows and GDP. I combined the two approaches usually taken in gravity studies. In general, either all negative and zero values of FDI and GDP will be deleted from the analysis, or a very small positive number will replace them. In the Dutch Central Bank data the division between missing data and a flow of 0 has been identified. Missing data are indeed missing in the original dataset, and a flow of 0 in the dataset means a flow between 0 and 1.000 .000 euro. Missing observations are dropped from the dataset, and values of zero FDI were replaced with the average value of 500.000 euro, In addition, I dropped the negative values from the analysis. instead of including them as a small positive value (negative values mean the sum of firms in a country divested in that country in a specific year. Replacing those values with small positive numbers would give the wrong conclusions). The total number of FDI values deleted from the database is 405 in total. Replacing all negative values with a small positive value of FDI instead of deleting them, does not change the results of the gravity regression significantly except for generating a lower fit (adjusted Rsquared of 0.42 ), but does lead to a complete group of outliers in the error analysis in section four.

2t The dataset contained 441 observations with missing values of GDP or distances. Those observations were dropped from the analysis.

${ }_{22}$ Andorra, Austria, Belgium. Channel Islands, Denmark, Faeroe Islands, Finland, France, Germany, Greece, Iceland, Ireland, Isle of Man, Italy, Liechtenstein, Luxembourg. Malta, Monaco, Netherlands, Norway, Portugal. San Marino, Spain, Sweden, Switzeriand, United Kingdom.
} 


\section{Table 5.4: Classification of transition countries, geographically and} economically

\begin{tabular}{|c|c|c|c|c|}
\hline \multicolumn{5}{|c|}{ Economic division } \\
\hline & & European accession countries & $\begin{array}{l}\text { Rest of Central and } \\
\text { Eastern Europe }\end{array}$ & Central Asia \\
\hline \multirow[t]{2}{*}{ Geographic division } & $\begin{array}{l}\text { Central } \\
\text { and } \\
\text { Eastern } \\
\text { Europe }\end{array}$ & $\begin{array}{l}\text { Bulgaria (negotiating) } \\
\text { Czech Republic } \\
\text { Estonia } \\
\text { Hungary } \\
\text { Latvia } \\
\text { Lithuania } \\
\text { Poland } \\
\text { Romania (negotiating) } \\
\text { Slovak Republic } \\
\text { Slovenia }\end{array}$ & $\begin{array}{l}\text { Albania } \\
\text { Bosnia-Herzegovina } \\
\text { Croatia } \\
\text { Macedonia } \\
\text { Yugoslavia }\end{array}$ & 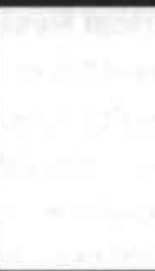 \\
\hline & $\begin{array}{l}\text { former } \\
\text { Soviet } \\
\text { Union }\end{array}$ & (1) & $\begin{array}{l}\text { Armenia } \\
\text { Azerbaijan } \\
\text { Belarus } \\
\text { Georgia } \\
\text { Moldova } \\
\text { Russia } \\
\text { Ukraine }\end{array}$ & $\begin{array}{l}\text { Kazakhstan } \\
\text { Kyrgyzstan } \\
\text { Tajikistan } \\
\text { Turkmenistan } \\
\text { Uzbekistan }\end{array}$ \\
\hline
\end{tabular}

Table 5.5: Summary statistics 2001

\begin{tabular}{|c|c|c|c|c|c|c|}
\hline & Western Europe & E.U. Accession & CEE res! & $\begin{array}{l}\text { CEEC rest } \\
\text { excl. } \\
\text { Russia }\end{array}$ & Russia & $\begin{array}{l}\text { Centra: } \\
\text { Asia }\end{array}$ \\
\hline $\begin{array}{l}\text { Number of } \\
\text { countries }\end{array}$ & 25 & 10 & 12 & 11 & 1 & 5 \\
\hline Population (min.) & 20.5 & 10.4 & 20.7 & 9.5 & 144.8 & 11.3 \\
\hline GDP (min. USD) & 437891.0 & 401157.3 & 34625.7 & 9596.1 & 309951.2 & 8440.2 \\
\hline GDP per capita & 23677.9 & 4267.0 & 1348.2 & 1276.2 & 2140.4 & 706.7 \\
\hline FDI in million USD & 437.8 & 24.1 & 27.2 & 1.21 & 312.6 & 0.7 \\
\hline $\begin{array}{l}\text { FDI per capita } \\
\text { (min. USD) }\end{array}$ & 149.8 & 1.36 & 0.33 & 0.17 & 2.11 & 0.04 \\
\hline Distance & 1023 & 1268 & 2036 & 2025 & 2157 & 4848 \\
\hline
\end{tabular}

Source: 1) Population, GDP and GDP per capita from WDI 2001 (for Western Europe $n=19$ ), 2)FDI from De Nederiandsche Bank database 2001. Central Asia for 2000,3) Distance between Amsterdam and host country capital in $\mathrm{km}$, as the crow flies (own calculations (Internet distance calculator)).

The variable Transition countries takes the value one for all countries located in Central and Eastern Europe and the former Soviet Union undergoing the transition from a planned economy to a market economy. These transition countries have been subdivided in categories marked by dummy variables in order to take their geographic position and economic development into account. Geographically, the transition countries are divided in Central and Eastern European countries and former Soviet Union countries. Economically, there is a clear division between those countries entering the EU or negotiating EU accession which are economically most developed, the rest of Central and Eastern Europe and the countries of Central Asia. Table 5.4 shows this classification of countries.

In section 5.5.2, the database is extended with macroeconomic and social indicators from the WDI 2001 dataset, and financial variables from the IFS statistics for monetary and financial variables. In addition, three different risk indicators: country risk, political risk and economic risk are taken from the euromoney database. ${ }^{23}$ Given that the WDI and IFS databases are large, and not all variables are

\footnotetext{
${ }^{23}$ Euromoney provides a score twice a year, ranging from 0 to 100 with 0 being a very high risk and 100 being a very low risk. I used yearly averages for the years after 1993, when two scores were available per year. For the years before 1993 the available
} 
available for all sample countries and the time period 1987-2001, I made a selection of variables to include in the regression. These variables are classified into subgroups, and a summary is included in Annex 5.1 table A1. Summary statistics for the main gravity variables for the main regions are included in table 5.5 .

\subsection{Empirical Results}

\subsubsection{Standard Gravity equation}

Dutch yearly FDI flows are very volatile, and there is no time effect visible..$^{24}$ In order to explain the size of the flows, I start with a basic gravity model, extending that with regional dummies to capture the long run equilibrium level. The first analysis includes the basic gravity model variables, being a constant, GDP of the host country, population of the host country and the distance between the capital of the home country, Amsterdam, and the capital of the host country:

$$
\ln F D I_{i j}=\beta_{0}+\beta_{1} \ln G D P_{j}+\beta_{2} \ln P O P_{j}+\beta_{3} \ln D i s t_{i j}+\varepsilon_{i j}
$$

with:

$$
\begin{aligned}
& F I_{i j}=\quad \text { outward investment flows from the Netherlands to a host country, in million USD. } \\
& G D P_{j}=\quad \text { the gross domestic product of the host country in million USD. } \\
& P o p_{j}=\quad \text { the population of the host country in millions of inhabitants. } \\
& \text { Dist } t_{j}=\quad \text { the distance between Amsterdam and the host country capital in } \mathrm{km} \text {, as the crow flies. }
\end{aligned}
$$

In line with the literature, FDI flows are expected to be higher if the GDP of the host country is higher, the host country population is larger, and the distance to the host country is smaller. Using region dummies for the transition countries will allow concluding whether or not Dutch firms are investing in this region proportionally to their other investments worldwide. This analysis will also be undertaken on a yearly basis, in order to see possible turning points in FDI relationships to certain countries. When estimating the basic gravity model, the results are as expected. In table 5.6, the joint coefficients are significant, and the explanatory power is remarkably high, given the fact that only the three basic variables have been used (adjusted R-squared of 0.52 ). All three variables display the expected sign. GDP and distance are significant at a one percent level, and population is insignificant. ${ }^{25}$ In order to see whether countries in the transition countries indeed receive FDI flows based on their gravity values, regional dummies are added to the gravity equation.

I used the regional dummies as defined in table 5.4, namely Western Europe, the EU accession countries, the rest of Central and Eastern Europe and Central Asia. If the coefficient for the dummy variable is significantly positive, a country already receives more than the expected FDI inflow. When negative, countries in that specific region receive less Dutch FDI than expected based on their GDP, population size and distance. If the coefficient is insignificant, there is no substantial evidence that a region receives proportionally more or less FDI than other countries in the world.

score was used as yearly average. Political risk scores are only available from 1992 onwards. The economic risk is available starting 1986, but 1988 and 1989 are missing. These values are substituted by the average of the 1987 and 1990 score. Country risk scores are available for all years.

${ }_{24}^{24}$ When estimating the basic gravity model with the extension of the variable year the variable year was insignificant. Also when estimating FDI only with explanatory variable year the variable was insignificant.

${ }^{25}$ When clustering the results over countries in order to take into account that FDI flows to a certain country may not vary too much per year, I find no changes in the result. 


\begin{tabular}{|l|l|}
\begin{tabular}{l} 
Table 5.6: Basic Gravity model for Dutch outward investments \\
\hline
\end{tabular} \\
\hline CDP & 0.268 \\
\hline & $(33.67)^{* *}$ \\
\hline Population & 0.040 \\
\hline & $(1.85)$ \\
\hline Distance & -0.370 \\
\hline & $(8.46)^{* *}$ \\
\hline Constant & 1.293 \\
\hline & $(3.22)^{* *}$ \\
\hline Observations & 2301 \\
\hline Adjusted R-squared & 0.52 \\
\hline
\end{tabular}

Absolute value of $t$ statistics in parentheses. " significant at $5 \% ; "$ " significant at $1 \%$

All variables are included as the natural logarithm In, or as dummy variable, see Annex 5.1 for details.

Table 5.7: Basic Gravity model of Dutch outward FDI with regional disparities

\begin{tabular}{|l|l|l|l|l|l|l|}
\hline & Basic & \multicolumn{2}{l}{ Western Europe EU accession } & Rest of CEEC & \multicolumn{1}{l|}{ Central Asia } & All \\
\hline GDP & 0.268 & 0.220 & 0.267 & 0.253 & 0.264 & 0.215 \\
\hline & $(33.67)^{* *}$ & $(24.20)^{* *}$ & $(32.96)^{* *}$ & $(31.82)^{* *}$ & $(33.15)^{* *}$ & $(23.79)^{* *}$ \\
\hline & 0.040 & 0.127 & 0.042 & 0.068 & 0.049 & 0.141 \\
\hline & $(1.85)$ & $(5.51)^{* *}$ & $(1.91)$ & $(3.16)^{* *}$ & $(2.24)^{*}$ & $(6.18)^{* *}$ \\
\hline & -0.370 & -0.042 & -0.384 & -0.493 & -0.372 & -0.180 \\
\hline & $(8.46)^{* *}$ & $(0.78)$ & $(8.09)^{* *}$ & $(11.02)^{* *}$ & $(8.54)^{* *}$ & $(2.43)^{*}$ \\
\hline Distance & & 1.822 & & & & 1.507 \\
\hline Western Europe & & $(10.07)^{* *}$ & & & & $(6.98)^{* *}$ \\
\hline & & & -0.139 & & & 0.144 \\
\hline EU accession & & & $(0.80)$ & & & $(0.72)$ \\
\hline Rest of CEEC & & & & -1.509 & & -1.158 \\
\hline & & & & $(9.61)^{* *}$ & & $(6.64)^{* *}$ \\
\hline Central Asia & & & & & -0.886 & -0.974 \\
\hline & & & & & $(3.72)^{* *}$ & $(4.19)^{* *}$ \\
\hline Constant & 1.293 & -1.277 & 1.437 & 2.546 & 1.360 & 0.053 \\
\hline & $(3.22)^{* *}$ & $(2.73)^{* *}$ & $(3.26)^{* *}$ & $(6.14)^{* *}$ & $(3.40)^{* *}$ & $(0.08)$ \\
\hline Observations & 2301 & 2301 & 2301 & 2301 & 2301 & 2301 \\
\hline Adjusted R-squared & 0.52 & 0.54 & 0.52 & 0.54 & 0.52 & 0.56 \\
\hline
\end{tabular}

Absolute value of $\mathrm{t}$ statistics in parentheses, ${ }^{*}$ significant at $5 \% ;{ }^{*}$ significant at $1 \%$

All variables are included as the natural logarithm in, or as dummy variable, see Annex 5.1 for details.

The results in the table 5.7 display some interesting facts. The coefficients for GDP, population and distance have the same sign, and are of similar magnitudes for all regions. In terms of significance of the coefficients, the regression including Western Europe as a regional dummy variable shows a different picture than the other regressions, since distance is insignificant but population size becomes more important, with a higher coefficient, than in the other regions. 
Table 5.8: Gravity estimations with regional dummies and time variable

\begin{tabular}{|c|c|c|c|c|c|c|}
\hline & Basic & Western Europe & EU accession & Rest of CEEC & Central Asia & All \\
\hline \multirow[t]{2}{*}{ GDP } & 0.268 & 0.220 & 0.267 & 0.253 & 0.265 & 0.215 \\
\hline & $(33.70)^{* *}$ & $(24.22)^{* *}$ & $(32.99)^{* *}$ & $(31.85)^{* *}$ & $(33.18)^{* *}$ & $(23.82)^{* *}$ \\
\hline \multirow[t]{2}{*}{ Population } & 0.040 & 0.126 & 0.042 & 0.068 & 0.049 & 0.141 \\
\hline & $(1.83)$ & $(5.50)^{* *}$ & $(1.90)$ & $(3.14)^{* *}$ & $(2.23)^{*}$ & $(6.17)^{* *}$ \\
\hline \multirow[t]{2}{*}{ Distance } & -0.369 & -0.041 & -0.384 & -0.492 & -0.372 & -0.179 \\
\hline & $(8.46)^{* *}$ & $(0.77)$ & $(8.09)^{* *}$ & $(11.00)^{* *}$ & $(8.54)^{* *}$ & $(2.41)^{\circ}$ \\
\hline \multirow[t]{2}{*}{ Time } & 0.013 & 0.014 & 0.013 & 0.011 & 0.013 & 0.011 \\
\hline & $(1.57)$ & $(1.65)$ & $(1.58)$ & $(1.36)$ & $(1.50)$ & $(1.38)$ \\
\hline \multirow[t]{2}{*}{ Western Europe } & & 1.824 & & & & 1.511 \\
\hline & & $(10.08)^{* *}$ & & & & $(7.00)^{* *}$ \\
\hline \multirow[t]{2}{*}{ EU Accession } & & & -0.142 & & & 0.145 \\
\hline & & & $(0.81)$ & & & $(0.73)$ \\
\hline \multirow[t]{2}{*}{ Rest of CEEC } & & & t & -1.503 & & -1.151 \\
\hline & & & & $(9.57)^{* *}$ & & $(6.60)^{* *}$ \\
\hline \multirow[t]{2}{*}{ Central Asia } & & & & & -0.879 & -0.966 \\
\hline & & & & & $(3.68)^{* *}$ & $(4.16)^{* *}$ \\
\hline \multirow[t]{2}{*}{ Constant } & 1.196 & -1.378 & 1.342 & 2.459 & 1.267 & -0.042 \\
\hline & $(2.95)^{* *}$ & $(2.92)^{* *}$ & $(3.02)^{* *}$ & $(5.86)^{* *}$ & $(3.13)^{* *}$ & $(0.06)$ \\
\hline Observations & 2301 & 2301 & 2301 & 2301 & 2301 & 2301 \\
\hline Adjusted R-squared & 0.52 & 0.54 & 0.52 & 0.54 & 0.52 & 0.56 \\
\hline
\end{tabular}

Absolute value of $t$ statistics in parentheses, " significant at $5 \%: "{ }^{*}$ significant at $1 \%$

All variables are included as the natural logarithm in, or as dummy variable, see Annex 5.1 for details.

These coefficients are an indication that countries further away are be disadvantaged with respect to Dutch FDI inflow as long as they are member countries of the EU. ${ }^{26}$ For the regressions with other regional dummies this distance effect is significantly negative: countries further away from the Netherlands, ceteris paribus, receive less FDI. Thus, the inclusion of the Western Europe dummy compensates for the effect distance has within the EU. Its high and significant coefficient indicates that Dutch FDI in the EU was significantly higher than expected based on the gravity variables of the Western European countries. In fact, the flows were six percent higher compared to Dutch investment behavior in the rest of the world. This positive relationship cannot be detected for the transition countries, as reflected by the negative coefficients for the regional dummy. This negative effect is highest for the countries in Central and Eastern Europe that are not negotiating EU accession yet. They receive only about 20 percent of the Dutch investment inflow that is expected based on their GDP, population size and distance. The coefficient for the EU accession countries is insignificant, indicating that those counties do receive the amount of FDI as expected. They do not face the negative effect of transition anymore. However, they also do not have the positive regional effect from being a EU member, since the coefficient is still not significantly different from zero. Given that they are on the verge of entering the EU, and the Western European countries have a positive regional effect, continuous increase of inflows is to be expected for the accession countries in the coming years. ${ }^{27}$ Including all regional dummies jointly does not lead to different results compared to including

\footnotetext{
${ }^{20}$ This can be caused by the presence of free movement of persons. goods and services, eliminating procedures at borders, and making travel costs less high.

${ }_{27}$ Bulgaria and Romania are in this analysis included in the EU accession countries, even though they are not entering the EU in 2004. However, including these countries in the CEECRest group does not lead to significant changes. The Euaccession
} 
the regional dummies separately.

In table 5.8 a time effect is included, starting in 1988. This time variable is included to cover the expected effect that the FDI flows in the late 1980 s and early 1990 s was low, as a direct result of the closeness of the region the second half of the 20th century. As a result, you can expect a catch up effect, which would be indicated by a positive time trend. However, the variable time is insignificant, and incapable to capture the transition effect sufficiently. In order to double check whether this transition effect exists, a yearly analysis is done. Table 5.9 contains the yearly regression results. The coefficients for the gravity variables and the Western European dummy variable do not lead to surprises. Like the time variable, which was unable to capture a transition effect, the regional dummies also do not give evidence for a time shift. ${ }^{2 b}$ The yearly regressions for EU accession countries are half of the time positive and negative, but always insignificant. The rest of Central and Eastern Europe and Central Asia show consistent negative coefficients, but only the coefficient of the rest of Central and Eastern Europe is significant in half of the years. This insignificance is an indication that the EU accession countries and Central Asian countries have received FDI inflows in line with what is expected, whereas only the Rest of Central and Eastern Europe received below what is expected, and therefore they can expect a catch up effect to take place. The regressions confirm the previously detected regional disparities between the EU accession countries and rest of the CEECs and Central Asia. A remaining question is why these regional dummy coefficients are of such importance in the gravity equation. It is unlikely that receiving a low inflow of Dutch FDI can be attributed mainly to a geographic variable. In fact, the use of a regional dummy variable simplifies the results considerably, and oversimplifies reality.

The large impact of the regional dummy variable is probably not a geographical effect, but has macro-economic, social or cultural underlying reasons. This statement will be tested in section 5.5 .2 where I add several additional variables in order to see whether the large regional impact is indeed explainable by additional variables, or if the deviation is simply explained through geography. It is also very well possible that the regional dummy effect is biased because of an unequal division of FDI among the countries within a region. For example, the positive effect of including the EU accession dummy may be the result of high FDI flows to the top three transition countries Poland, Hungary and the Czech Republic, while the remaining countries in the region are performing less well with respect to attracting FDI. In section 5.5.3 these effects will be studied further.

${ }^{20}$ The absence of a time effect could be the result of the database. I only have data from 1987 onward, thus only two years before the start of the transition is included. Possibly, this time period before transition is too short to indicate a clear breaking point after 1989. 
Table 5.9: Gravity estimations on a yearly basis, including regional dummles

\begin{tabular}{|c|c|c|c|c|c|c|c|c|c|c|c|c|c|c|c|}
\hline & igei & $10 \div 5$ & $i=k^{i}$ & :95010 & $16 \overline{1}^{\circ}$ & iบ:5: & 1 gists & 1994 & 1595 & 1995 & 1997 & $159 d$ & 1505 & 2000 & $200:$ \\
\hline \multirow[t]{2}{*}{ GDP } & 0.18 & 0.25 & 0.22 & 0.24 & 0.26 & 0.17 & 0.24 & 0.21 & 0.18 & 0.27 & 0.17 & 0.21 & 0.25 & 0.22 & 0.18 \\
\hline & $(4.65)^{-*}$ & $(7.71)^{\circ *}$ & $(7,10)^{* *}$ & $(6.01)^{* *}$ & $(7.20)^{* *}$ & $(4.91)^{2 n}$ & $(6.48)^{-\ldots}$ & $(5,18)^{*}$ & $(4.81)^{* *}$ & $(9.08)^{* *}$ & $(4.29)^{*}$ & $(5.91)^{*}$ & $(7.38)^{* *}$ & $(6.14)^{n}$ & $(5.59)^{* \prime}$ \\
\hline \multirow[t]{2}{*}{ Population } & 0.15 & 0.06 & 0.12 & 0.19 & 0.01 & 0.20 & 0.13 & 0.13 & 0.24 & 0.11 & 0.17 & 0.19 & 0.01 & 0.14 & 0.22 \\
\hline & $(1.63)$ & $(0.69)$ & $(1.46)$ & $(1.94)$ & $(0.13)$ & $(2.22)^{\circ}$ & $(1.36)$ & $(1.30)$ & $(2.56)^{\circ}$ & $(1.51)$ & {$[1.75]$} & $(2.04)^{\circ}$ & $(0.12)$ & $(1,68)$ & $(2.51)^{\circ}$ \\
\hline \multirow[t]{2}{*}{ Distance } & 0.00 & -0.47 & -0.22 & 0.18 & -0.34 & -0.09 & -0.42 & 0.017 & $-0.36 i$ & -0.40 & -0.10 & -0.29 & -0.30 & 0.16 & -0.20 \\
\hline & $(0.01)$ & $(1.81)$ & $(0.75)$ & $(0.55)$ & $(1.16)$ & $(0.28)$ & $(1.34)$ & $(0.20)$ & $(1.26)$ & $(1.57)$ & $(0.31)$ & $(0.99)$ & $(1.15)$ & $(0.58)$ & $(0.74)$ \\
\hline \multirow[t]{2}{*}{ Western Europe } & 1,86 & -0.17 & 1.35 & 2.48 & 1.15 & 2.39 & 0.85 & 242 & 1.49 & 0.20 & 1.78 & 1.30 & 0.91 & 2.51 & 1.77 \\
\hline & $(2.18)^{\prime \prime}$ & $(0.22)$ & $(1.66)$ & $(2.71)^{-}$ & $(1,38)$ & $(2.86)^{* *}$ & $(0.9 \boldsymbol{B})$ & $(2.56)^{\circ}$ & (1.71) & $(0.26)$ & $(1,81)$ & (1.53) & $(1,13)$ & $(3.08)^{* *}$ & $(2.22)^{\circ}$ \\
\hline \multirow[t]{2}{*}{ EU accession } & 1.49 & -0.53 & 0.62 & 0.87 & .0 .79 & -0.27 & -0.84 & 1.63 & -0.60 & 0.61 & 0.83 & -1.00 & 0.25 & 0.25 & -0.24 \\
\hline & $(1.88)$ & $(0.74)$ & $(0.79)$ & $(1.08)$ & $(1.00)$ & $(0.34)$ & $(0.93)$ & $(1.79)$ & $(0.79)$ & $(0.61)$ & $(0.95)$ & $(1.29)$ & $(0.36)$ & $(0.33)$ & $(0.36 \mathrm{i})$ \\
\hline \multirow[t]{2}{*}{ Rest of CEEEC } & -0.72 & -1.65 & -1.72 & -0.05 & -1.56 & -1.65 & -1.12 & -0.56 & -0.96 & .9 .57 & -0.61 & -1.69 & -1.57 & -1.10 & -0.83 \\
\hline & $(1.12)$ & $(2.83)^{* *}$ & $(2.55)^{*}$ & $(0.08)$ & $(2.31)^{\circ}$ & $(2.33)^{\circ}$ & $(1.51)$ & $(0.72)$ & $(1.43)$ & $(2.72)^{*}$ & $(0.77)$ & $(2.27)^{x}$ & $(2.27)^{2}$ & $(1.68)$ & $(1.29)$ \\
\hline \multirow[t]{2}{*}{ Central Assia } & -1.43 & -1.44 & -1.57 & -0.66 & -0.24 & 0.22 & -0.53 & -1.31 & -1.49 & -1.51 & .0 .99 & -1.47 & -0.24 & -0.79 & -1.17 \\
\hline & $(1.82)$ & $(1.82)$ & $(1.78)$ & $(0.82)$ & $(0.31)$ & $(0.22)$ & $(0.55)$ & $(1.28)$ & $(0.87)$ & $(1.93)$ & $(0.87)$ & $(1.71)$ & $(0.30)$ & $(0.79)$ & $(1.29)$ \\
\hline \multirow[t]{2}{*}{ Canstant } & -1.26 & 2.26 & 0.49 & .3 .33 & 1.28 & -0.47 & 2.00 & -204 & 1.73 & 1.47 & .0 .28 & 0.98 & 0.98 & -2.75 & 0.47 \\
\hline & $(0.50)$ & $(0.98)$ & $(0.19)$ & $(1.29)$ & $(0.47)$ & $(0.17)$ & $(0.72)$ & $(0.69)$ & $(0.68)$ & $(0.65)$ & $(0.10)$ & $(0.38)$ & $(0.42)$ & $(1,11)$ & $(0.20)$ \\
\hline Observations & 156 & 162 & 153 & 147 & 152 & 155 & 151 & 148 & 151 & 365 & 159 & 152 & 151 & 151 & 148 \\
\hline Adjusted R-squared & 0.49 & 0.59 & 0.54 & 0.61 & 0.59 & 0.52 & 0.53 & 0.48 & 0.58 & 0.62 & 0.41 & 0.57 & 0.57 & 0.56 & 0.59 \\
\hline
\end{tabular}

Absolute value of $t$ statistics in parentheses. "significant at $5 \%$; " significant at $1 \%$

All variables are included as the natural logarithm in, or as dummy variable, see Annex 5.1 for details. 


\subsubsection{What explains under- and overinvestment?}

52 percent of FDI inflows are explained by basic gravity variables, giving the long run perspective. There still is a huge volatility in FDI that is not taken into account in this model. It thus remains interesting to see which additional variables can be influential in explaining the short run volatility in FDI flows. First, a geographic continent variable is added to the basic gravity variables. As can be seen in table 5.10 , the continent coefficients are significantly different from zero. This significance confirms the validity of the research question whether it is really geography that explains FDI flows and magnitudes, or if there are in fact different underlying reasons. To increase the understanding of the magnitude of Dutch FDI flows, model two to eight include infrastructure and lagged FDI, and categories religion, macroeconomic, sector, balance of payments, and risk indicators. A description of all variables, the abbreviation used, how they are included and the sources, as well as the followed selection procedure of the variables is included in Annex A5.1. ${ }^{23}$

All models have an equal or better fit than the basic gravity model, and the joint variables remain significant. In addition, several of the added variables are significant. As expected, the geographical dummies included in model one add a lot of explanatory power to the model, but the question remains what the underlying reasons are. With the Western European countries as baseline category, assuming the Netherlands is trading most with other EU countries, all other continents' coefficients are expected to have a negative sign. Contrary to expectations, countries located in North America attract significantly more FDI than the countries in Western Europe. With the exception of South America, South East Asia and the rest of the world, all continents indeed receive significantly less FDI than Western European countries. Including religion gives the expected results. Countries with a similar religion as the Netherlands, Christianity, attract significantly more FDI than countries with a predominantly different religion. There is no real difference in the size of the coefficients of the three major religions (Muslim, Orthodox and Buddhism). Larger countries measured by land area attract significantly less FDI than is expected, but countries with a better-developed infrastructure, measured in kilometers of highways. ${ }^{30}$ In order to see which effect is dominant, dividing land area over kilometers of highway in a country creates the variable infrastructure. Countries with a less-developed infrastructure attract significantly less FDI than countries with a more developed road net (model three). The coefficient of population decreases as well as the variable infrastructure is included, thus as countries become more developed in terms of infrastructure provisions, population size becomes less important since it becomes more convenient and less costly to do business also in smaller countries. In addition, having a large country area with a relatively small population size is not negative as long as the infrastructure is developed well.

Model four, including macroeconomic variables, is harder to interpret. The exchange rate negatively influences FDI inflows, and population becomes insignificant, though the link between those two effects is unclear. ${ }^{31}$ Agricultural countries attract less FDI than industrial or service oriented countries (model five). ${ }^{32}$

\footnotetext{
${ }^{2}$ Some variables that can be expected to influence FDI because of financial, cost-related or socio-economic aspects are not included in the model due to missing data. Examples of such variables are the costs of labor, education level, interest rates and poverty rates. This exclusion does not mean I do not believe those variables to be influential; on the contrary, I believe they can have a large influence on FDI. One of the planned steps for future research is to extend our database and include those variables.

${ }^{\circ}$ Both regressions were run including the variable land area and highways separately. The results are not included in the table, but the combined variable "infrastructure" is included. If the coefficient is negative it means that a better infrastructure attracts FDI (a higher "infrastructure value indicates the country has a less developed infrastructure).

"In this macroeconomic model interest rates are missing. Interest rates in both home and host countries could be good determinants for FDI flows, since financing of investments is often difficult and frequently mentioned by firms as reason why firms decided not to invest. See for instance van de Laar (2004), Klapper et al. (2002) or de Haas et al. (2002).

12 This is in line with the country development path, that less developed countries often specialize more in less R\&D intensive products such as agriculture, and more developed countries specialize in industry and services. More developed countries (high GDP per capita) also receive more $\mathrm{FDI}$ inflows. (InFDI $=-1.99+0.33 \ln$ GDPpercapita, with GDP per capita significant at one percent and
} 
Table 5.10: Gravity model with additional variables

\begin{tabular}{|c|c|c|c|c|c|c|c|c|c|}
\hline & $\begin{array}{l}\text { Model } 1 \\
\text { Continent: }\end{array}$ & $\begin{array}{l}\text { Model } 2 \\
\text { Religion }\end{array}$ & $\begin{array}{l}\text { Model } 3 \\
\text { Infrastructure }\end{array}$ & & $\begin{array}{l}\text { Model } 4 \\
\text { Macro } \\
\text { economic }\end{array}$ & Model 5 & $\begin{array}{l}\text { Model } 6 \\
\text { Bop }\end{array}$ & $\begin{array}{l}\text { Model } 7 \\
\text { Risk }\end{array}$ & $\begin{array}{l}\text { Model } 8 \\
\text { Lagged } \\
\mathrm{FDI}\end{array}$ \\
\hline \multirow[t]{2}{*}{ GDP } & 0.162 & 0.233 & 0.238 & GDP & 0.256 & 0.242 & 0.087 & 0.095 & 0.130 \\
\hline & $(16.85)^{* *}$ & $(27.56)^{* *}$ & $(28.46)^{*-}$ & & $(30.69)^{* *}$ & $(28.31)^{* *}$ & $(4.20)^{* *}$ & $(7.72)^{*-}$ & $(15.16)^{* *}$ \\
\hline \multirow[t]{2}{*}{ Population } & 0.214 & 0.167 & 0.100 & Population & b.029 & 0.092 & -0.064 & 0.335 & 0.004 \\
\hline & $(8.73)^{* *}$ & $(7.24)^{* *}$ & $(4.457)^{* *}$ & & $(0.40)$ & $(3.77)^{* *}$ & $(1.08)$ & $(10.27)^{* *}$ & $(0.22)$ \\
\hline \multirow[t]{2}{*}{ Distance } & -0.696 & -0.443 & -0.294 & Distance & -0.426 & -0.407 & -0.405 & -0.165 & -0.173 \\
\hline & $(8.07)^{* *}$ & $(9.88)^{* *}$ & $(6.42)^{* *}$ & & $(9.20)^{* *}$ & $(8.95)^{* *}$ & $(5.09)^{* *}$ & $(3.06)^{* *}$ & $(4.45)^{* *}$ \\
\hline \multirow[t]{2}{*}{ Africa } & -1.5089 & & & Exchange rate & -0.026 & & & & \\
\hline & $(7.04)^{n *}$ & & & & $(5.39)^{* *}$ & & & & \\
\hline \multirow[t]{2}{*}{ Asia } & -1.821 & & & Labor Force & 0.045 & & & & \\
\hline & $(6.71)^{* *}$ & & & & $(0.62)$ & & & & \\
\hline \multirow[t]{2}{*}{\begin{tabular}{|l|} 
Central \\
America \\
\end{tabular}} & -0.709 & & & Agriculture & & -0.065 & & & \\
\hline & $(2.82)^{\circ}$ & & & & & $(5.61)^{* *}$ & & & \\
\hline \multirow[t]{2}{*}{ EU accession } & -1.657 & & & Industry & & 0.097 & & & \\
\hline & $(8.45)^{* *}$ & & & & & $(2.71)^{* *}$ & & & \\
\hline \multirow[t]{2}{*}{ CEEC Rest } & -2.766 & & & Services & & 0.145 & & & \\
\hline & $(13.47)^{*}$ & & & & & $(3.45)^{* *}$ & & & \\
\hline \multirow[t]{2}{*}{ Central Asia } & -2.184 & & & Goods Export & & & -0.799 & & \\
\hline & $(7.34)^{* *}$ & & & & & & $(3.37)^{* *}$ & & \\
\hline \multirow[t]{2}{*}{ Middle East } & -1.276 & & & Goods Import & & & 0.880 & & \\
\hline & $(5.91)^{* *}$ & & & & & & $(2.57)^{*}$ & & \\
\hline \multirow[t]{2}{*}{ Rest of World } & -0.541 & & & Services Export & & & 0.231 & & \\
\hline & $(1.90)$ & & & & & & $(1.36)$ & & \\
\hline \multirow[t]{2}{*}{ South America } & 0.390 & & & Services import & & & 0.117 & & \\
\hline & $(1.40)$ & & & & & & $(0.46)$ & & \\
\hline \multirow[t]{2}{*}{ North America } & 1.705 & & & Income Export & & & 0.000 & & \\
\hline & $(5.54)^{* *}$ & & & & & & $(0.00)$ & & \\
\hline \multirow[t]{2}{*}{$\begin{array}{l}\text { South East } \\
\text { Asia }\end{array}$} & 0.265 & & & Income Import & & & 0.793 & & \\
\hline & $(0.94)$ & & & & & & $(6.64)^{* *}$ & & \\
\hline \multirow[t]{2}{*}{ Muslim } & & -1.248 & & Trade Export & & & -0.054 & & \\
\hline & & $(11.98)^{* *}$ & & & & & $(0.66)$ & & \\
\hline \multirow[t]{2}{*}{ Orthodox } & & -1.510 & & Trade Import & & & -0.051 & & \\
\hline & & $(9.32)^{* *}$ & & & & & $(0.67)$ & & \\
\hline \multirow[t]{2}{*}{ Buddhism } & & -1.384 & & Capital Export & & & 0.106 & & \\
\hline & & $(7.95)^{* *}$ & & & & & $(2.64)^{* *}$ & & \\
\hline \multirow[t]{2}{*}{ Mixture } & & -0.549 & & Capital Import & & & -0.068 & & \\
\hline & & $(5.76)^{* *}$ & & & & & $(1.50)$ & & \\
\hline \multirow[t]{2}{*}{ Other } & & -1.135 & & Country risk & & & & 0.019 & \\
\hline & & $(5.55)^{* *}$ & & & & & & $(2.77)^{* *}$ & \\
\hline \multirow[t]{6}{*}{ Infrastructure } & & & -1.157 & Political risk & & & & 0.119 & \\
\hline & & & $(9.79)^{* *}$ & & & & & $(4.97)^{*}$ & \\
\hline & & & & Economic risk & & & & 0.005 & \\
\hline & & & & & & & & $(1.04)$ & \\
\hline & & & & Lagged FDI & & & & & 0.550 \\
\hline & & & & & & & & & $(29.78)^{* *}$ \\
\hline Constant & 5.945 & 2.690 & -2.941 & Constant & 1.775 & -2.149 & -5.526 & -1.424 & 0.535 \\
\hline & $(9.65)^{* *}$ & $(6.34)^{* *}$ & $(5.47)^{* *}$ & & $(1.71)$ & $(1.72)$ & $(3.47)^{* *}$ & $(2.80)^{* *}$ & $(1.52)$ \\
\hline Observations & 2301 & 2301 & 2241 & Observations & 2100 & 2010 & 599 & 1303 & 1902 \\
\hline $\begin{array}{l}\text { Adjusted R- } \\
\text { squared }\end{array}$ & 0.62 & 0.56 & 0.55 & $\begin{array}{l}\text { Adjusted R- } \\
\text { squared }\end{array}$ & 0.53 & b.52 & 0.69 & b.62 & 0.69 \\
\hline
\end{tabular}


The export of goods negatively influences FDI inflows, and the imports are positively significant. Thus, as exports from the Netherlands to a host country increase (imports for the host county), FDI flows also increase, and thus trade and FDI are complementary. The income flows in the country also positively increase FDI. This relationship seems logical, given that FDI is essentially income to the host country. As expected, less risky countries receive significantly more FDI, with political risk being the most important risk factor. ${ }^{33}$ The (one-year) lagged FDI also positively influences this year's inflow. In this model (model eight) population becomes insignificant, indicating lagged FDI includes a size effect of FDI flows making country size unnecessary.

In order to see if there are variables that specifically explain FDI in countries that receive proportionally a lot of (respectively very little) investments, I created two dummy variables called UnderFDI and OverFDI (see section 5.3.2). From the countries with positive residuals in the basic gravity model, the observations within the upper half of the distribution have been marked as OverFDI observations, and the observations in the lowest 50 percent of the negative residual group are marked as UnderFDI observations. Multiplying these dummy variables with the added variables creates interaction variables, in order to see if some variables display different effects for countries receiving more FDI than can be expected, average receivers and countries that are receiving less FDI than can be expected. For example, a country at war will most likely receive low inflows of FDI. In addition, I expect the political stability of such a country to be lower than that of countries not at war. As such, l expect the interaction variable created by multiplying the UnderFDI dummy and the political risk indicator to be large negative and significant, whereas I expect the coefficient to be less large for the overinvesting countries. Table 5.11 shows the results of the eight gravity models used in table 5.10, with the addition of OverFDI and UnderFDI interaction terms for all variables except the basic gravity variables. The analysis shows that for all models the fit increases significantly, with adjusted $R^{2}$ between 0.77 and 0.94 . In all models the UnderFDI and OverFDI interaction terms are highly significant and they carry opposite signs, whereas the coefficient and significance of the original variable diminishes. When I look at the impact of the Over and UnderFDI variables for the different specifications, I notice several interesting things. Originally, the signs for the continent coefficients South America and South East Asia were positive. Now, they have become negative. However, the coefficients for the overinvestment interaction term are high and significant at the one percent level.

This result is an indication that in those regions there are some countries that are attracting large inflows of FDI, and are included in the "OverFDI" category. These countries influence the general coefficient probably to such a large extent that the coefficient became positive, whereas this positive effect now is taken into account in the interaction term. Thus, without the interaction term the conclusion of the gravity model is that these regions receive more FDI than can be expected based on their basic gravity performance. With the inclusion of the interaction term, for South America the conclusion has to be that in general this continent receives FDI according to the gravity predictions, but there are some countries within this continent that receive significantly more, and some countries that receive significantly less. For South East Asia the shift is even more visible, since instead of having a positive significant coefficient, it now has a negative significant coefficient. Thus, on average countries in this region receive significantly less than expected, with an additional effect for the least receiving countries, but there also some countries that receive significantly more than predicted.

\footnotetext{
3) Also when taken separately, political risk has a significant positive coefficient of 0.19 , and country and economic risk of 0.04 . ${ }^{3}$ A variable including lagged GDP has been included as well. However, the value added of this variable was minimal. Though positive and significant, the coefficient off GDP was decreasing with exactly the size of the lagged GDP coefficient. Thus GDP and lagged GDP were substitutes.
} 
Table 5.11: Gravity Model wlth Added Variables and OverFDI/UnderFDI Interaction Terms

\begin{tabular}{|c|c|c|c|c|c|c|c|c|c|c|c|c|c|c|c|}
\hline \multirow{3}{*}{$\begin{array}{l}\text { Continent } \\
\text { GDP }\end{array}$} & \multicolumn{3}{|c|}{ Roligion } & \multicolumn{2}{|l|}{ Infrastructure } & \multicolumn{2}{|l|}{ Macroecon } & \multicolumn{2}{|l|}{ Sector } & \multicolumn{2}{|l|}{ Bop } & \multicolumn{2}{|l|}{ Risk } & \multicolumn{2}{|l|}{ LagrodFDI } \\
\hline & 0.202 & $G D P$ & 0.236 & GDP & 0.244 & GDP & 0.246 & GDP & 0.238 & GDP & 0.210 & GDP & 0.179 & GDP & 0.178 \\
\hline & $(35.50)^{\mathrm{n}}$ & & $(37.41)^{*}$ & & $(53.08)^{* *}$ & & $(6067)^{*}$ & & $(57.60)^{n}$ & & $(1997)^{*}$ & & $(24.00)^{*}$ & & $(2229)^{*}$ \\
\hline \multirow{2}{*}{ Population } & 0.135 & Population & 0.155 & Population & 0.050 & Population & -0.003 & Population & 0.074 & Population & -0.006 & Population & 0.142 & Population & 0.026 \\
\hline & $(9.02)^{n *}$ & & $(9.16)^{* *}$ & & $(3.86)^{*}$ & & $(0.08)$ & & $(6.01)^{*-}$ & & $(0.21)$ & & $(7.19)^{* *}$ & & $(1.55)$ \\
\hline \multirow[t]{2}{*}{ Distence } & 0.715 & Distance & -0.493 & Distance & -0.489 & Distanco. & -0.406 & Distance & -0.477 & Distance & -0.542 & Distance & 0.275 & Distances & -0.097 \\
\hline & $(14.22)^{\mathrm{N}}$ & & $(14.96)^{* *}$ & & $(19.42)^{*}$ & & $(20.97)^{*}$ & & $(21.68)^{*}$ & & $(13.92)^{*}$ & & $(8.67)^{*}$ & & $(2.82)^{\mathrm{r} *}$ \\
\hline \multirow[t]{2}{*}{ Africa } & -1.037 & Muslim & -0.759 & infrastructure & -0.244 & Exchangerate & -0.022 & Agriculture & -0.025 & GoodsE & -0.088 & Countryisis & 0.016 & lagFDI & 0,415 \\
\hline & $(7.57)^{\circ *}$ & & $(7.01)^{*}$ & & $(3.73)^{*}$ & & $(6.43)^{*-}$ & & $(238)^{\circ}$. & & $0.64)$ & & $299)^{*}$ & & $(18.29)^{*}$ \\
\hline \multirow{2}{*}{ OAfrica } & 2.647 & Omuslim & 2.501 & Oinfra & 2198 & OExchange & 0.015 & Oagricuture & -0.016 & OGoodsE & 0.450 & Dcountryrisk & 0.030 & OlagFDI & 0364 \\
\hline & $(22.87)^{*}$ & & $(13.46)^{* *}$ & & $(50.00)^{* \prime}$ & & $(2.77)^{*-}$ & & $(1.21)$ & & $(1.25)$ & & $(2.95)^{* *}$ & & $(15,14)^{\mathrm{e}}$ \\
\hline \multirow[t]{2}{*}{ UAfrica } & -1.217 & Umustim & -1.570 & Uinfra & -1.119 & UExchange & 0,023 & Uagriculture & 0.025 & UgoodsE & -0.416 & Ucountryrisk & -0.015 & UlagFDI & -0.392 \\
\hline & $(14.74)^{n}$ & & $(12.40)^{* *}$ & & $(31.34)^{* *}$ & & $(4.21)^{* \prime}$ & & $(1.75)$ & & $(1.44)$ & & $(1.74)$ & & $(12.58)^{*}$ \\
\hline \multirow[t]{2}{*}{ Asia } & -0.693 & Orthodox & 0.176 & & & Labour Force & 0.070 & Industry & 0.007 & GoodsM & 0.276 & Political risk & 0.036 & & \\
\hline & $(4.04)^{\prime \prime}$ & & $(0.79)$ & & & & $(1.98)^{\circ}$ & & $(0.34)$ & & $(1,25)$ & & $(2.00)^{\circ}$ & & \\
\hline \multirow[t]{2}{*}{ OAsia } & 2252 & Oonthodox & 1.677 & & & OLF & 0159 & Oindustry & 0.079 & OgoodsM & -0.675 & Opoliticalrisk & 0.183 & & \\
\hline & $(6.66)^{* *}$ & & $(4.94)^{\prime \prime}$ & & & & $(2268)^{\prime \prime}$ & & $(1.91)$ & & $(1.58)$ & & $(5.00)^{* *}$ & & \\
\hline \multirow[t]{2}{*}{ UAsia } & -2.459 & Uorthodox & -2.627 & & & ULF & -0.142 & Uindustry & -0.031 & UgoodsM & 0.113 & Upoliticalrisk & -0.013 & & \\
\hline & $(13.97)^{* *}$ & & $(10.26)^{* \prime}$ & & & & $(19.24)^{* *}$ & & $(1.03)$ & & $(0.31)$ & & $(0.47)$ & & \\
\hline \multirow[t]{2}{*}{ CentralAmerica } & -0.612 & Budism & -0.831 & & & & & Services & 0.063 & ServicesE & 0.095 & Economicrisk & 0.003 & & \\
\hline & $(4.06)^{* *}$ & & $(5.71)^{-*}$ & & & & & & $(2.68)^{* *}$ & & $(0.81)$ & & $(0.70)$ & & \\
\hline \multirow[t]{2}{*}{ OCenAmerica } & 2.965 & Obudism & 2.746 & & & & & Oservices & 0.060 & OservicesE & 0.232 & Deconomicrisk & 0.054 & & \\
\hline & $(19.78)^{* \prime}$ & & $(6.40)^{\prime \prime}$ & & & & & & $(1,49)$ & & $(1.08)$ & & $(6.86)^{* *}$ & & \\
\hline \multirow[t]{2}{*}{ UCenAmericas } & -1.203 & Ubudism & -3.512 & & & & & Uservices & -0.073 & UservicesE & -0.509 & Uecongmicrisk & -0.020 & & \\
\hline & $(8.25)^{* *}$ & & $(11.92)^{*}=$ & & & & & & $(240)^{*}$ & & $(3.27)^{* *}$ & & $(3.23)^{* *}$ & & \\
\hline \multirow[t]{2}{*}{ EUaccession } & -0.732 & Muture & -0.816 & & & & & & & ServicesM & -0.238 & & & & \\
\hline & $(3.97)^{* *}$ & & $(9.57)^{*-1}$ & & & & & & & & $(1.44)$ & & & & \\
\hline OEUaccess & 2326 & Omixture & 2.883 & & & & & & & OservicesM & 0.818 & & & & \\
\hline & $(10,45)^{* 0}$ & & $(22.45)^{-5}$ & & & & & & & & $(2.53)^{\circ}$ & & & & \\
\hline UEUacoess & -2.601 & Umixture & -1.291 & & & & & & & UservicesM & 0.583 & & & & \\
\hline & $(12.80)^{* *}$ & & $(10.75)^{* *}$ & & & & & & & & $(2.38)^{*}$ & & & & \\
\hline CEECRest & -0.766 & Other & -0.456 & & & & & & & IncomeE & 0.117 & & & & \\
\hline & $(3.57)^{* *}$ & & $(1.95)$ & & & & & & & & $(2.21)^{*}$ & & & & \\
\hline OCEECRest & 1,890 & Oother & 2.983 & & & & & & & OincomeE & -0.376 & & & & \\
\hline & $(5.05)^{* *}$ & & $(6.41)^{*}$ & & & & & & & & $(3.70)^{20}$ & & & & \\
\hline UCEECResi & -2.117 & Uother & -1.930 & & & & & & & UincomeE & -0.170 & & & & \\
\hline & $(9.88)^{*}$ & & (6.50) & & & & & & & & $(2.14)^{\circ}$ & & & & \\
\hline CentraiAsia & -1.515 & & & & & & & & & incorneM & 0.191 & & & & \\
\hline & $(465)^{* *}$ & & & & & & & & & & $(2.57)^{\circ}$ & & & & \\
\hline OCentralAsia & 4.019 & & & & & & & & & OincomeM & -0.011 & & & & \\
\hline & $(8.00)^{* *}$ & & & & & & & & & & $(0.07)$ & & & & \\
\hline UCentralAsia & -0.715 & & & & & & & & & UincomeM & 0.406 & & & & \\
\hline & $(2,16)^{*}$ & & & & & & & & & & $(2.93)^{*=}$ & & & & \\
\hline
\end{tabular}


Chapter 5 Explaining foreign direct investment nows to Central and Eastern Europe and Central Asia a gravity approach

\begin{tabular}{|c|c|c|c|c|c|c|c|c|c|c|c|c|c|c|c|}
\hline MiddleEast & -0.348 & & & & & & & & & TradeE & 0.019 & & & & \\
\hline & $(2.12)^{\circ}$ & & & & & & & & & & $(0.37)$ & & & 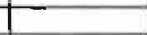 & \\
\hline \multirow{2}{*}{ OMiddleEast } & 2.236 & & & & & & & & & OtradeE & -0.218 & & & & \\
\hline & $(11,12)^{n}$ & & & & & & & & & & $(2.23)$ & & & & \\
\hline \multirow[t]{2}{*}{ UMiddieEas: } & -2.111 & & & & & & & & & UtradeE & -0.138 & & & & \\
\hline & $(13.07)^{0.7}$ & & & & & & & & & & $(1.58)$ & & & & \\
\hline \multirow[t]{2}{*}{ RestofWorld } & -0.424 & & & & & & & & & TradeM & -0.059 & & & & \\
\hline & $(2.55)^{2}$ & & & & & & & & & & $(1,16)$ & & & & \\
\hline \multirow{2}{*}{ ORestofWorid } & 2.995 & & & & & & & & & OtradeM & -0.455 & & & & \\
\hline & $(12.75)^{\circ-}$ & & & & & & & & & 1 & $(1.94)$ & & & 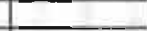 & \\
\hline \multirow{2}{*}{ URestonWorld } & -1027 & & & & & & & & & UtradeM & -0.001 & & & 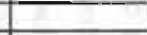 & \\
\hline & $(2.74)^{\prime \prime}$ & & & & & & & & & 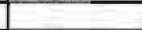 & $(0.01)$ & & & & \\
\hline \multirow[t]{2}{*}{ SouthAmerica } & -0.125 & & & & & & & & & CapitalE & -0.009 & & & & \\
\hline & $(0.68)$ & & & & & & & & & 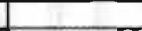 & $(0.35)$ & & & 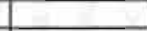 & \\
\hline \multirow[t]{2}{*}{ OSouthAmerica } & 2.341 & & & & & & & & & OcapitailE & -0.011 & & & & \\
\hline & $(14.32)^{* *}$ & & & & & & & & & & $(0.21)$ & & & & \\
\hline \multirow[t]{2}{*}{ USouthAmerica } & -1.586 & & & & & & & & & UcapitalE & 0.178 & & & & \\
\hline & $(6.49)^{*}$ & & & & & & & & & & $(4.25)^{* *}$ & & & & \\
\hline \multirow{2}{*}{ NorthAmorica } & 0.608 & & & & & & & & & Capitaim & 0.057 & & & & \\
\hline & $(2.53)^{*}$ & & & & & & & & & 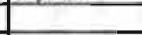 & $(1.99)^{*}$ & & & & \\
\hline \multirow[t]{2}{*}{ ONorthAmerica } & 2.664 & & & & & & & & & bcapitalm & 0.059 & & & & \\
\hline & $(9.70)^{*}$ & & & & & & & & & & $(1.11)$ & & & & \\
\hline \multirow[t]{2}{*}{ UNorthAmerica } & -2.748 & & & & & & & & & UcapitalM & -0.207 & & & & \\
\hline & $(5.54)^{\circ-0}$ & & & & & & & & & & $\left(4.33 \mathrm{~F}^{*}\right.$ & & & & \\
\hline \multirow[t]{2}{*}{ SouthEastasia } & -0.587 & & & & & & & & & & & & & & \\
\hline & $(3.18)^{*-}$ & & & & & & & & & & & & & & \\
\hline \multirow{2}{*}{ OSEAsia } & 3.058 & & & & & & & & & 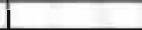 & & 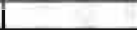 & & & \\
\hline & $(18.60)^{*-*}$ & & & & & & & & & & & & & & \\
\hline \multirow[t]{2}{*}{ USEAsia } & -0.991 & & & & & & & & & & & & & 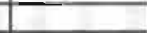 & \\
\hline & $(4.00)^{*}-$ & & & & & & & & & & & & & & \\
\hline \multirow[t]{2}{*}{ Constant } & 5.433 & Constant & 3.081 & Constant & -1.424 & Constant & 1.793 & Constant & 1.395 & Constant & 1.437 & Constant & 0.084 & Constant & -0.612 \\
\hline & $(15.05)^{*-1}$ & & $(9.84)^{* *}$ & & $(4.19)^{* *}$ & & $(3.64)^{* \prime}$ & & $(2.32)^{\circ}$ & & $(1.87)$ & & $(0.28)$ & 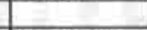 & $(1.97)^{*}$ \\
\hline Observations & 2301 & Observations & 2301 & Observations & 2241 & Observations & 2100 & Observations & 2010 & Observations & 599 & Observations & 1303 & Observations. & 1902 \\
\hline $\begin{array}{l}\text { Adjustod R- } \\
\text { squared }\end{array}$ & 0.87 & $\begin{array}{l}\text { Adjusted R- } \\
\text { squared }\end{array}$ & $0 . \pi$ & $\begin{array}{l}\text { Adjusted R- } \\
\text { squared }\end{array}$ & 0.82 & $\begin{array}{l}\text { Adjusted R- } \\
\text { squared }\end{array}$ & 0.90 & $\begin{array}{l}\text { Adjusted } R \text {. } \\
\text { squared }\end{array}$ & 0.89 & $\begin{array}{l}\text { Adjusted R- } \\
\text { squared }\end{array}$ & 0.94 & $\begin{array}{l}\text { Adjusted R- } \\
\text { squared }\end{array}$ & 0.87 & $\begin{array}{l}\text { Adjusted R- } \\
\text { squared }\end{array}$ & 0.77 \\
\hline
\end{tabular}


Inclusion of religion does not show surprises; countries with Christianity remain the most successful in attracting Dutch FDI.

The effect of the infrastructure variable remains negative (meaning less developed infrastructure attracts less FDI). However, if infrastructure is included, the size effect measured by population decreases. As was evident from table 5.10 as well, this result indicates that large countries in terms of population (like Russia) are not necessarily advantaged by large inflows of FDI and large countries in terms of land area (like Canada) are not necessarily in a disadvantageous situation. If infrastructure is well provided, this substitutes for the size effect.

The results of the specification including sector are interesting. Being an agricultural country clearly acts as a negative factor for attracting Dutch FDI, whereas industry has no effect and services show small positive effects. These results are confirmed by the Balance of Payment model, that shows imports and exports if goods are insignificant, and the service inflows and outflows of a host country as well, except for the underreceiving host countries. Thus in general, countries' imports and exports of goods and services have no clear effect on FDI inflows. This conclusion is contradictory to the results of table 5.10, where FDI and exports from the Netherlands to the host countries were complementary.

With respect to the specification including the risk indicators, it is hard to draw sensible conclusions, also because they show high correlation. ${ }^{35}$ Lower country risk (as reflected by a higher score) clearly positively influences FDI, but the political score seems to act in a reverse way. A high political risk increases Dutch FDI.

The impact of lagged FDI shows the expected significant results, but does not lead to a much better fit with inclusion of the interaction terms.

In general, the interaction terms increase the understanding of the gravity forces in the short run. It seems fair to conclude that a linear gravity model is an oversimplification of reality, and the use of non-linear estimation techniques, or a division of countries in high FDI receivers and low FDI receivers shows that certain countries react differently to certain variables.

\subsubsection{Residual analysis for transition economies}

As the basic gravity model already shows, the amounts of FDI to transition economies vary substantially within the region since the signs and sizes of regional dummy coefficients show large deviations for the EU accession countries, the rest of the CEEC and Central Asia, In section 5.2 became clear that a large part of this deviation is explained by variables omitted in the basic model, including the interaction variables emphasizing an additional effect for high and low receivers. Part of these regional effects is also the result of heavy influence of only a subset of countries, causing an upward or downward bias in the regional average. There can be a misspecification of the dummy variables for the regions, which leads to incorrect conclusions based on those dummies.

When including all transition countries as separate dummy variables, the results show that the Czech Republic and Hungary receive significantly more FDI than can be expected on the basis of

\footnotetext{
${ }^{25}$ There is a correlation of about 0.9 among all three risk indicators. Included separately, all coefficients show the expected sign and are significant. A lower risk increases FDI, this is especially so for the over receivers, and there is a negative effect for the under receivers. The model combining all three indicators has the best fit.
} 
their gravity equation, and Poland is the only country with a positive insignificant coefficient. ${ }^{36}$ Studying the average residuals from the basic gravity model for all the years from the transition countries gives similar results. Only Poland, Hungary, the Czech Republic, Slovak Republic and Kazakhstan have positive residuals, all other countries have negative residuals. These five countries thus positively influence the regional dummy coefficient, possibly causing the EU accession dummy to be insignificant, and reducing the negative significance of the Central Asia dummy.

In table 5.12 variations of the basic gravity model with new regional dummy variables are estimated. The EU accession countries are divided in a EU1 group consisting of Poland, Hungary, the Czech Republic and the Slovak Republic, and a EU2 group with the remaining six countries. The dummy for the rest of the CEECs remains unchanged.

Kazakhstan is excluded from the Central Asia group, and included as a separate dummy. The results show that for both the EU accession countries and the Central Asian countries the coefficients change dramatically. The ten EU accession countries combined receive less FDI that can be expected based on the gravity variables When divided, the four most advanced EU accession countries (EU1) receive significantly more FDI than predicted by the gravity variables, whereas the six remaining countries (EU2) receive significantly less. In Central Asia, Kazakhstan receives an inflow of FDI as can be expected, since its coefficient is insignificant, but the other Central Asian countries (CenAsia1) now have a larger negative significant coefficient.

Both adding variables to the gravity model in order to explain short-term volatility in FDI flows, as well as the definition of the regional dummy variables influence the gravity results significantly. A more elaborate analysis of the countries receiving a lot more that can be expected (OverFDI) or less than expected (UnderFDI) adds to understanding FDI flows to transition countries. "Because the groups of countries that receive a lot more (less) than can be expected are defined each year, trends in the inclusion of countries from the different regions in the OverFDI group and UnderFDI group can be expected.

For example, Western European countries receive on average relatively more FDI, and are expected to be more included in the OverFDI group and less in the UnderFDI group than for instance Central Asian countries.

\footnotetext{
${ }^{*}$ All other countries have a significantly negative coefficient, except for Azerbaijan, Bulgaria, Estonia, Kazakhstan, Romania and the Slovak Republic, that have negative but insignificant coefficients.

17 OverFDI = upper 50 percent of the positive residual distribution, UnderFDI = lowest 50 percent of the negative residual distribution.
} 
Table 5.12: Basic gravity model with new definition of regional dummies

\begin{tabular}{|c|c|c|c|c|c|c|c|c|}
\hline & EUaccessio & CentralAsia & All & EU1 & EU2 & CentralAsia & Kazakhstan & All new \\
\hline \multirow[t]{2}{*}{ GDP } & 0.267 & 0.263 & 0.242 & 0.272 & 0.262 & 0.263 & 0.268 & 0.242 \\
\hline & $(32.97)^{* *}$ & $(32.91)^{* *}$ & $(29.64)^{* *}$ & $(34.14)^{* *}$ & $(32.77)^{* *}$ & $(32.95)^{* *}$ & $(33.58)^{* *}$ & $(29.88)^{* *}$ \\
\hline \multirow[t]{2}{*}{ Population } & 0.038 & 0.049 & 0.086 & 0.029 & 0.043 & 0.048 & 0.038 & 0.082 \\
\hline & -1.75 & $(2.22)^{*}$ & $(3.94)^{* *}$ & $-1,34$ & $(1.98)^{*}$ & $(2.20)^{*}$ & $-1,72$ & $(3.77)^{* *}$ \\
\hline \multirow[t]{2}{*}{ Distance } & -0.382 & -0.382 & -0.575 & -0.313 & -0.433 & -0.383 & -0.376 & -0.562 \\
\hline & $(8.04)^{* *}$ & $(8.76)^{* *}$ & $(11.64)^{* *}$ & $(6.91)^{* *}$ & $(9.57)^{* *}$ & $(8.78)^{* *}$ & $(8.59)^{* *}$ & $(11.48)^{*}$ \\
\hline \multirow[t]{2}{*}{ EU accession } & -0.056 & & -0.503 & & & & & \\
\hline & -0.32 & & $(2.86)^{* *}$ & & & & & \\
\hline \multirow[t]{2}{*}{ Rest of CEEC } & & & -1.777 & & & & & -1.761 \\
\hline & & & $(10.58)^{* *}$ & & & & & $(10.58)^{* *}$ \\
\hline \multirow[t]{2}{*}{ Central Asia } & & -0.874 & -1.085 & & & & & \\
\hline & & $(4.11)^{* *}$ & $(5.19)^{*-}$ & & & - & Z & \\
\hline \multirow[t]{2}{*}{ EU1 } & & & & 1.288 & & & . & 0.692 \\
\hline & & & & $(5.05)^{* *}$ & & & & $(2.74)^{* *}$ \\
\hline \multirow[t]{2}{*}{ EU2 } & & & & & -1.02 & & & -1.329 \\
\hline & & & & & $(4.69)^{* *}$ & & & $(6.18)^{* *}$ \\
\hline \multirow[t]{2}{*}{ Central Asia1 } & & & & & & -0.998 & & -1.206 \\
\hline & & & & & & $(4.40)^{* *}$ & & $(5.46)^{* *}$ \\
\hline \multirow[t]{2}{*}{ Kazakhstan } & & & & & & & 0.021 & -0.21 \\
\hline & & & & & & & -0.04 & -0.37 \\
\hline \multirow[t]{2}{*}{ Constant } & 1.409 & 1.463 & 3.395 & 0.756 & 1.915 & 1.47 & 1.351 & 3.294 \\
\hline & $(3.20)^{* *}$ & $(3.64)^{* *}$ & $(7.33)^{* *}$ & -1.81 & $(4.58)^{* *}$ & $(3.66)^{* *}$ & $(3.36)^{* *}$ & $(7.17)^{* *}$ \\
\hline Observations & 2296 & 2296 & 2296 & 2296 & 2296 & 2296 & 2296 & 2296 \\
\hline Adjusted R-squared & 0.52 & 0.53 & 0.55 & 0.53 & 0.53 & 0.53 & 0.52 & 0.56 \\
\hline
\end{tabular}

Absolute value of $t$ statistics in parentheses, ${ }^{*}$ significant at $5 \%$; ${ }^{*}$ significant at $1 \%$

All variables are included as the natural logarithm In, or as dummy variable, see Annex 5.1 for details.

Time trends can be visible as well. If countries from the EU accession group receive more FDI since the start if their negotiation process, their inclusion in the UnderFDI group should be declining. and their inclusion in the OverFDI group should be increasing. Table 5.13 shows that the inclusion of countries in the overperforming and underperforming group varies largely per region. Countries from the EU and the EU accession region are often included in the OverFDI receivers (on average 21 percent and 25 percent respectively), while countries from the rest of the CEEC and Central Asia are rarely included (on average only three percent and ten percent). However, countries from the CEEC not entering the EU and Central Asia as two regions are more often included in the group of underreceivers (65-64 percent). In addition countries from the EU accession region are on average still more often included in the underperforming category than in the overperforming group (39 percent versus 25 percent of the countries). Only for the EU countries the average percentage of countries included in the Under receiving group is 13 percent, so countries from the EU are not often receiving far less FDI than can be expected based on their gravity variables. The column Total shows the total number of countries included in that category in 1987-2000. The EU countries are more often included in the OverFDI category than in the UnderFDI group ( 73 versus 44 times) whereas the transition countries are more often included in the UnderFDI category. 
Table 5.13: Countries included in OverFDI/UnderFDI group by region

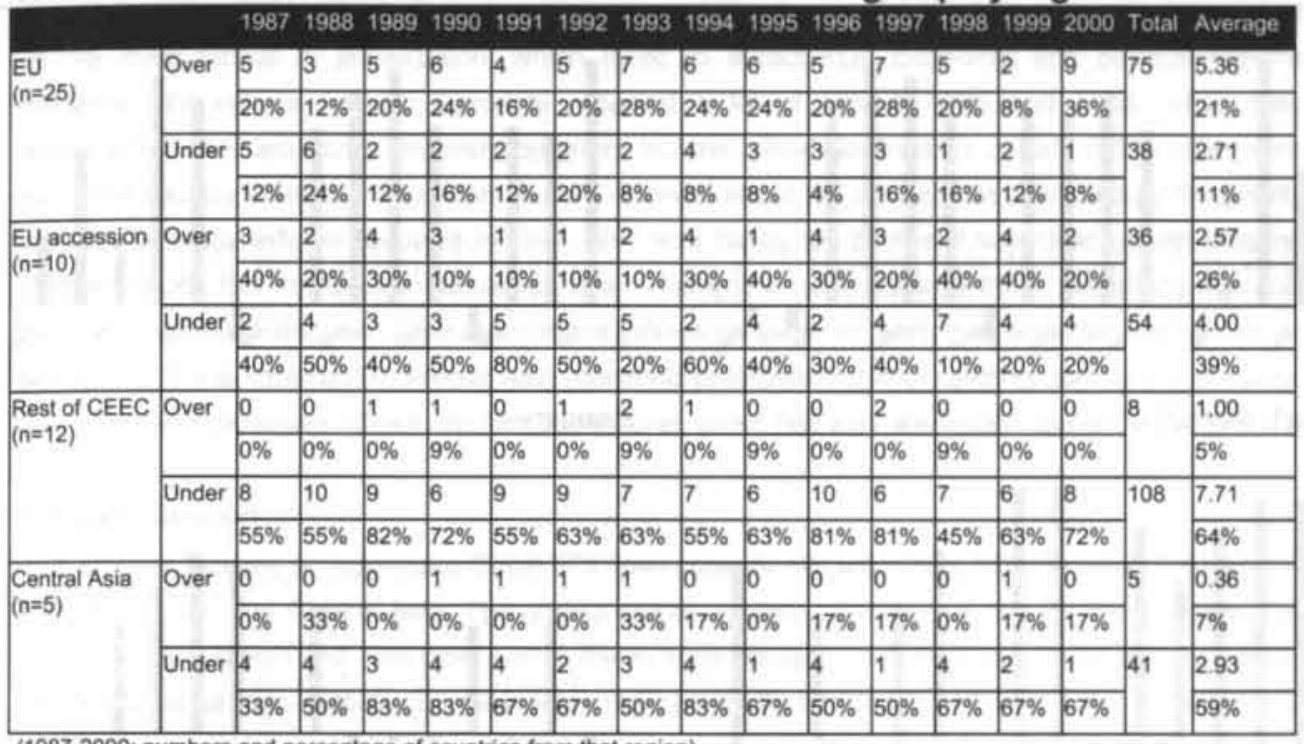

(1987-2000: numbers and percentage of countries from that region)

Studying the inclusion of countries from the region on a yearly basis shows the development of the region as a result of opening up for investment. If Dutch FDI went more often to transition countries than to countries in the rest of the world (catch up effect compared to the world), you would expect these countries to be relatively less often included in the UnderFDI group, and more often in the OverFDI category. The data do not confirm this expectation. There appears to be no time trend, so countries are not moving out of the UnderFDI category or into the OverFDI category in the last years. Table 5.14 includes country specific performance, and represents the actual and predicted FDI for 1987-2000. As expected, and confirmed by the regressions using country dummies, only Hungary and the Czech Republic, clearly have larger actual than predicted FDI. Poland and Romania also have higher actual FDI than predicted in more than half of the years. All countries have large volatility in actual FDI whereas the predicted FDI is stable. This finding is in line with the gravity model theory. The basic gravity model only provides a long run equilibrium level, and short run volatility is not taken into account. For countries reforming so drastically, and only recently allowing FDI, a structural prediction model is not very valuable given that these short run developments are major determinants of FDI and largely overiooked by the basic gravity model. Still some interesting country specific findings are detected. The Czech Republic, Hungary and Poland almost constantly receive more FDI than predicted by the gravity model. Some of the FDI inflows can be directly linked to the countries respective policies. For example the method of privatization is important. Hungary and Poland's main form of privatization of former state owned enterprises were the direct sales, also to foreigners, encouraging FDI inflows. The Czech Republic, and Russia opted for voucher privatization, making direct ownership of foreigners harder to achieve. The flows to the Slovak republic before 1993 are included in the Czech inflows, since the two countries only split in January 1993. 


\section{Table 5.14: Residual analysis CEECs}
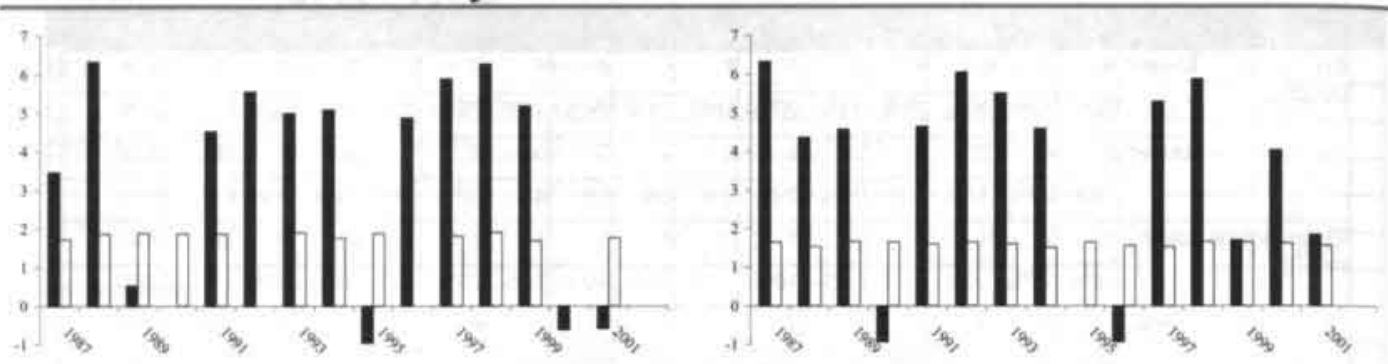

Czech Republic

\section{Hungary}
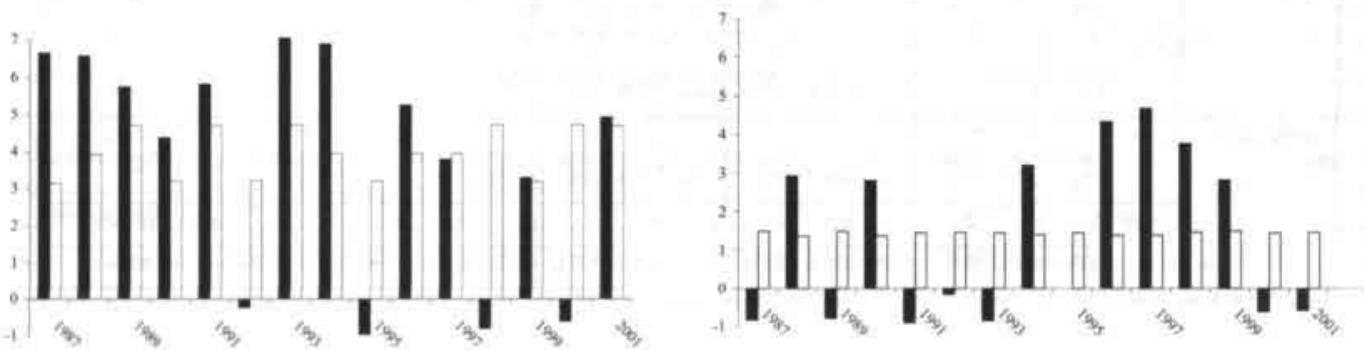

Poland (1)

Romania
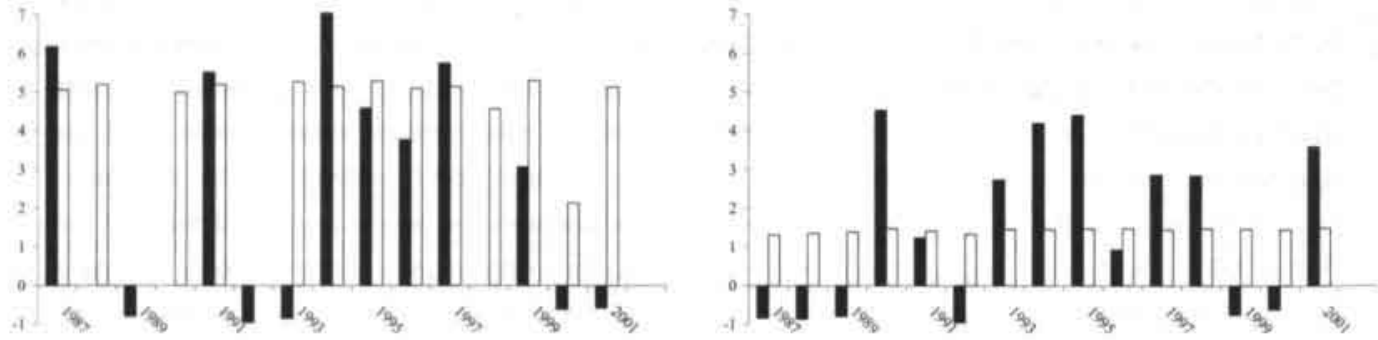

Russia

The Slovak Republic
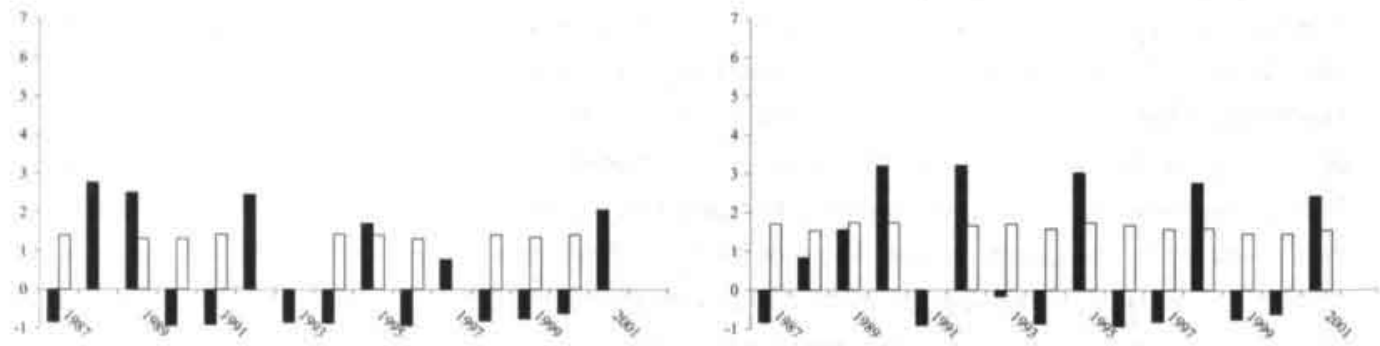

Slovenia

Ukraine

Actual (log of) FDI in black columns, predicted (log of) FDI in white columns (based on basic gravity model)

(1) The reason predicted FDI for Poland is not stable is because of missing values for GDP in 1988, 1994, 1996 and 1997.

Those values were replaced with averages of the previous and next year, not reflecting the actual situation fully correct. 
After 1993, the Slovak Republic opted for direct sales as main form of privatization, allowing for large inflows in 1993 to 1995. Romania, Slovenia and Ukraine used management-employee buyouts as the main format of privatization, which failed to attract FDI. Economic and political reforms influence FDI inflows heavily. Romania received a lot of FDI in 1995 and 1996, when they implemented their economic recovery program, but the inflow declined as quickly in the next years when the country entered a recession. Russia received about the amounts as predicted by the gravity model. The major inflows occurred in 1994-1997 was during the period of economic growth (second Yeltsin period), but the inflows decreased again during the ruble crisis of 1998, remaining low until 2001. In the Slovak Republic a decrease in the inflows occurred in 1998, the period Mr. Meciar was in power. As Prime Minister Mr. Meciar also assumed presidential power, putting democracy at stake. Slovenian and Ukrainian inflows are hard to interpret, given that they are highly volatile.

\subsection{Conclusion}

This chapter focuses on aggregate Dutch FDI flows, specifically explaining FDI inflows to Central and Eastern Europe and Central Asia. The gravity model is taken as the basic tool for the analysis. The methodology followed and data used add to the existing literature in three fields. There are substantial theoretical advantages, new and interesting empirical results and practical implications. Theoretically, the approach adds to the existing research in several ways. First, much can be learned from the basic gravity model when it is interpreted as a long run equilibrium model. The basic gravity variables explain FDI flows to a large extent, and their explanatory power merits the model's inclusion in a study of this kind. However, the basic model fails to incorporate volatility of FDI flows. Thus, the unexplained variance of the basic model should be treated with care, and studying this unexplained variance increases the insight into the nature and pattern of investment flows. Second, a rich and elaborate dataset can enrich the results obtained from a gravity model. Most importantly, erroneous conclusions based on omitted countries or regions (as opposed to omitted variables) can be avoided. Catch up effects of certain countries or regions can only be detected if there are a representative number of countries included to measure the general trend of FDI flows. Similarly, substitution between countries can only be proven if the pool of countries in addition to the countries studied is large enough. Finally, having a large database eliminates the chance of having a sample bias. Most gravity studies use a database including data from developed (OECD) countries as a basis, since those data are most easily accessible, and add data on the region studied. However, selecting countries on availability of the data most often means excluding those countries, which are relatively less developed, and receive lower FDI inflows. As a result, the FDI flows will be upwardly biased, and results derived from those data will be incorrect. By including 207 countries, almost the whole world, in this database and using all of the countries information to estimate the gravity model, this problem is avoided in this chapter. Third, as mentioned already, the basic gravity model is a simple linear regression, including only three explanatory variables. Besides omitting variables, assuming linearity can also be a theoretical drawback of the model. In an attempt to deal with the problem of omitted variables, 60 additional indicators have been added to the basic gravity equation. The study also allows for nonlinearity, by creating dummy variables for countries receiving far more (less) FDI than can be expected based on the basic gravity model, and using those dummy variables to add interaction 
effects. Results show that certain explanatory variables have a relationship with FDI flows that is of a nonlinear nature.

Empirically, the focus of the chapter was to explain the size and pattern of Dutch FDI flows to transition countries. The first result is that there is no evidence of an overall catch-up effect of the region. In general the expectations are that transition countries, after having been closed to FDI for a long period, should be catching up and receiving relatively large FDI inflows. However, the more one controls for the heterogeneity of the transition countries in the data set (through the inclusion of the basic gravity variables, additional variables, and interaction effects), the greater the evidence that there is no such a thing as an overall upward gravity pull for these countries. There is also no reason to assume the flows of Dutch FDI to the EU accession countries will increase in 2004, once the first eight countries join the EU. Currently, those countries have already reached their long run equilibrium level. The rest of the transition countries are still receiving FDI inflows below their long run equilibrium level, but those countries are not affected by EU accession. Thus, also for those countries it is not realistic to expect a more than average increase in FDI inflows in 2004. A careful conclusion that follows also from the literature overview is that past evidence in favor of such an effect is the result of measurement bias. Second, there is no reason to believe in a regional FDI impact. The nature of investments is such that the relative amount of FDI a country receives is mostly dependent on its own characteristics, and far less on the region in which it is situated. The fact that Hungary and the Czech Republic receive large inflows of FDI is not due to the fact that they are situated in Central Europe. For instance the Slovak Republic, also situated in this region, performs less in attracting FDI. Third, in line with what has been found elsewhere, I find some weak evidence of a complementary relation between FDI and trade. Thus, there is no support for the argument that firms first explore the market by exporting, and engage in an FDI later. More likely, companies follow their customer. Dutch firms are exporting goods and services to Dutch companies abroad (increasing the import of the host country), and Dutch companies abroad transport or sell their goods again in the Netherlands (increasing the export of the host country).

These results incorporate some practical implications for transition economies, and business making investment decision. The main lesson learned for transition economies trying to attract FDI is that the own country performance is the main trigger for FDI. Promotion of the country can have some influence, but given that there is no evidence of substitution of FDI between countries, the country will not attract FDI that would have otherwise gone to neighboring countries. In addition there is no specific regional effect. There is a large deviation in country performance within each region, thus the fact that a country is located in a well performing region does not necessarily mean the country is doing well in attracting FDI. Besides size, distance and economic performance, factors like historical ties, religion, accessibility, and country risks influence FDI flows. For example a stable political environment, good institutions and infrastructure are increasing the FDI flows. Free trade is another important factor in increasing FDI, given that trade and FDI are complementary. Opening up for trade increases the FDI flows, and a higher FDI stock in the country again leads to higher trade, both beneficial for the host country. Summarizing for transition countries, not all countries in the EU accession region are doing well in attracting FDI flows. FDI does not follow a stable time pattern, since volatility in flows over the years is high. When I look at individual countries, the Czech Republic 
and Hungary, and to a lesser extent Poland are the star performers in the region when it comes to attracting FDI. A second tier group consists of Romania and the Slovak Republic. There is no evidence that those countries can account for large catch up effects once joining the EU in 2004. The FDI flows to other countries in the region are instable, perhaps reflecting the situation in these countries. However, for those countries, as well as the countries in the rest of Central and Eastern Europe and Central Asia, an increase in FDI flows can be expected within the near future. 



\section{Annex 5.1 Added variables to the basic gravity model}

Table A5.1: Added variables to the basic gravity model

\begin{tabular}{|c|c|c|c|}
\hline Variable name & Included in analyses as: & Measurement Unit & Database \\
\hline Foreign Direct Investment & Ln FDI & $\begin{array}{l}\text { Yearly FDI flows } \\
\text { FDI in millions of USD (3) }\end{array}$ & DNB Data \\
\hline GDP & - $n$ GDP & GDP in millions of USD & WDI 2001 \\
\hline Population & - $n$ Population & Population in millions & WDI 2001 \\
\hline Distance & In Distance & Distance in $\mathrm{Km}$ & $\begin{array}{l}\text { Distance } \\
\text { calculator }\end{array}$ \\
\hline Time & Time & $\begin{array}{l}1987-2001 \\
1987=1,1988=2 \quad \ldots .2001=15\end{array}$ & \\
\hline Regional dummy & $\begin{array}{l}\text { Europe baseline (1) } \\
\text { Africa } \\
\text { Asia } \\
\text { Central America } \\
\text { EUAccession = } 10 \text { EU accession } \\
\text { countries } \\
\text { Rest of CEEC = Central and Eastern } \\
\text { European countries not entering EU } \\
\text { Central Asia } \\
\text { Middle East } \\
\text { South America } \\
\text { North America } \\
\text { South East Asia } \\
\text { Rest of World = Rest of the world (4) }\end{array}$ & $\begin{array}{l}\text { Dummy variable: } \\
\text { One if located in region, zero } \\
\text { otherwise }\end{array}$ & CIA factbook \\
\hline FDI stock in 87 & Not included & FDI in miltion USD & DNB Data \\
\hline Land area & In Land area & Number of square kilometers & WDI 2001 \\
\hline Religion dummy & $\begin{array}{l}\text { Christianity baseline } \\
\text { Muslim } \\
\text { Orthodox } \\
\text { Buddhism } \\
\text { Mixture } \\
\text { Other (5) }\end{array}$ & $\begin{array}{l}\text { Dummy variable: } \\
\text { One if majority of the country has that } \\
\text { religion, zero otherwise }\end{array}$ & CIA factbook \\
\hline Highways & Ln Highway & Highways in km & CIA factbook \\
\hline Infrastructure & Ln (land area/highways) & Land area in $\mathrm{km}^{2}$, highways in $\mathrm{km}$. & $\begin{array}{l}\text { WDI } 2001 \text { and } \\
\text { CIA factbook }\end{array}$ \\
\hline Railways & Not included & Passenger-km per year & CIA factbook \\
\hline Roads & Not included & $\begin{array}{l}\text { Total network of paved roads excl. } \\
\text { highways in } \mathrm{km}\end{array}$ & WDI 2001 \\
\hline Final consumption expenditure & Not included & Million current USD & WDI 2001 \\
\hline Gross domestic savings & Not included & Million current USD & WDi 2001 \\
\hline $\begin{array}{l}\text { Household final consumption } \\
\text { expenditure }\end{array}$ & Not included & Million current USD & WDI 2001 \\
\hline Net income from abroad & Not included & Miltion current US\$ & WDi 2001 \\
\hline Age dependency ratio & Not included & $\begin{array}{l}\text { Ratio of dependents to working-age } \\
\text { population }\end{array}$ & WDI 2001 \\
\hline Agriculture share & Not included & $\begin{array}{l}\text { Value added of agriculture as } \\
\text { percentage of GDP }\end{array}$ & WDI 2001 \\
\hline Agriculture & In Agriculture & $\begin{array}{l}\text { Value added of agriculture in million } \\
\text { current USD }\end{array}$ & WDI 2001 \\
\hline Industrial share & Not included & $\begin{array}{l}\text { Value added of industry as } \\
\text { percentage of GDP }\end{array}$ & WDI 2001 \\
\hline Industry & In Industry & $\begin{array}{l}\text { Value added of industry in million } \\
\text { current USD }\end{array}$ & WDI 2001 \\
\hline Services share & Not included & $\begin{array}{l}\text { Value added of services as } \\
\text { percentage of GDP }\end{array}$ & WDI 2001 \\
\hline Services & In Services & $\begin{array}{l}\text { Value added of services in million } \\
\text { current USD }\end{array}$ & WDI 2001 \\
\hline Aid per capita & Not included & Million current USD & WDI 2001 \\
\hline $\begin{array}{l}\text { Domestic credit provided by } \\
\text { banking sector }\end{array}$ & Not included & Percent of GDP & WDI 2001 \\
\hline
\end{tabular}




\begin{tabular}{|c|c|c|c|}
\hline $\begin{array}{l}\text { Domestic credit to private } \\
\text { sector }\end{array}$ & Not included & Percent of GDP & WDI 2001 \\
\hline Gross capital formation & Not included & Percent of GDP & WDI 2001 \\
\hline Gross capital formation & Not included & Million current USD & WDI 2001 \\
\hline Gross fixed capital formation & Not included & Percent of GDP & WDI 2001 \\
\hline Gross fixed capital formation & Not included & Million current USD & WDI 2001 \\
\hline Gross private capital flows & Not included & Percent of GDP & WDI 2001 \\
\hline $\begin{array}{l}\text { Official development assistance } \\
\text { and official aid }\end{array}$ & Not included & Million current USD & WDI 2001 \\
\hline Financing from abroad & Not included & Percent of GDP & WDI 2001 \\
\hline Private fixed investment & Not included & $\begin{array}{l}\text { Percent of gross domestic fixed } \\
\text { investment }\end{array}$ & WDI 2001 \\
\hline Consumer price index & Not included & Index: $1995=100$ & WDI 2001 \\
\hline Inflation, consumer prices & Not included & $\begin{array}{l}\text { Annual percent increase of consumer } \\
\text { prices }\end{array}$ & WDI 2001 \\
\hline Inflation, GDP deflator & Not included & $\begin{array}{l}\text { Annual percent increase of GDP } \\
\text { deflator }\end{array}$ & WDI 2001 \\
\hline Official exchange rate & In Exchange rate & $\begin{array}{l}\text { Local Currency Unit per USD } \\
\text { Period average }\end{array}$ & WDI 2001 \\
\hline $\begin{array}{l}\text { PPP conversion factor to official } \\
\text { exchange rate ratio }\end{array}$ & Not included & Insignificant & WDI 2001 \\
\hline Unemployment & Not included & Percent of total labor force & WDI 2001 \\
\hline GDP deflator & Not included & Index, base year varies by country & WDI 2001 \\
\hline Labor force & In Labor Force & Labor force total in million & WDI 2001 \\
\hline Net taxes on products & Not included & Current USD & WDI 2001 \\
\hline Goods export & In Export of goods & $\begin{array}{l}\text { Exports by host country in million } \\
\text { USD }\end{array}$ & IFS statistics \\
\hline Goods import & Ln Import of goods & $\begin{array}{l}\text { Imports by host country in million } \\
\text { USD }\end{array}$ & IFS statistics \\
\hline Services export & In Export of services & Services credit in million USD & FS statistics \\
\hline Services Import & Ln import of services & Services debit in million USD & IFS statistics \\
\hline Income credit & Ln outflow of income & Income credit in million USD & IFS statistics \\
\hline Income debit & Ln inflow of income & Income debit in million USD & FS statistics \\
\hline Transactions credit & In outflow of transactions & Current transfers credit in million USD & IFS statistics \\
\hline Transactions debit & Ln inflow of transactions & Current transfers debit in million USD & FS statistics \\
\hline Capital Account credit & In outflow of capital & $\begin{array}{l}\text { Capital account credit, not including } \\
\text { exceptions, in million USD }\end{array}$ & FS statistics \\
\hline Capital Account debit & In inflow of capital & $\begin{array}{l}\text { Capital account debit, not including } \\
\text { exceptions, in million USD }\end{array}$ & IFS statistics \\
\hline Capital Account balance & Not included & $\begin{array}{l}\text { Not included since capital account } \\
\text { debit and credit included separately }\end{array}$ & IFS statistics \\
\hline Trade as percentage of GDP & Not included & (Trade/GDP)*100percent & IFS statistics \\
\hline Country risk indicator & In country risk & $\begin{array}{l}\text { Country risk score between } 0 \text { and } 10, \\
0 \text { is risky, } 10 \text { is riskless }\end{array}$ & Euromoney \\
\hline Political risk indicator & Ln political risk & $\begin{array}{l}\text { Political risk score between } 0 \text { and } 10 \\
0 \text { is risky, } 10 \text { is riskless }\end{array}$ & Euromoney \\
\hline Economic risk indicator & In economic risk & $\begin{array}{l}\text { Economic risk score between } 0 \text { and } \\
10,0 \text { is risky, } 10 \text { is riskless }\end{array}$ & Euromoney \\
\hline Lagged FDI & In Lagged FDI & FDI lagged with one year & DNB \\
\hline Lagged GDP & Not included & $\begin{array}{l}\text { GDP lagged with one year } \\
\text { See note (2) }\end{array}$ & WDI \\
\hline
\end{tabular}

DNB data: De Nederlandsche Bank balance of payment data 2002

WDI 2001: World Development Indicators 2001

IFS statistics: International Financial Statistics

CIA factbook: Central Intelligence Agency data 2002

Distance calculator: Internet site http $/ / \mathrm{hw} w$.indo.com/distance/

Euromoney: Euromoney indicators - Internet site unw. euromoney com

Note (1): A categorical variable for continents was highly significant. However, since the purpose of the chapter is to explain the enormous effect of geographical position with underlying factors, these high coefficients should be interpreted as confirmation that geography may have undertying reasons, and the size of the coefficients only validates our research question. 
Note (2): Ln (Lagged GDP) was also significantly different from zero, but when included the coefficient of InGDP was decreased by the size of the coefficient of the lagged GDP. The total effect of GDP remained the same, the addition of lagged GDP only created a shift in the coefficients. I therefore decided not to include it in the regression.

Note (3): In the Dutch Central Bank data the division between missing data and a flow of 0 has been identified. Missing data are indeed missing in the original dataset and a flow of 0 in the dataset means a flow between 0 and 1.000 .000 euro. Missing observations are dropped from our dataset and values of zero FDI were replaced with the average value of 500.000 euro.

Note (4): Rest of the word includes Antarctic, Arctic and Oceania

Note (5): Dominant religion $>75 \%$ of the country, Mixture: more religions with $25-50 \%$ followers in one country, other includes dominantly Jewish, Hinduism, Indigenous and Atheist countries

All variables in the table were added to the gravity regression per variable to see whether their influence on FDI is significant. Most factors were significant, though the fit of the complete regression hardly improved. The insignificant variables were dropped from the dataset. The remaining variables are included per category and jointly in the gravity equation.

As a control test, I performed two stepwise regressions, one in which I started with the basic gravity model and added all variables that were five percent significant (forward inclusion, starting with variable with lowest p) and one in which I started with the complete regression and eliminated all variables that were not significant at five percent level (starting with the variable with highest $p$ ). These tests showed that in order to explain FDI the gravity model in itself is fairly accurate and only few additional variables increase the fit and significantly influence FDI. Those are the variables export/import of goods, income debit and credit, land area and highways. These results clearly coincide with the existing literature, where the effect of additional variables is also limited. As a result of this selection process, I include: Continent, Religion, Infrastructure (combining land area and highways), Sector division as percentage of GDP, Inflation, Total Labor Force, Balance of Payment data, Risk indicators and Lagged FDI in the regression discussed in the chapter. 



\section{Annex 5.2 Countries included in the analysis}

\begin{tabular}{|c|c|c|c|c|c|c|c|c|c|}
\hline 1 & Afghanistan & 43 & Comoros & 85 & Iceland & 127 & Moldova & 169 & Solomon Islands \\
\hline 2 & Albania & 44 & \begin{tabular}{|l|} 
Congo, Dem. \\
Rep. \\
\end{tabular} & 86 & India & 128 & Monaco & 170 & Somalia \\
\hline 3 & Algeria & 45 & \begin{tabular}{|l} 
Congo, Rep. \\
\end{tabular} & 87 & Indonesia & 129 & Mongolia & 171 & South Africa \\
\hline 4 & American Samoa & 46 & \begin{tabular}{|l} 
Costa Rica \\
\end{tabular} & 88 & Iran, Islamic Rep. & 130 & Morocco & 172 & Spain \\
\hline$\frac{7}{5}$ & Andorma & 47 & Cotc d'Ivoire & 89 & Irag & 131 & Mozambique & 173 & Sri Lanka \\
\hline 6 & Angola & 48 & Croatia & 90 & Ireland & 132 & Myanmar & 174 & St. Kitts and Nevis \\
\hline 7 & $\begin{array}{l}\text { Antigua and } \\
\text { Barbuda }\end{array}$ & 49 & Cuba & 91 & Isle of Man & 133 & Namibia & 175 & St. Lucia \\
\hline 8 & Argentina & 50 & Cyprus & 92 & Israel & 134 & Nepal & 176 & $\begin{array}{l}\text { St. Vincent and the } \\
\text { Grenadines }\end{array}$ \\
\hline 9 & Armenia & 51 & \begin{tabular}{|l|} 
Czech \\
Republic \\
\end{tabular} & 93 & Italy & 135 & Netheriands & 177 & Sudan \\
\hline 10 & Aruba & 52 & Denmark & 94 & Jamaica & 136 & \begin{tabular}{|l|} 
Netherlands \\
Antilles \\
\end{tabular} & 178 & Suriname \\
\hline 11 & Australia & 53 & Dibouti & 95 & Japan & 137 & New Caledonia & 179 & Swaziland \\
\hline 12 & Austria & 54 & Dominica & 96 & Jordan & 138 & New Zealand & 180 & Sweden \\
\hline 13 & Azerbajian & 55 & $\begin{array}{l}\text { Dominican } \\
\text { Republic }\end{array}$ & 97 & Kazakhstan & 139 & Nicaragua & 181 & Switzerland \\
\hline 14 & Bahamas, The & 56 & Ecuador & 98 & Kenya & 140 & \begin{tabular}{|l} 
Niger \\
\end{tabular} & 182 & Syrian Arab Republic \\
\hline 15 & Bahrain & 57 & $\begin{array}{l}\text { Egypt, Arab } \\
\text { Rep. }\end{array}$ & 99 & Kiribati & $14 \mid$ & Nigeria & 183 & Tajikistan \\
\hline 16 & Bangladesh & 58 & El Salvador & 100 & Korea, Dem. Rep. & 142 & $\begin{array}{l}\begin{array}{l}\text { Northem Mariana } \\
\text { Islands }\end{array} \\
\end{array}$ & 184 & Tanzania \\
\hline 17 & Barbados & 59 & $\begin{array}{l}\text { Equatorial } \\
\text { Guinea }\end{array}$ & 101 & Korea, Rep. & 143 & Norway & 185 & Thailand \\
\hline 18 & Belarus & 60 & \begin{tabular}{|l} 
Eritrea \\
\end{tabular} & 102 & Kuwait & 144 & Oman & 186 & Togo \\
\hline 19 & Belgium & 61 & \begin{tabular}{|l} 
Estonia \\
\end{tabular} & 103 & Kyrgyz Republic & 145 & \begin{tabular}{|l} 
Pakistan \\
\end{tabular} & 187 & Tonga \\
\hline 20 & Belize & 62 & Ethiopia & 104 & Lao PDR & 146 & Palau & 188 & Trinidad and Tobago \\
\hline 21 & Benin & 63 & \begin{tabular}{|l} 
Faeroe Islands \\
\end{tabular} & 105 & Latvia & 147 & Panama & 189 & Tunisia \\
\hline 22 & Bermuda & 64 & Fiji & 106 & Lebanon & 148 & $\begin{array}{l}\text { Papua New } \\
\text { Guinea }\end{array}$ & 190 & Turkey \\
\hline 23 & Bhutan & 65 & Finland & 107 & Lesotho & 149 & Paraguay & 191 & Turkmenistan \\
\hline 24 & Bolivia & 66 & France & 108 & Liberia & 150 & Peru & 192 & Uganda \\
\hline 25 & $\begin{array}{l}\text { Bosnia and } \\
\text { Herzegovina }\end{array}$ & 67 & \begin{tabular}{|l|} 
French \\
Polynesia \\
\end{tabular} & 109 & Libya & $|5|$ & Philippines & 193 & Ukraine \\
\hline 26 & Botswana & 68 & \begin{tabular}{|l} 
Gabon \\
\end{tabular} & 110 & Liechtenstein & 152 & Poland & 194 & United Arab Emirates \\
\hline 27 & Brazil & 69 & Gambia, The & 111 & Lithuania & 153 & Portugal & 195 & United Kingdom \\
\hline 28 & Brunei & 70 & Georgia & 112 & Luxembourg & 154 & Puerto Rico & 196 & United States \\
\hline 29 & Bulgaria & 71 & Germany & 113 & Macao, China & 155 & Qatar & 197 & \begin{tabular}{|l} 
Uruguay \\
\end{tabular} \\
\hline 30 & \begin{tabular}{|l} 
Burkina Faso \\
\end{tabular} & 72 & \begin{tabular}{|l} 
Ghana \\
\end{tabular} & 114 & Macedonia, FYR & 156 & Romania & 198 & Uzbekistan \\
\hline 31 & Burundi & 73 & Greece & 115 & Madagascar & 157 & $\begin{array}{l}\text { Russian } \\
\text { Federation }\end{array}$ & 199 & Vanuatu \\
\hline 32 & Cambodia & 74 & Greenland & 116 & Malawi & 158 & Rwanda & 200 & Venezuela, RB \\
\hline 33 & Cameroon & 75 & Grenada & 117 & Malaysia & 159 & Samoa & 201 & Vietnam \\
\hline 34 & Canada & 76 & Guam & 118 & Maldives & 160 & \begin{tabular}{|l|} 
San Marino \\
\end{tabular} & 202 & Virgin Islands (U.S.) \\
\hline 35 & Cape Verde & 77 & Guatemala & 119 & Mali & 161 & $\begin{array}{l}\text { Sao Tome and } \\
\text { Principe }\end{array}$ & 203 & West Bank and Gaza \\
\hline 36 & Cayman Islands & 78 & Guinca & 120 & Malta & 162 & Saudi Arabia & 204 & Yemen, Rep. \\
\hline 37 & $\begin{array}{l}\text { Central African } \\
\text { Republic } \\
\end{array}$ & 79 & Guinca-Bissau & 121 & Marshall Islands & 163 & Senegal & 205 & Yugoslavia, Fed. Rep. \\
\hline 38 & Chad & 80 & \begin{tabular}{|l} 
Guyana \\
\end{tabular} & 122 & Mauritania & 164 & Seychelles & 206 & Zambia \\
\hline 39 & Channel Islands & 81 & Haiti & 123 & Mauritius & 165 & Sierra Leone & 207 & Zimbabwe \\
\hline 40 & \begin{tabular}{|l} 
Chile \\
\end{tabular} & 82 & Honduras & 124 & Mayotle & 166 & Singapore & & \\
\hline 41 & China & 83 & $\begin{array}{l}\text { Hong Kong. } \\
\text { China }\end{array}$ & 125 & Mexico & 167 & Slovak Republic & & \\
\hline 42 & Colombia & 84 & Hungary & 126 & $\begin{array}{l}\text { Micronesia, Fed. } \\
\text { Sts. }\end{array}$ & 168 & Slovenia & & \\
\hline
\end{tabular}





\section{Chapter 6 Integrating emotions and intuition in FDI decision- making}

"The people went about their business looking uncompromisingly stern, and the atmosphere, though not hostile, was hardly one of geniality. A privileged few sat outside cafes sipping coffee and basking in the winter sun, but laughter and frivolity was not the order of the day. I guess that the years spending living under an oppressive regime with its institutionalised system of secret police and informers had left the population favouring a cautious approach to any public display of emotions. Not here the heated street-corner debates of Southern Europe with raised voices and animated gesticulations, but instead a measured, deadpan exchange of the required information. No frills."

(Tony Hawks (2000), Playing the Moldovans at Tennis)

\subsection{Introduction}

The previous chapters of this dissertation were based on concepts of economic rationality.' In chapter two the option theory was described as an investment decision theory. Based on the assumptions of the option theory, firms chose the best investment alternative by estimating the expected values of alternative investment options. By doing so, firms allow for uncertainty and take irreversible set-up costs into account. In chapter four, the assumption that there is full information was relaxed and the costs and benefits of obtaining information were introduced. Collecting information has certain costs, but the benefits are that it reduces uncertainty surrounding the investment decision. Firms collect information as long as the benefits of the information exceed the costs of collecting. Still firms decide whether to invest in an FDI based on expected Net Present Value information only.

Several results from the survey among Dutch firms considering an investment in Central or Eastern Europe, or Central Asia (the CEE region) are hard to interpret using these theories, since the theories only focus on the objective decision rules and ignore the influence of the subjective decision-maker. The focus of this chapter is therefore on the decision-maker and his or her influence on the investment decision. ${ }^{2}$ In section 6.2 of this chapter the survey data are discussed, specifically the questions that asked for individual influence or personal aspects of the decision-maker. Such personal influence is difficult to interpret using standard economic theories and hard to integrate in expected NPV calculations.

In section 6.3 the findings of section 6.2 are interpreted using the concept of bounded rationality. Bounded rationality refers to the fact that firms do not attempt to search for all investment possibilities but choose a for all parties satisficing solution. Behavioral economics takes this as a starting point and extend economic theory based on empirical tests. Several theories add to our understanding of investment decision in the light of the survey results, like network theories, learning/experience

\footnotetext{
'In fact basic economic theory requires three sets of assumptions to hold:

- Limited and given resources, given tastes/preferences and technology.

- Pure economic goods, perfect information and perfect competition.

- Absence of value judgments.

"Ideas and concepts included in this chapter are in part based on the article "Emotions and Foreign Direct investment: a theoretical and empirical exploration" by M. van de Laar and C. de Neubourg (2004).
} 
theories and the limitation of cognition.

However, also with bounded rationality the influence of the decision-maker is ignored, even though there is consensus among psychologists and economists that each individual behaves differently in an investment decision-making process. It is important to consider the differences of decision-makers on an investment decision. Interesting questions are for instance to what extent the different personal aspects influence the final decision, how individuals interpret the information, how they value the final decision and how confident they feel about an investment. In section 6.4 the impact of the decisionmaker on an investment choice is stressed using the concepts of emotion and intuition. Emotions are defined as multifaceted processes that unfold over time and cannot be directed or prevented. People experience emotions and lack tools to resist them. An example is anger. Imagine a businessman that started a firm in Poland in the early 1990s, whose firm went bankrupt due to malicious practices of the Polish business partner. It is very likely that the businessman feels angry when thinking about an investment in Poland and that this negative emotion will inevitably influence an investment decision with respect to a new investment in Poland. Another example is sudden collective eagerness to invest in a certain region. History learns that sometimes a country or region becomes "hot", without economic trends that can explain an increased interest from investors. FDI flows are based on not much more than positive expectations, as if companies blindly follow their fellow investors and fail to analyze the investment climate objectively. This happened for instance in Russia in the mid-1990s.'

Intuition is defined as thoughts that are reached with little apparent effort and typically without conscious awareness. They involve little or no conscious deliberation. A businessman can intuitively think an investment in Russia is a good idea, without making an analysis to back up this intuitive judgment. Intuition can be a good or bad tool in decision-making, but either way it is likely to influence the opinion of the decision-maker.

In section 6.5 a framework is given regarding how to integrate the rationally based economic theories, concept of bounded rationality and emotions and intuition in one decision-making process. Section 6.6 summarizes the difficulties with the inclusion of emotions and intuition in economic models. These difficulties range from defining emotions and intuition, measuring them and including them in a model. Section 6.7 concludes.

\subsection{Survey results}

\subsubsection{The survey data}

During the preparation of the survey on FDI decisions of Dutch firms the informed observer approach was followed. In the interviews we asked decision-makers to comment on the research questions and draft questionnaire. Several interesting facts became apparent with respect to firms' investment decisions. Firms were not only considering profit expectations when deciding to invest but often had very personal motivations for investment. Many decision-makers indicated in the interviews that they initially had noneconomic motivations for the choice of country in which to invest. Examples are a firm that invested in Hungary because the manager had participated in an exchange programme in Budapest during his study. He enjoyed living in Budapest and became aware of the growing market economy and the possibilities for him to set up a business there. Another example is a Bulgarian

\footnotetext{
${ }^{3} \mathrm{FDI}$ and other investments and loans were flowing to Russia in enormous amounts, without the proper economic improvements to support these investments. Similar inflows occured in Asia at the same time. In 1997 both the Asia crisis set in and the Russian bubble bursted (EBRD (1998).
} 
entrepreneur that lived in the Netherlands for decades. After Bulgaria opened its borders to trade and foreign investments, he considered investing in Bulgaria. The firms in the previous examples did not consider several alternative host countries, but only looked at the possibilities to invest in one specific country. Another firm that participated in the interviews was invited by a foreign business partner to take over the business in Moldova. This Dutch firm did not consider any other alternative that could be more profitable but solely focused on the one business in which to invest. The last example is the owner of a firm that set up foreign affiliates in Romania with the purpose of training local people to run the business profitably. Once the location was operating self-sufficiently, the Dutch owner sold the firm to the local management. The incentive to invest was purely altruistic; the Dutch firm was breaking even at best but still invested with the purpose of assisting in the development of the sector and training local managers.

Based on these conversations I included some questions in the questionnaire that could give some insight in the importance these kind of "personal" factors of the decision-maker in the decision-making process. I like to stress that in most cases the presence of personal factors does not mean that the decision to invest is not based on making profits. With exception of the last example, all the firms I spoke with intended to make a profit and the fact that they relied on these kinds of personal factors did not mean that they did not sufficiently evaluate whether the expected NPV was positive as well. However, the personal motivations made them consider only one specific investment possibility. disregarding other possibly more profitable alternatives.

The survey was held among Dutch firms that were interested in investing in the CEE region. The survey had a response rate of 23.4 percent. The analysis in Annex A indicated there was a nonresponse bias in favor of larger, older firms and firms with an investment in the CEE region. In order to take these nonresponse biases into account, the analysis of the data was done with and without correction weights for nonresponse bias. In the regular analysis the data were taken with each observation weighted as one. For the weighted analysis a probability is calculated for each respondent that a firm with certain characteristics would answer the survey. The data were weighted using the inverse probability of response, thus taking the nonresponse bias into account. ${ }^{.}$The results of the weighted analysis do not significantly differ from the unweighted regressions; therefore only the unweighted results are included in this analysis.

As in any survey, the data are subjective. Firms are asked to answer the questions to their best knowledge and their answers are treated as reliable information. Still, interpretation of the question can differ over respondents and recollection of certain events can be distorted given the time that elapsed since the event occurred and the questionnaire was filled out. Therefore, in this chapter the results of the survey are treated as "facts", but the results derived from the analysis should be interpreted with care.

\footnotetext{
${ }_{3}^{4}$ Characteristics used are sector, size and age of the firm.

${ }^{3}$ For example, the chance that a large industrial firm responds to the survey is 0.2 , or 20 percent. In the unweighted analysis the answers of this firm were included with a weight of one. In the weighted analysis, the answers were valued with a factor of $1 / 0.2$, thus with a weight of five.
} 


\section{Box 6.1: Questions from the survey}

21. Did you make any investment analysis to estimate the possibility of success of the investment?

(only 1 answer possible)

[] Yes, only for the country of the $1^{\text {st }}$ investment

2 [] Yes, for the country of our $1^{\text {st }}$ investment and multiple other countries

3 [] No, no calculation was made. The company chose for the country of our $1^{\text {st }}$ investment because:

22. What were the 4 most important actions during your decision-making process, in chronological order (for instance first the choice of a country, afterwards the search for an appropriate local partner). (please enter in each box an action of your investment decision-making progress, in chronological order)

1.
3.
4.

23. Which one of the following aspects was a specific reason for your company to make the investment analysis for the country of your $1^{\text {st }}$ investment?

(multiple answers possible)

1 There was already a trade relation with one or more companies in that country

2 [] There was a good contact person to work with in that country

3 [] Other companies in that sector achieved good results in that country

4 [ The owner or employees of the Dutch firm are from that country

5 [] Your partner or direct family members are from the country of your $1^{\text {st }}$ investment

6 [] Friends or acquaintances are from the country of your $1^{\text {st }}$ investment

7 [] The owner or employees of the Dutch firm were willing to work in the country of your $1^{\text {st }}$ investmen

8 [] Your partner or direct family was willing to work in the country of your $1^{\text {st }}$ investment

9 [ $]$ Friends or acquaintances were willing to work in the country of your $1^{\text {st }}$ investment

10 [] Language knowledge of the country of your $1^{\text {st }}$ investment in the Dutch firm available

11 [] Positive personal experiences in the country of your $1^{\text {st }}$ investment, for instance because of travel experiences

12 - Other, namely: 


\subsubsection{Interesting findings during the analysis of the data}

Following the standard rational economic theory, as for instance the option theory is (chapter two). economic actors maximize their utility or profit given stable tastes and preferences and full information. Translated to the investment decision, firms invest in the country that provides them with the highest expected profit. A general assumption is that firms base their investment decision on an investment analysis, in which they consider and evaluate the available information of the investment alternatives. The concept of an investment analysis is vague, since this analysis is different for all respondents. Some firms collect all kinds of economic information, insert this information in complicated, possibly computerized systems that analyze and compare several country alternatives. Other firms, for instance, only consider three main aspects of each investment alternative and base their choice on those aspects. Still, rational economic theory assumes that firms consider the information available while making an investment decision. As previously mentioned, during the preparation of the survey it became obvious that many firms were not only influenced by economic motivations when making an investment decision, but also relied on "personal motivations". One firm invested in Moldova without considering any other alternatives because the entrepreneur married a Moldovan woman. The company was still not structurally profitable after several years in operation, but on average broke even. This was sufficiently satisfying for the entrepreneur, since it gave him the opportunity to live in Moldova. In this specific case, it was not important whether the firm would have been more profitable in another country, since the entrepreneur did not choose its location for economic reasons, but for personal reasons. Any other country was not interesting to him.

The survey included several questions that shed light on the "personal motivations" entrepreneurs have when making an investment decision, as well as the frequency at which these factors influence the decision. First, question 21 asked firms if they made an investment analysis. Firms were free to define for themselves what they considered an analysis and were asked to mention if they made it for one or several countries. 59 percent of the firms did not make any investment analysis. For noninvestors this percentage was higher ( 75 percent) than for the investors ( 28 percent). ${ }^{6}$ The large percentage of noninvestors not making an analysis was partly the result of the 168 firms that indicated they did not even consider an FDI in the CEE region, either because they were not interested in an FDI or because they were not interested in investing in the CEE region (see also figure 4.1 in chapter four). When adjusted to response probability using sample weights, the difference between investors and noninvestors remained remarkable, thought the percentages of firms not making an investment analysis was decreased percentage wise. The most mentioned reasons why firms did not make any investment calculation were:

- They were not interested in an FDI in general.

- They were not interested in an investment in the CEE region specifically.

- They already had personal relations with individuals in the respective country.

- They received an invitation of a business partner in the host country, requesting the firm to invest in their company or to extend existing business relations.

- Investing was a logical result after opening of the market and with growth of the market.

- The country was the only investment possibility due to availability of certain natural resources.

\footnotetext{
"Investors are firms that at the time of the survey had an FDI in the CEE region. Noninvestors are those firms that were interested in the CEE region, but decided not to invest.
} 
Table 6.1: The most important steps of decision-making

\begin{tabular}{|c|c|c|c|c|c|c|}
\hline & $\begin{array}{l}\text { Number } \\
(n=58)\end{array}$ & $\begin{array}{l}\text { Percentage of } \\
\text { investors }\end{array}$ & $\begin{array}{l}\text { Percentage } \\
\text { of investors } \\
\text { choice } \\
\text { options } \\
\text { (322 choice } \\
\text { options) }\end{array}$ & $\begin{array}{l}\text { Number } \\
(n=36)\end{array}$ & $\begin{array}{l}\text { Percentage of } \\
\text { noninvestors }\end{array}$ & $\begin{array}{l}\text { Percentage of } \\
\text { noninvestor } \\
\text { choice options } \\
\text { (144 choice } \\
\text { options) }\end{array}$ \\
\hline Choice countryfocation & 36 & $62 \%$ & $16 \%$ & 14 & $39 \%$ & $10 \%$ \\
\hline Market analysis & 23 & $40 \%$ & $10 \%$ & 15 & $42 \%$ & $10 \%$ \\
\hline Choice partner & 13 & $22 \%$ & $6 \%$ & 15 & $42 \%$ & $10 \%$ \\
\hline Become operational & 12 & $21 \%$ & $5 \%$ & 2 & $6 \%$ & $1 \%$ \\
\hline Company analysis & 10 & $17 \%$ & $4 \%$ & 15 & $42 \%$ & $10 \%$ \\
\hline Availability employees & 10 & $17 \%$ & $4 \%$ & 2 & $6 \%$ & $1 \%$ \\
\hline $\begin{array}{l}\text { Previous business } \\
\text { relations }\end{array}$ & 9 & $16 \%$ & $4 \%$ & 2 & $6 \%$ & $1 \%$ \\
\hline Personal motivations & 7 & $12 \%$ & $3 \%$ & 0 & $0 \%$ & $0 \%$ \\
\hline $\begin{array}{l}\text { Set up legal structure } \\
\text { company }\end{array}$ & 7 & $12 \%$ & $3 \%$ & 0 & $0 \%$ & $0 \%$ \\
\hline Other & 6 & $10 \%$ & $3 \%$ & 6 & $17 \%$ & $4 \%$ \\
\hline Contacts & 5 & $9 \%$ & $2 \%$ & 8 & $22 \%$ & $6 \%$ \\
\hline Visit country & 5 & $9 \%$ & $2 \%$ & 1 & $3 \%$ & $1 \%$ \\
\hline Demand from CEEC & 4 & $7 \%$ & $2 \%$ & 3 & $8 \%$ & $2 \%$ \\
\hline $\begin{array}{l}\text { Choice mode set up } \\
\text { company }\end{array}$ & 4 & $7 \%$ & $2 \%$ & 1 & $3 \%$ & $1 \%$ \\
\hline Preparation NL. & 3 & $5 \%$ & $1 \%$ & 4 & $11 \%$ & $3 \%$ \\
\hline Experience & 2 & $3 \%$ & $1 \%$ & 3 & $8 \%$ & $2 \%$ \\
\hline Natural resources & 2 & $3 \%$ & $1 \%$ & 2 & $6 \%$ & $1 \%$ \\
\hline Negotiation phase & 2 & $3 \%$ & $1 \%$ & 1 & $3 \%$ & $1 \%$ \\
\hline Costs & 2 & $3 \%$ & $1 \%$ & 0 & $0 \%$ & $0 \%$ \\
\hline Media & 1 & $2 \%$ & $0 \%$ & 4 & $11 \%$ & $3 \%$ \\
\hline
\end{tabular}

Source: Survey Dutch Direct Investment in CEEC and FSU, Maastricht University, 2000.

From this question it became evident that many firms do not use investment analysis as a tool for decision-making. They have other motivations for investing and know without further research whether they want to invest.

The second question, number 23 in box 6.1, was an open question. The participating companies that made an investment analysis specified the four most important actions/steps during their decision-making process. Given that the question was an open question, it led to a large variety of answers (see table 6.1). The first column of the investors and noninvestors contains the percentages per group. For example, nine percent of the investors mentioned that contacts in the region were an important factor in their decision.

The second column of the investors and noninvestors compare the results per answer option. Each firm had four answer possibilities, leading to 322 and 144 answer options respectively. Thus, e.g. ten percent of the answers of the noninvestors indicated that choosing a country or location for the FDI was an important step in decision-making. The choice of country or location and doing a market/company analysis are important factors in the decision-making for both investors and noninvestors. Previous business relations and contacts in the country were also often mentioned as separate reasons to consider in the investment process. Investors often mentioned personal motivations. 12,5 percent of all investors indicated that one important factor in their decision-making 
was of a clearly personal nature. Surprisingly, of the firms that finally did not invest, personal motivations were not given by any of the respondents. Personal contacts and personal experience with a country were mentioned by a significant number of the investors and noninvestors, indicating these aspects are important in the decision-making process. The results highlight that companies that do make an investment analysis also incorporate personal variables in the decision-making process. The firms that invested more often mentioned personal motivations. This could mean that personal motivations are of importance in FDI decisions. In other words, once there is a personal motivation, the chance the investment is made is higher. I test that hypothesis later in this paragraph.'

The third closed question from the questionnaire among Dutch businesses was included to test whether some specific personal factors play a role in the decision-making analysis. All firms that seriously considered an investment in the CEE region, irrespective of whether they finally invested, were asked if several personal variables influenced their FDI decision. If these factors were marked as important, personal motivations influence decision-making. If they were marked significantly more by those firms that did invest in the CEE region than by noninvestors, it is an indication that personal motivations positively influence foreign direct investment decisions in the region.

The following personal variables were included in the questionnaire:

- Available contact person in the country: Having a contact person can be considered as a form of personal relations. If a firm or businessman has contact with one or several persons in the country, it can use the knowledge of this person. As such, the risk of investing will be perceived as lower.

- Owner or employee of the Dutch firm, partner, family, friends or relatives has the nationality of the host economy: When the nationality of someone within the firm is from the host country, there is always a personal involvement of that individual with that specific country. Most probably the individuals will feel more secure investing in their native country. In addition the individual might still have a certain network of contacts, being relatives and friends in the country, again decreasing the risk of investing.

- Owner or employee, partner, family, friends or relatives are willing to work in the host country: If an individual is personally interested in spending time in the host economy, the outcome of the investment decision personally affects the individual and this influences the final decision. There will be some degree of self-efficacy as well. If a person is considering working in the country himself, he or she is very likely convinced of the success of the investment.

- Language knowledge available: If a person speaks the language, he or she will be able to communicate better and use the language knowledge to deal with administration and build a network quicker. Language knowledge can also influence the self-efficacy of a person positively.

- Positive personal experiences: Due to whatever positive personal experience, the individual will be more personally involved in the country, have positive images when thinking about the country and possibly also feel more confident in engaging in an FDI.

\footnotetext{
'The weighted results did not differ a lot from the unweighted percentages.
} 


\section{Table 6.2: Personal Factors: investors and noninvestors}

\begin{tabular}{|c|c|c|}
\hline Variable & $\begin{array}{l}\text { Percentage of investors for which } \\
\text { this variable had impact on the } \\
\text { investment decision }\end{array}$ & $\begin{array}{l}\text { Percentage of noninvestors for which } \\
\text { this variable had impact on the } \\
\text { investment decision }\end{array}$ \\
\hline Available contact person in the country & $69 \%$ & $63 \%$ \\
\hline $\begin{array}{l}\text { Owner, employee, partner, family, or } \\
\text { friend of the Dutch firm have the } \\
\text { nationality of the host economy }\end{array}$ & $19 \%$ & $9 \%$ \\
\hline $\begin{array}{l}\text { Owner, employee, partner, family, or } \\
\text { friend of the Dutch firm are willing to } \\
\text { work in that country }\end{array}$ & $14 \%$ & $14 \%$ \\
\hline Language knowledge available & $19 \%$ & $20 \%$ \\
\hline Positive personal experiences & $33 \%$ & $20 \%$ \\
\hline
\end{tabular}

Source: Survey Dutch Direct investment in CEEC and FSU, Maastricht University, 2000

Note: Of the 90 firms included, 56 firms were investors in the CEE region and 34 were noninvestors

Table 6.2 shows the numbers and percentages of firms that responded to each of the abovementioned variables. The variable "contacts in the CEE region" is of crucial importance in the decision-making process. Almost 70 percent of all firms answered that having contacts in a country was a specific reason for their company to consider an FDI in that country.

Positive experiences, language knowledge and family or friends from the region play important roles in the decision-making process as well. Firms that invested in the region indicate more often that personal variables influenced their decision. However, for none of the variables was the difference between investors and noninvestors significant."

So far, all three tests indicate that personal factors are important in the decision-making process. First, personal motivations could be a reason for firms not to make any investment calculations. Second, if firms make an investment calculation they often include personal variables in their calculation. Thus, it is interesting to test whether personal variables influence the final investment decision. Can one say that firms with a personal motivation are also more likely to set up an FDI in a transition country?

In order to test that I created three different personal coefficients dummy variables. The variable "no analysis" is a dummy variable that is zero in case companies made an investment analysis and one if they made no analysis but made a decision based on other factors. The second dummy variable "personal1" takes the value one for firms that have a contact person in the host country or were invited by business relations to invest in the host country. Those factors can be seen as indicators of presence of a social network. However, having a network is not the only benefit; having a network automatically involves personal involvement, such as trust in the people in the network and trust in the information provided by the network, resulting in a more confident feeling about the investment. The third variable, "personal2", measures personal involvement in the narrowest definition. The dummy variable takes the value one only if strict personal motivations are displayed either in the reasons for not making an investment calculation", in the open questions ${ }^{10}$ (table 6.1) or in the closed question" (table 6.2).

\footnotetext{
"For each of the variables a Pearson chi2 test was done to see whether the data for investors and noninvestors were independent. In none of the cases was the difference in outcomes between investors and noninvestors significant. The dummy variable was set at one if the reasons for not making an investment calculation was a personal one.

${ }^{10}$ The dummy variable was set at one if in the open question the firms answer fell in the category personal motivations (see table 6.1).

"The dummy variable is set at one if the answer options "the owner, friends or family are from the host country", "the owner. friends or family are willing to work in the host country". "someone from the firm speaks the language of the host country" or There were positive experiences in the country' were marked as motivations for the investment (table 6.2, box 6.1 question 23).
} 
Table 6.3: Logit analysis on who invests in the CEE region and who does not

\begin{tabular}{|c|c|c|c|c|c|c|}
\hline & -1 & -2 & -3 & 4 & & -4 \\
\hline & Basic model & No analysis & Social network and experience & Personal motivations & Small firms & Large firms \\
\hline \multirow[t]{2}{*}{ Agriculture } & 0.274 & 0.386 & 0.408 & -0.158 & 0.120 & -0.586 \\
\hline & $(0.59)$ & $(0.82)$ & $(0.79)$ & $(0.28)$ & $(0.16)$ & $(0.50)$ \\
\hline \multirow{2}{*}{ Construction } & -0.296 & -0.185 & 0.177 & 0.829 & 0.608 & 1.865 \\
\hline & $(0.48)$ & $(0.29)$ & $(0.27)$ & $(0.93)$ & $(0.52)$ & $(1.30)$ \\
\hline \multirow[t]{2}{*}{ Logistics } & 1.210 & 1.191 & 1.366 & 1.492 & 2.971 & 0.825 \\
\hline & $(2.22)^{*}$ & $(2.14)^{*}$ & $(2.31)^{*}$ & $(1.96)^{\circ}$ & $(2.07)^{*}$ & $(0.74)$ \\
\hline \multirow[t]{2}{*}{ Retail } & 0.172 & 0.134 & 0.305 & 0.169 & 0.387 & 2.174 \\
\hline & $(0.42)$ & $(0.32)$ & $(0.68)$ & $(0.32)$ & $(0.59)$ & $(1.63)$ \\
\hline \multirow[t]{2}{*}{ Other } & 1.110 & 1.140 & 1.291 & 0.801 & 0.236 & 1.922 \\
\hline & $(2.18)^{*}$ & $(2.22)^{\circ}$ & $(2.35)^{*}$ & $(1.22)$ & $(0.25)$ & $(1.72)$ \\
\hline \multirow[t]{2}{*}{ Age } & -0.014 & -0.012 & -0.013 & -0.009 & -0.031 & -0.011 \\
\hline & $(2.41)^{\circ}$ & $(2.15)^{*}$ & $(2.08)^{\circ}$ & $(1.44)$ & $(2.11)^{*}$ & $(0.89)$ \\
\hline \multirow[t]{2}{*}{ Size } & 0.000 & 0.000 & 0.000 & 0,000 & 0.027 & 0.000 \\
\hline & $(1.43)$ & $(1.51)$ & $(1.77)$ & $(2.66)^{* *}$ & (1.79) & $(2.28)^{\circ}$ \\
\hline \multirow[t]{2}{*}{ No analysis } & & 1.091 & 1.565 & 3.474 & 4.330 & 4.845 \\
\hline & . & $(2.66)^{* *}$ & $(3.64)^{* *}$ & $(5.54)^{* *}$ & $(3.62)^{* *}$ & $(3.49)^{* *}$ \\
\hline \multirow[t]{2}{*}{ Social network and experience } & 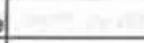 & & 2.002 & 3.913 & 5.218 & 3.745 \\
\hline & & & $(4.79)^{* *}$ & $(6.31)^{n *}$ & $(4.25)^{n+*}$ & $(3.71)^{* *}$ \\
\hline \multirow[t]{2}{*}{ Personal motivation } & & & & 3.891 & 5.264 & 3.352 \\
\hline & & & & $(6.35)^{* *}$ & $(4.37)^{* *}$ & $(3.12)^{* *}$ \\
\hline \multirow[t]{2}{*}{ Constant } & -0.445 & -0.677 & -1.231 & -3.153 & -4.664 & -2.779 \\
\hline & $(1.46)$ & $(2.11)^{*}$ & $(3.39)^{* *}$ & $(5.19)^{* *}$ & $(3.75)^{* *}$ & $(2,72)^{* *}$ \\
\hline Pseudo R2 & 0.068 & 0.0929 & 0.1781 & 0.388 & 0.468 & 0.417 \\
\hline Observations & 225 & 225 & 225 & 225 & 150 & 75 \\
\hline
\end{tabular}

Absolute value of $z$ statistics in parentheses ${ }^{*}$ Significant at $10 \%,{ }^{*}$ significant at $5 \%, \cdots$ significant at $1 \%$

Source: Survey Dutch Direct Investment in CEEC and FSU, Maastricht University, 2000

The sector Industry is taken as the baseline sector.

Firms with less than 100 employees are small (model 5); firms with more than 101 employees are large (model 6).

The control variables included were a sector variable ${ }^{12}$, age of the Dutch firm at the time if the FDI decision" ${ }^{13}$ and size of the Dutch firm measured in number of employees at the time of the FDI decision". The results of the logit analysis displayed in table $6,3,{ }^{15}$

Six different versions of the regression are included. The first model only includes control variables. Models two, three and four include the dummy variables for personal influence. Models five and six are equal to model four in terms of variables included, but the sample is divided in two strata; small and large firms. The main conclusion is that personal influence has a positive significant impact on the decision-making, meaning that firms that indicate personal factors play a role in the FDI

\footnotetext{
${ }^{12}$ Six dummy variables were defined using one-digit SB1 code, with Agriculture, including Agriculture (A), Fishery (B) and Natural resources, Industry (D), Construction (F), Transport (1), Trade (K) and Other including E (Electricity, Gas and Water), H (Hotel, Restaurants), J (Financial institutions), L (Government/NGO), M (Education), N (Health), O (Environment), P (Private households) and Q (Extraterritorial bodies). A table with more detailed SBI codes is included in Annex B.

All firms older than 100 years were included as being 100 years old.

${ }^{14}$ As primary source the answers from the questionnaire were taken. I included the number of employees of 1989, 1994 or 1999, depending on which year closest preceded the year of the investment decision. Whenever data for that specific year were missing. I used the number of employees from the later years as a proxy.

${ }^{13}$ Firms can only be included in one dummy-groups. Thus, if for instance the dummy personal motivations equals one, the variabels no analysis and social network and experience are zero. There is no difference between the unweighted and weighted analysis in sign or significance of the variables. The interpretation of the coefficients remained the same.
} 
a higher chance of investing. In the basic model (model one) the only significant control factors were the sectors logistic and other and the age of the firm. Firms in the sectors logistic and other have a higher odd to invest in the CEE region than firms in the sector industry. Age influences the investment decision negatively; older firms are less likely to invest in an FDI in a transition country than younger firms. Model two tests whether making a decision without investment analysis increases the chance a firm invests in the CEE region. This is indeed true, since the coefficient of the variable no analysis is positive and significant at a five percent level. Firms that did not make an investment decision based on an analysis but on other motivations are more likely to invest in an FDI in the CEE region. The coefficients of the personal1 variables, added in the model three, increases the explanatory power of the model. The coefficient is positive and significant at a five percent level. Thus, having a social network or a contact person significantly increases the chance the firm invests. This can be due to the positive economic values attached to having a network, but the results can also be interpreted as the positive effect of a having a network on the personal attitude of the decision-maker towards investing. Model four, that includes the strictest dummy for personal motivations, increases the explanatory power of the model even more. This dummy variable is positive and significant and the fit of the model is higher than the fit of model one, two and three. This indicates that firms with a direct personal link to a country are more likely to invest. Dividing the sample in two strata, small and large firms, shows that the influence of the personal dummy variables is higher for small firms than for large firms, indicating that personal involvement in the host country has more impact in small firms than in large firms.

Concluding, the analysis indicates that personal motivations indeed have a positive influence on the investment decision. If personal motivations are present firms are more likely to invest in the CEE region.

\subsection{Bounded Rationality}

Within the economic literature there are several models or theories that can add to explaining the large impact of the personal variables in FDI decision-making. One example is the theory of bounded rationality. Given rational choice, firms may not be utility (profit) maximizing and full information is absent. Decision-making under uncertainty is difficult, since predicting the future is not easy and humans face cognitive limitations. These critiques to neoclassical theory are largely accepted and the theory is adjusted based on empirical evidence (Simon (1997)). ${ }^{16}$ The term bounded rationality is used to "describe the complete range of limitations in human knowledge and human computation that prevent economic actors in the real world from behaving in ways that approximate the predictions of classical and neoclassical theory; including the absence of complete and consistent utility functions for ordering all possible choices, inability to generate more than a small fraction of the possible relevant alternatives, including the inability to assign consistent and realistic probabilities to uncertain future events" (Simon (1955)). The solution that bounded rationality refers to is that firms do not attempt to search for all investment possibilities but choose solution satisficing to all parties (Simon (1997)).

Cognitive limitations can be a way to explain the large influence of personal motivations in investment decisions. Given that decision-makers face cognitive limitations, they have to rely on other sources of information, or decision factors, when making an investment decision. For FDI decisions it

"Simon (1997), Models of Bounded Rationality. 
means that human cognition is insufficient to make complicated expected utility calculations, as often used in investment decision models. It is simply not possible to consider all FDI possibilities available - which means considering all countries in the world as possible host countries. Thus, before even considering an analysis several choices have to be made in order to limit the possible investment alternatives, so as to keep the choice options within the boundaries of human cognition. This notion is in line with the fact that 75 percent of the noninvestors did not make an analysis related to FDI in a transition country. They excluded this region beforehand in order to limit the number of alternatives. Explanations for the large influence of personal motivations, as mentioned in table 6.2, can be given by network theories and experience or learning theories."

Network theory is based on the idea that there is an economic value attached to the social network you have. There is "a network if individuals are variably connected to one another as a function of prior contact, exchange and attendant emotions" (Burt (2000)). The structure of relations among people and organizations in a market, being strong or weak relationships, can affect or even replace information. Replacement occurs when the information provision is so limited and unclear that people rely completely on their networks when making decisions. In the survey, about 70 percent of the firms had a contact person in the region and 10-20 percent of the firms indicated that the owner or other related persons were of the host country nationality. One of the positive effects of having the nationality of a country or having contact persons in a country is that there is a network in place in the host country when starting the FDI. Having a network of contact persons, relatives and friends or business relations in a country provides a firm with direct sources of information. These individuals have expertise related to the host country and can advice the firm at relatively low cost. They decrease the uncertainty attached to the investment decision and their presence leads to a higher chance that a firm invests.

Experience and learning theories provide another explanation of the significant presence of personal motivations in section 6.2. Cognitive learning theories and social learning theories describe the possible effects of experience (Martin (2001)). The basis of cognitive learning is that individuals develop cognitive frameworks that allow them to interact more effectively in a certain environment. Experience assists the individual in decision-making, determining behavioral options and choosing a certain behavior. After evaluating the outcome, individuals can learn from their previous experience again and use this new knowledge in the next decision they have to make. The evaluation, or feedback from previous choices is essential in cognitive learning. Social and experiential learning relates to the idea that within each environment people learn and experience different things and thus automatically learn different things that are attached to that specific social setting. For example children in the Netherlands learn Dutch cultural habits from their parents, but those are not useful when used in, for instance, a country in the Middle East. The process of socialization can be seen as a period of experience and placed in a different social setting people experience new things and learn from these experiences. This idea is incorporated in the Kolb learning cycle (Martin (2001))."

Having experience with the host country directly or indirectly enables a firm to evaluate the experiences and use this knowledge to make the current choices. For example, a person with the

\footnotetext{
The intention in this section is not to fully elaborate on these theories, but only to indicate that there are several economic theories that can explain the presence of the personal motivations, among which the two mentioned here.

the Kolb learning cycle connects the following aspects:

Experience $\rightarrow$ Reflection $\rightarrow$ Generalization $\rightarrow$ Experimentation $\rightarrow$ Experience etc.
} 
nationality of the host country or with friends, family or relatives in or from the host country has more direct or indirect experience with the host country. He or she has experienced certain national or cultural habits directly or learned about the cultures indirectly from others and is able to adjust to those customs easier than someone who is completely unfamiliar with the national habits. Equally, previous business experience in a country, or having a FDI in another country in the region provides a firm with feedback on doing business that is useful for the current investment. Examples are information on the procedural regulations, which enables a firm to deal with the appropriate institutions and apply for the necessary documents quicker. In addition, the firm already has some experience in the different social environment. Having this social experience not only implies that there exists a social network a firm can rely on, but also the knowledge of the business culture is greater. Lastly, language knowledge is mentioned as important factor in decision-making by about 20 percent of the firms (table 6.2). Speaking the language of the host country directly decreases the costs of obtaining information, thereby decreasing uncertainty of doing business in a foreign country. Local regulations, institutional processes and so on can be undertaken in the host country language, leading to less costly information acquisition and less distortion of information content.

All information sources and experience the firm has regarding the host country, in the form of networks, experience and knowledge eases the investment decision. Where human cognition fails to understand and analyze all investment possibilities, these factors help the firm to make informed decisions by relying on the network of people that can assist during the investment period and trusting the knowledge obtained during previous experiences. The fact that the personal motivations are so often mentioned by the firms is an indication that personal motivations can be considered a way to deal with limited human cognition and assist the firm in selecting a satisficing solution using networks and experience.

\subsection{The role of emotions and intuition}

So far the economic explanations, rational and including the concept of bounded rationality, focus on the FDI decision-making process. The decision and the decision rules are a central feature in these theories. However, psychological literature suggests there are also psychological factors influencing the decision-maker, as such influencing the choice to invest. The personal motivations mentioned in section 6.2 that influence the investment decision are directly linked to the decision-maker instead of the decision process or decision rules. Despite the fact that a good deal of the variance is still left unexplained by the FDI-theories, such psychological aspects remain largely absent from the decision models. In this section, two aspects of psychological decision-making influencing the decision-maker, emotions and intuition, are introduced as possible sources of explanation for FDI decisions.

The fact that emotions and intuition have been largely absent in economic decision theory does not mean that emotions and intuition are ignored entirely in modern developments in economic analysis. Emotions are gaining importance and the discussion on inclusion of the concepts in economic theory is becoming more regular (Allen et al. (1992)). How individuals behave, feel and make a judgment is considered more and more a crucial determinant of choices (Kaufman (1999)). Evidently, in the psychological literature theories on emotions are more popular (see e.g. Lewis and Haviland (1993), Oatley and Jenkins (1998), Wollheim (1999)). The impact of intuition is less often discussed than emotions, but is also gaining importance (Hogarth (2001)). In section 6.4.1 and 6.4.2 the concepts of 
emotion and intuition are defined and their influence on decision-makers is summarized based on the current literature. Being an economist, I abstain from psychological discussions surrounding the two concepts and settle for definitions that are commonly used and suitable for this chapter, without entering the discussion of what to include or exclude for both terms. In section 6.4 .3 the influence of emotion and intuition is linked to decision-making by means of a utility model.

\subsubsection{Emotion and economics}

Within the literature there is no consensus on the definition of emotion; each researcher generally defines a working definition of emotions. For this chapter a commonly used definition is adopted that is suitable for the economic application and refrains from using psychological specifications. ${ }^{10}$ Emotions are both psychological and physiological subjective experiences and include facial action, central or peripheral nervous system activation, cognitive changes and behavioral action tendencies (Frijda (1986)). ${ }^{20}$ Emotions are multifaceted processes that unfold over time. They are manifest in multiple channels and the channels themselves are loosely coupled and interact in a complex way (Venables (1986), Larsen and Fredrickson (1999)). Emotions cannot be directed or prevented. People undergo emotions, without means of resisting them. People can avoid situations in which they know they will face emotions (for example a person that is alcohol addicted can avoid going to bars), or they can equip themselves with strategies to deal with the emotion (for instance angry people often use the "golden rule" to count to ten before responding, instead of responding immediately), but they cannot avoid emotions themselves.

There are two kinds of emotions, visceral and anticipated emotions. Visceral emotions are immediate emotions that occur at the time of the decision, like anger or happiness. Anticipated emotions occur after the decision is made, like for instance regret. Visceral emotions are thus more important when making an investment decision.

In economics, the attempts to incorporate emotions in regular theory are limited, although more apparent during the last decade. (Frank (1988), Elster (1998), Hanoch (2002)) Economists more often use anticipated emotions, even though visceral emotions are basic to daily life and decision-making. Emotions are often linked to consumer theories and test for instance to what extent consumers regret their purchase. Visceral emotions play an essential role in human behavior, but face two main complications. First, they often make people behave in ways that are not necessarily beneficial for them. Second, people underestimate the effect of visceral factors on their own current and future behavior (Loewenstein (2000)). ${ }^{21}$

\footnotetext{
${ }^{19}$ My starting point is that each individual has physiological and psychological reactions (body and mind). In this chapter the focus is on the psychological influences. The psychological part can roughly be divided in two categories of processes: thinking capacity and feeling capacity. Emotions and intuition largely affect the feelings of an individual. As mentioned, emotions can lead to physiological reactions as well, but those reactions do not influence investment decisions, whereas I argue that the emotions leading to those reactions do (based on Keizer (1987)),

${ }^{20}$ Emotions always have an intentional object, being a person or a state of affairs (envious of someone, sad because of something). Emotional states are characterized by hormonal changes and change in the autonomic nervous system and have characteristic observable expressions (for instance a smile). Emotions can be located on a pleasure-pain scale, including a neutral point of emotional indifference (valence) and often lead to action tendencies (for instance anger and hurting someone, love and touching. shame and hiding) (Frijda (1986)).

2 Loewenstein (2000) mentions the example of road rage. When asked in advance, people recognize that it is not in their selfinterest to assault another driver that they find irritating, but in real life emotions often lead to such assaults. Kaufman (1999) gives another example in his illustration of a homosexual man being infected with the HIV virus due to having engaged in unsafe sex. The man admitted it was not in his self-interest to practice unsafe sex, but driven by the emotion of happiness and love this knowledge became less important. Especially in this last example the short-term emotions driving a decision lead to very important consequences.
} 
Specific applications of emotions in economics are found in game theory (Bosman and van Winden (2002), Dufwenberg (2002), Selten (1998)) and consumer behavior (Allen et al. (1992), van Dolen et al. (2001), Aaker and Willems (1998)). In other fields, research is done to see to what extent emotions are linked to decisions. Examples are the studies that link happiness and the position in the labor market (Clark and Oswald (1994), Blanchflower and Oswald (1992)(1998), Oswald (1997)) and the analyses that explore the relation between emotions, culture and economic performance (Casson (1993), Altman (2001), Gutter et al. (1999)) and social cognition (Stajkovic et al (1998)). The conclusion of almost all of these publications is that emotions are an important significant factor in decision-making.

Inclusion of emotions in economic models or frameworks is rare. Based on the literature I reviewed, the only models integrating emotions and economics use utility theory, measuring emotions as costs and benefits (Loewenstein (2000), Elster (1998), Frank (1988)). Loewenstein highlights the fact that people highly value their current emotions and underestimate future emotions when maximizing utility today. He uses utility functions, including consumption and emotional states, to show the difference between what people should be maximizing versus what they are maximizing due to emotions. Translated to a firm's investment decisions, his argument is that at the moment of their investment decision entrepreneurs behave largely under the influence of their emotion on that specific day and underestimate the impact of the future. With respect to decisions under uncertainty, Loewenstein argues that peoples cognitive evaluation of risks often diverge from the emotional reaction to those risks. In other words, a positive country risk rating in an economic analysis does not imply the entrepreneur also personally considers the country equally risky. ${ }^{22}$ Elster (1998) states emotions can be seen as psychic costs or benefits that enter a utility function. Here valence becomes important. Valence implies that emotions can be measured on a scale from low to high. Elster uses an example of Becker's analysis to illustrate the economic integration of emotions. Meeting a beggar induces guilt of being wealthy, which can be considered an (indirect) cost. In addition, you may give money to the beggar to get rid of the bad feeling, which is a direct cost. Thus, emotion itself can be cost (or benefit), or the emotion can lead to a cost (or benefit). The larger the emotion is, the higher the costs or benefits will be in economic terms. Frank (1988) also translates emotions in cost and benefit terminology. Examples are the costs and benefits of marriage, or the costs and benefits of cheating in cooperative ventures. In his appendix he derives a formal version of the commitment model, including payoff functions of honest and dishonest persons engaging in joint ventures, also taking costs of scrutiny into account.

None of these economic applications combines both economic motivations for decisions with emotions. They only describe the influence of emotions and indicate how to include them in economics terms, thereby losing any interaction effects between economics and emotions. Kaufman (1999) and Hanoch (2002) integrate emotions and economics; their research is built upon section 4.3.

\subsubsection{Intuition and economics}

Intuition is defined as thoughts that are reached with little apparent effort and typically without

\footnotetext{
${ }^{2}$ It is commonly known that, even though rationally risks remain constant, it feels as if risks become higher when they come closer. For example, a war is more threatening if it is between your neighboring countries instead of at the other side of the world. Equally, a country can have consistent medium risk ratings, but may feel more risky if you have to live there with your family. Or, a bungee jump today is considered scarier than a bungee jump next year, even though the risks remain equal.
} 
conscious awareness. They involve little or no conscious deliberation. Intuition can be backward based (based on interpreting past experiences) or forward based (predictions based on beliefs of what may happen). Intuition is often immediate, includes a feeling of certainty and may be based on inadequate information (Hogarth (2001)).

All people have intuition and all people process information differently. Often the choices we make are based on intuition and occur automatically. There are two systems of acquiring intuition, tacit and deliberate. Intuition is formed tacitly, without effort ${ }^{2}$ and deliberately by learning. People learn from experience, both their own experience and experience of others (what other people tell them) and form intuition based on this experience. For example, a hairdresser intuitively cuts someone's hair straight, but does not know how to shut down a computer, whereas a researcher daily working with computers intuitively shuts down his computer at the end of the day. Intuition does not have to be correct; intuition can lead to automatic action that is suboptimal. For instance prejudices can be the motivation for intuitive decisions that lead people to make suboptimal decisions. People are unable to suppress intuition as automatic thoughts, but it is possible to use deliberate learning in order to avoid acting upon tacit prejudices. ${ }^{2 t}$

Intuition is continually used to make decisions. Primitive choices made subconsciously are in general good choices. ${ }^{25}$ For sophisticated choices, intuition may not be the best guideline. For sophisticated choices intuition might be better used as a weak signal and models or rules established based on human rational could be more successful choice guidelines (Hogarth (2001)).

Intuition is seldom integrated in investment decision-making literature. One research in consumer literature argues that intuition can be used to compensate for missing product information when making a decision (Broniarczyk and Alba (1994)). A second application including intuition relates to company performance. The argument is that companies can perform better if they use the intuition of experienced managers. Integrating analysis and intuition of managers leads to a better balance between rational activities and use of experience in the form of intuition (Harvey and Novicevic (2002), Mc Ginnis (1984)).

\subsubsection{Role of emotions and intuition in decision-making}

Even though it is generally accepted that emotions and intuition influence decision-making processes of individuals, their inclusion in economic theory, without losing the values of emotions and intuition, is not simple. Standard economic theory on FDI decision processes under uncertainty requires rational agents reviewing options and their probabilities. They should estimate the Net Present Value as the main indicator for future success and finally base (non-) investment decisions on the ranking of the options according to that indicator and the related probabilities. The functionality of the theoretical framework depends crucially on two basic assumptions related to the decision-making and decisionmaker, namely "given tastes and preferences" and "perfect information". The outcomes of the economic decision-making model are of course a simplification of reality, but lead to interesting

\footnotetext{
${ }_{23}^{23}$ Experientially, for example avoiding bumping into someone while walking on the street by stepping aside.

${ }^{24}$ Assume an employer with the prejudice that men work harder than women has a vacancy. There are two applicants, a male and a female. On paper the female applicant is the better one. If he intuitively follows this prejudice when hiring employees and he has to choose between a man and women, he hires the male worker even if that man is less qualified than the female applicant.

Such as not crossing the street if a car passes, without deliberately thinking about the costs and benefits of not crossing now, but later.
} 
conclusions. However, those conclusions are only realized when the simplifying assumptions are considered to hold. The incorporation of intuition and emotions into this particular part of theory on the one hand indicates that these assumptions do not always hold, but on the other hand can be interpreted as safeguards of the theory, as is argued below.

Stability in tastes and preferences is an important prerequisite for rational choice models to work. What is important is that decision-makers know their tastes and preferences and once identified, adhere to the same preference ordering. The concept of a utility curve is based on this stability. Known and stable utility curves are a necessity for being able to estimate the outcome of decisions. The model becomes completely volatile and unpredictable if investors for example at one moment prefer higher revenues above higher total profit in one particular country, but prefer the opposite the next moment or in another country. This is a strong assumption. It not only requires that all the decision-makers know their preferences (it is a cognitive framework) but also that they do not change them. Emotions and intuition do not come into play. The assumption of perfect information is equally strong, complex and encompassing. It requires that all the information on all relevant characteristics of the goods is available to all market parties (all consumers and all producers) and it also requires that perfect information holds even for future markets. The assumption of perfect information seems to be very restrictive and it is hard to understand how any market can ever comply with these conditions. The introduction of emotions and intuition will not help us a lot in this context; they complicate the analysis further by introducing noncognitive elements into the decision-making process and further blur the assumption of perfect information.

The concept of bounded rationality already recognizes these points of critique and argues that due to cognitive limitations people settle for a suboptimal satisficing solution. Kaufman (1999) builds on this concept and introduces emotions as an additional source of bounded rationality, besides cognition. He argues that, even though the emotional process is largely explainable in rational terms, the behavior caused by emotional states can be irrational. Insufficient or excessive emotions cause suboptimal decisions or performance. With too little emotional intensity people suffer from insufficient physical and mental arousal to perform optimally, while too much emotion causes a person to be so aroused that thinking and physical self control become disorganized and this deteriorates performance as well. Kaufman uses the Yerkes-Dodson law to explain the impact of emotional bounded rationality. This is visualized in figure 6.1. On the horizontal axis, the level of emotional arousal is placed on a scale from low to high, with as optimal emotional level A2. The vertical axis measures performance (or utility). The bell-shaped curve is the Yerkes-Dodson curve, showing the effect of emotions on performance. If there would be a pure rational world, the optimal performance is at the level of $P_{\max }$. However, due to cognitive limitations there is bounded rationality leading to a satisficing sub-optimal performance of P2. Kaufman argues that this level of performance is only achieved if emotional arousal is optimal, at level A2. If emotions are too weak (for instance at A1), or too strong (A3), they further deteriorate performance to a level of P1. The decrease of performance from the optimal level $P_{\max }$ to $P 2$ is caused by cognitive bounded rationality and the decrease from $P 2$ to $\mathrm{P} 1$ by emotional bounded rationality.

Applying Kaufman's theory to decision-making, the absence of emotions leads to worse choices than in the presence of a limited degree of emotions, as long as they do not become excessive. However, in Kaufman's approach, emotions can never improve decision-making. 


\section{Figure 6.1: The relationship between arousal and performance}

Performance

$P_{\max }$

P2

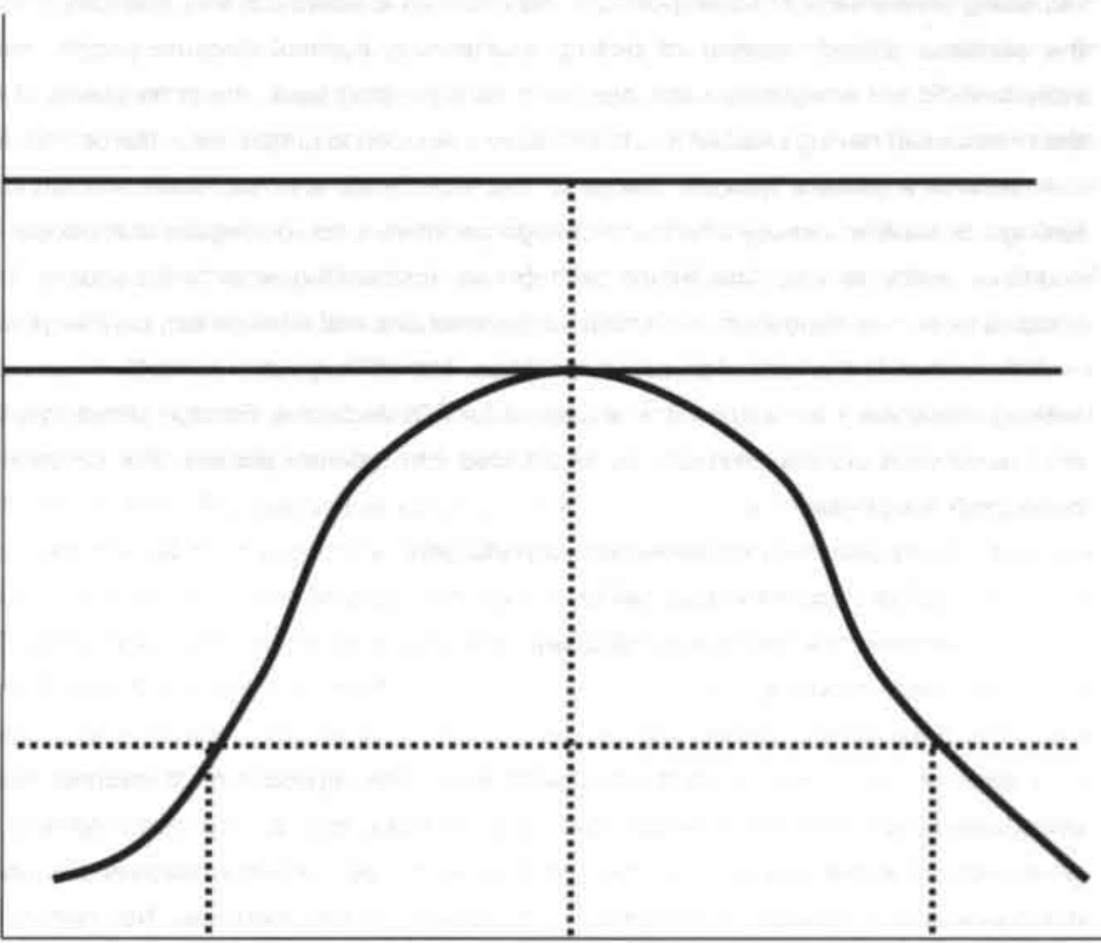

A1

A2

A3

They not only lead to weaker performance compared to neoclassical economic solutions, but also to deterioration compared to the bounded rationality solution. Or, as Kaufman states, they add a source of bounded rationality, extending the effect of bounded rationality due to cognitive limitations with additional emotional distortions.

Following Hanoch's line of reasoning (2002), I would like to turn the argument around and argue that allowing emotions and intuition to play a role in the decision-making process rescues the rational choice model in a certain way. The basic argument is that, even without emotions and intuition, one cannot believe in the assumptions of stable preferences and perfect information. Decision-makers need a device to deal with instability in preferences and imperfect information. This device is the recognition that emotions and intuition exist and are allowed to enter the decision-making process (the cognitive acceptance of emotions and intuition). Hanoch (2002) elaborates the stable taste argument in detail. His main point is that emotions (and I add intuition) can function as a tool to prioritize tastes and preferences. Time, or attention, is a scarce resource and people simply cannot analyze all preference decisions. Given that in reality preferences are not stable, but fluctuate per situation and over time, adjustments in priorities are constantly made. This can be done in a slow, analytical manner, but also quickly, based on emotions and intuition. Hanoch argues that these quick 
decisions are not necessarily the best solutions, even though sometimes they are, but they are satisficing solutions. An example he mentions is an individual walking through the woods with the aim of picking blueberries. At some point the individual encounters a snake and jumps back. At that point the priorities shifted; instead of picking blueberries, survival became priority number one. The individual did not analytically calculate the costs if jumping back, the probabilities of being bitten and the revenues of having blueberries, but intuitively decided to jump back - the optimal solution.

A second argument Hanoch makes is that individuals are not "cold calculating machines" and feelings or intuition directly affect and change priorities. Last, he argues that people do not have the cognitive ability to calculate future probabilities (calculating what will happen), but instead they imagine what may happen. In this imagination, emotions and intuition can play large roles.

With respect to the lack of perfect information, Hanoch argues that intuition can serve as a tool for making decisions. I will extend this argument for FDI decisions. Foreign Direct Investment decisions are based on a process that can be subdivided into different phases. For convenience purposes I distinguish five phases:

1. Start searching for investment opportunities.

2. Select information to consider.

3. Interpret the information collected.

4. Stop searching.

5. Evaluate the options and decide.

In each of the phases perfect information is a near impossibility: it requires that all investment opportunities are considered before making a decision, only at any given moment but also at any given moment in the future. It also requires that all the relevant information is available and collected, interpreted and evaluated by an investor. This requirement is unrealistic. No investor is able to review all investment opportunities, including future ones, before making a decision. Nor is an investor able to grasp the complexity of all the information that becomes available and evaluate it in an internally consistent way. All investors need a device to limit the options and to allow them to make a decision based on less than perfect information. This device can be the use of emotions and intuition. They become a functional tool in actually making decisions by helping the investor limit the review and decision process. Emotions and intuition may trigger a search in some circumstances and withhold investors from searching in others, limiting the alternatives that an investor considers. Emotions may help the investor to interpret the (imperfect) information and, finally, emotions may assist the investor in deciding when to stop searching or evaluating. Interpreted in this particular way, it is not surprising that emotions and intuition have been observed to play a crucial role in investment decisions. They do not replace calculations or rational considerations; they make them possible by limiting the costs.

Emotions, like goals, norms, values and instincts, include factors that cannot be captured by economic arguments. These factors are different for each individual. Intuition is also formed individually and based on experience. The degree people rely on their intuition varies. As a result, emotion and intuition influence decision-makers differently, thus different individuals respond to a specific economic problem in a particular way.

In the fifth section of this paper I therefore try to model a decision-making framework that includes both business-economic decision-making rules and the impact of emotions and intuition on decisionmaking. 


\subsection{A decision-making model including emotions}

Emotions and intuition can be included in an economic choice model in different ways. The two extreme variations are either not to include emotions and intuition at all in the decision-making and only use economic arguments (slow, analytical decisions), or to base a decision only on emotions or intuition and exclude any economic arguments (quick, intuitive or emotional decision). Combinations in decision-making, which use both aspects, are most likely. The decision-maker then takes economic, emotional and intuitional aspects of a decision into account and together they determine the outcome of the decision. A less direct way for emotions and intuition to be involved in decisionmaking is by influencing all other variables determining the final decision. Limiting the number of variables and estimating a value of economic indicators used in a calculation is not a uniformly decided process for all decision-makers. Different variables will be selected by different individuals and interpreted differently. Emotions and intuition can be used as a tool to deal with imperfect information in order to limit the information and also influence interpretation of the variables, for instance through imagination. An example is valuation of an indicator that is nominally equal for all decision-makers, like the GDP of a country. The valuation and interpretation varies per decisionmaker and depends very much on the emotion and intuition of the decision-maker. What one person considers a sufficiently high GDP can be an insufficiently low GDP for another decision-maker.

It is impossible to say if emotional or intuitive decisions lead to more successful decisions than a decision following only economic arguments. Research on intuition shows that in general intuitive decisions are less consistent and overall less successful than decisions based on predetermined rules (Hogarth (2001)). Still, the main question is if the two can even be considered separately. Emotions or intuition influence decision-making and empirical research almost always points out that emotions and intuition are influential and significant. It is thus hard to explain that emotional or intuitive behavior has been excluded from direct decision-making models so far and empirically the impact of emotional factors on direct investment decisions has not been tested. The results described in section 6.2 are consistent with the idea that emotions and intuition influence FDI decisions. The results are no hard evidence of a direct influence, but they do validate the assumption that inclusion of an emotional or intuitional component in the decision-making model would be realistic.

In this section a decision-making model is described that includes both economic and emotional influences. Intuition is mainly influential at the time of the actual decision and less included as utility increasing or decreasing factor. It does however influence a lot whether a decision will be quick intuitive or slow analytic and functions as a selection mechanism for information. The principle of a utility maximization model is followed, in which individuals are considered rational in the economic sense, meaning they are utility maximizing. I realize the inconsistency in using a rational neoclassical model, which is based on the assumption that I earlier called unrealistic. However, in section 6.4.3 I argued exactly that emotions and intuition are the tools to make models work, given the fact that the assumptions are not realistic. 
Figure 6.2: Utility function Net Present Value

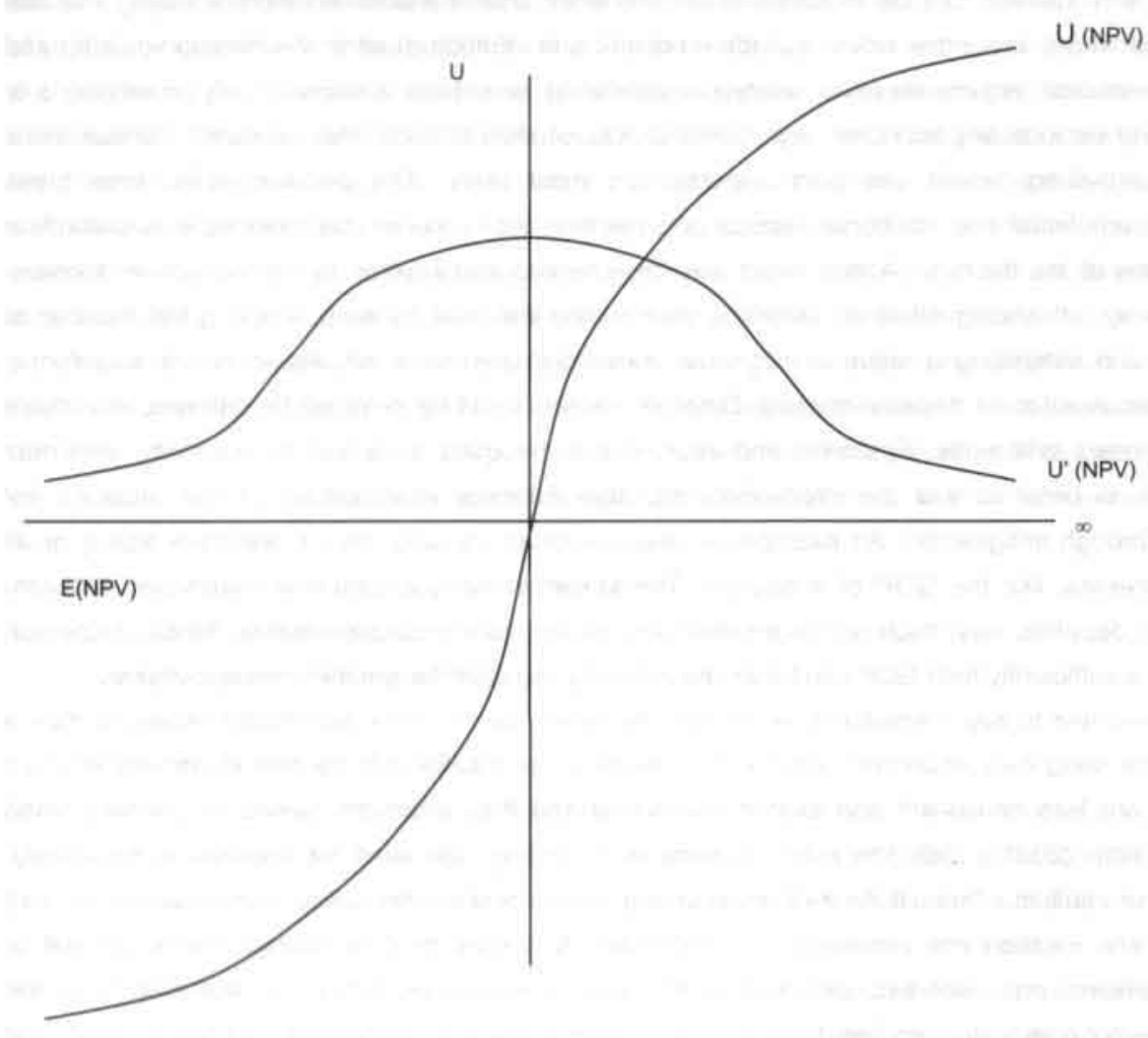

Emotions and intuition inherently influence the valuation of NPV, given the fact that they are used to select investment alternatives and information sources and help value indicators and make future prognoses or imaginations. The utility based on the expected net present value is shown in figure 6.2.

The utility is positive (negative respectively) when the E(NPV) is positive (negative). The marginal utility curve of $E(N P V)$ is always positive, increasing when the $E(N P V)$ is negative, highest when $E(N P V)=0$ and afterwards declining towards zero.

The factors determining the utility of the decision-maker are less clear. ${ }^{26}$ Imagine an entrepreneur that considers investing in Poland. The "business part" of the decision (the profit expectations) is already incorporated in the utility of the firm. The "personal preferences" of the businessman are included in the utility of the decision-maker. Here emotions are very important. If the entrepreneur wants to go to Poland, enjoys living abroad and believes he will be successful, he will have a high positive utility. This utility is higher than his personal utility of not investing. If, on the other hand, the

\footnotetext{
${ }^{2 x}$ In the case of more decision-makers, the sum of their personal utility can be included here.
} 
businessman has a family that does not want to join him to Poland, he may have very sad feelings when he considers investing and his personal utility of not investing is higher. While intuitively clear, the most important problem is how to measure these personal preferences. ${ }^{2 t}$ How do you specify emotions and their intensity (see for instance Larsen and Fredrickson (1999), Van Dolen et al. (2001). Blamey (1998), Bosman and van Winden (2002))? In general, each study selects a number of emotions, which are specifically related to their research. Emotional variables that could be included in the investment decision-making function are variables related to Emotional Intelligence (instinct, intuition), Emotional Involvement (interest, love, hate), Self-Efficacy (confidence and trust), Individual Experience and Individual Relations (trust, comfort, familiarity, safety). However, how to measure those factors and how to transform them to interpretable variables is a difficult issue.

In order to make the utility of the decision-maker comparable to the utility of the expected NPV the inputs in the utility function of the decision-maker, here called emotions $(\varepsilon)$, need to be translated into money value. By dividing the utility of the emotions over the marginal utility of money $(\mathrm{M})^{2 \mathrm{~s}}$, an Emotional Coefficient (EC) displays the additional revenue in money terms a decision-maker gets due to emotions (see equation two).

(2) $\quad E C=U(\varepsilon) / U^{\prime}(M)$

The utility of emotions $U(E C)$ is depicted in figure $6.3 \mathrm{a}, \mathrm{b}$ and c. Figure $6.3 \mathrm{a}$ describes the size of emotions when taking the size of a firm into account. The larger a firm is, the smaller is the influence of emotions is on the decision-making. A small firm has only one decision-maker that is personally affected by the decision. The emotions of the decision-maker weight more heavily during the decisionmaking process than if a decision is taken by a large multinational corporation, following a standard investment process (see figure 6.3a). This is also confirmed by the results of model five and six in table 6.3. The same downward slope exists for the utility of money. Smaller firms have less money available, they have a larger utility of money than larger firms. Thus, the marginal utility of money declines as firms increase in size, but remains positive (see figure 6.3b).

\footnotetext{
"The argument of emotional influence can aiso be applied to for instance people from the former Dutch colonies or immigrants in the Netherlands. While living in the Netherlands now, they will have a clear emotional link with their home country and thus investments in their home country are (emotionally) more interesting to them than investments in any other country.

The model follows the discrimination theory of Becker, 1971
} 
Figure 6.3a/3b/3c: Utility function Emotional Coefficient

Figure 6.3a

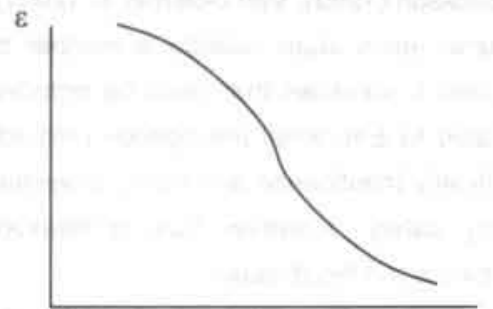

Figure 6.3c

size firm
Figure 6.3b

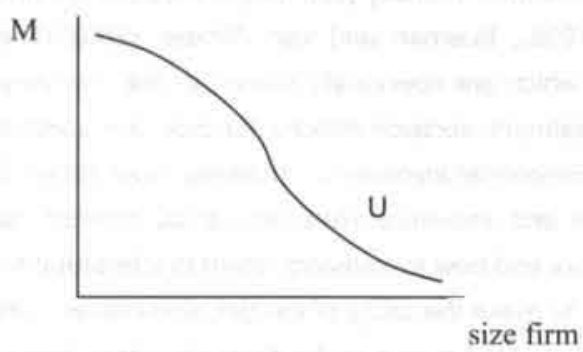

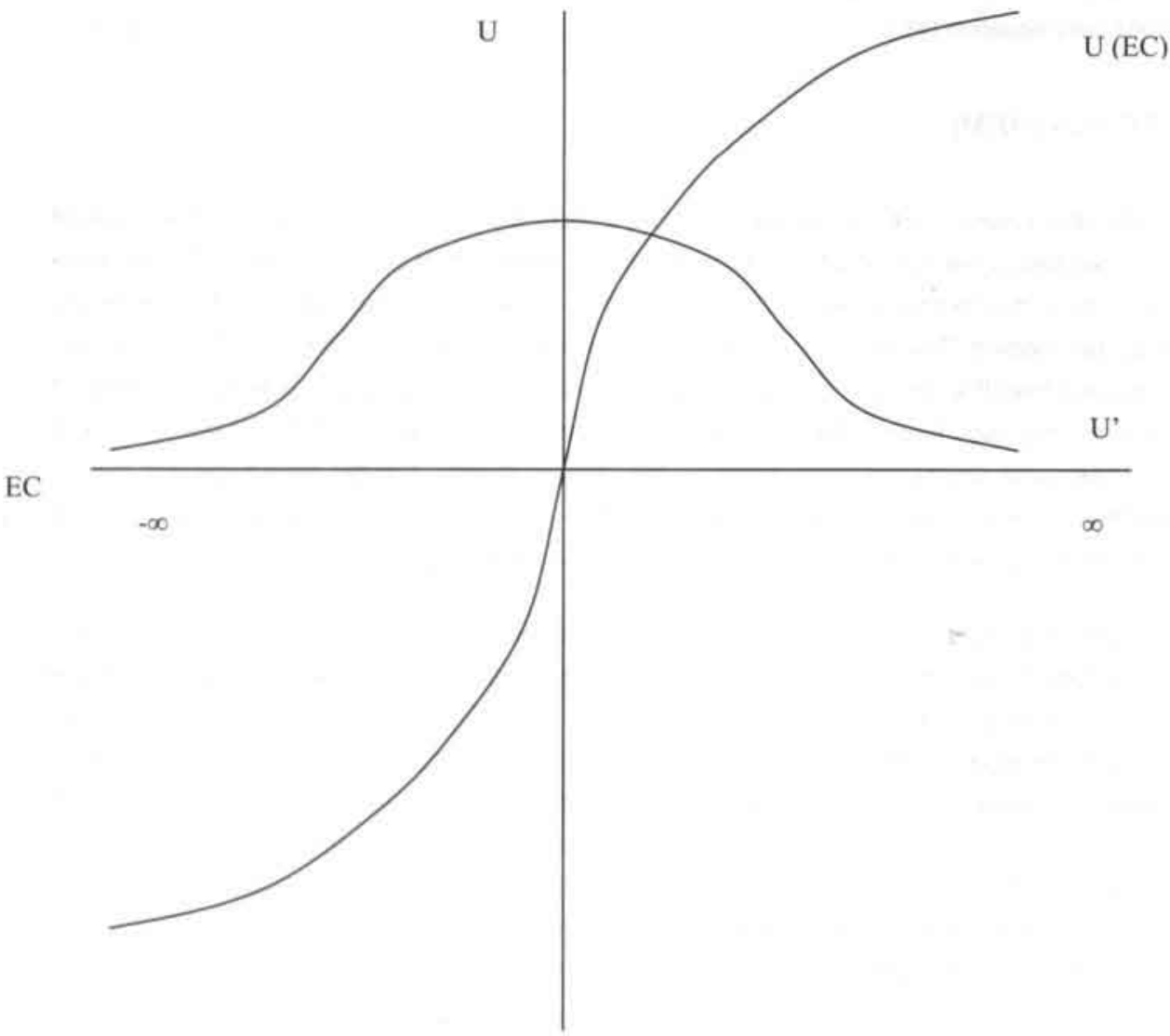


Combining emotions and the marginal utility of money in the utility function of emotions, $U(E C)$, these two effects level out for small and large firms. Small firms have a higher level of $\varepsilon$, but also a higher level of $U^{\prime}(M)$ and large firms have lower influence by emotions, but also a lower marginal utility of money. Therefore the utility function of emotions increases with positive emotions, but with diminishing returns. ${ }^{29}$ Including these specifications in equation one gives

(3) $U(F D I)=U(E(N P V)+U(E C)$.

The additive utility function (equation one) adds the utility functions of the $E$ (NPV) (figure 6.2 ) and the emotional coefficient (figure 6.3c). A firm only invests if either both utilities are positive, or if one of the two factors dominates positively.

The theory coincides with the literature described in section 6.4.3. If an investment decision is made following the rational, slow approach, the decision is based only on the utility obtained from the economic calculations. In this model that means that $U(E(N P V))$ is the sole factor in decision-making and $U(E C)$ is not considered. If, on the other hand, the quick, emotional approach is taken, $U(E C)$ is the sole factor of decision-making and economic calculations are not valued. The same is true if intuition is the main choice determinant; in that case the intuitive judgment overrules or heavily influences the interpretation of both utility functions. More likely is the scenario that economic calculations and emotional influence jointly determine decision-making. If $U(E(N P V))$ and $U(E C)$ are either both positive or both negative, the decision to invest is not difficult. If $U(E(N P V)$ and $U(E C)$ are of contradictory signs, the decision will be more uncertain. ${ }^{30}$

Interactions between the two utility factors are also possible. If the utility from emotions $U(E C)$ is strongly positive, these strong positive emotions can positively influence the business-economic perspective of the market as well. Equally, a high expected NPV can give the decision-maker happy or exciting feelings. To include interaction effects in the model, an interaction effect containing $\left.U(E(N P V))^{*} E C\right)$ can be added to the model.

Applying this model to explain the survey results adds to the understanding of certain FDI decisions. In section 6.2.1 four examples were mentioned of investments that were hard to explain using rational economic theory. I argued that all four examples were to some extent driven by emotions and intuition. The first two examples, an entrepreneur that invested in Budapest after spending his study time there and a Dutch entrepreneur with Bulgarian nationality who invested in Bulgaria, clearly exhibit a degree of the personal involvement with the country of their choice. Their utility of the decision-maker was most likely higher for the country they invested in than for any other transition country. As long as their E(NPV) exceeded zero, they did not even consider another investment alternative, because of their personal preferences. Similarly, the third entrepreneur was invited by a Moldovan contact person to engage in a joint venture with his firm in Moldova. This contact person provided the Dutch entrepreneur a stable investment environment, an already present

\footnotetext{
The difference between for instance slightly negative, neutral $(0)$ and slightly positive emotions on utility is larger than the difference between positive and very positive emotions. Therefore the marginal utility is positive but small at very negative and very positive levels of EC.

An example of an investment decision is a manager of a small company that considers investing in Hungary, including the fact that the manager has to move to Hungary. If he expects Hungary to be a profitable market (U(NPV>0) and also experiences positive emotions with respect to Hungary. $(\mathrm{U}(\mathrm{EC})>0)$, he will definitely invest in the country. However, if the business-economic calculations are positive $(\mathrm{U}(\mathrm{NPV})>0$ ) but the manager is totally against living in Hungary $(\mathrm{U}(\mathrm{EC}) \rightarrow-\infty)$, he will decide not to invest.
} 
network and directly available knowledge of the country. Again, if the Dutch entrepreneur felt positive about this investment and if the E(NPV) of the investment exceeded zero, there was no reason for the Dutch firm to consider alternative investments in the region. Even though alternatives could be more profitable, relying on the contact person and valuing the benefits this person bring in terms of more security lead to high personal preference of the entrepreneur, high enough on which to base the investment decision. The last example mentioned was the altruistic Dutch firm investing in Romania. The firm invested in the Romanian counterpart up to the point the Romanian firm was profitable. Once that happened, the Dutch firm sold its shares to the Romanian partner and started a new enterprise in Romania. Reasons to engage in such kind of investments are purely development-oriented, in order to assist a country in development. Profit was no motivation, but the personal utility of the decisionmaker was higher than the negative utility derived from only loss making or at best break-even investments. These examples show that relying on emotions and intuition can make analysis obsolete. Indeed, 59 percent of the firms in the survey did not make an analysis and made a quick emotional decision to invest. In addition, the personal motivations increase the chance that a firm invests, since these personal motivations add to a positive utility of the decision-maker.

\subsection{Difficulties of modeling emotions and intuition and including emotions and intuition in empirical research}

\subsubsection{Defining emotions and intuition}

In psychology literature there are several basic handbooks covering all aspects of emotions. Emotions alone already have more than 90 different definitions (Larsen (1999)). There is no full agreement among researchers on how to define emotions or intuition. As a result, in empirical research emotions are often introduced with a research specific working definition. According to Larsen and Fredrickson (1999) this approach is recommended since it limits possible misinterpretation of the results and makes choosing between the different kinds of emotions and emotion measures easier.

With respect to intuition also different definitions are used, but there are less different kinds of intuition than there are kinds of emotion, making the problem less complicated (the most common deviations are tacit or deliberate intuition and backward or forward based intuition, Hogarth (2001)).

Defining a working definition specific for each research, after which the measures of emotion are selected, prevents the risk of getting stuck in the discussion on the appropriateness of the definition. However, it makes comparison among research harder since different starting points are used. The creation of a commonly used framework including different kinds of emotions and intuition, measures of emotions and intuition and the advantages and disadvantages of specific measurements of emotions would be a useful tool for empirical research.

Including emotions and intuition in FDI decision-making model also raises the question how tastes and preferences deviate from emotions and intuition. Do emotions and intuition only influence the tastes and preferences or do they influence decision-making given the tastes and preferences. If a person is happier in a certain scenario, is that an emotion, or does he or she adjust his preferences towards that scenario? Are emotions short run and tastes and preferences long run? Further research is needed. 


\subsubsection{Measuring emotions and intuition}

Emotions can be measured; they have a valence scale. Someone can be not angry, a little angry or very angry. However, there are several measurement issues that need to be taken into account, specifically with respect to reliability, timing, context and validity. Measuring emotions is mainly subjective, only an individual himself can be fully aware of his or her own emotions. A little angry for individual one can be very angry for individual two. There is no reliability check of the "true emotions" of an individual. In addition, emotions take time. Sometimes emotions occur at once; sometimes they are part of a gradual process. The scale of emotions depends on timing. It is for instance likely that an individual is very angry at time of an accident, but as time passes the anger decreases. In addition, people underestimate the effect of visceral factors on their own current and future behavior and when asked before a certain event, emotions are underestimated or even misdirected, as are their effects. (Loewenstein (2000)).

Emotions also vary distinctively depending on the context. Imagine two firms considering investing in Slovenia, one of the most stable transition countries. Firm one only considered investing in more stable EU countries, whereas firm two until now focused on an FDI in the less stable countries of Africa. Given this context, firm one finds Slovenia a risky country, whereas firm two finds it a very stable FDI alternative, even though in fact the risk rate of Slovenia is equal for both firms.

The last difficulty with measuring emotions is validity. Given that emotion is such a broad term, which includes many aspects, it is hard to give evidence on the role of emotions. Emotions can be linked to many other variables and interactions, making it hard to prove the impact of emotions. For a detailed overview of these measurement issues, see Larsen and Fredrickson (1999).

Measuring emotions can be done through self-reports (subjective, each individual determines the kind and size of emotion using single or multiple-item measures), by observers or through measuring the more physiological signs such as for instance facial expressions, brain actions, or vocal measures. With respect to FDI decisions, emotions are less clearly visible since they are based on longer-term feelings. As a result, those emotions are probably best captured by subjective selfreports, by means of surveys or interviews, which raise the problems of reliability and context.

Intuition is, like emotion, present in every individual. Some intuition is innate, some is learned. Some people rely more on their intuition than others, but all individuals have intuition. Intuition cannot be scaled from little intuitive to very intuitive. It is possible, though, to make a distinction between choices based on analysis and choices based on intuition. Using self-report methods, it is possible to indicate to what extent people rely on their intuition. Of course, similar measurement problems occur as described for emotions.

\subsubsection{Modeling emotions and intuition}

Even though a substantial amount of research exists on emotions and intuition, their inclusion in FDI decision-making models is rare. In individual decision-making inclusion is more common, but since a firm's decision is less personal and (often) includes several decision-makers it is not possible to simply adopt one of those approaches without changes. The main motivation to opt for the subjective utility model was the simplicity of the model. An additive utility function allows highlighting the fact that emotions and intuition can be included in decision-making formulas and influence the decision at several levels. Most dominant is of course the separate utility function for the decision-maker, 
including the personal utility the decision-maker gets from the choice. As the explanation already mentions, this factor is translated into money terms, taking into account the size of the firm. It can also incorporate the sum of utility of several decision-makers. There is also an indirect influence of emotions and intuition, such as the interpretation of the variables included in NPV calculation. Equally, the variables included in the firm's utility function also influence the decision-makers utility.

Including emotions and intuition do not necessarily lead to suboptimal decisions. First, because of the utility gained by decision-maker, the total utility of an investment possibility can exceed the alternative option with a higher NPV but lower utility of the decision-maker. Personal preferences can weigh heavier than profit motivations. Second, emotion and intuition can be a good tool in decisionmaking. Analytical decisions take time and given the cognitive limitation of humans, emotions and intuition can be the factors making it possible for individuals to make a decision, whereas they otherwise waited to invest.

Having said that, the model is just a first attempt. It can be easily criticized, but as Loewenstein (2001) mentions "no one theory is correct. Decision-makers utilize multiple modes of decision-making. such as decisions based on reasons, affect, cost-benefit calculations and so on". However, there is no guideline on how to model these different decision modes. Therefore I give three suggestions of different approaches of the model, or how to incorporate emotions and intuition differently.

First, within the choice of a subjective utility model, different alternatives to include emotions and intuition are possible. In section 6.5 I chose for a utility function for both the decision and the decisionmaker. A second format is to include emotions and intuition as costs or benefits in the decision utility function. Besides expected revenues and expected costs of the FDI, the costs and benefits of emotions are also discounted in the final decision. ${ }^{31}$ Another possibility is to include emotions and intuition as multiplicative factor. If the emotional or intuitional choice is to invest, the decision variables are interpreted more positively by the decision-maker than if the emotional or intuitional choice would be not to invest. A last example of including emotions and intuition in the utility function is through proxy variables. Variables like salary, housing conditions or the quality of education system can be included as happiness indicators. If in country one those conditions are much better than in country two, the investor probably is happier in country one than in country two and the value of this happiness can be incorporated into the decision model.

An alternative model for the subjective utility model used in section 6.5 is the prospect theory. First formulated by Kahneman and Tversky (1979), it is an alternative method of explaining individual choices under risk. It explains effects found by individuals in decision-making in three specific areas that the utility theory does not incorporate, called the certainty effect, isolation effect and reflection effect. The certainty effect means that people are risk averse. They undervalue probable outcomes in comparison to certain outcomes. With respect to FDI decisions, this risk aversion can be an explanation as to why firms invest more often in low risk countries, even if the expected NPV of a high-risk country is higher. ${ }^{22}$ The isolation effect stands for the idea that, if given two alternatives, people consider only different aspects of the alternatives in their decision and ignore the components that are common to both alternatives. The reflection effect stipulates that choices between negative

\footnotetext{
"Examples could be the costs of plane tickets paid for your children because of guilt from taking them away from their current living environment, like school, clubs and friends.

${ }^{2}$ For example a certain NPV of an FDI in Hungary of 100 would be preferred to an FDI in Russia with $50 \%$ probability of an NPV of 300 and $50 \%$ NPV of 0 .
} 
proposals are equal to similar choice of positive proposals. In order to incorporate those effects in the model, prospect theory models decisions based on values given by individuals to gains or losses compared to a reference point." In addition, prospect theory uses decision weights in comparison to probabilities in order to take risk aversion into account (Kahneman and Tversky (1979), Edwards $\left.(1996)^{34}\right)$. Given that individuals make FDI decisions, it seems reasonable that prospect theory not only better explains individual decision-making, but also firm decision-making. However, this new insight does not change the content of the message in this chapter, which explains that emotions and intuition could add to understanding FDI decisions and should be explicitly included in a decisionmaking theory. Even if the shift from utility to prospect theory were made, the question remains as to how to include emotions and intuition in this theory.

\subsection{Conclusion}

Emotions and intuition are still largely absent in economic theory, though the inclusion of emotions and intuition in, for example, game theory or consumer behavior theory is becoming more current. However, in decision-making theories emotions have not yet been included. This is surprising, given the fact that studies on emotions indicate that they do influence decisions and that in addition they can be considered a tool to ease difficult decision-making problems.

Several results of the survey to Dutch investment decisions indicate that personal preferences can be very influential and important in FDI decisions.

In section 6.3 the results of the personal influence in decision-making are explained using the concept of bounded rationality. Given that humans face cognitive limitations and that affects their behavior, they may rely on other decision tools, such as experience or social networks. In section 6.4 an alternative explanation is offered, arguing that emotions and intuition influence investment decisions. They not only directly influence the decision-making process by dealing with uncertainty and incomplete information, but they also have a large impact on the decision-maker. The problem of including emotions and intuition in economic theory lies in the fact that they are an element that contradicts neoclassical rational behavior. In section 6.4.3 I argue that instead of causing a problem for the neoclassical assumptions, they can also be considered a solution, given the strict assumptions of stable tastes and preferences and perfect information are unlikely to hold anyway. Emotions and intuition can be a tool to deal with unstable tastes and preferences by means of quick prioritizing, as well as a tool to limit information search.

In section 6.5 a microeconomic model, based on utility maximization, is developed that includes the utility of a firm as well as the utility of a decision-maker. As such it includes both economic decisionmaking variables and an emotional coefficient.

This research was just a first attempt to include emotions in decision-making theory. The theoretical part only included a first step to incorporate emotions in FDI decisions, keeping the model rather limited. The empirical results should also be treated with care, given the fact that the measurement of emotions is a complicated issue and the results can be interpreted and explained in various ways.

\footnotetext{
17 Losing ten euros is considered much worse if your wealth is only ten euros than if your wealth is 10.000 euros. Therefore. prospect theory takes the change in wealth into account (ten euros), as well as the reference point (ten or 10.000 euros). whereas utility theory only considers total wealth.

"Edwards (1996) gives an excellent literature review of the prospect theory, including explanation of the theory and an overview of empirical work supporting and rejecting prospect theory.
} 
However, the results allow us to say that emotions and intuition are of importance in decision-making. Future research is needed in both the theoretical embedment in economic theory and empirical tests to the influence of emotions. Such research may shed more light on the added value of the inclusion of emotions and intuition in economic decision-making models, which again may lead to better explanatory power of the actual decision-making processes of firms. 


\section{Chapter 7 Conclusion}

\subsection{Motivation}

After the start of transition in 1989, the countries in Central and Eastern Europe and Central Asia liberalized their markets for goods, services and investments. Foreign trade and foreign investments were now freely allowed, thus imports, exports and foreign direct investment flows (FDI) have increased steadily since then. It is generally accepted that the impact of FDI is positive for the receiving country, since it not only provides capital but also knowledge in the form of human capital and technology, and employment possibilities. Therefore, almost all transition countries not only quickly changed their legal frameworks in order to allow FDI but also often established institutions with the purpose of facilitating FDI.

FDI is spread unevenly over the transition countries. More developed transition countries, such as Poland, Hungary and the Czech Republic, have received a large share of the total flows to the region, whereas the FDI invested in the Central Asian countries can be considered minimal.

Most Dutch firms with an FDI in a transition country also invested in the Central European countries, that are economically and politically most developed and geographically and culturally closest to the Netherlands. It is interesting to study this development, since it is questionable if the best investment possibilities are indeed in those Central European countries instead of in other geographically more distant and economically less developed transition countries. Those countries have a more risky investment climate, but the advantages such as the presence of natural resources or the absence of competition could outweigh the disadvantage of a higher investment risk.

This dissertation focused on all aspects of an FDI decision to an uncertain region such as Central and Eastern Europe and Central Asia. The purpose was to obtain a better idea of the complete investment decision process of Dutch firms investing abroad. The research questions were i) Which firm characteristics increase the chance a firm invests, ii) What does the investment decision process of firms look like and is it different for investors and noninvestors?, iii) Which country determinants attract Dutch investments to transition countries? and iv) How does personal influence relate to direct investment decisions?

Those questions were answered using firm level data obtained by a survey among Dutch enterprises and Dutch macroeconomic FDI data. Section 7.2 contains a summary of the chapters. In section 7.3 some practical advice based on the results of this study is discussed. This advice is not only directed to the Dutch enterprises making an investment decision, but also to Dutch and foreign institutions advising those firms as well as to foreign countries trying to attract FDI.

\subsection{Summary}

The dissertation can be divided in three parts. Part one, chapter two, three and four, provide a microlevel analysis. Chapter two gives an overview of the real option theory used in this dissertation. Chapters three and four tests whether the predictions from the option theory described in chapter two are realistic for Dutch firms. Chapter three focuses on the firm characteristics explaining and influencing FDI flows. Chapter four elaborates on the investment decision process of firms and links the investment decision process to the actual investment decision. In part two (chapter five) the influence of macrolevel country determinants on FDI is studied. In part three (chapter six) the role of 
emotions and intuition in an FDI decision is placed central.

In part one, chapter two gives an description of the real option model and relates the model to FDI decisions. The real option model is very suitable to model FDI decisions to transition countries, since it explicitly includes timing of an investment and uncertainty. Firms select one or several countries in which they consider investing. Based on an investment analysis, taking factors like timing and uncertainty into account, they make an investment decision. The real option model predicts that firms postpone an investment more often if uncertainty increases. Extensions of the model, derived in section 2.4 and 2.5 , add that postponement is more likely if a firm considers several countries to invest in and if those countries differ in country risk.

The real option model, as most economic decision theories, assumes that profit is the main motivation for a firm to invest in a foreign country. While it is clear that commercial firms are pursuing profit, the decision to invest in a transition country is not necessarily based on profit expectations only. Many other economic and noneconomic factors can influence the decision to invest. The option model predicts that firms invest if the expected profit is positive. However, the model does not specify how this expected profit is derived. Firms can use economic indicators to estimate the expected profit, but equally firms may not have the time, information and money available to spend on the decisionmaking analysis, skip the whole economic approach and base their decision on emotions or intuition.

In order to become aware of the process of investment decisions of firms, whether they make an analysis and if so, which factors they include, a survey was held among Dutch enterprises that were interested in the transition region. In annex A the methodology of this survey is described.

In chapter three and four determinants of FDI are studied. Based on the assumptions and expectations of the real option model hypotheses are formulated and tested using the survey data. Chapter three focuses on firm characteristics. The firms included in the sample are all firms that at some point between 1989 and 2000 were interested in investing in a transition country. Of the firms that considered international activities, the ones that decided to become active in a transition country are significantly larger than the firms that decided not to invest and they more often had previous business relations with one or several firms in the transition region. The logit regressions, testing which characteristics influence the chance a firm will invest in the transition region, all indicate the firm characteristics may not be the main explanatory variables for investment decisions. In fact, only larger firms are more likely to invest. The age, sector, number of owners and percentage of Dutch ownership do not influence the investment choice. Transition time influences the investment decision: the more time that has elapsed after transition started, the more likely firms are to invest. Experience effects are of great importance in explaining investment behavior as well; having experience increases the chance firms will invest (again) in the region. These results are in line with the option model expectations.

Chapter four describes the internal decision-making process of a firm. The main question is how or on what basis firms make an investment decision. Several hypotheses were derived from the assumptions the option model builds on as well as the predictions of the theoretical extensions of the model in chapter two. These hypotheses were tested in section 4.3. One of the interesting findings was that many firms decided not to invest without entering the decision process, without applying any decision rule or without making an investment analysis. With respect to the firms that made an investment analysis, the data show three interesting findings. First, the internal investment analysis 
was equally extensive for firms that decided to invest and firms that decided not to invest. This finding contradicts the idea that firms that decide not to invest are less well informed than firms that decide to invest. Second, firms with an FDI in a transition country prepare following direct investments equally well or even more thoroughly than their first investment in the region. The presence of experience with an FDI in the region does not lead to a less extensive analysis before the decision. Third, the extensiveness of the investment analysis influences the success evaluation of the firm positively, though the differences are small. Concluding, there is a large variation in the way firms prepare an investment decision. In section 4.5 a framework is developed to explain this finding by comparing the costs of collecting information with the benefits of the information in terms of decreased uncertainty surrounding the investment decision. Firms collect information as long as the benefits of this information exceed the costs of collecting the information. In addition, firms have a perceived risk of the direct investment and subjective (firm specific) risk threshold values. Firms invest if the perceived risk of the FDI is lower than a minimum risk threshold of investing and do not invest if the risk exceeds the maximum threshold of risk above which investment is no longer worthwhile. Between those two risk thresholds the firm postpones the investment decision and continues to collect information. By applying this framework, many of the findings contradicting the expectations based on the option model can be explained. First, firms do not need an investment analysis if their initial risk perception is above the maximum threshold or below the minimum threshold. If that happens they immediately decide to invest or not. Second, a long investment analysis period is no indication that firms invest eventually, since additional information can increase as well as decrease the perceived risk of the countries. Last, the fact that firms invest less and later in high-risk countries than in low-risk countries can be explained by an initial high-risk perception of investing in those countries. More information is needed in order to reduce the uncertainty of investing in high-risk countries before investments reach an acceptable risk level for the firms, below the minimum risk threshold.

Part two of the dissertation contains a macrolevel study. Chapter five focuses on aggregate Dutch FDI flows, specifically explaining FDI outflows to the transition countries. The gravity model is taken as the basic tool for the analysis. The basic gravity model performs well as a long run equilibrium model, but fails to incorporate volatility of FDI flows. In an attempt to explain FDI volatility, 60 additional indicators have been added to the basic gravity equation. In addition the study allows for nonlinearity by creating dummy variables for countries receiving far more (less) FDI than could be expected based on the basic gravity model and using those dummy variables to add interaction effects. Results show that certain explanatory variables have a nonlinear relationship with FDI flows. In general the expectations are that transition countries, after having been closed to FDI for a long period, should be catching up and receive relatively large FDI inflows. There is no evidence to support such a catch-up effect. The more one controls for the heterogeneity of the transition countries in the data set (through the inclusion of the basic gravity variables, additional variables and interaction effects), the larger the evidence that there is no such a thing as an overall upward gravity pull for these countries. There is also no reason to assume that the flows of Dutch FDI to the EU accession countries will increase in 2004 once the first eight countries join the EU. Currently, those countries have already reached their long run equilibrium levels. The other countries of Central and Eastern Europe and Central Asia still receive FDI inflows below their long run equilibrium level, but those countries are not affected by EU accession. There is some evidence of a complementary relation 
between $\mathrm{FDI}$ and trade.

Part three, chapter six, develops the idea that personal motivations are important in an FDI decision. Several results of the survey on Dutch investment decisions indicate that personal preferences can be very influential and important in FDI decisions. In chapter six personal motivations are highlighted and some possible explanations for those influences are given. Personal motivations are not often included in economic decision-making theories. In section 6.3 the presence of the personal influences in decision-making are explained using the concept of bounded rationality. Given the fact that humans face cognitive limitations and this affects their behavior, they rely on other decision tools, such as experience or social networks. In section 6.4 an alternative explanation is offered, posing that emotions and intuition influence investment decisions. Instead of causing a problem for the rationality assumptions generally included in economic theory, emotions and intuition can be considered a solution to decision-making problems given the fact that the strict assumptions of stable tastes and preferences and perfect information are unlikely to hold anyway. Emotions and intuition can be a tool to deal with unstable tastes and preferences and imperfect information by means of quickly prioritizing investment options, as well as by limiting information search. In section 6.5 a microeconomic model, based on utility maximization, is developed that includes the utility of a firm as well as the utility of a decision maker and as such both economic decision-making variables and the influence of emotions and intuition. Though basic, the model may be the first step to including emotions and intuition in economic decision-making models. As mentioned in section 6.6, there are numerous problems with including the concepts, ranging from definition problems, measurement problems and modeling issues, but given the concepts may be crucial for decision-making it is important to start the discussion, if only by including them in a basic model.

\subsection{Policy advice}

Based on this research, several conclusions can be drawn with respect to policy, not only for Dutch firms and institutions but also for government and institutions located in the host countries. There are three points of advice that are specifically apparent from this study. These three points of advice are discussed in more detail, divided into advice for the host country government, the investmentpromoting institutions and Dutch companies. The fact that three points of advice are selected does not mean these are the only points of advice that can be drawn from this research. At the end of this section several additional issues will be discussed briefly as well.

The first recommendation relates to the political and economic stability of the host country. In chapter five it becomes apparent that a lower country risk and political risk and a more developed business climate positively influence FDI inflows. In addition, the analysis in chapter four shows that firms often consider the economic and political developments of the host country in their investment decision processes. The firms in the survey mention many macroeconomic and political indicators as decision factors in the investment analysis. Both results indicate that FDI follows economic growth and development and does not initiate growth'. Country stability and performance are basic conditions for attracting FDI. For governments this result can be interpreted as an indication to initially focus their policy on 1) the introduction and implementation of democratic principles to create political

\footnotetext{
'The fact that FDI follows growth does not imply that once foreign direct investments reach a country, they do not stimulate growth as well. However, that relationship is not studied in this dissertation.
} 
stability, 2) the encouragement of economic development and economic growth and 3) the establishment of a good and stable legal and institutional basis. If such basic infrastructure is not present and minimal conditions with respect to political stability and economic development are not fulfilled by the host county, putting effort in attracting FDI will most likely be unsuccessful and establishing FDI-promoting institutions in the host country may not yet be a fruitful investment. The long run preconditions must be in place before short run FDI incentives will become useful. For FDIpromoting institutions in the Netherlands these basic conditions can be taken as a guideline to select the host countries on which the institutions focus. If basic conditions are missing, the interest of Dutch firms in those countries is low and focusing on those countries is costly. In addition, the macroeconomic and legal situation of the host country that do meet those basic conditions should be communicated clearly to interested firms. Summaries of legal regulations and lists of institutions present in the host country can be used, along with regular macroeconomic updates. This is in line with advice with respect to firms considering an investment in a transition country. Firms should realize that within the region, the distinctions between the countries are enormous; there are high risk countries, which do not fulfill the basic economic and legal conditions; there are medium risk countries that fulfill the basic conditions but are economically still risky and there are low risk countries, both economically and legally well developed. Before selecting a host country, firms should decide what risk level is acceptable in order to be able to evaluate whether their selected country fulfills their target.

The second recommendation based on this research is not to underestimate the importance of establishing a link between the firm interested in an FDI and the host country. In chapter three it was shown that having business relations with the region increases the chance a firm invests. The analysis in chapter four confirms this, since many firms with a contact person in the region considered an investment there and this contact person plays an important role in the decision-making procedure. In chapter six this fact is studied in more detail. Many of the firms indicated that personal motivations influenced their decision. The presence of a field of interest by someone in the firm, direct links between the firm and a contact person or institution in the host country, or personal motivations of the entrepreneur increase the chance a firm invests abroad. Thus, once an initial interest in the host country is present, firms become more aware of the possibilities for their firm to invest in that specific country. The role of personal motivations has been underestimated in FDI studies, but the survey results described in chapters three, four and six highlight that they are important factors in decisionmaking. In order to explore this field better, host country governments and FDI-supporting institutions could focus on the more personally oriented promotion. Governments can increase the awareness for their countries to a broader public by promoting for instance tourism or well-known country specific export products. But also less direct country promotion, through study exchange programs or city friendship links can lead to the creation of personal interests. Institutions can also opt for a personal approach instead of large-scale provision of basic information to many readers. The last may be cheaper, but fails to interest the reader personally. Smaller scale investments in for instance FDI networks, business study tours or trade fairs will reach fewer firms but may be more efficient in really convincing the firm an FDI is a good investment. Also more personally oriented activities, such as contacting host country nationals living abroad, or establishing links between local and foreign enterprises or regions can be useful to initiate a first interest in the host country. For Dutch companies 
there is also a piece of advice related to the personal relationships. In chapter six I argue that the utility of the decision maker should be taken into consideration when making an investment decision. If a person is interested in working in a certain country, this increases his or her enthusiasm and selfefficacy. Having a social network or contact person in a region probably positively influences the idea the individual has about a country. This personal interest and willingness to work in a country should be taken into account when making an investment decision.

The third recommendation relates to the uncertainty firms face when making an investment decision. Once a firm is interested in investing in a foreign country, it faces a lot of uncertainty related to the FDI. This uncertainty is very firm specific, varies between host countries and is affected by the timing of the investment. Given the fact that a firm can never obtain full information, uncertainty will always be present and means of decreasing uncertainty are therefore very important. Firms mentioned that lack of time and money, not necessarily the lack of profitable investment alternatives, are the main motivations for firms not to invest (chapter four). An investment analysis and investment preparations take a lot of time, most often from the higher management of a company. Therefore it would be an advantage if there were low-cost alternatives for the company to assist them with the investment analysis and preparation. The government of both host and home countries can assist firms by establishing (partly) public, nonprofit investment promotion institutions. Those institutions should have two forms of services, mass and individual. Mass information should be available at low cost, with the aim to introduce the host country to a firm, provide basic information about the country and reduce the firm's most elementary form of uncertainty. This can be done perhaps through the provision of easy comprehensible and accessible information materials related to the necessary procedural regulations of establishing an FDI, basic macroeconomic data or lists of institutions available to assist a firm during the investment procedure. In addition to providing large-scale general information, institutions should also provide tailor-made customer oriented services - at low cost - to seriously interested firms. The use of commercial consultancy services assisting in the investment decision process is very costly and specially small and medium sized firms are unable to afford such services. If those services were available at low cost, the firm would be able to decrease the uncertainty related to the FDI without having to spend a lot of time and money. This advantage increases the chance that a firm invests. Examples of individual services could be an individually organized study trip to a specific region or the provision of information related to a specific sector on request. In addition to providing those services the promotion of the availability of these institutions and services should be good. For example, many institutions in the host country are offering certain services, but firms are unaware of their existence. They generally operate at lower cost than Dutch institutions and are better informed on the situation in their region - but they should communicate their existence and the services they offer better to interested firms. Also Dutch nonprofit organizations can communicate the kind of services they offer better and could consider closer links with host country institutions. Companies themselves should realize that good preparation pays off. In chapter four I concluded that companies that had a more extensive investment analysis considered their FDI to be more successful now. They do not invest more often than firms with a limited preparation, but once they invest they benefit from their thorough investment analysis. Thus, it is beneficial for firms to use the institutions available at their full scope. This means not only institutions in the Netherlands, but also the ones in the host countries and not only the mass provision of information such as seminars 
and leaflets, but specifically also the more tailor-made services and sources of financial support.

Besides those three points of advice, more common results are found and confirmed by this study as well. Examples are the result in chapter five that trade and FDI are complementary and the result in chapter three that the presence of experience with trade within a firm increases the chance that the firm will start an FDI. In policy terms both findings imply that by promoting free trade, FDI also increases. Another example is the overall finding that long run stability and economic development is more important than short run advantages, such as low labor costs or cheap resources (chapter four). In policy terms, this means that incidental financial FDI incentives are less influential than incentives provided in the form of longer run agreements. As a last example, factors like the religion, the continent of the host country or geographical distance between home and host country are important determinants of FDI (chapter six). Countries of the same religion, located close to the home country in the same continent receive more FDI. FDI policies can thus be best targeted to the countries in the region, which are culturally and geographically closest to the host country.

"Humans answer the most important questions with their whole life. It doesn't matter what they say in between, which words and arguments they use to defend themselves. In the end, when everything is over, they answer the questions that the world so persistently keeps asking them with the facts of their life".

(Sándor Márai (2002), Embers) 



\title{
Annex A Methodology of the questionnaire research "The Foreign Direct Investment Decisions of Dutch Firms"
}

\begin{abstract}
"I have to admit,my heart was pounding and I was nervous. A long had a premonition that in Roulettenburg something would happen to me - my stay here would be a turning point in my life. It could not be any different and that is the way it would go.

It is of course ridiculous that I expect so much of this game for myself, but even more ridiculous seems the general opinion that is stupid and foolish to have high expectations of the game. Why should this game be worse than other ways of making money? Trade for instance?"
\end{abstract}

F.M. Dostojewski (1591), The Player)

\section{A1 Introduction}

The following annex describes the methodology of the questionnaire research, held in the spring of 2000. The questionnaire is designed to find out what factors influence the decision of Dutch firms to invest in a country in Central Europe, Eastern Europe or Central Asia, and what factors are crucial to selecting the country in which to invest. It was sent to 1550 Dutch firms that showed interest in investing in the CEE region during the years 1989-1999. Section A2 describes the set-up of the questionnaire. Section A3 gives an overview of the survey methodology. Section A4 provides some insight in the response rates and in section A5 the validity of the response will be tested using two nonresponse tests. Section A6 concludes.

\section{A2 The questionnaire}

The goal of the survey was to extract information needed to estimate an investment decision-making model directly from the firms that actually went through a decision-making process. As mode of the survey a mail questionnaire was chosen, since that left respondents the freedom to answer the survey questions at their convenience and look up information when needed. In addition the mail survey is the most cost-efficient survey method, making it possible to approach the complete survey population selected. Survey literature shows that response rates are comparable to other survey modes, supporting the choice of a mail survey.

\section{A2.1 The population}

The respondents of the survey had to be firms that were interested in investing in the CEE region in the past. In order to locate those firms a list of companies, provided by the Dutch Chambers of Commerce, was used. The list consisted of approximately 3000 addresses of Dutch firms that asked for documentation on the CEE region or participated in a seminar on investment opportunities in one of the target countries. ${ }^{2}$ The firms do not necessarily have a direct investment in, or trade relation with the CEE region, but applying for information or participation in a seminar is considered an indication

\footnotetext{
'Cooper and Schindler (2000), Dillman (1978). The total design method of Dillman was taken as a guideline to set up this survey.

${ }^{2}$ The seminars were organized by the NCH (Nederlandse Centrum van Handelsbevordering, Dutch Centre of Trade Promotion) or FENEDEX (Federatie van Nederlandse export promotie, Federation of Dutch Export Promotion).
} 
of serious interest.

The data available at the start of the survey were the firm name, address in the Netherlands, telephone number, fax number and contact person. To be included in the survey, the following conditions needed to be fulfilled:

1. The firm should be Dutch, registered under the Dutch law and fall under (at least a partial) Dutch ownership. 100 percent Foreign owned firms were excluded.

2. The firm should be commercial. Government organizations and voluntary and institutions were excluded.

3. During the last 10 years the firm should have had a business interest in the CEE region.

4. Each company could be included only once in the survey sample.

Since I opted for the mail survey approach, the entire population of 1550 firms could be included in the survey mailing.

\section{A2.2 The questions}

Two questionnaires were created: one for those companies with a direct investment in Central Europe, Eastern Europe or Central Asia, and one for those companies that did not have a direct investment in this region.

The following information was requested:

1. Characteristics of the Dutch firms

2. Information on the firm's Foreign direct investments

3. Investment calculations for the investment decision in the CEE region

4. Endogenous variables of the investment decision process

5. Exogenous variables of the investment decision process

6. The order of the investment decision-making process

7. Investment decision-making for follow-up FDI

8. Reasons for disinvestments in the CEE region

9. Motives for not investing in the CEE region

The two questionnaires are included in annex $B$.

\section{A3 The survey procedures}

Realistic response rates of mail questionnaires to private businesses lie between 20 and 30 percent. Given the fact that firms are not eager to participate in surveys in general, and the Netherlands traditionally has low response rates to mail surveys, a response rate of 20 percent was targeted. ${ }^{3}$

The survey preparation started in the summer of 1999. The draft questionnaire was constructed based on the results of a small study from 1998 among Dutch firms with a direct investment in Hungary ${ }^{4}$. Additional information used for the construction of the questionnaire was obtained by conversations with institutions in the Netherlands and Poland ${ }^{5}$. Dutch companies ${ }^{6}$ and several

\footnotetext{
${ }^{2}$ See for example Kriechel (1999) or Geuzinge, van Rooyen and Bakker (2000).

'The questionnaire focused specifically on the factors that influenced the firms' investment decision to go to Hungary. The sample consisted of 101 firms with a direct investment in Hungary, of which 50 respondents returned the survey after a very intensive follow-up procedure with both follow-up mail questionnaires and telephone calls.

${ }^{3}$ Dutch Chamber of Commerce, Central and Eastern Europe Desk. Amsterdam; NCH (Netheriands Center for Trade
} 
subsidiaries of Dutch companies in Moldova and Hungary ${ }^{7}$. Afterwards experienced survey designers at the National Opinion Research Center (NORC), Maastricht University, the Open University and the Free University commented on draft versions of the questionnaire and the set-up of the survey.

Respondents were informed that information on the research and the researcher was available on an Internet site. This Internet site contained a description of the research, a CV of the researcher, frequently asked questions, a confidentiality statement and a list of institutions that support the intention of the research.

In November 1999 a pre-test was undertaken, which included 48 randomly selected firms. No major problems were encountered during this testing. The response rate of the pre-test was 17 percent (see annex A1 table one). After the pre-test the questionnaires and mailing procedure were adjusted. The final mailing included an advance letter from the researcher, two questionnaires, a return envelope and a recommendation letter from the NCH (Dutch Centre of Trade Promotion). Two weeks after the initial mailing a follow up fax was sent to all companies that had not returned the questionnaire. A month later a complete new package, including both questionnaires was sent by mail to all companies that had not yet responded, followed by a reminder fax. The entire procedure was started in early February 2000, and in June 2000 the mailing procedure was considered finished.

During the mail survey procedure some errors in the database were detected, being that some firms included in the list were nonprofit, bankrupt or foreign-owned. Also several addresses in the original list were not up-to-date anymore, since many firms had changed location in the Netherlands. Therefore all addresses of the nonresponding firms were checked again using the Dutch telephone book, a firm registration database and an Internet search. ${ }^{8}$ Those firms of which the address were unknown in either one of those sources were marked as "firms that could not be located". All of these findings were marked in the database, and taken into account in the response rate calculation.

\section{A4 The response of the survey}

The response rate of the mail survey was 17.85 percent. Table two in the annex A1 gives an overview of the response of the mail survey response.

In July and August 2000 a telephone follow-up was undertaken in order to collect data for additional companies. Survey theory offers evidence that surveys with several modes of questioning offer larger response rates and lower nonresponse errors because by offering two different survey modes, the respondents could participate using the mode of surveying they prefer. ${ }^{9}$ The advantages of a telephone approach are the personal contact with the respondents, the possibility to directly convince the firm to participate in the survey and the possibility to approach many firms without having to spend time on traveling and the relatively low costs. In addition, selecting a sample from the nonrespondents of the mail survey and obtaining information of those firms will provide a clearer picture on the composition of the nonrespondents of the mail survey and therefore also the composition of the population. This method will be described in more detail in section A5.

Promotion. The Haque; Dutch Chamber of Commerce for Poland. The Hague: Ministry of Foreign Affairs, Directorate Central Europe, The Hague; Trade and Communication Centre Poznan - Noord Brabant. Poznan, Poland.

"Nine companies were asked to comment on the questionnaires during a meeting or telephone call. Seven of those firms responded to this request.

'One Dutch firm in Moldova and four Dutch firms in Hungary were visited in order to see to what extent the questions covered their actual procedure of investments decision or if some important aspects were lacking.

"The PTT "CD-foon was used as telephone database, and "Reach" was used as the company database

"See for instance Schindler and Cooper (2000) or Tomaskovic-Devey. Leiter and Denekamp (1994) 
Figure A1: Visualization of the mail survey response and telephone sample response

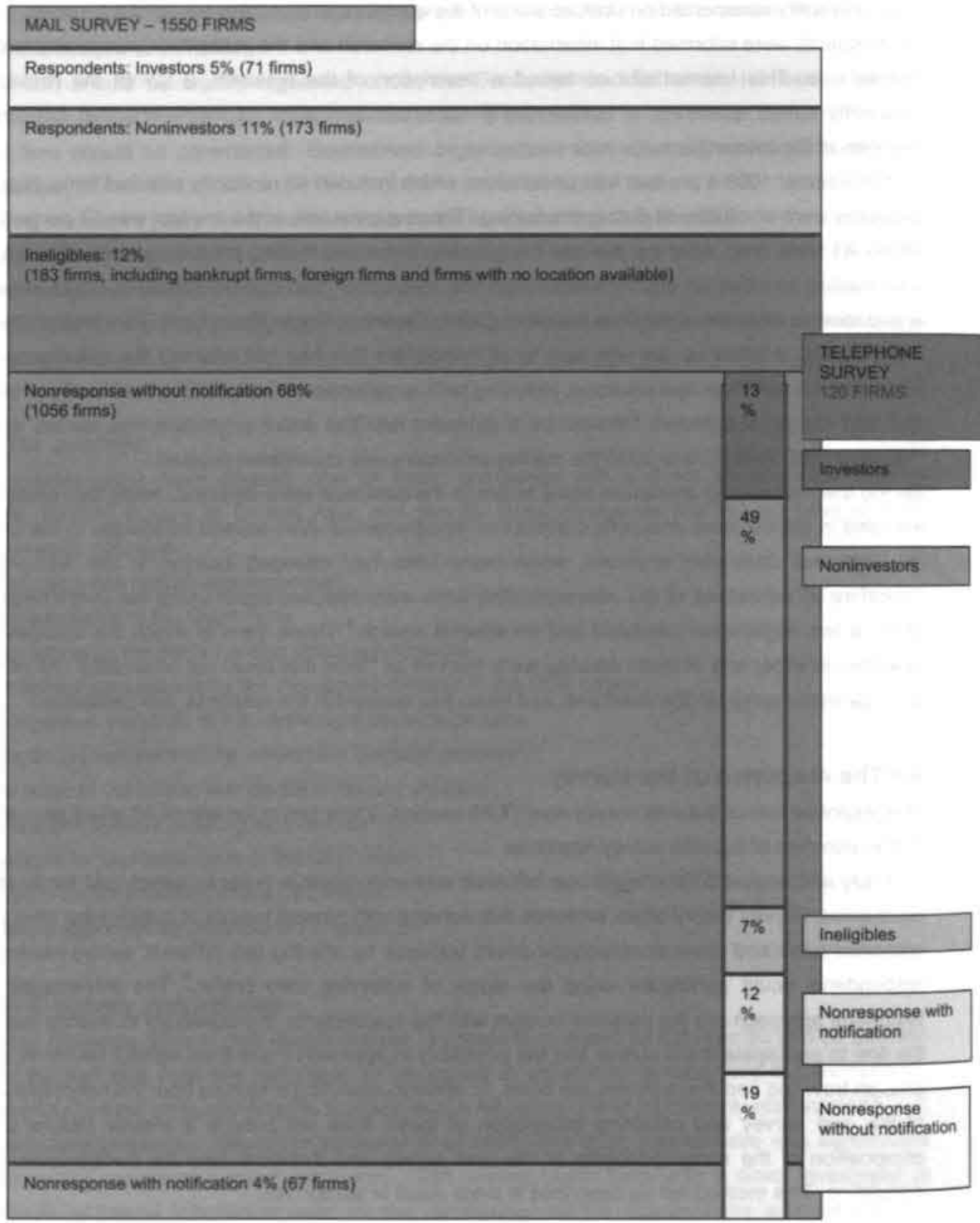


The main disadvantages of the telephone follow up were the fact that it is a time consuming survey mode for the interviewer and that the questionnaire was designed as a mail survey, so several questions were complicated to ask and answer by telephone. ${ }^{10}$ This could cause bias in the results of the telephone survey and make the phone response harder to compare with the mail results.

120 firms were selected at random from the mail survey nonresponse to compose the telephonesample of firms. ${ }^{11}$ Of those 120 firms five already had responded to the mail survey procedures, indicating they were not willing to participate in a survey. The remaining 115 firms were approached by telephone. Figure A1 represents the mail survey and telephone sample responses.

Table three in annex A1 describes the composition and response rates of the telephone follow up. The telephone response rate, 66.7 percent, was much higher than the response rate of the mail survey. During the telephone interview the respondents were asked what their motivations were for participating in the telephone survey and not the mail survey. The most frequently mentioned motivations were:

a) The mail questionnaire never reached the desk of the respondent.

b) The timing was better. The telephone survey was held in the summer period, when most firms were having a "low-profile or less busy period".

c) During the telephone survey the respondent was personally contacted, making it much harder to refuse participation.

d) All respondents could be explained why their response was important, even if they did not have an investment in CEE countries.

The total response rate of the questionnaire, including the mail and telephone survey, was 23.42 percent (see table A1).

Given the fact that two different modes of questioning were used in the survey, a check to see if the data could be jointly used in further analysis was done. Tabulations were made using investment status (investor CEEC, noninvestor CEEC, refusals, bankrupt, ineligibles, firms that could not be located, and nonresponse) and general firm characteristics (sector, location, age, number of employees). With respect to investment status, relatively more noninvestors participated in the telephone survey than in the mail survey, and this difference was statistically significant. The bankrupt firms, ineligible firms and firms that could not be located were about equal in the telephone and the mail surveys.

Even more important was the question whether the respondents of the mail survey were different in their basic characteristics from the respondents that participated by telephone. Therefore the characteristics sector, location, age and size of the respondents were used to test whether the respondents of both survey modes could be considered comparable, and if they could be jointly used in the further analysis of the data. The result of the tests showed that the majority of variables were not significantly different, irrespective to the response mode chosen by the respondents. The only exception is the variable age. The firms that responded in the mail survey were significantly younger than the firms that participated in the telephone survey.

\footnotetext{
"Several questions were stated as tables, and hard to communicate over the telephone since the visual effects were missing.

"The number of 120 firms was decided upon based on a time constraint. Conducting the telephone interviews took no more than two months' time for the researcher. This estimation turned out to be realistic.
} 


\section{Table A1: Response of the overall (among 1550 firms)}

\begin{tabular}{|c|c|c|}
\hline & Number of firms & Percentage of firms \\
\hline $\begin{array}{l}\text { Respondents: } \\
\text { Firms with an investment in CEEC } \\
\text { Firms without an investment in CEEC }\end{array}$ & $\begin{array}{r}86 \\
232 \\
\end{array}$ & $\begin{array}{r}5.6 \% \\
15.0 \% \\
\end{array}$ \\
\hline $\begin{array}{l}\text { Nonresponse: } \\
\text { Firm indicated it does not want to participate } \\
\text { Non response }\end{array}$ & $\begin{array}{r}76 \\
964 \\
\end{array}$ & $\begin{array}{r}4.9 \% \\
62.2 \% \\
\end{array}$ \\
\hline $\begin{array}{l}\text { Excluded from response calculation: } \\
\text { Firms does not exists anymore } \\
\text { Firm is foreign or not for profit } \\
\text { Firm can not be located }\end{array}$ & $\begin{array}{r}16 \\
29 \\
147 \\
\end{array}$ & $\begin{array}{l}1.0 \% \\
1.9 \% \\
9.5 \%\end{array}$ \\
\hline TOTAL & 1550 & $100 \%$ \\
\hline Response rate & & $23.42 \%$ \\
\hline
\end{tabular}

Note: response rate $=$ investors + noninvestors response / total sample size - firms excluded due to bankruptcy, ineligibility or firms without location

However, given the fact that age was the only control variable indicating that the firms responding to the mail and telephone may have different characteristics, mail and telephone responses can be added to one dataset without losing credibility. During the further analysis of the data, safety-tests were undertaken per item to check whether the telephone or mail mode of questioning significantly influenced the answer behavior.

\section{A5 Nonresponse bias}

In this last section of the annex I check whether there is a nonresponse bias in this survey. Motivation to do so is the possible need for correction of the data during further analysis. The nonresponse bias will be looked at in two different ways. The first test used the random telephone sample taken of the mail survey nonresponse to create a picture of what the entire population would look like with respect to investment status (investing in the CEE region or not). The second test used general firm characteristics of the whole survey population to check whether the respondents were significantly different from the nonrespondents.

In the first test I used the random telephone sample to estimate what the population of firms looked like with respect to investment status. The respondents and ineligible firms of the mail survey together were 27.5 percent of the total population. The random telephone sample, taken from the nonrespondents of the mail survey, therefore provided a picture of the composition of the additional 72.5 percent of the population. In order to give an as accurate as possible estimation of the composition of this 72.5 percent of the population, the 37 nonrespondents of the telephone sample were asked to answer seven core questions, including their investment status. ${ }^{12}$ An estimated composition of the population is included in table one of annex A2. From this table can be seen that noninvestors were underrepresented among the respondents of the survey, whereas the number of investors that responded was proportionally correct. The number of firms that could not be located may have been overestimated in the response of the survey. ${ }^{13}$

In the second test I used firm data available for the whole population and compared whether the respondents and the population could be considered equal with respect to those characteristics. At

\footnotetext{
${ }^{12}$ The additional information asked for was the sector of activity, year of set-up, number of locations, revenue in 1999 , number of employees in 1999 and ownership division of the company.

13 This overestimation may be due to the fact that with the telephone survey direct contact was made with the new owners /residents of the location the firm was registered. They could refer to the new location the firm moved to. It is harder to find new addresses in external sources, as is the case with the mail approach.
} 
the start of the survey the addresses of all firms were available, leaving the option to test whether the respondents were geographically clustered to one region, or evenly spread over the country. ${ }^{14}$ The locations in the Netherlands also gave the option to split up the firms according to size of their resident city, in order to test whether respondents were more likely to be located in a city or village than nonrespondents. ${ }^{15}$ In addition, external databases gave access to information on sector (SBI code) ${ }^{16}$, size (number of employees) and age (year of set-up in the Netherlands) for approximately 90-95 percent of the entire population (the actual percentage depending on the variable considered). These data can heip answer the questions whether the specific characteristics of the firm increased the likelihood of answering the questionnaire. The three categorical variables, sector, geography and urban or rural location of the firm, were included in a Pearson chi $^{2}$ test, checking the hypothesis that the control variables and response behavior of the firms were independent. I expected these variables not to have any influence on response behavior. This is the case for the geographic position in the Netherlands, and for the size of the city in which the firm is located. However, the sector in which the firm is active affects response behavior. The main differences between the respondents and the population were an overrepresentation of industrial firms among the respondents and an underrepresentation of agriculture and construction sector firms. The influence on response behavior of the two remaining variables, age of the firm and size of the firm (number of employees in 1999) was larger. I expected both larger and older firms to respond more often to the questionnaires. ${ }^{17}$ This was checked using a two-sample t-test. ${ }^{18}$ The results show that there is a significant difference in response behavior between older and younger firm. Those firms that did answer the questionnaire are older than those that did not answer the questionnaire. Equally, the size of the firms influenced response behavior positively, being that the survey respondents were larger than the nonresponding firms. ${ }^{19}$

In order to verify these results, a probit analysis was undertaken using all control variables both separately and jointly. With respect to sector of activity almost all sectors were less likely to participate in the survey than firms from the sector Industry (which was the largest sector, and taken as baseline). Only firms included in the sectors $O t h e r^{20}$ were more likely to answer the survey than the firms from the sector Industry. The sector of activity did significantly influence response behavior at a five percent level. Location in a specific region in the Netherlands did not influence response behavior significantly, neither when individually tested nor when jointly included in the probit analysis.

\footnotetext{
14 The firms are split into four regions (North, East, South, West) using their zip codes as geographic indicator.

5 The location of the firms was divided into three main categories, being villages with less than 10.000 inhabitants, villages or cities with between 10.000 and 50.000 inhabitants and cities with more than 50.000 inhabitants.

"Concerning sector activity, all firms are allocated using the standard coding appropriate in the Netherlands (SBi codes). Using these codes the firms were placed into 13 main categories.

"In Tomaskovic-Devey, Leiter and Thompson (1994) three factors are mentioned which influence response behavior, namely authority to respond (is the recipient allowed to respond), organizational capacity to respond (is it organizationally possible for the respondent to acquire all information to answer the survey) and motive to respond (are there enough individual and organizational reasons to respond). I would like to add a fourth factor, being time to respond, indicating that small firms often do not have as much human resources and time available to participate as larger firms. Larger firms tend to be more complex, and are expected to respond less to survey requests, based on the first two arguments. However, they do have more time and resources available (fourth argument), which would indicate they might respond more often than smaller firms. Based on experience in previous survey among Dutch firms in Hungary and the pretest I expect large firms to respond more often. it Age and size were both tested with equal and unequal variance assumptions. Using Bartiet's test, age is included with equal variance assumptions, and size with unequal variance assumptions though the results were not affected by this choice. The tests were also done with age and size categorized over ranges. The findings were comparable to the findings using the numerical variables.

"Remark that the variables age and size were also significantly positively correlated.

vo The sector Other includes Hotel and Restaurants sector, Government services, Education, health. Environment. Culture. Recreation, Private households and Extraterritorial organizations.
} 
The same is true for the size of the city or village in which the firm is located, this does not affect response behavior either.

With respect to the age and size of the firm, the results of the probit analysis confirmed the previous tests. Here I find that the older the firm is, the larger the probability is that this firm will participate in the survey. The likelihood of participating in the survey will also increase the larger the firm is. The results of the combined probit analysis are included in table two (annex A2).

Concluding from these nonresponse bias tests there are two important factors that need to be taken into account during further analysis of the data. Firstly, there is an under representation of noninvestors in the response of the survey. Secondly, larger and older firms are more likely to respond to the survey than smaller and younger firms, so they are over represented in the response of the survey.

\section{A6 Conclusions}

During the development of the survey, to focus has been to create a questionnaire that will both give sufficient information and will be clear and understandable for the respondents. Given that surveys among firms in general do not result in high response rates, and the Netherlands is a country that is known for low survey response, the response rate of 23.4 percent is satisfactory.

This response rate is achieved by using both a mail and telephone mode. Tests show there is no major deviation between the respondents of each mode, so the data can be grouped for further analysis.

The nonresponse bias test revealed that there is an under representation of firms without investment in the CEE region among the respondents. With respect to firm characteristics there is an overrepresentation of older and larger firms among the survey respondents. These two response biases will be taken into account during the analysis of the data. 


\section{Annex A1 Response rates}

\section{Table A1.1: Response of the pretest of 48 firms}

\begin{tabular}{|c|c|c|}
\hline & $\begin{array}{l}\text { Number } \\
\text { of firms: }\end{array}$ & $\begin{array}{l}\text { Percentage } \\
\text { of firms }\end{array}$ \\
\hline $\begin{array}{l}\text { Respondents: } \\
\text { Firms with an investment in CEEC } \\
\text { Firms without an investment in CEEC }\end{array}$ & $\begin{array}{l}2 \\
6 \\
\end{array}$ & $\begin{array}{r}4 \% \\
13 \% \\
\end{array}$ \\
\hline $\begin{array}{l}\text { Nonresponse: } \\
\text { Firm indicated it does not want to participate } \\
\text { Nonresponse }\end{array}$ & $\begin{array}{r}2 \\
36\end{array}$ & $\begin{array}{r}4 \% \\
75 \%\end{array}$ \\
\hline $\begin{array}{l}\text { Excluded from response calculation: } \\
\text { Firms does not exists anymore } \\
\text { Firm is foreign or not for profit } \\
\text { Firm can not be located }\end{array}$ & $\begin{array}{l}0 \\
1 \\
1 \\
\end{array}$ & $\begin{array}{l}0 \% \\
2 \% \\
2 \% \\
\end{array}$ \\
\hline TOTAL & 48 & $100 \%$ \\
\hline Response rate & & $17.39 \%$ \\
\hline
\end{tabular}

Note: response rate $=$ investors + noninvestors response / total sample size - firms excluded due to bankruptcy, ineligibility or firms without location

\section{Table A1.2: Response of the mail survey}

\begin{tabular}{|c|c|c|}
\hline & Number of firms & Percentage of lirms \\
\hline Respondents: & & \\
\hline Firms with an investment in CEEC & 71 & $4.58 \%$ \\
\hline Firms without an investment in CEEC & 173 & $11.16 \%$ \\
\hline Nonresponse: & & \\
\hline Firm indicated it does not want to participate & 67 & $4.32 \%$ \\
\hline Nonresponse & 1056 & $68.13 \%$ \\
\hline Excluded from response calculation: & & \\
\hline Firms does not exists anymore & 13 & $0.84 \%$ \\
\hline Firm is foreign or not for profit & 28 & $1.81 \%$ \\
\hline Firm can not be located & 142 & $9.16 \%$ \\
\hline TOTAL & 1550 & $100 \%$ \\
\hline Response rate & & $17.85 \%$ \\
\hline
\end{tabular}

Note: response rate $=$ investors + noninvestors response / total sample size - firms excluded due to bankruptcy, ineligibility or firms without location

\section{Table A1.3: Results of the telephone follow up among 120 firms}

\begin{tabular}{|l|r|r|}
\hline & Number of firms & Percentage of lirms \\
\hline Respondents: & 15 & $12.5 \%$ \\
Firms with an investment in CEEC & 59 & $49.2 \%$ \\
Firms without an investment in CEEC & 14 & $11.7 \%$ \\
\hline Nonresponse: & 23 & $19.2 \%$ \\
\hline Firm indicated it does not want to participate & 3 \\
Nonresponse & 3 \\
\hline Excluded from response calculation: & 1 \\
Firms does not exists anymore & 5 & $2.5 \%$ \\
Firm is foreign or not for profit & $0.8 \%$ \\
Firm can not be located & $4.2 \%$ \\
\hline TOTAL & $100 \%$ \\
\hline Response rate & $66.7 \%$ \\
\hline
\end{tabular}

Note: response rate $=$ investors + noninvestors response / total sample size - firms excluded due to bankruptcy, ineligibility or firms without location 



\section{Annex A2 Nonresponse bias tests}

\section{Table A2.1: Comparison of survey respondent with estimation of population composition}

\begin{tabular}{|c|c|c|c|c|}
\hline & Mair $(27.5 \%)$ & Sample" $(72.59)$ & Population & $\begin{array}{l}\text { Response } \\
\text { Survey.*. }\end{array}$ \\
\hline $\begin{array}{l}\text { Response } \\
\text { category }\end{array}$ & $\begin{array}{l}\text { percentage division } \\
\text { (nr. of firms) }\end{array}$ & $\begin{array}{l}\text { percentage division } \\
\text { ( } \mathrm{nr} \text {. of firms) }\end{array}$ & $\begin{array}{l}\text { weighted estimation of } \\
\text { percentage division }\end{array}$ & \\
\hline Investor & $\begin{array}{l}16.63 \% \\
(71)\end{array}$ & $\begin{array}{l}15.00 \% \\
(18)\end{array}$ & $15.45 \%$ & $16.86 \%$ \\
\hline Noninvestor & $\begin{array}{l}40.52 \\
(173) \\
\end{array}$ & $\begin{array}{l}76.67 \% \\
(92)\end{array}$ & $66.73 \%$ & $45.49 \%$ \\
\hline Bankrupt & $\begin{array}{l}3.04 \% \\
(13)\end{array}$ & $\begin{array}{l}2.50 \% \\
(3)\end{array}$ & $2.65 \%$ & $3.14 \%$ \\
\hline $\begin{array}{l}\text { Foreign owner I } \\
\text { Not for profit }\end{array}$ & $\begin{array}{l}6.56 \% \\
(28) \\
\end{array}$ & $\begin{array}{l}0.83 \% \\
(1)\end{array}$ & $2.41 \%$ & $5.69 \%$ \\
\hline \multirow[t]{2}{*}{$\begin{array}{l}\text { No location } \\
\text { available }\end{array}$} & $\begin{array}{l}33.26 \% \\
(142)\end{array}$ & $\begin{array}{l}5.00 \% \\
(6)\end{array}$ & $12.77 \%$ & $28.82 \%$ \\
\hline & $\begin{array}{l}100 \% \\
(427)\end{array}$ & $\begin{array}{l}100 \% \\
(120)\end{array}$ & $100 \%$ & $100 \%$ \\
\hline
\end{tabular}

- Percentage taken over the mail survey response excluding the nonresponse, together $27.5 \%$ of the total population.

*- Percentages are taken from the investment status of the randomly selected 120 firms of the telephone survey. They are weighted for $72.5 \%$ of the population.

... Percentage division of the response of the total survey (mail and telephone) excluding the nonresponse.

\section{Table A2.2: Probit analysis on response behaviour including all control variables}

\begin{tabular}{|c|c|c|c|c|c|c|}
\hline Variable & Coefficient & Standard error & $z$ & $P>|z|$ & \multicolumn{2}{|c|}{ 95\% Confidence Interval } \\
\hline Nature & -1.29145 & 0.1140559 & -11.32 & 0.000 & -1.514995 & -1.067904 \\
\hline Construction & -1.449753 & 0.1383312 & $-10,48$ & 0.000 & -1.720877 & -1.178629 \\
\hline Logistics & -0.6041813 & 0.1731393 & -3.49 & 0.000 & -0.943528 & -0.2648345 \\
\hline Finance & -1.182294 & 0.2338405 & -5.06 & 0.000 & -1.640613 & -0.7239752 \\
\hline Retail & -0.4260709 & 0.1359341 & -3.13 & 0.002 & -0.6924968 & -0.159645 \\
\hline Other & 0.4968404 & 0.2813449 & 1.77 & 0.077 & .0 .0545855 & 1.048266 \\
\hline Age & 0.0034519 & 0.0015161 & 2.28 & 0.023 & 0.0004804 & 0.0064234 \\
\hline Employment & 0.0000643 & 0.0000293 & 2.20 & 0.028 & $6.97 e^{-06}$ & 0.0001217 \\
\hline North & -0.2805169 & 0.1797716 & -1.56 & 0.119 & -0.6328628 & 0.071829 \\
\hline East & -0.0560796 & 0.1185736 & -0.47 & 0.636 & -0.2884796 & 0.1763204 \\
\hline South & -0.0111715 & 0.105124 & -0.11 & 0.915 & -0.2172109 & 0.1948678 \\
\hline Large village & 0.0280266 & 0.1024012 & 0.27 & 0.784 & -0.1726761 & 0.2287292 \\
\hline Village & 0.1009298 & 0.1055426 & 0.96 & 0.339 & $-0,1059299$ & 0.3077895 \\
\hline Constant & -0.0836204 & 0.1290381 & -0.65 & 0.517 & -0.3365304 & 0.1692897 \\
\hline
\end{tabular}

Number of obs $=1260$

LR chi2 $(13)=256.44$

Prob $>$ chi $2=0.0000$

Log likelihood $=-581.42005$

Pseudo $R 2=0.1807$ 



\title{
Annex B Questionnaire forms
}
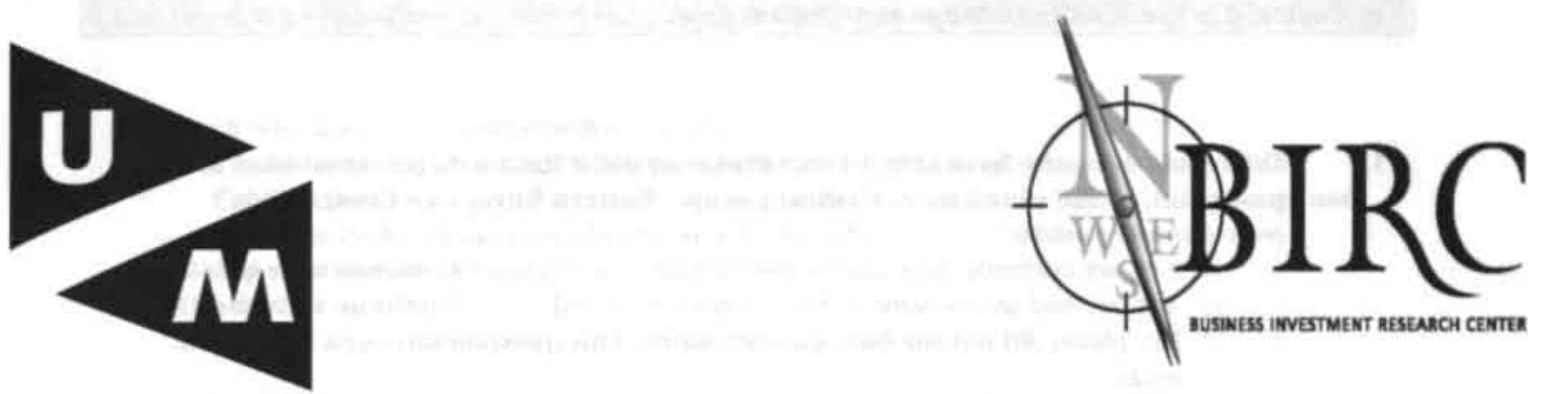

\section{QUESTIONNAIRE FOR DUTCH FIRMS WITH A DIRECT INVESTMENT IN CENTRAL EUROPE, EASTERN EUROPE OR CENTRAL ASIA}

The questions in this questionnaire are about the decision of Dutch firms to initiate a direct investment in one of the countries of Central Europe, Eastern Europe or Central Asia (further referred to as the CEE region). Foreign direct investments are newly started enterprises, takeovers of already existing local firms or joint ventures with a local company.

The questionnaire consists of 6 parts; $A$ to $F$ and it takes approximately 30 minutes to fill out.

We thank you in advance for your co-operation

\author{
Prof. Dr. Chris de Neubourg \\ Drs. Mindel van de Laar \\ Maastricht University
}

NOTE: These questionnaires are translated to English. The original Dutch version, filled out by the firms, is available at your request. 


\section{PART A: INVESTMENT PLANS IN THE CEE REGION}

The first 3 questions of this questionnaire are about possible investment plans of your company in Central Europe, Eastern Europe and Central Asia.

1. Does your company have a direct investment or did it have a direct investment in the past in one of the countries in Central Europe, Eastern Europe or Central Asia? (only I answer possible)

1 [] Yes, we currently have one or more direct investments. Continue with question 2

2 [] Yes, we had an investment that is currently closed. Continue with question 2

3 [ ] No, please fill out the blue questionnaire. This questionnaire can be thrown away.

2. Which one of the following countries in the CEE region, in which your company has no investment yet, would be the country of your first, second and third choice in which to invest at this moment, and which country do you consider the least attractive for your company to invest in at this moment?

(please write down the number of the country on the dotted line)

$\begin{array}{lllll}\text { Albania } & 10 & \text { Croatia } & 19 & \text { Serbia-Montenegro } \\ \text { Azerbaijan } & 11 & \text { Latvia } & 20 & \text { Slovenia } \\ \text { Bosnia-Herzegovina } & 12 & \text { Lithuania } & 21 & \text { Slovak Republic } \\ \text { Bulgaria } & 13 & \text { Macedonia } & 22 & \text { Tajikistan } \\ \text { Estonia } & 14 & \text { Moldova } & 23 & \text { Czech Republic } \\ \text { Georgia } & 15 & \text { Ukraine } & 24 & \text { Turkmenistan } \\ \text { Hungary } & 16 & \text { Poland } & 25 & \text { Uzbekistan } \\ \text { Kazakhstan } & 17 & \text { Romania } & 26 & \text { Belarus } \\ \text { Kyrgyzstan } & 18 & \text { Russia } & & \end{array}$

Number country of your $1^{\text {st }}$ choice:

Number country of your $2^{\text {nd }}$ choice:

Number country of your $3^{d}$ choice:

Number country of your last choice:

3. In which one of the following countries do you expect your company to invest in within the next two years?

This direct investment could in this case be your first investment in a specific country, but also a new investment in a country in which your firm is already active.

(multiple answers possible)

$\begin{array}{ll}\text { [] Albania } & 10 \text { [] Croatia } \\ \text { [] Azerbaijan } & 11 \text { [] Latvia } \\ \text { [] Bosnia-Herzegovina } & 12 \text { [] Lithuania } \\ \text { [] Bulgaria } & 13 \text { [] Macedonia } \\ \text { [] Estonia } & 14 \text { [] Moldova } \\ \text { [] Georgia } & 15 \text { [] Ukraine } \\ \text { [] Hungary } & 16 \text { [] Poland } \\ \text { [] Kazakhstan } & 17 \text { [] Romania } \\ \text { [] Kyrgyzstan } & 18 \text { [] Russia }\end{array}$

[] Albania

[] Azerbaijan

[] Bosnia-Herzegovina

[] Bulgaria

[] Estonia

[1 Georgia

[1 Hungary

[] Kyrgyzstan
Serbia-Montenegro

Slovak Republic

Tajikistan

Czech Republic

Turkmenistan

Belarus
19 [] Serbia-Montenegro

20 - Slovenia

21 [] Slovak Republic

22 [] Tajikistan

23. [] Czech Republic

24 [] Turkmenistan

25. [] Uzbekistan

26 [] Belarus 


\section{PART B: CHARACTERISTICS OF THE DUTCH FIRM}

The following 6 questions are about the activities of your company in THE NETHERLANDS

4. In which sector is your company active?

Please enter the main code according to the Dutch standard company codes of the Central Bureau of Statistics. A list of these codes is attached in Annex 1. If you do not know the code, please describe the activity briefly.

(only 1 answer possible)

SBI code:

5. In which year did your company start its activities in the Netherlands?

6. How many different locations / offices does your company have in the Netherlands?

7. What was the total revenue, profit, and number of employees working in your company in the Netherlands for last year (1999), 5 years ago (1994) and 10 years ago (1989)? If you do not know those data exactly, please make estimation. If your company was not operational in that year, please cross it out.

(please enter for each year your total revenue, profit and number of employees)

\begin{tabular}{|c|c|c|c|}
\hline Year & $\begin{array}{c}\text { Revenue before tax } \\
\text { (in guilders) }\end{array}$ & $\begin{array}{c}\text { Profit before taxes } \\
\text { (in guilders) }\end{array}$ & Number of employees \\
\hline 1989 & & & \\
\hline 1994 & & & \\
\hline 1999 & & & \\
\hline
\end{tabular}

8. What is the ownership structure of your Dutch company?

(please enter the ownership in percentages, adding to $100 \%$ )

Owner 1, nationality:

Owner 2, nationality:

Owner 3, nationality:

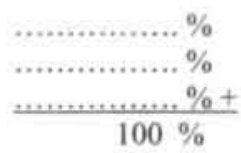

9. Are the decisions to invest in a foreign country made completely or partly by the Dutch company?

(only 1 answer possible)

1 [ Yes, a completely Dutch decision. Please continue with part C

2 [] Yes, the decision is made by the Dutch company in co-operation with the other owners. Please continue with part C

3 No, the decision is made by the foreign partners. This questionnaire is aimed at the investment decisions of Dutch companies. Since your foreign partner makes the foreign investment decisions of your company, the answers of your firm are not comparable with those of the other respondents. Please continue with part F. 


\section{PART C: INVESTMENTS IN THE CEE REGION}

Part C focuses specifically on your DIRECT INVESTMENTS in Central Europe, Eastern Europe and Central Asia. As direct investments we consider newly started companies, takeovers of a local firm by the Dutch company and joint ventures with a local firm in which the Dutch company is at least 10 percent owner.

10. In which countries in Central Europe, Eastern Europe and Central Asia (CEE region) does your company have one or more direct investments, and in which years were these started?

Please enter for each country the year of beginning for all your investment in that country, with a maximum of 5 per country. Please also enter those investments made before 1989.

(please enter for each country the starting year for all your investment in that country)

\begin{tabular}{|c|c|c|c|c|c|c|}
\hline & Country & $\begin{array}{l}\text { Year } \\
\text { opening } 1^{\text {st }} \\
\text { investment }\end{array}$ & $\begin{array}{l}\text { Year } \\
\text { opening } 2^{\text {nd }} \\
\text { investment }\end{array}$ & $\begin{array}{l}\text { Year } \\
\text { opening } 3^{\mathrm{d}} \\
\text { investment }\end{array}$ & $\begin{array}{l}\text { Year } \\
\text { opening } 4^{\text {th }} \\
\text { investment }\end{array}$ & $\begin{array}{l}\text { Year } \\
\text { opening } 5^{\text {th }} \\
\text { investment }\end{array}$ \\
\hline 1 & Albania & & & & & \\
\hline 2 & Azerbaijan & & & & & \\
\hline 3 & Bosnia-Herzegovina & & & & & \\
\hline 4 & Bulgaria & & & & & \\
\hline 5 & Estonia & & & & & \\
\hline 6 & Georgia & & & & & \\
\hline 7 & Hungary & & & & & \\
\hline 8 & Kazakhstan & & & & & \\
\hline 9 & Kyrgyzstan & & & & & \\
\hline 10 & Croatia & & & & & \\
\hline 11 & \begin{tabular}{|l|} 
Latvia \\
\end{tabular} & & & & & \\
\hline 12 & Lithuania & & & & & \\
\hline 13 & Macedonia & & & & & \\
\hline 14 & Moldova & & & & & \\
\hline 15 & Ukraine & & & & & \\
\hline 16 & Poland & & & & & \\
\hline 17 & Romania & & & & & \\
\hline 18 & Russia & & & & & \\
\hline 19 & \begin{tabular}{|l} 
Serbia-Montenegro \\
\end{tabular} & & & & - & \\
\hline 20 & Slovenia & & & & & \\
\hline 21 & Slovak Republic & & & & & \\
\hline 22 & Tajikistan & & & & & \\
\hline 23 & Czech Republic & & & & & \\
\hline 24 & Turkmenistan & & & & & \\
\hline 25 & Uzbekistan & & & & & \\
\hline 26 & Belarus & & & & & \\
\hline
\end{tabular}

The following questions are about the FIRST DIRECT INVESTMENT IN THE CEE REGION since 1989. 1989 is taken as focus year since after the fall of the Berlin wall in November 1989 the first countries in Eastern Europe and states of the Former Soviet Union broke with communism and started changing towards a market economy. 
11. What is the location of your first investment in the CEE region after 1989? Thereafter we will refer to this questionnaire as your " 1 " investment"

Name company.

City:

Country:

\section{From now on in this questionnaire we will refer to this company as your $1^{\text {st }}$ investment}

12. In which year is this $1^{\text {st }}$ investment made?

13. In which sector is your $1^{\text {st }}$ investment active?

Please enter the main code according to the Dutch standard company codes of the Central Bureau of Statistics. A list of these codes is attached in Annex 1. If you do not know the code, please describe the activity briefly.

(only I answer possible)

SBI code:

14. What were the total revenue, profit, and number of employees working in your $1^{\text {tt }}$ investment of last year (1999), 5 years ago $(1994)$ and 10 years ago $(1989)$ ? If you do not know those data exactly, please make estimation. If your $1^{\text {t }}$ investment was not operational in that year, please cross it out. (please enter for each year your total revenue, profit and number of employees)

\begin{tabular}{|c|c|c|c|}
\hline Year & $\begin{array}{c}\text { Revenue before tax } \\
\text { (in guilders) }\end{array}$ & $\begin{array}{c}\text { Profit before taxes } \\
\text { (in guilders) }\end{array}$ & Number of employees \\
\hline 1989 & & & \\
\hline 1994 & & & \\
\hline 1999 & & & \\
\hline
\end{tabular}

15. What kind of investment is your $1^{\text {st }}$ investment?

(only I answer possible)

[] Take-over of an existing local company

[] Completely new company

[] Joint venture with an existing local company

[] Joint venture with a completely new company

[] Purchase through the national privatization process

[0 Other:

16. What is the ownership structure of your $1^{\text {nt }}$ investment?

(please enter the ownership percentages, together adding to $100 \%$ )

Dutch owner:

Local owner, from the country of the $1^{\text {st }}$ investment:

Owner 3, nationality:

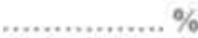

Owner 4, nationality:

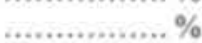

................\%

................ \%

Owner 5, nationality:

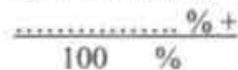


17. How did you finance your $1^{\text {st }}$ investment?

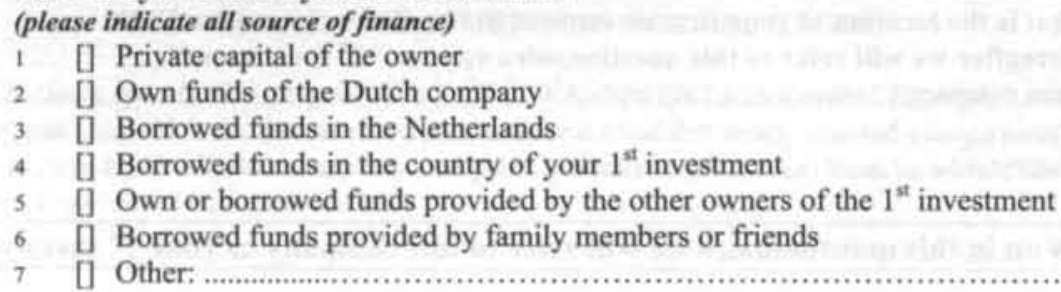

18. Did you receive a subsidy or other kind of support for your $1^{\text {st }}$ investment? (multiple answers possible)
1 [ No
2 [] Yes, subsidy from:
3 [] Yes, insurance from:
4 Y Yes, such as:

19. What was the trade relation with the country of your $1^{\text {st }}$ investment before you made your $1^{\text {st }}$ investment, and does this relation still exist for the $1^{\text {st }}$ investment or has it been ended? (multiple answers possible, please mark for the selected trade relations whether this activity still exists in the country of your $I^{\prime \prime}$ investment)

$\begin{array}{cc}\begin{array}{c}\text { Still } \\ \text { exists }\end{array} & \begin{array}{c}\text { No longer } \\ \text { exists }\end{array} \\ \text { [] } & {[]} \\ {[]} & {[]} \\ {[]} & {[]}\end{array}$




\section{PART D: THE INVESTMENT DECISION}

The following questions refer to the INVESTMENT DECISION PROCESS within your company, specifically focusing on the decision to make your $1^{t}$ INVESTMENT IN THE CEE REGION (as answered in question 11)

20. Which countries did your company consider as alternatives for the country where the $1^{\text {st }}$ investment in the region is made?

(multiple answers possible)

[] Countries in the CEE region:

\begin{tabular}{|c|c|c|c|c|c|}
\hline 1 & Albania & 10 & ] Croatia & 19[ & Serbia-Montenegro \\
\hline 2 & Azerbaijan & 11 & Latvia & 20 & Slovenia \\
\hline 3 & Bosnia-Herzegovina & 12 & Lithuania & 210 & Slovak Republic \\
\hline 4 & Bulgaria & 13 & Macedonia & 22 & Tajikistan \\
\hline 5 & Estonia & 14 & Moldova & 230 & Czech Republic \\
\hline 6 & Georgia & 15 & Ukraine & 240 & Turkmenistan \\
\hline 7 & Hungary & 16 & Poland & 25 & Uzbekistan \\
\hline 8 & Kazakhstan & 17 & Romania & 26 & Belarus \\
\hline 9 & Kyrgyzstan & 18 & Russia & & \\
\hline
\end{tabular}

21. Did you make any calculations to estimate the probability of success of the investment? (only 1 answer possible)

1 [] Yes, only for the country of the $1^{\text {st }}$ investment

2 [ Yes, for the country of our $1^{\text {st }}$ investment and multiple

3 other countries

Continue with question 22 the country of our $1^{\text {st }}$ investment because:

\section{Continue with part $\mathbf{E}$}

22. What were the 4 most important actions during your decision making process, in chronological order (for instance first the choice of country, afterwards the search for an appropriate local partner).

(please enter in each box an action of your first investment decision-making progress, in chronological order)

1.

2.

3.

4. 
23. Which one of the following was a specific reason for your company to make the investment analysis for the country of your $1^{\text {st }}$ investment?

(multiple answers possible)

1 [] There was already a trade relation with one or more companies in that country

2 ] There was a good contact person to work with in that country

3 Other companies in that sector achieved good results in that country

4 The owner or employees of the Dutch firm are from that country

5 [] Your partner or direct family members are from the country of your $1^{n t}$ investment

6 [] Friends or acquaintances are from the country of your $1^{\text {st }}$ investment

7 [1] The owner or employees of the Dutch firm were willing to work in the country of your $1^{\text {st }}$ investment

8 [] Your partner or direct family was willing to work in the country of your $1^{\text {st }}$ investment

9 [] Friends or acquaintances were willing to work in the country of your $\mathrm{I}^{\mathrm{A}}$ investment

10 Language knowledge of the country of your $1^{\text {st }}$ investment in the Dutch firm available

11 [] Positive personal experiences in the country of your $1^{\text {st }}$ investment, for instance travel experiences

12 [] Other:

\section{The following 3 questions are about the factors that your company considered when deciding} whether to invest in the country of your $1^{\text {st }}$ investment.

24. Which of the following factors did your company use when determining the EXPECTED REVENUE of your $1^{\text {tt }}$ investment? If a factor was important for your company to estimate the expected revenue, please mark if the factor influenced the estimation positively or negatively. Factors that were not important for your company may be skipped.

(please answer for all the factors that your company used to calculate the expected revenue)

\begin{tabular}{|c|c|c|c|c|c|c|}
\hline & $\begin{array}{l}\text { Factors considered to estimate the revenue of an investment in the } \\
\text { country of your } 1^{14} \text { investment }\end{array}$ & & The f: & $\begin{array}{l}\text { onsider } \\
\text { tor was }\end{array}$ & d, & \\
\hline & & $\begin{array}{c}\text { very } \\
\text { negative }\end{array}$ & negative & neutral & positive & $\begin{array}{c}\text { very } \\
\text { positive }\end{array}$ \\
\hline 1 & Number of inhabitants in the country of the $1^{\text {" investment }}$ & & & & & \\
\hline 2 & Income per capita in the country of the $\mathrm{I}^{\mathrm{s}}$ investment & & & & & \\
\hline 3 & Income growth in the country of the $\mathrm{I}^{\mathrm{S}}$ investment & & & & & \\
\hline 4 & Revenue of your company in the Netherlands & & & & & \\
\hline 5 & Revenue of your company in other foreign countries & & & & & \\
\hline 6 & Revenue of other companies in the country of the $1^{\text {th }}$ investment & & & & & \\
\hline 7 & $\begin{array}{l}\text { Revenue of the firm in the country of your } 1^{11} \text { investment that you consider } \\
\text { being your partner or want to take over }\end{array}$ & & & & & \\
\hline 8 & Expected market share in the country of your $1^{12}$ investment & & & & & \\
\hline 9 & Price of the sales product in the Netherlands & & & & & \\
\hline 10 & Price of the export product to the country of your $1^{\text {s }}$ investment & & & & & \\
\hline$\pi$ & $\begin{array}{l}\text { Price of the products of your competition in the country of your } 1^{\text {st }} \\
\text { investment }\end{array}$ & & & & & \\
\hline$\frac{12}{12}$ & Price of your product in other countries in the CEE region & & & & & \\
\hline 13 & Revenue obtained on existing export to the country of your $1^{\mathrm{s}}$ investment & & & & & \\
\hline 14 & Costs of the existing export to the country of your $\mathrm{I}^{\mathrm{a}}$ investment & & & & & \\
\hline 15 & Profit obtained from the exports to the country of your $1^{15}$ investment & & & & & \\
\hline 16 & $\begin{array}{l}\text { Competition present / absent in the country of your } 1^{\text {th }} \text { investment } \\
\text { (please cross out whatever is not appropriate) }\end{array}$ & & & & & \\
\hline 17 & Availability of your product in the country of your $1^{\text {" investment }}$ & & & & & \\
\hline 18 & Other: & & & & & \\
\hline 19 & Other: & & & & & \\
\hline
\end{tabular}


25. Which one of the following ORIENTATION ACTIVITIES did your company undertake during the investment decision-making process of your $1^{\text {st }}$ investment?

(multiple answers possible)

I [ Seminars /study days / lectures

2 . Study trips / orientation trips

3 [] Market research done by your own company

4 [ Market research and advice by an external consultant

5 [] Advice by institutions in the Netherlands (for instance chambers of commerce, ministries, embassies)

6 - Advice from institutions in the country of your $1^{\text {st }}$ investment (for instance foreign trade agencies, ministries, and privatization institutions)

7 [ Other:

8 O Other:

26. Which ones of the following costs did your company make in the first year after the positive investment decision?

Were these costs higher, equal or lower than the in advance expected costs?

Please skip those costs that were not made by your company. (please cross for all the costs that your company made in the first year after the investment)

\begin{tabular}{|c|c|c|c|c|c|}
\hline & Costs in the first year of the investment & \multicolumn{4}{|c|}{ Those costs were: } \\
\hline & 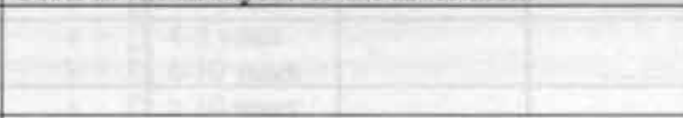 & $\begin{array}{c}\text { Not } \\
\text { expected }\end{array}$ & $\begin{array}{l}\text { Lower } \\
\text { than } \\
\text { expected }\end{array}$ & $\begin{array}{c}\text { As } \\
\text { expected }\end{array}$ & $\begin{array}{l}\text { Higher } \\
\text { than } \\
\text { expected }\end{array}$ \\
\hline 1 & $\begin{array}{l}\text { Building costs and restructuring costs of the building } \\
\text { in the country of your } 1^{\text {st investment }}\end{array}$ & & & & \\
\hline 2 & $\begin{array}{l}\text { Infrastructural improvements in the country of your } \\
1^{n} \text { investment } \\
\text { (for instance road improvement, streetlights) }\end{array}$ & & & & \\
\hline 3 & $\begin{array}{l}\text { Telephone connection in the country of your } 1^{\text {st }} \\
\text { investment }\end{array}$ & & & & \\
\hline 4 & Furniture location of the $1^{\text {st }}$ investment & & & & \\
\hline 5 & $\begin{array}{l}\text { Institutional costs } \\
\text { (for instance obtaining documents) }\end{array}$ & & & & \\
\hline 6 & $\begin{array}{l}\text { Informal payments in the country if the } 1^{\text {st }} \\
\text { investment }\end{array}$ & & & & \\
\hline 7 & Company specific machinery & & & & \\
\hline 8 & Other machinery & & & & \\
\hline 9 & $\begin{array}{l}\text { Rent or mortgage payments on the building in the } \\
\text { country of your } I^{\text {s }} \text { investment }\end{array}$ & & & & \\
\hline 10 & Wages of the personnel & & & & \\
\hline 11 & Training / retraining costs of the personnel & & & & \\
\hline 12 & Material resources for the production & & & & \\
\hline 13 & Consumption goods & & & & \\
\hline 14 & Other: & & & & \\
\hline 15 & Other: & & & & \\
\hline
\end{tabular}


27. Which of the following factors did your company take into account when making a RISK ANALYSIS for the country of your $1^{\text {st }}$ investment. Were the factors considered to be risk increasing or risk decreasing?

Factors that were not considered in the risk analysis may be skipped.

For instance: Your company did consider the factor "internal conflicts" in your risk analysis when deciding to invest in Russia, and the fact that Russia is involved in an internal conflict in Chechnya is risk increasing for Russia. (please answer for all the factors that your company considered in its risk-analysis)

\begin{tabular}{|c|c|c|c|c|}
\hline & \multirow[t]{2}{*}{$\begin{array}{c}\text { Factors considered for the risk analysis of the country } \\
\text { of your } 1^{\text {"t investment }}\end{array}$} & \multicolumn{3}{|c|}{$\begin{array}{l}\text { Factor considered } \\
\text { The factor was seen as: }\end{array}$} \\
\hline & & $\begin{array}{c}\text { Risk } \\
\text { decreasing }\end{array}$ & Neutral & $\begin{array}{l}\text { Risk } \\
\text { increasing }\end{array}$ \\
\hline & Political / cultural factors & & & \\
\hline $\mathrm{I}$ & Political stability & & & \\
\hline 2 & Political opinion of the government & & & \\
\hline 3 & Internal conflicts & & & \\
\hline 4 & External conflicts & & & \\
\hline 5 & Cultural difference with the Netherlands & & & \\
\hline 6 & Language knowledge in the country of the $1^{\text {If }}$ investment & & & \\
\hline 7 & Other: & & & \\
\hline 8 & Other: & & & \\
\hline & Economic factors & & & \\
\hline 9 & Distance to the Netherlands & & & \\
\hline 10 & Location with respect to other countries in the CEE region & & & \\
\hline 11 & Level of Gross National Income & & & \\
\hline 12 & Growth of the Gross National Income & & & \\
\hline 13 & Income per capita & & & \\
\hline 14 & Inflation percentage & & & \\
\hline 15 & Inflation fluctuations & & & \\
\hline 16 & Development and stability of the local currency & & & \\
\hline 17 & Unemployment rate & & & \\
\hline 18 & \begin{tabular}{|l|} 
Wage level \\
\end{tabular} & & & \\
\hline 19 & Wage increase & & & \\
\hline 20 & Education level & & & \\
\hline 21 & Privatization process & & & \\
\hline 23 & Restructuring of government services & & & \\
\hline 24 & $\begin{array}{l}\text { Presence of institutions to increase the foreign trade and } \\
\text { investment }\end{array}$ & & & \\
\hline 25 & $\begin{array}{l}\text { Bilateral or multilateral tax agreements with the } \\
\text { Netheriands }\end{array}$ & & & \\
\hline 26 & $\begin{array}{l}\text { Bilateral or multilateral trade agreements with the } \\
\text { Netherlands }\end{array}$ & & & \\
\hline 27 & Legal system and implementation & & & \\
\hline 28 & Negotiation stage entering the European Union & & & \\
\hline 29 & Other: & & & \\
\hline 30 & Other: & & & \\
\hline
\end{tabular}


28. How often did your company, during the period in which your company considered to invest, make an analysis using the chosen factors?

(only I answer possible)

1 [ Once

2 [ncidental

3 [] Monthly

4 [] Weekly

5 [] Daily

6 [] Continuous process

7 [] Other:

29. In how much time did you expect your $1^{\text {st }}$ investment to become profitable?

(only I answer possible)
1 [] Profitability is not a goal
2 [ ] $<1$ year
3 [] $2-3$ years
4 [] $4-5$ years
5 [] $6-10$ years
$6\left[\begin{array}{ll}6 & 10 \text { years }\end{array}\right.$

30. Are there, besides profitability, other goals that determine the success of your $1^{\text {nt }}$ investment?

\section{(multiple answers possible)}

1 [ Being present in the market

2 [] Growing market share

3 [] Brand name recognition in the market

4 [] Learning process for investments in other countries in the CEE region

5 OI Other:

31. With what do you compare your $1^{\text {st }}$ investment to determine its success?

(only I answer possible)

1 [] No comparison

2 [] The profit percentage of the Dutch firm

3 [] Interest revenues in the Netherlands

4 [] Interest revenues in the country of your $1^{\text {st }}$ investment

5 [] Revenue on stocks and shares

6 [] Revenue of obligations

7 [] The inflation percentage in the Netherlands

8 The inflation percentage in the country of your $1^{\text {st }}$ investment

9 [] Other: 
32. How long after your positive investment decision did your $1^{\text {st }}$ investment become operational?

(only 1 answer possible)

[] $<1$ month

[] 1-3 months

[] 4-6 months

[] $7-12$ months

5 [] Other,

33. Was this preparation time longer than expected?

(only 1 answer possible)

1 [] Yes, continue with question 34

2 [] No, continue with question 35

34. What were the most important reasons for delaying the implementation of your $1^{\text {st }}$ investment?

(multiple answers possible)

1 [] Disappointing results of the Dutch company

2 [] Disappointing expectations of the Dutch economy

3 [] Disappointing expectations of the world economy

4 [] Unstable economic situation in the country of your $1^{\text {st }}$ investment

5 [] Unstable political situation in the country of your $1^{\text {st }}$ investment

6 [] Company found a country that at that time was more appropriate for the investment

7 [] Negative company results of the firm to take over in the country of the $1^{\text {st }}$ investment

8 [] Financial reasons

9 [] Delay with the necessary documents

10 [] Difficulties with the partners / other owners of the $1^{\text {st }}$ investment

11 [] Other:

35. On the basis of which criteria will a decision to stop the $1^{\text {st }}$ investment be made? (multiple answers possible)

1 [] Company should be profitable after a certain number of years

2 [] The invested costs should be paid back after a certain number of years

3 [ A maximum amount of money to be invested by the Dutch company is reached

4 [] Other:

36 Is your $1^{\text {st }}$ investment still operational?

(only I answer possible)

I [ Y Yes

2 No, the $1^{\text {th }}$ investment is not operational anymore since $19 \ldots \ldots$

Reason:

Please continue with question 40 
37. How risky do you currently consider your $1^{\text {st }}$ investment, on a scale from 1 to 10 ? $(I=$ very risky, $10=$ not risky at all)

38. How risky do you currently consider the country of your $1^{\text {st }}$ investment, on a scale from 1 to 10 ?

( $I=$ very risky, $I 0=$ not risky at all)

39. What would at this moment be the 3 most important motivations that could lead to the closure of your $1^{\text {st }}$ investment?

(please mention 3 factors)

1.

2

3.

40. If you were to give your $1^{\text {st }}$ investment an overall grade for success, between 1 and 10 , what would be your choice?

$(I=$ not at all successful, $10=$ very successful $)$ 


\section{PART E: FOLLOW UP INVESTMENTS IN THE CEE REGION}

This part of the questionnaire is about the follow-up investments of your company in the CEE region. The questions will focus specifically on your last investment in this region.

41 Does your company have more than 1 direct investment in a country in Central Europe, Eastern Europe or Central Asia? Branches of your company in the same country are also considered as separate investments. (only 1 answer possible)

1. [] Yes Continue with question $\mathbf{4 2}$

2 [] No Continue with part $\mathbf{F}$

42. What is the location of your most recent investment in this area?

Name company:

City:

Country:

43. In which year was this investment made?

44. Was the analysis of your most recent investment more or less elaborate than the analysis of your first investment?

(only I answer possible)

I [ ] No analysis done

2 [] Less elaborate and less precise analysis

3 [] Exactly the same analysis

4 [ More elaborate and more precise analysis

45. How long after your positive investment decision did your most recent investment become operational?

(only 1 answer possible)

$$
\begin{array}{lll}
1 & {[]} & <1 \text { month } \\
2 & {[]} & 1-3 \text { months } \\
3 & {[]} & 4-6 \text { months } \\
4 & {[]} & 7-12 \text { months } \\
5 & {[]} & \text { Other, ............... }
\end{array}
$$

46. Was this preparation time longer than expected?

(only I answer possible)

1 [] Yes, continue with question 47

2 [] No, continue with question 48 
47. What were the most important reasons for delaying the implementation of your most recent investment?

(multiple answers possible)

1 [] Disappointing results of the Dutch company

2 [] Disappointing expectations of the Dutch economy

3 [] Disappointing expectations of the world economy

4 [] Unstable economic situation in the country of your most recent investment

5 [] Unstable political situation in the country of your most recent investment

6 [] Company found a country that at that time was more appropriate for the investment

7 [] Negative company results of the firm to take over in the country of the most recent investment

8 [] Financial reasons

9 [] Delay with the necessary documents

10 [] Difficulties with the partners / other owners of the most recent investment

11 [] Other:

48. Is your most recent investment still operational?

(only 1 answer possible)

1 [] Yes

2 [ ] No, the most recent investment is not operational anymore since $19 \ldots \ldots$.

Reason:

\section{Continue with question 51}

49. How risky do you currently consider your most recent investment, on a scale from 1 to 10?

$(I=$ very risky, $10=$ not risky at all)

50. How risky do you currently consider the country of your most recent investment, on a scale from 1 to 10 ?

$(I=$ very risky, $10=$ not risky at all $)$

51. If you were to give your most recent investment an overall grade for success, between 1 and 10 , what would be your choice?

( $I=$ not at all successful, $10=$ very successful) 


\section{PART F: GENERAL CHARACTERISTICS OF THE CONTACT PERSON}

Part $F$ consists of some questions on the characteristics of the person that filled out this questionnaire. These questions are necessary to send you the results of the survey. Also some additional space is included for your questions and comments.

52 Would you like to receive a summary of the survey results?

1 [ 1$]$ Yes

2 No

53. Name contact person (person that filled out the questionnaire)

54. Function contact person

55. Phone number contact person

56. Fax number contact person

57. E-mail address contact person

58. Are you prepared to participate in this research by means of a personal interview or some additional questions?
1 [] Yes
2 [ No

If you have additional questions or comments, you may enter them below and we will contact you:

You can also contact Mindel van de Laar, at the below mentioned address.

Thank you for your co-operation

Drs. Mindel van de Laar

Universiteit Maastricht

Postbus 616

6200 MD MAASTRICHT

tel: $\quad 043-3883653$

fax: $\quad 043-3884864$

e-mail: m.vandelaar@algec.unimaas.nl

Internet information page: http://www2.unimaas.nl/ fdewbae/ 
ANNEX 1: Standard Company codes of the Central Bureau of Statistics

\begin{tabular}{|c|c|c|c|}
\hline Code & Descripton & Code & Description \\
\hline A & Landbouw, jacht en Bosbouw & $\mathbf{F}$ & Bouwnijverheid \\
\hline 01 & $\begin{array}{l}\text { Landbouw, jacht en dienstverlening t.b.v. de } \\
\text { landbouw en jacht }\end{array}$ & 45 & Bouwnijverheid \\
\hline 02 & Bosbouw en dienstverlening t.b.v. de bosbouw & 52 & $\begin{array}{l}\text { Detailhandel en reparatie t.b.v. particulieren (excl. } \\
\text { auto's en motorfietsen en motorbrandstoffen) }\end{array}$ \\
\hline B & Visserij & $\mathbf{H}$ & Horeca \\
\hline 05 & $\begin{array}{l}\text { Visserij, kweken van vis en schaaldieren en } \\
\text { dienstverlening tb.v. de visserij }\end{array}$ & 55 & Horeca \\
\hline C & Winning van Delfstoffen & I & Vervoer, opslag en communicatie \\
\hline 10 & Turfwinning & 60 & Vervoer over land \\
\hline 11 & $\begin{array}{l}\text { Aardolie en aardgaswinning en dienstveriening t.b.v. } \\
\text { aardolie en aardgaswinning }\end{array}$ & 61 & Vervoer over water \\
\hline 14 & Zand - grint en kleiwinning & 62 & Vervoer door de lucht \\
\hline D & Industrie & 63 & Diensveriening t.b.v. het vervoer \\
\hline 15 & Vervaardiging van voedingsmiddelen en dranken & 64 & Post en telecommunicatie \\
\hline 16 & Verwerking van tabak & $\mathbf{J}$ & Financiēle instellingen \\
\hline 17 & Vervaardiging van textielwaren & 65 & $\begin{array}{l}\text { Financiēle instellingen (excl. Verzekeringswezen en } \\
\text { pensioenfondsen) }\end{array}$ \\
\hline 18 & $\begin{array}{l}\text { Vervaardiging van kleding: bereiden en verven van } \\
\text { bont }\end{array}$ & 66 & $\begin{array}{l}\text { Verzekeringswezen en pensioensfondsen (exel. } \\
\text { Verplichte sociale verzekeringen) }\end{array}$ \\
\hline 19 & $\begin{array}{l}\text { Vervaardiging van leer en lederwaren (excl. } \\
\text { Kleding) }\end{array}$ & 67 & $\begin{array}{l}\text { Activiteiten t.b.v. of verwant aan financièle } \\
\text { instellingen }\end{array}$ \\
\hline 20 & $\begin{array}{l}\text { Houtindustrie en vervaardiging van artikelen van } \\
\text { hout, kurk riet en vlechtwerk (excl. Meubelen) }\end{array}$ & $\mathbf{K}$ & $\begin{array}{l}\text { Verhuur van en handel in goed, verhuur van } \\
\text { roerende goederen en zakelijke dienstverlening }\end{array}$ \\
\hline 21 & Vervaardiging van papier, karton en kartonwaren & 70 & Verhuur van en handel in onroerend goed, \\
\hline 22 & $\begin{array}{l}\text { Uitgeverijen, drukkerijen en reproductie van } \\
\text { opgenomen media }\end{array}$ & 71 & $\begin{array}{l}\text { Verhuur van transportmiddelen, machines en } \\
\text { werktuigen zonder bedienend personeel en van } \\
\text { overige roerende goederen }\end{array}$ \\
\hline 23 & $\begin{array}{l}\text { Aardolie en steenkoolverwerkende industrie: } \\
\text { bewerking van splijt en kweekstoffen }\end{array}$ & 72 & Computerservice en informatietechnologic bureaus \\
\hline 24 & Vervaardiging van chemische producten & 73 & Speur - en ontwikkelingswerk \\
\hline 25 & $\begin{array}{l}\text { Vervaardiging van producten van rubber en } \\
\text { kunststof }\end{array}$ & 74 & Overige zakelijke dienstverlening \\
\hline 26 & $\begin{array}{l}\text { Vervaarding van glas, aardewerk, kalk en } \\
\text { gipsproducten }\end{array}$ & $\mathbf{L}$ & $\begin{array}{l}\text { Openbaar bestuur, overheidsdiensten en } \\
\text { verplichte sociale verzekeringen }\end{array}$ \\
\hline 27 & Vervaardiging van metalen in primaire vorm & 75 & $\begin{array}{l}\text { Openbaar bestuur, overheidsdiensten en verplichte } \\
\text { sociale verzekeringen }\end{array}$ \\
\hline 28 & Vervaardiging van producten van metaal & $\mathbf{M}$ & Onderwijs \\
\hline 29 & Vervaardiging van machines en apparaten & 80 & Onderwijs \\
\hline 30 & Vervaardiging van kantoormachines en computers & $\mathbf{N}$ & Gezondheids- en Welvijnszorg \\
\hline 31 & $\begin{array}{l}\text { Vervaardiging van overige elektrische machines, } \\
\text { apparaten en benodigdheden }\end{array}$ & 85 & Gezondheids - en Welzijnszorg \\
\hline 32 & $\begin{array}{l}\text { Vervaardiging van audio, video en telecommunicatic } \\
\text { - apparatuur en benodigdheden }\end{array}$ & $\mathbf{O}$ & $\begin{array}{l}\text { Milieudienstverlening, cultuur, recreatie en } \\
\text { overige dienstverlening }\end{array}$ \\
\hline 33 & $\begin{array}{l}\text { Vervaardiging van medische apparaten en } \\
\text { instrumenten, orthopedische artikelen e.d. }\end{array}$ & 90 & Milieudienstverlening \\
\hline 34 & $\begin{array}{l}\text { Vervaardiging van auto's, aanhangwagens en } \\
\text { opleggers }\end{array}$ & 91 & $\begin{array}{l}\text { Werkgevers-, werknemers - en beroepsorganisaties; } \\
\text { levensbeschouwelijke en politieke organisaties; } \\
\text { overige idetle organisaties. }\end{array}$ \\
\hline 35 & Vervaardiging van transportmiddelen & 92 & Cultuur, sport en recreatie \\
\hline 36 & $\begin{array}{l}\text { Vervaardiging van meubels, vervaardiging van } \\
\text { overige goederen }\end{array}$ & 93 & Overige dienstverlening \\
\hline 37 & Voorbereiding tot recycling & $\mathbf{P}$ & $\begin{array}{l}\text { Particuliere huishoudens met personeel in } \\
\text { loondienst }\end{array}$ \\
\hline $\mathbf{E}$ & $\begin{array}{l}\text { Productie en Distributie van Elektriciteit, } \\
\text { Aardgas en Water }\end{array}$ & 95 & Particuliere huishoudens met personeel in loondienst \\
\hline 40 & $\begin{array}{l}\text { Productie en distributie van elektriciteit, aardgas en } \\
\text { warm water }\end{array}$ & $\mathbf{Q}$ & Extraterritoriale lichamen en organisaties \\
\hline 41 & Winning en distributie van water & 99 & Extraterritoriale lichamen en organisaties \\
\hline
\end{tabular}



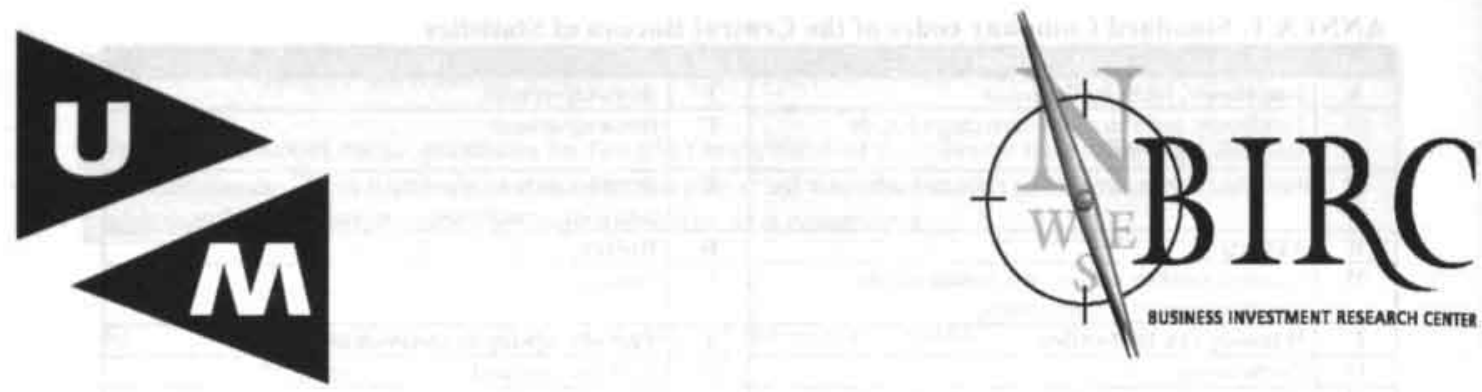

\section{QUESTIONNAIRE FOR DUTCH FIRMS WITH NO DIRECT INVESTMENT IN CENTRAL EUROPE, EASTERN EUROPE OR CENTRAL ASIA}

The questions in this questionnaire are about the choice of Dutch companies to start a direct investment in one of the countries of Central Europe, Eastern Europe or Central Asia (further referred to as the CEE region). Foreign direct investments are newly started enterprises, takeovers of already existing local firms or joint ventures with a local company.

The questionnaire consists of 5 parts, $A$ to $\mathbf{E}$, and takes approximately 15 minutes to fill out.

We thank you in advance for your co-operation

Prof. Dr. Chris de Neubourg

Drs. Mindel van de Laar

Maastricht University 


\section{PART A: INVESTMENT PLANS IN THE CEE REGION}

The first 3 questions of this questionnaire are about possible investment plans of your company in Central Europe, Eastern Europe and Central Asia.

1. Does your company have a direct investment or did it have a direct investment in the past in one of the countries in Central Europe, Eastern Europe or Central Asia? (only 1 answer possible)

1 [] Yes, we currently have one or more direct investments. Continue with question 2

2 [] Yes, we had an investment that is currently closed. Continue with question 2

3 [ No, please fill out the blue questionnaire. This questionnaire can be thrown away.

2. Which one of the following countries in the CEE region, in which your company has no investment yet, would be the country of your first, second and third choice in which to invest at this moment, and which country do you consider the least attractive for your company to invest in at this moment?

(please enter the number of the country on the dotted line)

$\begin{array}{llll}\text { 1 Albania } & 10 & \text { Croatia } \\ 2 & \text { Azerbaijan } & \text { 11 } & \text { Latvia } \\ 3 & \text { Bosnia-Herzegovina } & 12 & \text { Lithuania } \\ 4 & \text { Bulgaria } & 13 & \text { Macedonia } \\ 5 & \text { Estonia } & 14 & \text { Moldova } \\ 6 & \text { Georgia } & 15 & \text { Ukraine } \\ 7 & \text { Hungary } & 16 & \text { Poland } \\ 8 & \text { Kazakhstan } & 17 & \text { Romania } \\ 9 & \text { Kyrgyzstan } & 18 & \text { Russia }\end{array}$

$\begin{array}{ll}19 & \text { Serbia-Montenegro } \\ 20 & \text { Slovenia } \\ 21 & \text { Slovak Republic } \\ 22 & \text { Tajikistan } \\ 23 & \text { Czech Republic } \\ 24 & \text { Turkmenistan } \\ 25 & \text { Uzbekistan } \\ 26 & \text { Belarus }\end{array}$

Number country of your 1st choice:

Number country of your 2 nd choice:

Number country of your $3 \mathrm{~d}$ choice:

Number country of your last choice:

3. In which one of the following countries do you expect your company will invest in within the next two years?

This direct investment could in this case be your first investment in that specific country, but also a new investment in a country in which your firm is already active.

(multiple answers possible)

$\begin{array}{lll}1 & {[]} & \text { Albania } \\ 2 & {[]} & \text { Azerbaijan } \\ 3 & {[]} & \text { Bosnia-Herzegovina } \\ 4 & {[]} & \text { Bulgaria } \\ 5 & {[]} & \text { Estonia } \\ 6 & {[]} & \text { Georgia } \\ 7 & {[]} & \text { Hungary } \\ 8 & {[]} & \text { Kazakhstan } \\ 9 & {[]} & \text { Kyrgyzstan }\end{array}$

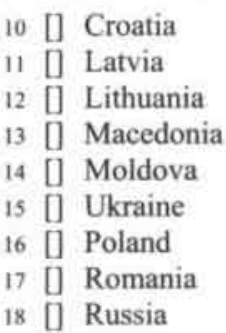

19 [] Serbia-Montenegro

20 [] Slovenia

21 [] Slovak Republic

22 [] Tajikistan

23 [] Czech Republic

24 [] Turkmenistan

25 [] Uzbekistan

26 [] Belarus 


\section{PART B: CHARACTERISTICS OF THE DUTCH FIRM}

\section{The following 6 questions are about the activities of your company in THE NETHERLANDS}

4. In which sector is your company active?

Please enter the main code according to the Dutch standard company codes of the Central Bureau of Statistics. A list of these codes is attached in annex 1 . If you do not know the code, please describe the activity briefly.

(only I answer possible)

SBI code:

5. In which year did your company start its activities in the Netherlands?

6. How many different locations / offices does your company have in the Netherlands?

7. What were the total revenue, profit, and the number of employees working in your company in the Netherlands the last year (1999), 5 years ago (1994) and 10 years ago (1989)?

If you do not know those data exactly, please make estimation. If your company was not operational in that year, please cross it out.

(please enter for each year your revenue, profit and number of employees)

\begin{tabular}{|c|c|c|c|}
\hline Year & $\begin{array}{c}\text { Revenue before tax } \\
\text { (in guilders) }\end{array}$ & $\begin{array}{c}\text { Profit before taxes } \\
\text { (in guilders) }\end{array}$ & Number of employees \\
\hline 1989 & & & \\
\hline 1994 & & & \\
\hline 1999 & & & \\
\hline
\end{tabular}

8. What is the ownership structure of your Dutch company?

(please enter the ownership in percentages, adding to $100 \%$ )

Owner 1, nationality:

Owner 2, nationality:

Owner 3, nationality:

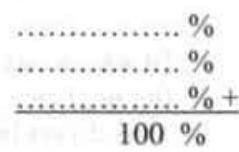

9. Are the decisions to invest in a foreign country made completely or partly by the Dutch company?

(only one answer possible)

1 [] Yes, completely Dutch decision

2 [] Yes the decision is made by the Dutch company in co-operation with the other owners Please continue with part C

Please continue with part C

3 [ No, the decision is made by the foreign partners. This questionnaire is aimed at the investment decisions of Dutch companies. Since your foreign partner makes the foreign investment decisions of your company, the answers of your firm are not comparable with those of the other respondents. Please continue with part $\mathbf{E}$ 
PART C: FOREIGN DIRECT INVESTMENTS

Part C focuses specifically on all your foreign direct investments worldwide

10. In how many countries worldwide does your company have a direct investment? (only one answer possible)

I [] No foreign direct investments

2 [ Foreign direct investment in countries

11. In which countries worldwide does your company have one or more direct investments, and in which year were these started?

(Please indicate per country where your company has direct investments by entering the starting year (maximum 3) of those investments)

\begin{tabular}{|c|c|c|c|c|}
\hline & Country & $\begin{array}{l}\text { Year start } 1^{\text {st }} \\
\text { investment }\end{array}$ & $\begin{array}{c}\text { Year start } 2^{\text {ndd }} \\
\text { investment }\end{array}$ & $\begin{array}{c}\text { Year start 3d } \\
\text { investment }\end{array}$ \\
\hline & Europe & & & \\
\hline 1 & Belgium & & & \\
\hline 2 & Denmark & & & \\
\hline 3 & Germany & & & \\
\hline 4 & Finland & & & \\
\hline 5 & France & & & \\
\hline 6 & Great-Britain & & & \\
\hline 7 & Ireland & & & \\
\hline 8 & Italy & & & \\
\hline 9 & \begin{tabular}{|l} 
Luxembourg \\
\end{tabular} & & & \\
\hline 10 & Austria & & & \\
\hline 11 & \begin{tabular}{|l|} 
Spain \\
\end{tabular} & & & \\
\hline 12 & \begin{tabular}{|l|} 
Sweden \\
\end{tabular} & & & \\
\hline 13 & Other: & & & \\
\hline 14 & Other: & & & \\
\hline & Other continents & z & & \\
\hline 15 & Dutch Antilles and Aruba & & & \\
\hline 16 & \begin{tabular}{|l|} 
Surinam \\
\end{tabular} & & & \\
\hline 17 & USA & & & \\
\hline 18 & Canada & & & \\
\hline 19 & Japan & & & \\
\hline 20 & Other: & & & \\
\hline 21 & Other: & & & \\
\hline
\end{tabular}


12. In which sector is the majority (more than half) of your foreign investments active? Please enter the main code that, according to the standard company codes of the Dutch Central Bureau of Statistics, is most applicable to your company. A list of those codes is included in Annex 1 (page 12)

(please enter only 1 code)

SBI code:

13. Did your company ever consider investing in a country in the CEE region? (only one answer possible)

1 [ [ Yes,

2 [] No, our company has never been interested in investing in a country in the CEE region

Continue with part D

14

Continue with question

14. What are the reasons your company never has been interested in the countries of the CEE region as possible investment locations? After this question, please continue with part E.
(multiple answers possible)
[] No interest in investing in a foreign country
[] The CEE region is economically not developed enough
[] The CEE region is politically too unstable
[] There is already too much competition in the CEE region
[] We supply the CEE region with exports from the Netherlands
[] There is not enough demand for our product in the CEE region
[] There is no finance available for such an investment
[] Our company has bad experiences with doing business with the CEE region
[] Other:

Continue with part $\mathrm{E}$ 


\section{PART D: CALCULATIONS FOR THE INVESTMENT DECISION}

The following questions are about the calculations your company makes before it determines to invest in a foreign country or not. The questions are specifically aimed at the country in the CEE region that your company has most recently considered investing in.

15. Which country in the CEE region has your company most recently considered to invest in? We will refer to this country as your CEE choice.

(only one answer possible)
[] Albania
10 [] Croatia
D Azerbaijan
11 [] Latvia
19 [] Serbia-Montenegro
[] Bosnia-Herzegovina
12 [1 Lithuania
20 [] Slovenia
[] Bulgaria
13 [] Macedonia
21 [] Slovak Republic
[] Estonia
14 [] Moldova
22 [] Tajikistan
[] Georgia
15 [] Ukraine
23 [] Czech Republic
[] Hungary
16 [] Poland
24 [] Turkmenistan
[] Kazakhstan
17 [] Romania
25 [] Uzbekistan
[] Kyrgyzstan
18 [] Russia

We will refer to this country as your CEE choice.

16. In which year did you consider to make this investment?

17. What kind of investment did you consider to make in your CEE choice?

(only one answer possible)

1 [] Take over of an existing company

2 [] Completely new company

3 [] Joint venture with an existing company

4 [] Joint venture with a completely new company

5 [] Purchase through the national privatization process

6 [] Other:.

18. How did you intent to finance your investment in the CEE choice?

(please cross all source of finance)

1 [] Private capital of the owner

2. [] Own funds of the Dutch company

3 [] Borrowed funds from the Netherlands

4 [] Borrowed funds from the country of your CEE choice

5 [] Own or borrowed funds from the other participants in your investment in the CEE choice

6 [] Borrowed funds from family or friends

7 [] Other 
19. What was the trade relation with your CEE choice at the time you considered an investment, and does this relation still exist?

(multiple answers possible, please mark for the selected trade relations whether this activity still exists with your CEE choice)

$\begin{array}{cc}\text { Still } & \text { No longer } \\ \text { exists } & \text { exists }\end{array}$

1 0 No trade relation

2 [] Export to the CEE choice

3 [] Imports from your CEE choice to the Netherlands

4 Other:

$\begin{array}{ll}{[]} & {[} \\ 0] & {[} \\ {[]} & {[}\end{array}$

20. When your company was interested in an investment in your CEE choice, did your company make any calculations to estimate the possibility of success of the investment? (only 1 answer possible)

1 [ Yes, only for your CEE choice

Continue with question 21

[] Yes, for multiple countries

[] Yes, for multiple countries, all in the CEE region

Continue with question 21

21. Which one of the following aspects was a specific reason for your company to make an investment analysis for your CEE choice?

\section{(multiple answers possible)}

1 [ There was already a trade relation with one or more companies in that country

2 [] There was a good contact-person to work with in that country

3 [] Other companies in that sector achieved good results in that country

4 [] The owner or employees of the Dutch firm are from that country

5 [] Your partner or direct family members are from the CEE choice

6 Friends or acquaintances are from the CEE choice

7 [] The owner or employees of the Dutch firm were willing to work in the CEE choice

8 Your partner or direct family was willing to work in the CEE choice

9 . Friends or acquaintances were willing to work in the CEE choice

10 [] Language knowledge of the CEE choice was in the Dutch firm available

11 Positive personal experiences in the CEE choice, for instance because of travel experiences

12

[] Other:

22. For which countries did your company make an investment analysis besides your CEE choice?

(multiple answers possible)

[] Countries in the CEE region:

\begin{tabular}{|c|c|c|c|c|c|}
\hline 1 & Albania & 10[] & Croatia & 19 [] & Serbia-Montenegro \\
\hline 2 & Azerbaijan & 11 [ & Latvia & 20[ & Slovenia \\
\hline 3 & Bosnia-Herzegovina & 12[ & Lithuania & 210 & Slovak Republic \\
\hline 4 & Bulgaria & 13[] & Macedonia & 22[ & Tajikistan \\
\hline 5 & Estonia & 14[] & Moldova & 23[] & Czech Republic \\
\hline 6 & Georgia & $15 \square$ & Ukraine & 24[] & Turkmenistan \\
\hline 7 & Hungary & 16[ & Poland & 25[ & Uzbekistan \\
\hline 8 & Kazakhstan & 17 [] & Romania & 26[] & Belarus \\
\hline 9 & Kyrgyzstan & 18[ & Russia & & \\
\hline
\end{tabular}


23. What were the $\mathbf{4}$ most important actions during your decision making process in chronological order (for instance first the choice of country, afterwards the search for an appropriate local partner) (please enter in each box an action of your investment decision in chronological order)

1.

2.

3.

4.

The following question is about the factors that your company considered when determining to invest in your CEE choice or not.

24. Which one of the following factors did your company use when determining the EXPECTED REVENU of an investment in your CEE choice? If a factor was important for your company when estimating the expected revenue, please mark if the factor influenced the attractiveness of the country positively or negatively. Factors that were not important for your company can be skipped.

(please answer for all the factors that your company used to calculate the expected revenue)

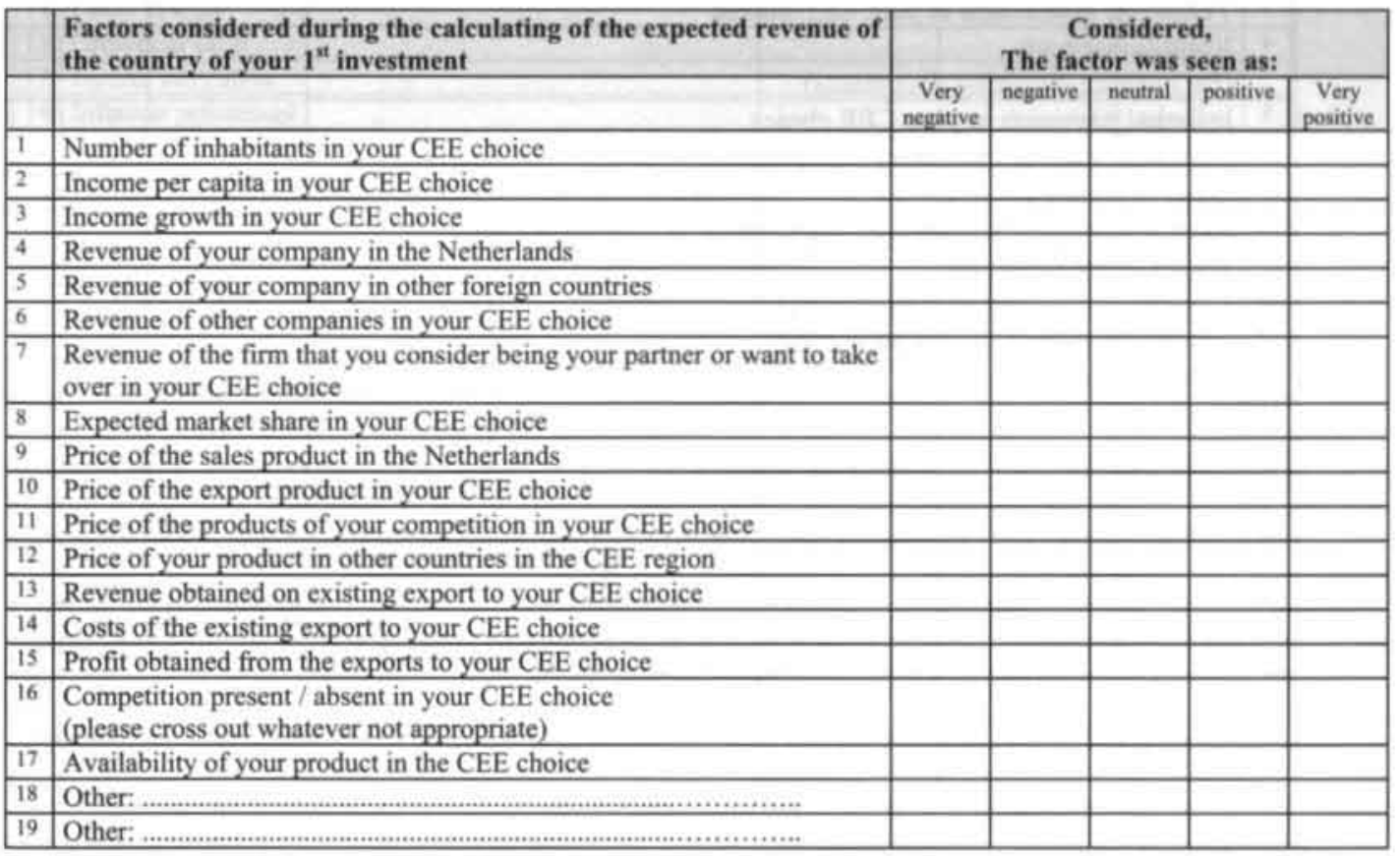


25. Which one of the following ORIENTATION ACTIVITIES did your company undertake during the investment decision process of a possible investment in your CEE choice?

\section{(multiple answers possible)}

1 [] Seminars / study days / lectures

2 [] Study trips / orientation trips

3 [] Market research done by your own company

4 [] Market research and advice by an external consultant

5 [] Advice by institutions in the Netherlands (for instance chambers of commerce, ministries, embassies)

6 [] Advice from institutions located in your CEE choice (for instance foreign trade agencies, ministries, and privatization institutions)

7 [] Other:

8 Other:

26. Which of the following costs did your company consider when determining the expected costs of your investment in your CEE choice? (please answer for all cost factors mentioned)

\begin{tabular}{|c|c|c|c|}
\hline & $4=x^{2}=$ & $\begin{array}{c}\text { Costs } \\
\text { considered }\end{array}$ & $\begin{array}{l}\text { Costs not } \\
\text { considered }\end{array}$ \\
\hline 1 & Build and restructure the building in your CEE choice & & \\
\hline 2 & $\begin{array}{l}\text { Infrastructural improvements in your CEE choice } \\
\text { (for instance road improvement, streetlights) }\end{array}$ & & \\
\hline 3 & Telephone connection in your CEE choice & & \\
\hline 4 & $\begin{array}{l}\text { Institutional costs } \\
\text { (for instance obtaining documents) }\end{array}$ & & \\
\hline 5 & Informal payments in your CEE choice & & \\
\hline 6 & Company specific machinery & & \\
\hline 7 & Other machinery & & \\
\hline 8 & Rent or mortgage payments on the building in your CEE choice & & \\
\hline 9 & Wages of the personnel & & \\
\hline 10 & Training / retraining of the personnel & & \\
\hline 11 & Material resources for the production & & \\
\hline 12 & Consumption goods & & \\
\hline 13 & Other: & & \\
\hline 14 & Other: & & \\
\hline
\end{tabular}


27. Which ones of the following factors did your company take into account when making a RISK ANALYSIS for a possible investment your CEE choice, and were these factors considered as risk increasing or risk decreasing?

Factors that were not considered in the risk analysis can be skipped.

For instance: You did consider the factor internal conflicts in your risk analysis when deciding to invest in Russia or not, and the fact that Russia is involved in an internal conflict in Chechnya is risk increasing for Russia.

(please answer for all the factors that your company considered in its risk-analysis)

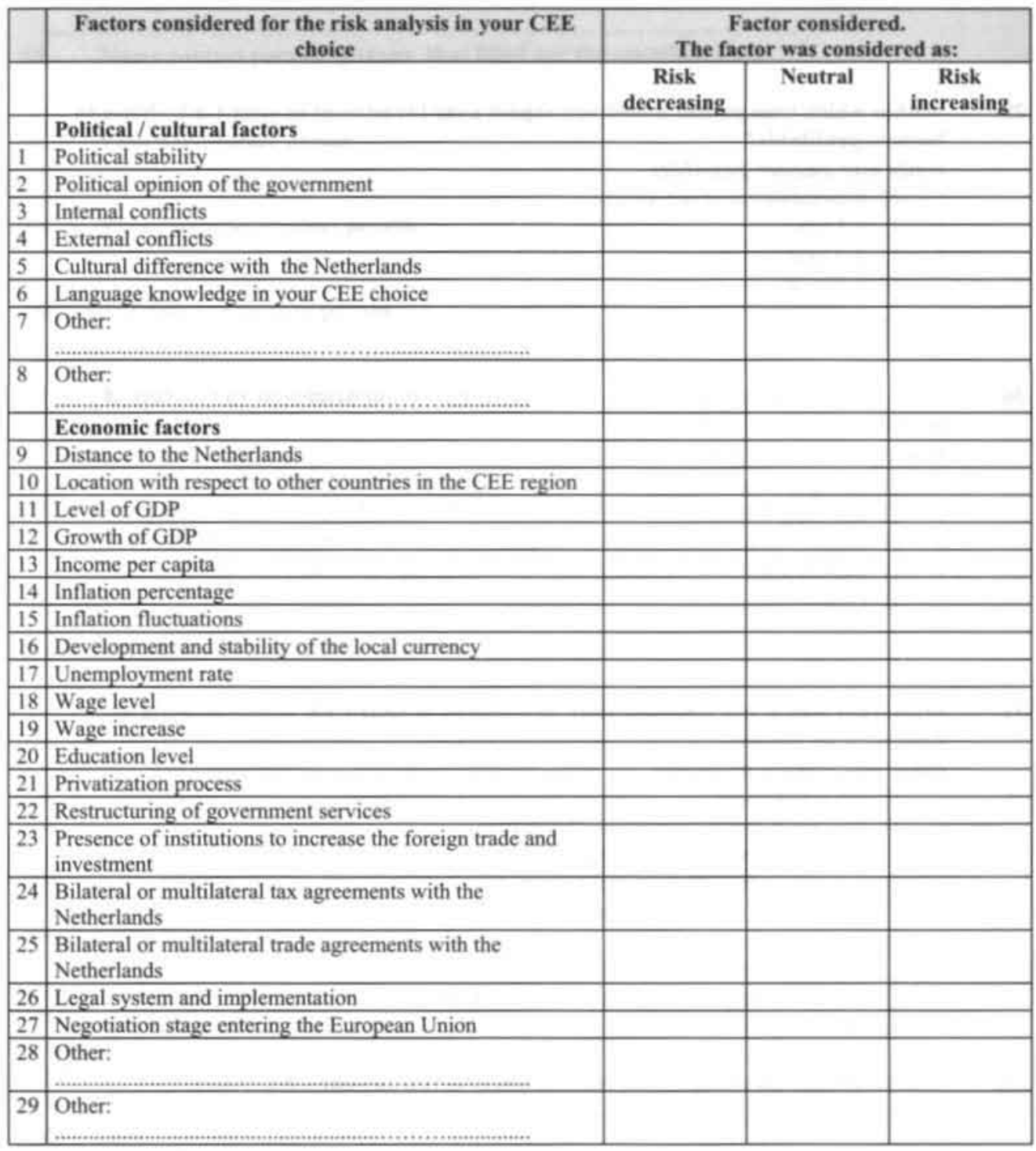


28. How often did your company, during the period in which your company considered to invest, make an analysis with the use of the chosen factors?

(only 1 answer possible)

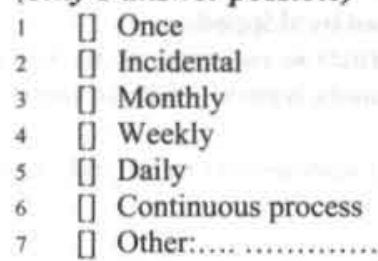

29. Within which time period would you expect your investment in your CEE choice to become profitable?

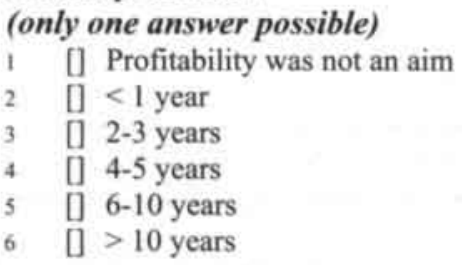

30. Were there, besides profitability, other aims that would determine the success of your investment in your CEE choice?

(multiple answers possible)

I [ Being present in the market

2 [] Growing market share

3 [] Brand name recognition in the market

4 [] Learning process for investments in other countries in the CEE region

5 [] Other:

31. With what would you compare your investment in your CEE choice in order to determine its success?

\section{(only one answer possible)}

1 [ ] No comparison

2 [] The profit percentage of the Dutch firm

3 [] Interest revenues in the Netherlands

4 [] Interest revenues in your CEE choice

5 [] Revenue on stocks and shares

6 [] Revenue of obligations

7 [ The inflation percentage in the Netherlands

8 [] The inflation percentage in your CEE choice

9 [] Other:

32. What were the most important reasons not to invest in your CEE choice?

1.

3. 


\section{PART E: GENERAL CHARACTERISTICS OF THE CONTACT PERSON}

Part $\mathbf{E}$ consists of some questions on the characteristics of the person that filled out this questionnaire. These questions are necessary to send you the results of the survey. Also some additional space is included for your questions and comments.

52 Would you like to receive a summary of the survey results?

1 [] Yes

2 [] No

53. Name contact person (person that filled out the questionnaire)

54. Function contact person

55. Phone number contact person

56. Fax number contact person

57. E-mail address contact person

58. Are you prepared to participate in this research by means of a personal interview or some additional questions?
1 [ [ Yes
2 [ No

If you have additional questions or comments, you can enter them below and we will contact you:

You can also contact Mindel van de Laar, at the below mentioned address.

Thank you for your co-operation

Drs. Mindel van de Laar

Universiteit Maastricht

Postbus 616

6200 MD MAASTRICHT

tel: $\quad 043-3883653$

fax: $\quad 043-3884864$

e-mail: m.vandelaar@algec.unimaas.nl

Internet information page: http://www2. unimaas.nl/ fdewbae/ 
ANNEX 1: Standard Company codes of the Central Bureau of Statistics

\begin{tabular}{|c|c|c|c|}
\hline Code. & Descripton & Code & Description \\
\hline $\mathbf{A}$ & Landbouw, jacht en Bosbouw & $\mathrm{F}$ & Bouwnijverheid \\
\hline 01 & $\begin{array}{l}\text { Landbouw, jacht en dienstverlening t.b.v. de landbouw en } \\
\text { jacht }\end{array}$ & 45 & Bouwnijverheid \\
\hline 02 & Bosbouw en dienstverlening t b. v, de bosbouw & 52 & $\begin{array}{l}\text { Detailhandel en reparatie L.b.v, particulieren (excl. auto's } \\
\text { en motorfietsen en motorbrandstoffen) }\end{array}$ \\
\hline B & Visserij & $\mathbf{H}$ & Horeca \\
\hline 05 & $\begin{array}{l}\text { Vissenj, kweken van vis en schaaldieren en dienstverlening } \\
\text { Lb.v. de visserij }\end{array}$ & 55 & Horeca \\
\hline C & Winning van Delfstoffen & 1 & Vervoer, opslag en communicatic \\
\hline 10 & Turfwinning & 60 & Vervoer over land \\
\hline II & $\begin{array}{l}\text { Aardolie en aardgaswinning en dienstveriening Lb.v, } \\
\text { aardolic en aardgaswinning }\end{array}$ & 61 & Vervoer over water \\
\hline 14 & Zand - grint en kleiwinning & 62 & Vervoer door de lucht \\
\hline $\mathbf{D}$ & Industrie & 63 & Diensverlening t.b.v. het vervoer \\
\hline 15 & Vervauirdiging van voedingsmiddelen en dranken & 64 & Post en telecommunicatic \\
\hline 16 & Verwerking van tabak & $\mathbf{J}$ & Financiele instellingen \\
\hline 17 & Vervaardiging van textieiwaren & 65 & $\begin{array}{l}\text { Financiêle instellingen (excl. Verzekeringswezen en } \\
\text { pensioenfondsen) }\end{array}$ \\
\hline 18 & Vervaardiging van kleding: bereiden en verven van bont & 66 & $\begin{array}{l}\text { Verzekeringswezen en pensioensfondsen (exel. Verplichte } \\
\text { sociale verzekeringen) }\end{array}$ \\
\hline 19 & Vervaardiging van leer en lederwaren (excl. Kleding) & 67 & Activiteiten L.b.v, of verwant aan financiêle instellingen \\
\hline 20 & $\begin{array}{l}\text { Houtindustric en vervaardiging van artikelen van hout, } \\
\text { kurk riet en vlechtwerk (exel. Meubelen) }\end{array}$ & $\mathbf{K}$ & $\begin{array}{l}\text { Verhuur van en handel in goed, verhuur van roerende } \\
\text { goederen en zakelijke dienstveriening }\end{array}$ \\
\hline 21 & Vervaardiging van papier, karton en kartonwaren & 70 & Verhuur van en handel in onroerend goed, \\
\hline 22 & $\begin{array}{l}\text { Uitgeverijen, drukkerijen en reproductic van opgenomen } \\
\text { media }\end{array}$ & 71 & $\begin{array}{l}\text { Verhuur van transportmiddelen, machines en werktuigen } \\
\text { zonder bedienend personeel en van overige roerende } \\
\text { goederen }\end{array}$ \\
\hline 23 & $\begin{array}{l}\text { Aardolie en steenkoolverwerkende industrie: bewerking } \\
\text { van splijt en kweekstoffen }\end{array}$ & 72 & Computerservice en informatietechnologie bureaus \\
\hline 24 & Vervaardiging van chemische producten & 73 & Speur - en ontwikkelingswerk \\
\hline 25 & Vervaardiging van producten van rubber en kunststof & 74 & Overige zakelijke dienstverlening \\
\hline 26 & Vervaarding van glas, aardewerk, kalk en gipsproducten & $\mathbf{L}$ & $\begin{array}{l}\text { Openbaar bestuur, overheidsdiensten en verplichte } \\
\text { sociale verzekeringen }\end{array}$ \\
\hline 27 & Vervaardiging vam metalen in primaire vorm & 75 & $\begin{array}{l}\text { Openbaar bestuur, overheidsdiensten en verplichte sociale } \\
\text { verzekeringen }\end{array}$ \\
\hline 28 & Vervaardiging van producten van metaal & $\mathbf{M}$ & Onderwijs \\
\hline 29 & Vervaardiging van machines en apparaten & 80 & Onderwijs \\
\hline 30 & Vervaardiging van kantoormachines en computers & $\mathbf{N}$ & Gezondheids-en Welzijnszorg \\
\hline 31 & $\begin{array}{l}\text { Vervaardiging van overige elektrische machines, apparaten } \\
\text { en benodigdheden }\end{array}$ & 85 & Gezondheids - en Welzijnszorg \\
\hline 32 & $\begin{array}{l}\text { Vervaardiging van audio, video en telecommunicatie - } \\
\text { apparatuur en benodigdheden }\end{array}$ & 0 & $\begin{array}{l}\text { Milieudienstverlening, cultuur, reereatie en overige } \\
\text { dienstverlening }\end{array}$ \\
\hline 33 & $\begin{array}{l}\text { Vervaardiging van medische apparaten en instrumenten, } \\
\text { orthopedische artikelen e.d. }\end{array}$ & 90 & Milieudienstveriening \\
\hline 34 & Vervaardiging van auto's, aanhangwagens en opleggers & 91 & $\begin{array}{l}\text { Werkgevers-, werknemers - en beroepsorganisaties: } \\
\text { levensbeschouwelijke en politieke organisaties; overige } \\
\text { ideele organisaties. }\end{array}$ \\
\hline 35 & Vervaardiging van transportmiddelen & 92 & Cultuur, sport en recreatic \\
\hline 36 & $\begin{array}{l}\text { Vervaardiging van meubels, vervaardiging van overige } \\
\text { goederen }\end{array}$ & 93 & Overige dienstverlening \\
\hline 37 & Voorbereiding tot recycling & $\mathbf{P}$ & Particuliere huishoudens met personeel in loondienst \\
\hline E & $\begin{array}{l}\text { Productie en Distributie van Elektriciteit, Aardgas en } \\
\text { Water }\end{array}$ & 95 & Particuliere huishoudens met personeel in loondienst \\
\hline 40 & $\begin{array}{l}\text { Productic en distributie van elektriciteit, aardgas en warm } \\
\text { water }\end{array}$ & Q & Extraterritoriale lichamen en organisaties \\
\hline 41 & Winning en distributie van water & 99 & Extraterritoriale lichamen en organisaties \\
\hline
\end{tabular}




\section{Bibliography}

- Aaker, J.L. and P. Williams (1998), "Empathy versus Pride: The influence of Emotional Appeal across Cultures", Joumal of Consumer Research, vol. 25. no. 3 (December). pp. 241-261.

- Abell, D.F. and T. Koellermeier (eds.) (1993), "Dynamic Entrepreneurship in Central and Eastern Europe", The Hague: DELWEL Publishers.

- Abraham, F. and J. Konings (1999), "Does the Opening of Centrat and Eastem Europe Threaten Employment in the West?", World Economy, 22 (4), pp. 585-601.

- Agarwal, J.P. (1996), 'Does Foreign Direct Investment contribute to unemployment in home countries', Kiel Institute for World Economics Working Paper, no. 765.

- Agarwal, S. and S.N. Ramaswami (1992), "Choice of foreign market entry mode: Impact of ownership, location and internationalization factors", Journal of International Business Studies, vol. 23, no. 1, pp. 1-28.

- Aizenman, J. and S.S. Yi (1997), "Controlled Openness and Foreign Direct Investment", NBER Working Paper, no. 6123.

- Alguacil, M.T., A. Cuadros and V. Orts (2002), "Foreign Direct Investment. Exports and Domestic Performance in Mexico: a Causality Analysis", Economics Letters, vol. 77, no. 3, pp. 371-376,

- Allen, C.T. K.A. Machleit and S. Schultz Kleine (1992), "A Comparison of Attitudes and Emotions as Predictors of Behavior at Diverse Levels of Behavioral Experience", Joumal of Consumer Research, vol. 18, no. 4, pp. 493-504.

- Altman, M. (2001), "Culture, human agency and economic theory: culture as a determinant of material welfare", Journal of Socio-economics, vol. 30, no. 5, pp. 379-391.

- Altomonte, C. (1998), "FDI in the CEEC's and the Theory of Real Options: an Empirical Assessment", LICOS Working Paper, no. 76, Centre for Transition Economics, Catholic University Leuven.

- Altomonte, C. (2000), "Economic Determinants and Institutional Frameworks: FDI in Economies in Transition", Transnational Corporations, 9 (2), pp. 75-106.

- Altomonte, C. and C. Guagliano (2003), "Comparative study of FDI in Central Europe and the Mediterranean", Economic Systems, vol. 27, no. 2, pp. 223-246.

- Anderson, S.P. and M. Engers (1994), "Strategic Investment and Timing of Entry", Intemational Economic Review, vol. 35. no. 4. pp. 833-853

- Andreff, W. (2002), "The New Multinational Corporations from Transition Countries", Economic Systems, vol. 26, no. 4, pp. $371-379$.

- Aturupane, C., S. Djankov and B. Hoekman (1997), "Determinants of Intra-Industry Trade between East and West Europe", World Bank Policy Research Working Paper, no. wps 1850.

- Baldwin, R., J. Francois and R. Portes (1997), "The Costs and Benefits of Eastern Enlargement the Impact on the EU and Central Europe", Economic Policy, vol. 12, no. 24, pp. 127-176.

- Barajas, A., R. Steiner and N. Salazar (2000), "The impact of liberalisation and foreign investment in Colombia's financial sector, Joumal of Development Economics, vol. 63, no. 1. pp. 157-196.

- Barkema, H., J. Bell and J. Pennings (1996), "Foreign Entry, Cultural Barriers and Learning", Strategic Management Joumal, vol. 17, no. 2, pp. 151-166.

- Barro, R.J. (1997), "Determinants of economic growth: A cross-country empirical study". Cambridge and London: MIT Press.

- Becker, G.S. (1971), "The economics of discrimination", 2nd ed., Chicago: University of Chicago Press.

- Beers, C. van and G. Biessen (1995), "Trade potential and structure of foreign trade: the case of Hungary and Poland", Rijksuniversiteit Leiden Research Memorandum, no. 1995.02.

- Belderbos, R. and M. Carree (2000), The Location of Japanese Investments in China: Agglomeration Effects, Keiretsu. and Firm Heterogeneity', NIBOR Working Paper, no. nib00/002, Maastricht University.

- Belderbos, R. (1992), "Large Multinational Enterprises Based in a Small Economy; Effects on Domestic Investment" Weltwirtschaftliches Archiv, 128 (3), pp. 543-557.

- Benito, G.R.G. and G. Gripsrud (1992), "The expansion of Foreign Direct Investments: discrete rational location choices or a cultural learning process?". Joumal of International Business Studies, 23 (3), pp. 461-476.

- Berengaut, J., A. Lopez-Carlos, F. Le Gall, D. Jones, R. Stern, A.M. Westin, E. Psalida and P. Garibaldi (1998), The Baltic Countries, from economic stabilisation to EU accession". IMF Occasional Paper, no. 173.

- Berg, A. (1994), "Does Macroeconomic Reform Cause Structural Adjustment: Lessons from Poland", Journal of Comparative Economics, vol. 18, no. 3, pp. 376-409.

- Bevan, A.A. and S. Estrin (2000). "The determinants of foreign direct investment in transition economies", CEPR Discussion Paper, no. 2638.

- Bikker, J.A. (1982), 'Vraag-Aanbodmodellen voor Stelsels van Geografisch Gespreide Markten, Toegepast op de Internationale Handel en op Ziekenhuisopnamen in Noord-Nederland". Amsterdam: VU Boekhandel/Uitgeverij.

- Bikker, J.A. (1987), "An International Trade Flow Model with Substitution: An Extension of the Gravity Model", Kyklos, 40 (3), pp. 315-337.

- Blamey, R.K. (1998), 'Decisiveness, attitude expression and symbolic responses in contingent valuation surveys", Joumal of Economic Behaviour and Organization, vol. 34, no. 4, pp. 577-601.

- Blanchard, O. (1997), "The economics of post-communist transition", New York and Oxford: Clarendon Press and Oxford University Press.

- Blanchflower, D.G. and A.J. Oswald (1992), "Entrepreneurship, happiness and supernormal retums: Evidence from Britain and the US:, NBER Working Paper, no. 4228.

- Blanchflower, D.G. and A.J. Oswald (1998), "What makes an entrepreneur', Journal of Labour Economics, 16 (1), pp. 2660.

- Blomstrom, M. and A. Kokko (1997), "Regional Integration and Foreign Direct Investment", NBER Working Paper, no. 6019.

- Bonin, J. and P. Wachtel (2000), "Financial Sector Development in Transition Economies: Lessons from the First Decade", Financial Markets, Institutions and Instruments, vol. 12, no. 1, pp. 1-66. 
- Borenzstein, E., J. de Gregorio and J.-W. Lee (1998), "How does Foreign Direct Investment Affect Economic Growth", Journal of Intermational Economics, vol. 45, no. 1. pp. 115-135.

- Bos, J.W.B. and M. van de Laar (2004), "Explaining Foreign Direct Investment in Central and Eastern Europe: an Extended Gravily Approach", Meteor Research Memorandum, RM/04/031

- Bos, M., G. Gelauff and R. de Mooij (1999), Transition and institutional change*, in: G. Biessen et al (eds.), The second decade: prospects for European integration after ten years of transition, The Hague: SDU Publishers, Ministry of Economic Affairs, pp. 49-72.

- Bosman, R. and F. van Winden (2002), "Emotional hazard in a power-to-take experiment", Economic Joumal, vol. 112, no. 476, pp. 147-169.

- Brabant, J. van (2001). "Transforming trade and payments in transition economies - the regional dimension", Joumal of Policy Modeling, vol, 23, no. 1. pp. 99-126.

- Brada, J.C. (1996), "Privatisation is transition, or is it?", Joumal of Economic Perspectives, 10 (2), pp. 67-86.

- Brainard, S.L. (1993), "An empirical assessment of the proximity-concentration tradeoff between multinational sales and trade", NBER Working Paper, no. 4580.

- Brander, J.A. and B.J. Spencer (1987), "Foreign Direct Investment with Unemployment and Endogeneous Taxes and Tarifts", Journal of International Economics, vol. 22, no. 3/4, pp. 257-279.

- Bratkowski, A., L. Grosfeld and J. Rostowski $(2000)$, "Investment and finance in de novo private firms: Empirical results from the Czech Republic, Hungary and Poland", Economics of Transition, 8 (1), pp. 101-116.

- Brenton, P. (ed.) (1999), Trade and investment in Europe; the impact of the next enlargement, Brussels: CEPS.

- Brenton, P. (1999a), "Removing the obstacles to deeper economic integration in the broad European trade area", CEPS Working Party Report, no. 22.

- Brenton, P. and D. Gros (1997). "Trade Reorientation and Recovery in Transition Economies", Oxford Review of Economic Policy, 13 (2), 65-76.

- Brenton, P. and F. di Mauro (1998), "Is there any potential in trade in sensitive industrial products between the CEECs and the EU?", World Economy, 21 (3), pp. 285-304.

- Brenton, P. and F, di Mauro (1999), "The potential magnitude and impact of FDI flows of CEECs", Joumal of Economic Integration, 14 (1), pp. 59-74.

- Brenton, P., D. Gros and G. Vandille (1997), "Output decline and recovery in the transition economies: causes and social concequences", Economics of Transition, 5 (1), pp. 113-130.

- Brenton, P., F. Di Mauro and M. Lucke (1999), "Economic integration and FDI: An empirical analysis of foreign investment in the EU and in Central and Eastern Europe-, Emperica, 26 (2), pp. 95-121.

- Brewer, T. (1991), "Foreign Direct Investment in Development: Patterns, Policies and Prospects", The World Bank Policy Research Working Paper, no. wps712.

- Brock, G.J. (1998), "Foreign Direct Investment in Russia's regions 1993-95: Why so little and where has it gone?". Economics of Transition, 6 (2), pp. 349-360.

- Broniarczyk, S.M. and J.W. Alba (1994), "The Role of Consumers' Intuitions in inference Making", Journal of Consumer Research, 21 (3), pp. 393-407.

- Brunetti, A., G. Kisunko and B. Weder (1997), "Institutions in transition: reliability of rules and economic performance in former socialist countries", World Bank Policy Research Working Paper, no. wps 1809.

- Buch, C.M. (1997), "Opening up for Foreign Banks: How Central and Eastem Europe can benefit,. Economics of Transition, 5 (2), pp. 339-366.

- Buch, C.M. and D. Piazolo (2000), "Capital and Trade Flows in Europe and the Impact on Enlargement". Kiel Institute for World Economics Working Paper, no. 1001.

- Buch, C.M. and L. Lusinyan (2002), "Short-Term Capital, Economic Transformation and EU accession", Deutsche Bundesbank Discussion Paper, no. 02/02.

- Buch, C.M., R.M. Kokta and D. Piazolo (2001), "Does the east get what would otherwise flow to the south? FDI Diversion in Europe", Kiel Institute for Worid Economics Working Paper, no. 1061.

- Buckley, P.J. and M. Casson (1981), "The Optimal Timing of a Foreign Direct Investment', Economic Joumal, vol. 91, no. 361, pp. 75-87.

- Buckley, P.J. and M. Casson (1998), "Models of the Multinational Enterprise", Journal of Intemational Business Studies, 29 (1), pp. $21-44$.

- Buiter, W.H., R. Lago and H. Rey (1997), "A portfoliio approach to a cross-sectoral and cross-national investment strategy in transition economies". Economics of Transition, 5 (1). 63-96.

- Buiter, W.H., R. Lago and N. Stern (1997), "Promoting an effective market economy in a changing world", EBRD Working Paper, no. 23.

- Burt, R.S. (2000), The Network Structure of Social Capital", in: R.I. Sutton and B.M. Staw (eds.), Research in Organisational Behavior: An annual series of analytical essays and critical reviews, vol.22, Amsterdam, London and New York: Elsevier Science, JAI Press.

- Calcagnini G, and E. Saltari (2001), "Investment and uncertainty: is there a potential role for common European policy?" Economic Letters, vol. 72, no. 1, pp. 61-65.

- Cantwell, J. and R. Narula (2001), "The eclectic paradigm in the global economy", International Journal of the Economics of Business, 8 (2), 155-172.

- Capel, J. (1992), "How to service a foreign market under uncertainty: a real option approach", European Joumal of Political Economy, vol. 8, no. 3, pp. 455-475.

- Carlin, W. and M. Landesmann (1997). "From theory into practice? Restructuring and dynamism in transition economies", Oxford Review of Economic Policy, 13 (2), pp. 77-105.

- Carmaux, O.J. and D. Huisman (1986), "Nederlandse investeringen in ontwikkelingslanden", SMO informatief, no. 86-2.

- Casson, M. (1993), "Cultural Determinants of Economic Performance". Joumal of Comparative Economics, vol. 17, no. 2, pp. 418-442.

- Caves R. and T.J. Lee, (1998), "Uncertain Outcomes of Foreign Investment: Determinants of the Dispersion of Profits after Large Acquisitions", Joumal of International Business Studies, 29 (3), pp. 563-581. 
- Chen, H. and T.Y. Chen (1998), "Network Linkages and Location Choice in Foreign Direct Investment", Joumal of Intemational Business Studies, 29 (3), pp. 445-467.

- Chi, T. and D. McGuire (1996), "Collaborative ventures and value of learning, Integrating the transaction costs and strategic option perspectives ion the choice of market entry modes*, Joumal of Intemational Business Studies, 27 (2), pp. 285-307.

- Claessens, S., D. Oks and R. Polastri (1998), "Capital Flows to Central and Eastem Europe and Former Soviet Union". World Bank Policy Research Working Paper, no. wps 1976.

- Clark, A.E. and A.J. Oswald (1994), "Unhapiness and Unemployment", Economic Joumal, vol. 104, no. 424, pp. 648-659.

- Cochrane, W.G. (1977), "Sampling Techniques", New York: John Wiley \& Sons, 3d ed.

- Coyne, E.J. (1995), Targeting the foreign direct investor: strategic motivation, investment size and developing country investment-attraction packages", Boston, Dordrecht: Kluwer Academic Publishers.

- Damijan, J., M. Knell, B. Majcen and M. Rojec (2003), The role of FDI, R\&D accumulation and trade in transferring technology to transition countries: evidence from firm panel data for eight transition countries", Economic Systems, vol. 27. no. 2, pp. 189-204.

- Davidson, W.H. (1980), "The location of foreign direct investment activity: country characteristics and experience effects", Journal of International Business Studies, vol. 11, no. 2, pp. 9-22.

- Deardorff, A.V. (1998), "Determinants of bilateral trade: does gravity work in a neoclassical world?", in: J.A. Frankel (ed.), The regionalization of the world economy, NBER project report series, Chicago and London: University of Chicago Press. pp. 7-22.

- Dillman, D.A. (1978), "Mail and telephone surveys: The total design method", Wiley-Interscience Publication, New York: John Wiley \& Sons.

- Dixit, A. (1989), "Entry and exit under uncertainty", Joumal of Political Economy, vol. 97, no. 3, pp. 620-638.

- Dixit, A. (1992), "Investment and hysteresis", Joumal of Economic Perspectives, 6 (1), pp. 107-132.

- Dixit, A. and R.S. Pindyck (1994), "Investment under uncertainty", Princeton: Princeton University Press.

- Djankov, S. and B. Hoekman (1996), "Intra-Industry Trade, Foreign Direct Investment and the Reorientation of Eastern European Exports', CEPR Discussion Paper, no. 1377.

- Djankov, S. and B. Hoekman (2000), "Foreign Investment and Productivity Growth in Czech Enterprises", World Bank Economic Review, vol.14, no. 1, pp. 49-64.

- Djarova, J. (2004), "Cross-border investing: the case of Central and Eastern Europe", Kluwer Academic Publishers, Boston, Dordrecht, New York

- Dohm, R. (1996), "EU Enlargement and Transformation in Eastern Europe: Consequences for Foreign Direct Investment in Europe", Konjunkturpolitik, 42 (2-3), pp. 113-132.

- Dolen, W. van, J. Lemmink, J. Mattsson and I. Rhoen (2001). "Affective consumer responses in service encounters: the emotional content in narratives of critical incidents", Joumal of Economic Psychology, vol. 22, no. 3, pp. 359-376.

- Dufwenberg, M. (2002), "Marital investments, time consistency and emotions", Journal of Economic Behavior and Organisations, vol. 48, no. 1, pp. 57-69.

- Dunning, J.H. (1977), "Trade, location of economic activity and the MNE: A search for an eclectic approach", in: B. Ohlin, P.O. Hesselborn and P.M. Wijkman (eds.). The international allocation of economic activity, London: Macmillan, pp. 395418.

- Dunning, J.H. (1988), "Explaining International Production", London and Boston: Unwin Hyman.

- Dunning, J.H. (1993), "Governments and Multinational Enterprises: From Confrontation to Co-operation?" in: L. Eden and E.H. Potter (eds.), Multinationals in the global political economy, New York: St. Martin's Press and London: Macmillan Press, pp. 59-83.

- Dunning, J.H. (1993), 'The globalization of business: The challange of the 1990s", London: Routledge.

- Dunning, J.H. (2000), The eclectic paradigm as an envelope for economic and business theories of MNE activity", International Business Review, 9 (2), pp. 163-190.

- Dunning, J.H. (2001), "The eclectic (OLI) paradigm of international production: past, present and future", International Joumal of the Economics of Business, 8 (2). pp. 173-190.

- Dunning, J.H. and R. Narula (1999), "Developing Countries versus multinationals in a globalising world: the dangers of falling behind", Forum for Development Studies, 0 (2), pp. 261-287.

- Dunning. J.H. and R. Narula (eds.) (1996), "Foreign Direct Investment and Governments: Catalysts for Economic Restructuring", London: Routledge.

- Eaton, J. and A. Tamura (1996), "Japanese and U.S, exports and investment as conduits of growth", NBER Working Paper, no. 5457.

- Ebbersbach, A. (1987), "The Development of Socialist Foreign Trade Theory in the Conditions of the 1980s", Soviet and Eastern European Foreign Trade, 23 (2), pp. 94-117.

- EBRD (1999), "Transition report 1999: Ten years of transition", London: EBRD.

- EBRD (1998), "The Russian crisis", Transition report 1998", London: EBRD, pp. 12-19.

- Edwards, K.D. (1996), "Prospect theory: A literature review', International Review of Financial Analysis, 5 (1), pp. 19-38.

- Eliasson, G. (1997), "Investment incentives in the formerly planned economies", in: T. Haavisto (ed.), The transition to a market economy. Transformation and reform in the Baltic States, Cheltenham: Edward Elgar Publising. pp. 182-210.

- Ellman, M. (1997), "The political economy of transformation", Oxford Review of Economic Policy, 13 (2), pp. $23-32$.

- Elster, J. (1998), "Emotions and Economic Theory", Joumal of Economic Literature, vol. xxxvi, no. 1, pp. 47-74.

- Erramilli, M.K. and C.P. Rao (1993), "Service firms' international entry-mode choice: A modified transaction-cost analysis approach", Journal of Marketing, 57 (3), pp. 19-38.

- Fehr, E. and A. Falk (2002), "Psychological foundations of incentives", Joseph Schumpeter Lecture, European Economic Review, vol. 46, no. 4-5, pp. 687-724.

- Fidrmuc, J. and J. Fidrmuc (2000), "Disintegration and trade", CEPR Discussion Paper, no 2641.

- Fidrmuc, J. and Th. Nowotny (2000), "The effect of the EU's Eastern European Enlargement on Austria - Austria's specific position", Focus on Transition, vol.5, no. 1, Oesterreichische Nationalbank, Vienna, pp. 100-131. 

- Kogut, B. and H. Singh (1988), "Entering the United States by Joint Venture: Competitive Rivalry and Industry Structure", in F.J. Contractor and P. Lorange (eds.), Cooperative Strategies in International Business, Lexington and Toronto: Lexicon, pp. 241-251.

- Kogut, B, and N. Kulatilaka (1994), "Options thinking and platform investment: investigation opportunity", California Management Review, 36 (2), pp. 52-71.

- Koivu, T. (2002), "Do efficient banking sectors accelerate economic growth in transition countries?", BOFITDdiscussion Paper, no. 14.

- Konings, J. (1999), 'The Effect of Direct Foreign Investment on Domestic Firms: Evidence from Firm Level Panel Data in Emerging Economies", LICOS Working Paper, 86. Centre for Transition Economics, Catholic University Leuven.

- Konrad, K.A. and K.E. Lommerud (2001), "Foreign Direct Investment, Intra-Firm Trade and Ownership Structure", European Economic Review, vol. 45, no. 3, pp. 475-494.

- Koop. M.J. (1997), 'Trade, Foreign Direct Investment and Multinational Enterprises in a General Equilibrium Model", Kiel Institute for World Economics Working Paper, no. 833.

- Kopits, G. (2002), "Central European EU Accession and Latin American Integration: Mutual Lessons in Macroeconomic Design", Oesterreichische Nationalbank Working Paper, no. 75.

- Kornai, J. (1992), "The socialist system: The political economy of communism", Princeton: Princeton University Press.

- Kriechel, B. (2001), "Non-Response in the 1999 Fokker Survey of Displaced Workers", Mimeo Maastricht University.

- Kriechel, B. (2003), "Heterogeneity among displaced workers", PhD thesis, Maastricht University.

- Krishna, K., A. Ozyildirim and N.R. Swanson (2003), "Trade, investment and growth: nexus, analysis and prognosis", Joumal of Development Economics, vol. 70, no. 2, pp. 479-499.

- Kuiper. W.G. (1991), "Investeringen in Oost-Europa - fiscale aspecten", Fiscale en juridische documentatie voor intemationaal zakendoen, no. 27.

- Kvint, V. (1994), "Don't give up on Russia", Harvard Business Review, 72 (2), pp. 62-74.

- Laar, van de M. and W. Letterie (2004), "The delaying effect of financing constraints on investment", Bulletin of Economic Research, 56(3), 271-282

- Laar, van de M. and C. De Neubourg (2004), "Emotions and foreign direct investment: a theoretical and empirical exploration", Meteor research memorandum, 04/013.

- Laar, van de M. (2004), Financing Dutch direct investments to transition economies, Meteor research memorandum. $04 / 029$

- Lankes H.P. and A.J. Venables (1996), "Foreign Direct investment in economic transition: The changing pattern of investments", Economics of Transition, 4 (2), pp. 331-347.

- Lankes, H.-P, and N. Stern (1999), "Capital Flows to Central and Eastern Europe and Former Soviet Union", EBRD Working Paper, no. 27.

- Lansbury, M., N. Pain and K. Smitkova (1996), "Foreign Direct Investment in Central Europe since 1990: An Econometric Study'. National Institute Economic Review, vol, 0, no. 156 (May), pp. 104-124.

- Larsen, R.J. and B.L. Fredrickson (1999), "Measurement Issues in Emotion Research", in: D. Kahneman, E. Diener and N. Schwarz (eds.), Well-Being: the Foundations of Hedonic Psychology. New York: Russel Sage Foundation, pp. 40-60.

- Leeuw, E.D. de and M. Collins (1997), "Data collection methods and survey quality: An overview", in: L. Lyberg, P. Biemer, M. Collins, E. de Leeuw, D. Trewin, C. Dippo, \& N. Schwarz (eds), Survey Measurement and Process Quality, New York: Wiley and Sons Inc., pp. 199-220.

- Lehmann, A. (1999), "Country risks and the investment activity of US multinationals in develoing countries", IMF Working Paper, no. 99/133.

- Lehmann, A. (2002), "Foreign Direct Investment in Emerging Markets: Income, Repatriation and Financial Vulnerabilities" IMF Working Paper, 02/47.

- Lewis, M. and J. Haviland-Jones (1993), "Handbook of Emotions", New York: Guilford Press.

- Li, J. and S. Guisinger (1992). "The globalisation of service multinationals in the TRIAD regions: Japan, Westem Europe and North America", Joumal of Intermational Business Studies, vol. 23, no. 4, pp. 675-696.

- Linnemann, H. (1966), "An econometric study of international trade flows", Amsterdam: North Holland.

- Lipschitz, L., T. Lane and A. Mourmouras (2002), "Capital flows to transition economies: master or servant?, IMF Working Paper, 02/11.

- Loewenstein, G. (2000), "Emotions in economic theory and economic behavior", American Economic Review, 90 (2), pp. $426-432$

- Loewenstein, G. (2001). "The creative destruction of decision research", Journal of Consumer Research, vol. 28, no, 3, pp. 499-505.

- Loewenstein, G., D. Read and R. Baumeister (eds.) (2003), 'Time and decision: Economic and psychological perspectives on intertemporal choice", New York: Russel Sage Foundation.

- Loewenstein, G., E.U. Weber, C.K. Hsee and N. Weich (2001), "Risks as feelings", Psychological Bulletin, 127 (2), pp 267-286.

- Loftus, E.F. (1997), "Researchers are showing how suggestion and imagination can create memories of events that did not actually occur", Scientific American, September, pp. 51-55.

- Luo, Y. (1995), "Business strategy, market structure and performance in international joint ventures in China". Management International Review, 35 (3), pp. 241-264.

- Luo, Y. (1997), "Partner selection and venturing succes: the case of joint ventures with firms in the People's Republic of China:, Organization Science, 8 (6), 648-662.

- Luo, Y. (1998), Timing of Investment and International Expansion Performance in China", Joumal of International Business Studies, vol. 29, no. 2, pp. 391-407.

- Luo, Y. and J.J. Tan (1998), "A comparison of multinational and domestic firms in an emerging market: A strategic choice perspective", Joumal of International Management, 4 (1), pp. 21-40.

- Luthans, F., A.D. Stajkovic and E. Ibrayeva (2000), "Environmental and Psychological Challenges Facing Entrepreneurial Development in Transitional Economies", Joumal of World Business, 35 (1), pp. 95-110.

- Maddala, G.S. (1983), "Limited-dependent and qualitative variables in econometrics, Cambridge University Press, Cambridge. 
- Markusen, J.R. and A.J. Venables (1998), "Multinational Firms and the new trade theory", Joumal of Intemational Economics, vol. 46, no. 2, pp. 183-203.

- Martin, J. (2001), 'Organizational behaviour', London: Thompson Leaming, 2nd ed.

- Martinez-Zarzoso, I and F. Nowak-Lehmann (2003), "Augmented Gravity Model: An Empirical Application to Mercosur-EU Trade Flows', Journal of Applied Economics, 6 (2), pp. 291-316.

- Mayhew, A (1998), "Preparing for accession: problems for the associated countries", in: A. Mayhew (ed.), Recreating Europe: The EU's policy towards Central and Eastern Europe, Cambridge/New York: Cambridge University Press, pp. 200-235.

- McDonald, R.L. and D.R. Siegel (1985), "Investment and the value of the firm when there is an option to shut down", International Economic Review, 26 (2), pp. 331-349.

- McDonaid, R.L. and D.R. Siegel (1986), "The value of waiting to invest', Quarterly Joumal of Economics, 101 (4), pp. 707727.

- McGinnis, M. (1984), "The key to strategic planning; integrating analysis and intuition". Sloan Management Review, vol. 26, no. 1 (Fall), pp. 45-52.

- Mello, L.R. de (1998), "Foreign Direct Investment-Led Growth: Evidenve from Time Series and Panel Data", Oxford Economic Papers, vol. 51, no. 1, pp. 133-151.

- Meyer, K. (1995), "Direct Foreign Investment in Eastern Europe: The Role of Labor Costs", Comparative Economic Studies, 37 (4), pp. 69-88.

- Meyer, K. (1995), "Factor Cost Oriented Direct Foreign Investment: East Asia versus Eastern Europe", paper presented at the European International Business Academy Conference, Urbino, Italy, 10-12 December.

- Meyer, K. (1995), "Foreign Direct Investment in the Early Years of Economic Transition: A Survey", Economics of Transition, 3 (3), pp. 301-320.

- Meyer, K. (1998), "Direct Investment in Economies in Transition", New Horizons in International Business Series. Cheltenham: Edward Elgar Publishing. 1st ed.

- Meyer, K. and Ch. Pind (1999), The Slow Growth of Foreign Direct Investment in the Soviet Union Successor States", Economics of Transition, 7 (1), pp. 201-214.

- Mellgaard, H.P, and P.B. Overgaard (1999), "Partnerships, Buy-Out Options and Investment in Emerging Markets", Scandinavian Journal of Economics, 101 (4), pp. 651-672.

- Moretto, M. (2000), "Irreversible investment with uncertainty and strategic behavior", Economic Modelling, vol. 17, no. 4. pp. $589-617$.

- Moretto, M. and P. Valbonesi (1999), 'Foreign Direct Investment, Policy Uncertainty and Irreversibility, An Option Pricing Approach", International Review of Economics and Business (RISEC), 46 (4), pp. 653-675.

- Morsink, R.L.A. (1997), "Corporate Networking and Foreign Direct Investment Explaining the Mosaic of Geographical Investment Patterns under Different Corporate Strategies". Proefschrift Erasmus Universiteit Rotterdam

- Motta, M. and G. Norman (1993), "Eastern European Economic Integration and Foreign Direct investment", Joumal of Economics and Management Strategy, 2 (4), pp. 483-507.

- Mudambi, R. (1998), The role of Duration in Multinational Investment Strategies", Joumal of International Business Studies, 29 (2), 239-261.

- Narula, R. (1994). "Locational determinants of inward and outward FDI activity", Merit Working Paper, no. 1994-025, Maastricht University.

- Narula, R. (1996), "Multinational investment and economic structure: Globalisation and competitiveness", Studies in Intemational Business and the World Economy, vol, 4, London and New York: Routledge.

- National Opinion Reseach Center (2001), "Methodology report on the small business finance survey, NORC Project Report.

- Nilsson, L. (2000), Trade integration and the EU economic membership criteria", European Joumal of Political Economy. vol, 16, no. 4, pp. $807-827$.

- Oatley, K and J.M. Jenkins (1996), "Understanding emotions", Cambridge, MA: Blackwell Publishers.

- OECD (1993), 'Promoting Foreign Direct Investment in Developing Countries", Paris: OECD, pp. 1-85.

- OECD (1993-now), "OECD Reviews on Foreign Direct Investments", Paris: OECD.

- Oswald, A.J. (1997), "Hapiness and Economic Performance", Economic Joumal, vol. 107, no. 445, pp. 1815-1831.

- Paliwoda, S.J. (1994), "Investing in Eastem Europe: capitalising on emerging markets", Wokingham: Addison-Wesley.

- Pelkmans, J., D. Gros and J. Núnez Ferrer (2000), 'Long-Run Economic Aspects of European Union's Eastern Enlargement", WRR Working Document, no. w109.

- Pennings, E. and L. Sleuwaegen (2000), "The Choice and Timing of Foreign Market Entry under Uncertainty", CEPR Discussion Paper, no. 2470.

- Sleuwaegen L. and E. Pennings (2000), "International relocation: firm and industry determinants", Economics Letters, 67. pp. $179-186$.

- Peters, S.D. (2000), "Culture and the Effect on Entry Timing: Case of Poland, the Czech Republic and Hungary', Academy of International Business Conference, Fall.

- Piazolo, D. (1996), "Trade Integration Between Eastern and Western Europe: Politics Follows the Market", Keel Institute for World Economics Working Paper, no. 745.

- Piazolo, D. (2000), "Eastern Europe between transition and accession: an analysis of reform requirements", Kiel Institute for World Economics Working Paper, no. 991.

- Pindyck, R.S. (1991), "Irreversibility, Uncertainty, and Investment", Jouma/ of Economic Literature, vol. XXIX, no. 3, pp. $1110-1148$.

- Pissarides, F. (2001), "Financial Structures to Promote Private Sector Development in South-Eastern Europe", EBRD Working Paper, no. 64.

- Rabin, M. (2002), "A perspective on psychiology and economics", Alfred Marshall Lecture, European Economic Review, vol. 46 , no. 4-5, pp. 657-685.

- Raijman, R. (2001), "Determinants of entrepreneurial intentions: Mexican immigrants in Chicago", Joumal of SocioEconomics, vol, 30, no. 5, pp. 393-411. 
- Recanatini, F., S.J. Wallsten and L.C. Xu (1999), "Surveying Surveys and Questioning Questions: Learning from the World Bank Experience", World Bank Policy Research Working Paper, no. wps2307.

- Reis, A.B. (2001), "On the welfare effects of foreign investment", Joumal of International Economics, vol. 54, no. 2, pp. 411-427.

- Repkine, A. and P. Walsh (1998), "European Trade and Foreign Direct Investment. U-shaping industrial output in Central Europe: Theory and Evidence", LICOS Discussion Paper, 73, Centre for Transition Economics, Catholic University Leuven.

- Resmini, L. (1999), "The determinants of Foreign Direct investments into the CEECs: New evidence from sectoral patterns", LICOS Discussion Paper, 83, Centre for Transition Economics, Catholic University Leuven.

- Rivoli, P. and E. Salorio (1996), "Foreign Direct Investment and Investment under Uncertainty", Joumal of International Business Studies, 27 (2), pp. 335-357,

- Rodrik, D. (1989), "Policy uncertainty and private investments in developing countries", NBER Working Paper, no. 2999.

- Rodrik, D. (1992), "Foreign trade in Eastern Europe's transition: early results", NBER Working Paper, no. 4064.

- Schneider, F. and B.S. Frey (1885), "Economic and Political Determinants and Foreign Direct Investmens", World Development, vol. 13, no. 2, pp. 161-175.

- Selten, R. (1998), "Features of experimentally observed bounded rationality", European Economic Review, vol. 42, nos. 35. pp. 413-436.

- SER (1993), "Sociaal-economische betrekkingen met Midden-en Oost-Europa", SERAdviezen, no. 1993/16.

- Simon, H.A. (1955), "Models of bounded rationality", vol. 1. Cambridge, MA: MIT Press.

- Simon, H.A. (1982), "Models of bounded rationality", vol. 2, Cambridge, MA: MIT Press.

- Simon, H.A. (1997), "Models of bounded rationality', vol. 3, Cambridge, MA. MIT Press.

- Sinn, H.-W. and A.J. Weichenrieder (1997), "Foreign Direct Investment, Political Resentment and the Privatization Process in Eastern Europe", Economic Policy, vol. 12, no. 24, pp. 177-198.

- Stajkovic, A.D. and F. Luthans (1998), "Self-efficacy and work-related performance: a meta-analysis", Psychological Bulletin, 124 (2), pp. 240-261.

- Svejnar, J. (2002), Transition economies: performance and challenges", Journal of Economic Perspectives, 16 (1), 3-28.

- Svetlicic, M. (1997), "Outward Foreign Direct Investment by Central European Economies and Restructuring", University of Ljubljana Working Paper, no. 59.

- Szanyi, M. (1998), "Experiences with Foreign Direct Investment in Eastern Europe: Advantages and Disadvantages". Eastem European Economics, 36 (3). pp. 28-48.

- Tan, B. and I. Vertinsky (1996), "Foreign Direct Investment by Japanese Electroniscs Firms in the United States and Canada: Modelling the Timing of Entry. Joumal of International Business Studies, vol. 27, no. 4, pp. 655-681.

- Thomas, J. and T. Worrail (1994), "Foreign Direct investment and the Risk of Expropriation", Review of Economic Studies, vol. 61, no. 1, pp. 81-108.

- Tirole, J. (1988), "The theory of industrial organizaton", Cambridge and London: MIT Press.

- Tirole, J. (2002), "Rational irrationality: some economics of self management", Presidential Address, European Economic Review, vol, 46, nos. 4-5, pp. 633-655.

- Tomaskovic-Devey, D.. J. Leiter and S. Thompson (1994), "Organizational Survey Nonresponse", Administrative Science Quarterty, vol. 39, no.3, pp. 439-457.

- Trigeorgis, L. (1996), "Real options: Managerial flexibility and strategy in resource allocation", Cambridge and London: MIT Press.

- Tse K.L. and A. Buckley (1995), "Real operating options and Foreign Direct Investment - A synthesis of international business and financial theory, Nyenrode University Research Paper Series, no. 1995/09.

- Ursacki, T. and I. Vertinsky (1992), "Choice of entry timing and scale by foreign banks in Japan and Korea", Journal of Banking and Finance, vol. 16, no, 2, pp. 405-421.

- Valdivieso, L.M. (1998), "Macroeconomic Developments in the Baltics, Russia and Other Countries in the Former Sovie! Union, 1992-1997, IMF Occasional Paper, no. 175.

- VNO-NCW (1997), "Nota Midden en Oost Europa", The Hague: VNO-NCW.

- Vonnegut, A. (2000), "Real Option Theories and Investment in Emerging Economies", Emerging Market Review, vol. 1. no. 1, pp. $82-100$.

- Wadeson, N. (2000). "Bounded rationality, meta-rationality and the theory of international business", in: M. Casson (ed.) Models of International Businss, Cheltenham: Edward Elgar Publishing Ltd., pp. 94-116.

- Walkenhorst, P. (2001). "Determinants of Foreign Direct Investment in the Food Industry: The case of Poland", Agribusiness, 17 (3), pp. 383-395.

- Welfens, P.J.J. and P. Jasinski (1994), "Privatisation and Foreign Direct Investemnt in Transforming Economies". Aldershot: Dartmouth Publishers Co.

- Williamson, J.H. (1994). The political economy of policy reform", Washington, DC: Institute for International Economics.

- Wollheim, R. (1999), "On the emotions", New Haven: Yale University Press.

- Wolozin, H. (2002), "The individual in economic analysis: toward psychology of economic behavior", Joumal of Socioeconomics, vol. 31, no. 1, pp. 45-57.

- Yates, F. (1980), "Sampling methods for censuses and surveys", Charles Griffin and Company Ltd., 4th ed.

- Zecchini, S. (ed.) (1997), "Lessons from the economic transition: Central and Eastern Europe in the 1990s", Dordrecht, Boston: Kluwer Academic Publishers. 



\section{Nederlandse samenvatting}

De val van de Berlijnse Muur, op 9 november 1989, was een van de meest onverwachte, indrukwekkende en belangrijke gebeurtenissen van de vorige eeuw. De landen in Centraal- en OostEuropa keerden zich af van de Sovjet-Unie en begonnen de hervormingen van een socialistische planeconomie naar een democratische markteconomie. Niet lang daarna, in 1991, viel de Sovjet-Unie in vijftien onafhankelijke staten uiteen. De veranderingen voor deze landen waren enorm. Op korte termijn moesten de prijzen worden geliberaliseerd en de landen openden hun grenzen voor buitenlandse handel en investeringen.

Het is algemeen aanvaard dat met name directe investeringen een positieve invloed hebben op de economie van het ontvangende land. Dit brengt niet alleen kapitaal maar ook kennis in de vorm van menselijk kapitaal en technologie en werkgelegenheid met zich mee. Om die reden hebben bijna alle transitielanden hun wetgeving snel aangepast om buitenlandse investeringen toe te staan en te faciliteren.

Ook voor Nederland was dit van belang. Niet alleen verdween de vijandigheid tussen Oost en West met het beëindigen van de koude oorlog, maar op het hetzelfde moment opende zich een enorme markt voor handel en investeringen. Buitenlandse handel en investeringen waren tijdens de communistische periode zo minimaal mogelijk gehouden. Sinds 1989 zijn de handels- en investeringsstromen vanuit Nederland naar Centraal- en Oost-Europa en Centraal-Azië constant gestegen.

De buitenlandse investeringen zijn ongelijk verdeeld over de transitielanden. De meer ontwikkelde landen, zoals Polen, Tsjechië en Hongarije, ontvingen een groot deel van de totale investeringsstromen, terwijl de directe investeringen in bijvoorbeeld de Centraalaziatische landen minimaal zijn. Ook de Nederlandse bedrijven met een investering in een transitieland hebben veelal geïnvesteerd in de Centraaleuropese landen, die economische en politiek het meest stabiel zijn en geografisch en cultureel het dichtst bij Nederland liggen. Het is interessant deze ontwikkeling te bestuderen, omdat het de vraag is of de beste investeringsmogelijkheden wel in Centraal-Europa liggen, in plaats van in de geografisch verder gelegen, economisch minder ontwikkelde landen. Deze landen hebben een risicovoller investeringsklimaat, maar de voordelen zoals bijvoorbeeld de aanwezigheid van natuurlijke grondstoffen of de afwezigheid van concurrentie kunnen mogelijk zwaarder wegen dan de nadelen van een hoger investeringsrisico.

Dit proefschrift richt zich op alle aspecten van een directe investeringsbeslissing naar een onzekere regio als Centraal- en Oost-Europa en Centraal-Azië. Directe investeringen zijn investeringen waarbij een Nederlandse bedrijf voor meer dan tien procent eigendom is van een bedrijf in het buitenland en zich actief bezighoudt met het management van dat bedrijf. Het doel van dit proefschrift is een completer beeld te krijgen van de processen die ten grondslag liggen aan de beslissing van Nederlandse bedrijven om te investeren. De onderzoeksvragen zijn i) Welke kenmerken van Nederlandse bedrijven verhogen de kans dat een bedrijf in een transitieland investeert? ii) Hoe ziet het investeringsbeslissingsproces van een bedrijf eruit en is dat anders voor investeerders dan voor bedrijven die besluiten niet te investeren?iii) Welke landkenmerken van transitielanden trekken Nederlandse investeringen aan? en iv) Hoe beïnvloeden persoonlijke aspecten en motivaties een investeringsbeslissing? 
Het proefschrift kan worden verdeeld in drie delen. Deel een, dat bestaat hoofdstuk twee, drie en vier, bevat een microniveau analyse. In hoofdstuk twee wordt het optiemodel beschreven en verder uitgewerkt. In hoofdstuk drie en vier worden de veronderstellingen en conclusies van het optiemodel getest. Hoofdstuk drie richt zich op de bedrijfskenmerken die directe investeringsstromen verklaren en beïnvloeden. Hoofdstuk vier gaat over het investeringsbeslissingsproces van een bedrijf en relateert dit proces aan de uitkomst van de uiteindelijke keuze. Deel twee bevat een macroniveau analyses van Nederlandse directe investeringsstromen; hoofdstuk vijf beschrijt de invloed van landenkenmerken op directe investeringsstromen. Deel drie, hoofdstuk zes, onderzoekt de rol van emoties en intuittie bij een investeringskeuze.

Deel een van deze studie bevat een microniveau analyse. Hoofdstuk 2 geeft een overzicht van het optiemodel. Het optiemodel is gekozen als model omdat het zeer geschikt is om investeringen naar transitielanden te beschrijven. Bedrijven kiezen een of meerdere landen waarin ze mogelijk willen investeren. Op basis van een investeringsanalyse, met inachtneming van factoren zoals timing en onzekerheid, nemen bedrijven een uiteindelijk de beslissing om al dan niet te investeren en zo ja, in welk land. Het optiemodel voorspelt dat bedrijven een investering vaker zullen uitstellen als onzekerheid omtrent de investering groter is. Uitbereidingen van het model, in sectie 2.4 en 2.5 . voegen toe dat uitstel vaker voorkomt als bedrijven meerdere landen selecteren om mogelijk een investering in te doen en als deze landen onderling veel in risico verschillen. Hoewel het optiemodel duidelijk aangeeft wanneer bedrijven zullen investeren, namelijk als de verwachte netto toegevoegde waarde positief is, geeft het niet aan hoe deze waarde berekend moet worden en welke factoren meegenomen dienen te worden in een dergelijke berekening. Om meer te weten te komen over het investeringsbeslissingsproces van bedrijven, of ze een analyse maken en zo ja, welke factoren ze dan meenemen in die analyse, is een enquête onderzoek uitgevoerd. Deze enquête is gehouden onder Nederlandse bedrijven die tussen 1989 en 2000 geïnteresseerd waren in de transitielanden. In annex $\mathrm{A}$ is de methodologie van de enquête beschreven en in annex $\mathrm{B}$ zijn de enquêtes toegevoegd.

In hoofdstuk drie en vier worden de veronderstellingen en conclusies van het optiemodel in hoofdstuk twee getest. Hoofdstuk drie is gericht op bedrijfskenmerken. De bedrijven in het enquêteonderzoek waren allemaal in meer of mindere mate geïnteresseerd in investeringen in de transitielanden tussen 1989 en 2000. Dit hoofdstuk behandelt de vraag of bedrijven die in transitielanden investeren gemeenschappelijke bedrijfskenmerken bezitten. Analyse toont aan dat bedrijfskenmerken niet de belangrijkste verklarende variabelen zijn voor een investeringsbeslissing. Met name ervaring met handel in de regio en ervaring met investeringen in de regio verhogen de kans dat een bedrijf nogmaals zal investeren. In hoofdstuk vier wordt gekeken naar hoe bedrijven een buitenlandse investeringsbeslissing nemen. Veel bedrijven maken een keuze zonder enige investeringsanalyse. Voor wat betreft de bedrijven die wel een analyse maken, zijn er drie interessante bevindingen. Ten eerste was een dergelijke analyse even uitgebreid voor bedrijven die investeerden en bedrijven die niet investeerden. Het idee dat bedrijven die niet investeren minder goed geïnformeerd zijn is dus op grond van deze data incorrect. Ten tweede was, voor bedrijven met meerdere directe investeringen in de regio, de analyse voor de latere investeringen even uitgebreid als de analyse voor hun eerste investering. Ervaring leidt dus niet tot een minder uitgebreide voorbereiding van investeringen. Maar, ten derde, een uitgebreide investeringsanalyse heeft wel een positieve invloed op de succesevaluatie van bedrijven. Bedrijven die de investering met een 
uitgebreidere analyse hebben voorbereid zijn achteraf positiever over het functioneren van hun investering. In sectie 4.5 zijn deze bevindingen omgezet in een raamwerk, waarin investeringskeuzes worden gemaakt op grond van een risico-inschatting van het land, de kosten van het verzamelen van informatie en de opbrengsten van de informatie in de vorm van verminderde onzekerheid van de investeringskeuze.

Deel twee van het proefschrift, hoofdstuk vijf, behandelt geaggregeerde Nederlandse investeringsstromen. Door middel van het gravity model, aangevuld met 60 variabelen, worden de investeringsstromen naar de transitielanden bestudeerd. Vaak wordt aangenomen dat de transitielanden, nadat ze zoveel jaren gesloten zijn geweest voor buitenlandse investeringen, hun achterstand nu versneld inhalen en relatief veel instroom van investeringen ontvangen. De resultaten bieden geen bewijs voor deze veronderstelling. Hoe meer er gecontroleerd wordt voor landenkenmerken en verschillen tussen de landen van de regio, hoe duidelijker wordt dat er geen regiogericht inhaaleffect bestaat. Er is ook geen reden aan te nemen dat de landen die in 2004 zijn toegetreden tot de Europese Unie hogere instromen van Nederlandse investeringen zullen ontvangen, aangezien deze landen al op hun lange-termijnevenwichtsniveau zitten. De overige transitielanden zitten momenteel nog onder hun lange-termijnevenwichtsniveau, maar aangezien zij niet toetreden tot de EU wordt ook daar geen positieve schok verwacht.

In deel drie, hoofdstuk zes, wordt gekeken in hoeverre naast onzekerheid, kosten en opbrengsten ook persoonlijke motivaties een rol spelen bij een directe investeringskeuze. Meerdere antwoorden in de enquête duiden erop dat persoonlijke redenen belangrijk en invloedrijk zijn voor de uiteindelijke keuze. In sectie 6.2 worden deze persoonlijke motivaties beschreven. Dergelijke motivaties worden niet vaak in overweging genomen in economische beslissingstheorieên, hoewel uit de literatuur blijkt dat ze wel degelijk van invloed zijn op investeringsbeslissingen. In sectie 6.4 wordt beargumenteerd dat individuen, gezien de complexiteit van investeringskeuzes en afwezigheid van perfecte informatie, hun emoties en intuïtie kunnen gebruiken om keuzes te maken. In sectie 6.5 wordt deze argumentatie omgezet in een micro-economisch nuts-maximalisatiemodel, waarbij zowel het nut van het bedrijf als het nut van de beslisser van invloed zijn op de uiteindelijke keuze.

In hoofdstuk zeven wordt een samenvatting van het proefschrift gegeven, inclusief een sectie waarin beleidsadviezen op grond van de analyses worden gegeven. 



\section{Biography}

Mindel M. van de Laar was born on August 15., 1973 in Amsterdam, the Netherlands. She attended secondary school at Sint-Joriscollege in Eindhoven (1985-1992). In 1992 she enrolled as a student International Economic Studies at Maastricht University, from which she graduated in April 1997. During this period she worked as research assistant and teaching assistant at Maastricht University, was assistant-consultant on a labor market survey project for the EU in Bulgaria (1994) and researcher for the Dutch Chambers of Commerce studying Dutch business activities in Poland (1996). In addition, she studied a semester at George Washington University, Washington DC, USA (1996).

After graduation she has worked part-time on a dissertation at Maastricht University, for the International Economics Department. She was also a member of the Business Investment Research Center (BIRC) and involved in teaching, mainly the graduate course "Economies in Transition". In 1999 she visited the National Opinion Research Center in Chicago, USA, to study survey techniques (1999).

She combined her work at the University with part-time consultancy activities. Her main involvement was in the World Bank Social Protection Management Project in Moldova (1998-2002). In addition, she has been active in many smaller project, such as the master training of Hungarian students (Maastricht University), reviewing the Lithuanian Annual Social Report (UNPD), coordinator for first year economic students with non-Dutch nationality and the organization of the Maastricht Interdisciplinary Economic Lecture series (Maastricht University). 
